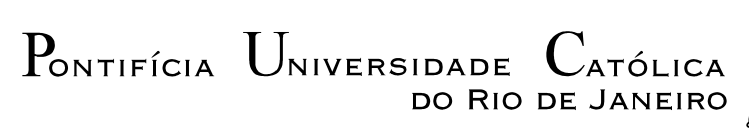

Bárbara Cardoso Gomes

\begin{abstract}
Ferramenta Gráfico-Interativa para Análise Não Linear Física de Pórticos Planos de Concreto Armado Considerando o Diagrama Momento-Curvatura
\end{abstract}

Dissertação de Mestrado

Dissertação apresentada como requisito parcial para obtenção do grau de Mestre pelo Programa de Pós-Graduação em Engenharia Civil da PUC-Rio. Área de Concentração: Estruturas.

Orientador: $\quad$ Prof. Luiz Fernando Martha Coorientador: Prof. Sergio Hampshire C. Santos 
Bárbara Cardoso Gomes

\section{Ferramenta Gráfico-Interativa para Análise Não Linear Física de Pórticos Planos de Concreto Armado Considerando o Diagrama Momento-Curvatura}

Dissertação apresentada como requisito parcial para obtenção do título de Mestre pelo Programa de Pós-Graduação em Engenharia Civil da PUC-Rio. Área de Concentração: Estruturas. Aprovada pela Comissão Examinadora abaixo assinada.

Professor Luiz Fernando Martha Orientador Departamento de Engenharia Civil e Ambiental- PUC-Rio

Professor Sergio Hampshire de Carvalho Santos Coorientador Departamento de Estruturas - Escola Politécnica da UFRJ

Professora Maria Elizabeth da Nóbrega Tavares Departamento de Estruturas - Faculdade de Engenharia da UERJ

Professor Daniel Carlos Taissum Cardoso Departamento de Engenharia Civil e Ambiental- PUC-Rio 
Todos os direitos reservados. É proibida a reprodução total ou parcial do trabalho sem autorização da universidade, da autora e do orientador.

\section{Bárbara Cardoso Gomes}

Graduou-se em Engenharia Civil com ênfase em Estruturas pela Universidade Federal do Rio de Janeiro (UFRJ) em 2017. Ingressou no mestrado da PUC-Rio em 2017 na área de Estruturas. Durante o mestrado participou de dois congressos na área de estruturas, apresentando um artigo no $60^{\circ}$ Congresso Brasileiro do Concreto. Atualmente é professora temporária de nível técnico no programa federal Pronatec.

Ficha Catalográfica

Gomes, Bárbara Cardoso

Ferramenta gráfico-interativa para análise não linear física de pórticos planos de concreto armado considerando o diagrama momento-curvatura / Bárbara Cardoso Gomes; orientadores: Luiz Fernando Martha, Sergio Hampshire C. Santos. -2019.

143 f.: il. color.; $30 \mathrm{~cm}$

Dissertação (mestrado) - Pontifícia Universidade Católica do Rio de Janeiro, Departamento de Engenharia Civil e Ambiental, 2019.

Inclui bibliografia

1. Engenharia Civil e Ambiental - Teses. 2. Concreto armado. 3. Ferramenta gráfica interativa. 4. Redução da rigidez por fissuração. 5. Análise não linear física. 6. Análise estrutural. I. Martha, Luiz Fernando. II. Santos, Sergio Hampshire C. III. Pontifícia Universidade Católica do Rio de Janeiro. Departamento de Engenharia Civil e Ambiental. IV. Título. 


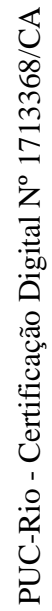

Para minha amada avó, Terezinha. 


\section{Agradecimentos}

O presente trabalho foi realizado com apoio da Coordenação de Aperfeiçoamento de Pessoal de Nível Superior - Brasil (CAPES) - Código de Financiamento 001.

Aos meus orientadores Luiz Fernando Martha e Sergio Hampshire pela paciencia, ensinamentos e tempo empenhado.

Ao Tecgraf pelo espaço cedido.

À minha família, por todo amor, compreensão e apoio aos meus sonhos. Em especial meu avô Claudio Jorge e minha tia Margot, que diariamente convivem comigo e são tão compreensíveis e amáveis, sendo personagens principais na formação do ser que eu sou. Um agradecimento imensurável a minha avó Terezinha. Aos meus pais Sandra e Luiz Claudio e meu irmão Guilherme, que são meus grandes amigos e sempre me apoiaram e respeitaram minhas escolhas.

Aos meus queridos amigos que fiz durante o mestrado, em especial Mariana Motta, Luiza Marinho, Aldo Nogueira e Patrícia Rocha. Aos meus amigos externos que foram muito parceiros. À Aline Pereira que foi tão presente ao longo desses dois anos. 


\section{Resumo}

Gomes, Bárbara Cardoso; Martha, Luiz Fernando; Santos, Sergio Hampshire de Carvalho. Ferramenta gráfico-interativa para análise não linear física de pórticos planos de concreto armado considerando o diagrama momento-curvatura. Rio de Janeiro, 2019. 143p. Dissertação de Mestrado - Departamento de Engenharia Civil e Ambiental, Pontifícia Universidade Católica do Rio de Janeiro.

O presente trabalho visa dar complemento à ferramenta gráfica interativa previamente criada com a finalidade de modelar e dimensionar vigas e pilares em concreto armado, inserindo no dimensionamento a não linearidade física. A ferramenta existente tem como base o programa FTOOL, que de maneira didática permite modelar e realiza análise estrutural em duas dimensões, resultando em deslocamentos, reações e esforços internos. Com base nos esforços e dados iniciais da estrutura tais como materiais, seções e cobrimento, a nova ferramenta altera a rigidez das seções para que se considere os efeitos de fissuração e fluência do concreto, além da relação não linear entre tensão e deformação. É necessário inserir uma análise da rigidez das seções, que após a fissuração da peça, na transição do Estádio I para o Estádio II, têm sua rigidez reduzida, cálculo este feito pela rigidez secante obtida pelos diagramas momento-curvatura. Desta forma, é necessário reavaliar a rigidez das diversas seções de maneira iterativa, fazendo-se a redistribuição de esforços de acordo com a variação das rijezas nas seções dos elementos estruturais. Propõe-se a comparação entre a recomendação da NBR 6118:2014, item 15.7.3, para consideração aproximada da não linearidade física e a rigidez secante obtida pelas relações momento-curvatura, tanto para os pilares como para as vigas. Para isso são estudados três exemplos de estruturas onde compara-se os resultados obtidos para os esforços internos, armadura e deslocamento.

\section{Palavras-chave}

Concreto Armado; Ferramenta Gráfica Interativa; Redução da Rigidez por Fissuração; Análise Não Linear Física; Análise Estrutural; Dimensionamento; Pórtico Plano. 


\section{Abstract}

Gomes, Bárbara Cardoso; Martha, Luiz Fernando Advisor; Santos, Sergio Hampshire de Carvalho Co-advisor. Graphics-interactive tool for material non-linear analysis of reinforced concrete plane frames considering moment-curvature diagram. Rio de Janeiro, 2019. 143p. Dissertação de Mestrado - Departamento de Engenharia Civil e Ambiental, Pontifícia Universidade Católica do Rio de Janeiro.

The present work aims to complement the graphic-interactive tool previously created for modeling and designing reinforced concrete beams and columns, introducing the material nonlinearity in the design. The existant tool is based on the FTOOL program, which didactically allows to model and performs structural analysis in two dimensions, resulting in deflections, reactions ans internal forces. Based on the forces and initial data of the structure such as materials, cross sections and concrete covering, the new tool changes the cross sections stiffnesses to consider the effects of concrete cracking and creep, besides the nonlinear relationships between tensions and deformations. It is necessary to introduce an analysis of the section stiffnesses, which after cracking, in the transition between stages I and II, presents a reduction in its stiffiness, that is evaluated by the secant stiffness from the moment-curvature diagrams. Thus, it is necessary to reevaluate the stiffness of the several sections iteratively, performing the redistribuition of the forces according to the vaiation of stiffness on the structural elements. It is proposed the comparison between the recommendation of NBR 6118 (ABNT, 2014), in its topic 15.7.3, for the approximate consideration of material nonlinearity and the secant stiffness obtained by the moment-curvature relationships, both for columns and beams. So three examples of structures are studied, in which the results obtained for internal forces, reinforcement and displacement are compared.

\section{Keywords}

Reinforced Concrete; Graphics-interactive Tool; Stiffness Reduction by Cracking; Nonlinear Material Analysis; Structural Analysis; Design; Plane Frame. 


\section{Sumário}

1 Introdução 19

1.1. Motivação 19

1.2. Objetivos 20

1.3. Escopo 21

2 Revisão Bibliográfica 22

2.1. Analogia da viga conjugada 22

2.2. Análise Não Linear 28

2.2.1. Abordagem da Norma Brasileira 31

2.2.2. Abordagem das Normas Internacionais 33

2.3. Relação Momento-Curvatura 41

3 Metodologia 46

3.1. Definição da Estrutura 46

3.1.1. Definição dos Materiais 46

3.1.2. Definição da Estrutura 48

3.1.3. Carregamentos Atuantes 53

3.2. Obtenção da Curva Momento-Curvatura 53

3.2.1. Processo Iterativo - Variação da Linha Neutra e Curvatura 54

3.2.2. Convergência da Força Normal 63

$\begin{array}{ll}\text { 3.2.3. Força Resistente da Seção } & 67\end{array}$

3.2.4. Momento Resistente da Seção 74

3.3. Aplicação da Rigidez Secante no Modelo Estrutural 76

3.3.1. Nós de Integração 78

3.3.2. Método de Integração 83

3.4. Consideração da Fluência 85

4 Aplicação do Método - Exemplos e Resultados 88

4.1. Exemplo 1 - Viga Contínua 88

4.1.1. Modelo Estrutural - Análise Inicial 88

4.1.2. Redução da Rigidez - Convergência do Modelo 93

$\begin{array}{ll}\text { 4.1.3. Deslocamentos } & 100\end{array}$ 
4.1.4. Fluência do Concreto 104

4.2. Exemplo 2 - Pilar 112

4.2.1. Modelo Estrutural - Análise Inicial 112

4.2.2. Redução da Rigidez - Convergência do Modelo 113

4.2.3. Deslocamentos 116

4.2.4. Fluência do Concreto 118

4.3. Exemplo 3 - Pórtico 120

4.3.1. Modelo Estrutural - Análise Inicial 120

4.3.2. Redução da Rigidez - Convergência do Modelo 122

$\begin{array}{lr}\text { 4.3.3. Deslocamentos } & 129\end{array}$

$\begin{array}{lr}\text { 4.3.4. Fluência do Concreto } & 131\end{array}$

$\begin{array}{ll}5 \text { Conclusões } & 138\end{array}$

6 Referências bibliográficas 141 


\section{Lista de Figuras}

Figura 2.1- Parâmetros de rigidez à torção 26

Figura 2.2 - Viga real e viga conjugada 26

Figura 2.3 - Diagrama de momentos fletores da viga real 26

Figura 2.4 - Diagrama de momentos fletores decomposto em duas parcelas referentes aos momentos aplicados nas extremidades

Figura 2.5 - Diagrama tensão-deformação - Adaptada da figura 8.2 da NBR 6118(ABNT, 2014)

Figura 2.6 - Diagramas da tensão e deformação no concreto 30

Figura 2.7 - Método P-Delta

Figura 2.8 - Diagrama momento-curvatura - Figura 15.1 da NBR 6118 (ABNT, 2014)

Figura 2.9 - Diagramas da tensão e deformação no concreto - $\mathrm{ACl}$ (2015)

Figura 2.10 - Diagrama tensão-deformação - Figura 3.2 do EN 19921-1:2004

Figura 2.11 - Diagrama parábola-retângulo da tensão-deformação -

Figura 3.3 do EN 1992-1-1:2004

Figura 2.12 - Distribuição retangular da seção - Figura 3.5 do EN 19921-1:2004

Figura 2.13 - Diagrama tensão-deformação - Figura 5.1-3 do Model Code 2010

Figura 2.14 - Seção de exemplo para construção do momentocurvatura

Figura 2.15 - Momento curvatura do pilar dado

Figura 2.16 - Diagrama momento-curvatura obtido pelo M-k UFRJ (Castro, 2011).

Figura 2.17 - Interface com pré-visualização - Capiba (Souza Júnior, 2012). 
Figura 2.18 - Diagrama momento-curvatura obtido pelo Capiba (Souza Júnior, 2012).

Figura 2.19 - Sobreposição dos diagramas obtidos pelos três programas.

Figura 3.1 - Menu para definição do material - FTOOL

Figura 3.2 - Menu para definição da geometria do pilar com seção retangular - FTOOL

Figura 3.3 - Menu para definição da geometria da viga com seção retangular - FTOOL

Figura 3.4 - Menus para definição da geometria da viga com seções $T$,

L e I - FTOOL

Figura 3.5 - Opções de inserção de carregamento: (a) carga pontual;

(b) momento pontual; (c) carga uniformemente distribuída; (d) carga linearmente variável; (e) temperatura - FTOOL

Figura 3.6 - Exemplo de Curva Momento-Curvatura obtida pelo programa

Figura 3.7 - Domínios de ELU de uma seção transversal - Figura 17.1 da NBR 6118 (ABNT, 2014)

Figura 3.8 - Diagrama de deformações - Analogia ao domínio $1 \quad 56$

Figura 3.9 - Diagrama de deformações - Analogia ao domínio $2 \quad 58$

Figura 3.10 - Diagrama de deformações - Analogia ao domínio $3 \quad 60$ Figura 3.11 - Diagrama de deformações - Analogia ao domínios 4 e 4a

Figura 3.12 - Diagrama de deformações - Analogia ao domínio 562

Figura 3.13 - Método da Bisseção

Figura 3.14 - Gráfico Normal-Curvatura para uma seção genérica -

Pontos de descontinuidade da derivada em destaque

Figura 3.15 - Diagrama tensão-deformação - Figura 8.2 da NBR 6118 (ABNT, 2014)

Figura 3.16 - Deformações dos limites de integração da tensão de compressão no concreto

Figura 3.17 - Seção genérica com deformação $\varepsilon x$ em uma fibra a distância $z$ do topo da seção 
Figura 3.19 - Diagrama de tensão-deformação para aços de armaduras passivas -Figura 8.4 da NBR 6118(ABNT, 2014)

Figura 3.20 - Fluxograma do método de obtenção da rigidez secante 76 Figura 3.21 - Viga biengastada com rotação $\rho$ na extremidade inicial. 77 Figura 3.22 - (a) Modelo estrutural; (b) Diagrama de Momento Fletor; (c) Diagrama de armadura adotada.

Figura 3.23 - Sobreposição do diagrama de momentos fletores com a redução da rigidez (a) Por trechos com 0,0 m; (b) Por trechos com 0,2 m; (c) Passo 0,5 m ao longo do vão.

Figura 3.24 - (a) Modelo estrutural; (b) Diagrama de Momentos Fletores; (c) Diagrama de armadura adotada.

Figura 3.25 - Redução da rigidez ao longo do pilar (a) Passo 0,0 m; (b) Passo 0,2 m.

Figura 3.26 - Gráficos das funções de integração (a) Função de grau zero; (b) Função de grau um; (c) Função de grau dois.

Figura 4.1 - Planta da formas da estrutura - Adaptada da Figura 4.11 de Chust e Figueiredo (2015)

Figura 4.2 - Esquema estrutural com valor característico do carregamento de V101

Figura 4.3 - Esquema estrutural com valor de cálculo do carregamento de V101.

Figura 4.4 - Diagrama de momento fletor com valores de cálculo [kN.m].

Figura 4.5 - Diagrama de armaduras necessárias $\left[\mathrm{cm}^{2}\right]$.

Figura 4.6 - Diagrama de armaduras adotadas [ $\mathrm{cm} 2]$.

Figura 4.7 - Trechos para integração da estrutura - Meio vão por simetria

Figura 4.8 - Nós de integração considerando os passos propostos: (a) 0,0 m; (b) $1,0 \mathrm{~m}$; (c) $0,5 \mathrm{~m}$; (d) 0,2 m.

Figura 4.9 - Iteração 0 - Diagrama de Momento Fletor [kN.m]- Análise Linear

Figura 4.10 - Iteração 1 - Diagrama de Momento Fletor [kN.m]. 96

Figura 4.11 - Iteração 2 - Diagrama de Momento Fletor kN.m. 96

Figura 4.12 - Iteração 3 - Diagrama de Momento Fletor [kN.m]. 96 
Figura 4.13 - Iteração 4 - Diagrama de Momento Fletor [kN.m].

Figura 4.14 - Iteração 5 - Diagrama de Momento Fletor [kN.m]. 97

Figura 4.15 - Iteração 6 - Diagrama de Momento Fletor [kN.m]. 97

Figura 4.16 - Iteração 7 - Diagrama de Momento Fletor [kN.m]. 97

Figura 4.17 - Diagrama Momento-Curvatura - Seção com Momento Positivo

Figura 4.18- Diagrama Momento-Curvatura - Seção com Momento Negativo

Figura 4.19 - Iteração 0 - Deslocamento vertical da viga $[\mathrm{mm}]$.

Figura 4.20 - Iteração 1 - Deslocamento vertical da viga [mm]. 100

Figura 4.21 - Iteração 2 - Deslocamento vertical da viga $[\mathrm{mm}]$.

Figura 4.22 - Iteração 3 - Deslocamento vertical da viga $[\mathrm{mm}]$.

Figura 4.23 - Iteração 4 - Deslocamento vertical da viga $[\mathrm{mm}]$.

Figura 4.24 - Iteração 5 - Deslocamento vertical da viga [mm]. 101

Figura 4.25 - Iteração 6 - Deslocamento vertical da viga $[\mathrm{mm}]$.

Figura 4.26 - Iteração 0 - Deslocamento vertical da viga - ELS -

Aceitação visual $[\mathrm{mm}]$. 103

Figura 4.27 - Iteração 6 - Deslocamento vertical da viga - ELS Aceitação visual $[\mathrm{mm}]$.

Figura 4.28 - Iteração 0 - Deslocamento vertical da viga - ELS Vibrações $[\mathrm{mm}]$.

Figura 4.29 - Iteração 6 - Deslocamento vertical da viga - ELS Vibrações $[\mathrm{mm}]$.

Figura 4.30 - Iteração 0 (a) Diagrama de momento fletor [kN.m]; (b) Armadura calculada [ $\left.\mathrm{cm}^{2}\right]$; (c) Armadura adotada [ $\left.\mathrm{cm}^{2}\right]$.

Figura 4.31 - Iteração 5 (a) Diagrama de momento fletor [kN.m]; (b) Armadura calculada [ $\left.\mathrm{cm}^{2}\right]$; (c) Armadura adotada [ $\left.\mathrm{cm}^{2}\right]$.

Figura 4.32 - Gráfico de redução da rigidez com sobreposição do diagrama de momentos fletores no eixo secundário

Figura 4.33 -Combinação de ações - ELS - Aceitação visual

Figura 4.34 -Deslocamento vertical da viga - ELS - Aceitação visual [mm]

Figura 4.35 -Combinação de ações - ELS - Vibrações 
Figura 4.36 -Deslocamento vertical da viga - ELS - Vibrações [mm] 110 Figura 4.37 - Curva Momento-Curvatura para os dados valores de fluência.

Figura 4.38 - (as) Esquema estrutural do pilar com o carregamento dado; (b) Diagrama de momento fletor [kN.m]; (c) Armadura calculada [cm²]; (d) Armadura adotada [cm²].

Figura 4.39 - Exemplo 2 - Diagrama Momento Curvatura

Figura 4.40 - Diagrama de momento fletor [kN.m] com os valores de momento utilizados na integração dos nós (a) Passo 0,0 m; (b) Passo 1,0 m; (c) Passo 0,5 m; (d) Passo 0,2 m;

Figura 4.41 - Redução na rigidez ao longo do vão do pilar (a) Passo 0,0 m; (b) Passo 1,0 m; (c) Passo 0,5 m; (d) Passo 0,2 m;

Figura 4.42 - Deformada do pilar - Análise Linear $[\mathrm{mm}]$.

Figura 4.43 - Deslocamento horizontal [mm] para análise não linear (a) Passo 0,0 m; (b) Passo 1,0 m; (c) Passo 0,5 m; (d) Passo 0,2 m; 117 Figura 4.44 - Redução na rigidez ao longo do vão do pilar com passo 0,2m (a) Análise não linear; (b) Análise não linear com fluência.

Figura 4.45 - Deformada do pilar [mm] obtida com passo $0,2 \mathrm{~m}$ para (a) Análise linear; (b) Análise não linear; (c) Análise não linear com fluência.

Figura 4.46 - Pórtico plano.

Figura 4.47 - Diagramas de análise do pórtico (a) Momento Fletor [kN.m] ; (b) Normal [kN].

Figura 4.48 - Diagramas de análise do pórtico (a) Armadura calculada [cm²]; (b) Armadura adotada [ $\left.\mathrm{cm}^{2}\right]$.

Figura 4.49 - Diagrama de armadura adotadas

Figura 4.50 - Pórtico plano com nome das vigas e pilares analisados. 123 Figura 4.51 - Redução na rigidez ao longo do vão de P2a (a) Passo 0,0 m; (b) Passo 1,0 m; (c) Passo 0,5 m; (d) Passo 0,2 m;

Figura 4.52 - Diagrama momento-curvatura para a seção do pilar P2a com carregamento normal de $-8118,3 \mathrm{kN}$.

Figura 4.53 - Redução na rigidez ao longo do vão de V1a (a) Passo 0,0 m; (b) Passo 1,0 m; (c) Passo 0,5 m; (d) Passo 0,2 m; 
Figura 4.54 - Iteração 0 - Diagrama de Momento Fletor - Análise Linear [kN.m].

Figura 4.55 - Iterações - Diagrama de Momento Fletor [kN.m].

Figura 4.56 - Diagrama de armadura para o passo 0,2 m (a) Calculada [cm²]; (b) Adotada [cm²].

Figura 4.57 - Diagrama de armadura para o passo 0,5 m (a) Calculada [cm²]; (b) Adotada [ $\left.\mathrm{cm}^{2}\right]$.

Figura 4.58 - Diagrama de armadura para o passo 1,0 m (a) Calculada [ $\left.\mathrm{cm}^{2}\right]$; (b) Adotada [ $\left.\mathrm{cm}^{2}\right]$.

Figura 4.59 - Pórtico plano com os nós para análise dos deslocamentos.

Figura 4.60 - Deformada do pórtico [mm] (a) Análise linear; (b) Análise não linear.

Figura 4.61 - Análise Linear (a) Diagrama de momento fletor [kN.m];

(b) Diagrama de normal [kN]; (c) Armadura calculada [cm²]; (d) Armadura adotada [ $\left.\mathrm{cm}^{2}\right]$.

Figura 4.62 - Análise Não linear com fluência (a) Diagrama de momento fletor [kN.m]; (b) Diagrama de normal [kN]; (c) Armadura calculada [cm²]; (d) Armadura adotada [ $\left.\mathrm{cm}^{2}\right]$.

Figura 4.63 - Diagramas de redução da rigidez no pilar P2a ao final da convergência (a) Não linear; (b) Não Linear com fluência.

Figura 4.64 - Diagramas de redução da rigidez na viga V1a ao final da convergência (a) Não linear; (b) Não Linear com fluência.

Figura 4.65 - Sobreposição dos gráficos de redução da rigidez na análise não linear com e sem fluência.

Figura 4.66 - Deformada do pórtico [mm] - Análise não linear com fluência.

Figura 4.67 - Efeitos de segunda ordem. 


\section{Lista de Tabelas}

Tabela 2.1 - Comparação: equações de equilíbrio e de compatibilidade

Tabela 2.2 - Analogia da Viga Conjugada 23

Tabela 2.3 - Conversão das restrições de apoio 25

Tabela 2.4 - Valores de $\beta 1$ para distribuição retangular de tensão no concreto -Tabela 22.2.2.4.3 do Building Code - ACl (2015) 34

Tabela 2.5 - Momento de inercia e área da seção permitida para análise elástica - Tabela 6.6.3.1.1(a) do Building Code - ACI (2015) 35 Tabela 2.6 - Momento de inercia alternativo para análise elástica Tabela 6.6.3.1.1(b) do Building Code - ACl (2015) 35 Tabela 2.7 - Propriedades da seção 42 Tabela 2.8 - Pontos de alteração na inclinação da curva momentocurvatura.

Tabela 2.9 - Valores de momento máximo e curvatura limite.

Tabela 3.1 - Coeficientes de ponderação das resistências no estadolimite último (ELU) - Tabela 12.1 da NBR 6118(ABNT, 2014)

Tabela 3.2 - Hipóteses análogas aos domínios 1 e 5 - Intervalos de deformação no concreto e curvatura.

Tabela 3.3 - Hipóteses análogas aos domínios 2, 3 e 4 - Intervalos da linha neutra e curvatura

Tabela 3.4 - Coeficientes de fluência e retração - Tabela 8.2 da NBR

6118: (ABNT, 2014)

Tabela 4.1 - Resultado do cálculo das armaduras pelos dois métodos 93 Tabela 4.2 - Convergência dos modelos - Relação dos nós de integração

Tabela 4.3 - Armadura final da seção de momento positivo com passo de $0,2 \mathrm{~m}$.

Tabela 4.4- Armadura final da seção de momento negativo com passo de $0,2 \mathrm{~m}$. 
Tabela 4.5 - Valores dos deslocamentos obtidos com a redução da inércia

Tabela 4.6 - Resultado das flechas obtidas para verificação ELS 104

Tabela 4.7 - Coeficientes de fluência e retração - Tabela 8.2 da NBR 6118(ABNT, 2014)

Tabela 4.8 - Armadura final da seção de momento positivo com passo de $0,0 \mathrm{~m}$ considerando a fluência: $\varphi=2,8$

Tabela 4.9 - Armadura final da seção de momento negativo com passo de $0,0 \mathrm{~m}$ considerando a fluência: $\varphi=2,8$

Tabela 4.10 - Comparação entre momentos, armadura calculada e adotada com as três análises - Seção com momento máximo positivo.108 Tabela 4.11 - Comparação entre momentos, armadura calculada e adotada com as três análises - Seção com momento máximo negativo

Tabela 4.12 - Resultado das flechas obtidas para verificação ELS

Tabela 4.13 - Valores de redução da rigidez na seção crítica para cada curva considerando os coeficientes de fluência.

Tabela 4.14 - Valores de redução da rigidez em seção com momento abaixo de fissuração para cada curva considerando os coeficientes de fluência.

Tabela 4.15 - Resumos dos valores de deslocamento no topo da seção para os passos dados.

Tabela 4.16 - Coeficientes de fluência e retração - Tabela 8.2 da NBR 6118(ABNT, 2014)

Tabela 4.17 - Comparação entre os valores de inércia secante, redução e deslocamento.

Tabela 4.18 - Convergência dos modelos - Relação dos nós de integração

Tabela 4.19 - Comparativo entre os deslocamentos com análise linear e não linear.

Tabela 4.20 - Coeficientes de fluência e retração - Tabela 8.2 da NBR

6118(ABNT, 2014)

Tabela 4.21 - Comparativo das três análises no pilar P2a.

Tabela 4.22 - Comparativo das três análises na viga V1a. 
Tabela 4.23 - Comparação dos deslocamentos obtidos.

Tabela 4.24 - Efeitos de segunda ordem. 


\section{Introdução}

\subsection{Motivação}

Sendo o concreto o material mais utilizado na construção civil no Brasil, deve-se atentar aos seus diferentes comportamentos particulares. Observa-se a resistência boa à compressão e baixa à tração. Quando exposto a um carregamento de tração, o concreto fissura e perde sua capacidade resistente na área fissurada. Desta forma, adota-se na construção o compósito concreto armado, com matriz de concreto e reforço de aço, que se complementam em suas propriedades.

Para o dimensionamento em solicitações normais, todas as forças de tração são resistidas pelo aço e considera-se do concreto apenas a parte comprimida da seção. Na análise estrutural, é necessário se avaliar a contribuição do concreto na rigidez da seção. Observa-se a necessidade de se avaliar a rigidez das várias seções ao longo de um vão, seja em um pilar ou em uma viga, que tem seu valor alterado de acordo com a fissuração da seção. Sendo a fissuração uma característica do material concreto, esta análise será não linear física, nomenclatura dada à não linearidade causada pelas características do material.

Num primeiro momento desta pesquisa, a análise não linear física foi estudada pela autora (Gomes, 2017) a partir de relações momento-curvatura. Foi analisado um edifício próximo à realidade com carregamentos reais. Este foi prédimensionado e após o dimensionamento com as seções definidas, inseriu-se a análise da não linearidade física. Os resultados podem ser observados no trabalho citado. A redução da rigidez obtida para os pilares foi da ordem de 0,3 . Porém, na metodologia adotada, as inércias das seções foram alteradas manualmente em cada seção, se restringindo apenas aos pilares do edifício, numa malha pouco refinada. Dado que o resultado obtido ficou bem distante do coeficiente 0,8 sugerido pela NBR 6118 (ABNT, 2014) em seu item 15.7.3, deseja-se evoluir para um melhor estudo da redução, com uma malha mais refinada e abrangendo seções das vigas e pilares. Assim, propõe-se o desenvolvimento de uma ferramenta computacional 
capaz de alterar as rijezas das seções de acordo com um dado refinamento. Assim, a pesquisa vai de encontro ao programa FTOOL (2015).

Sendo o FTOOL, um programa de análise estrutural com base no método dos deslocamentos, amplamente utilizado com objetivo educacional, observam-se as constantes contribuições que este vem recebendo para que seja também um programa para análise e dimensionamento de estruturas de concreto armado. Em 2004, Niskier (2004) acrescentou o dimensionamento de vigas em concreto armado ao programa, tendo como base a NBR 6118. Em 2017, Silva (2017) contribuiu com o dimensionamento de pilares, acrescentando a não linearidade geométrica e atualizando os métodos de dimensionamento para a revisão 2014 da NBR 6118 (ABNT, 2014). Neste trabalho acrescenta-se a não linearidade física, conforme exposto anteriormente, considerando a redução da rigidez causada pela fissuração do concreto.

Assim, propõe-se uma análise com inércia variável nas seções de concreto. Observa-se que é um processo complexo e com maior custo computacional, porém como as estruturas vêm se tornando maiores e mais esbeltas, tornam-se necessárias análises mais sofisticadas. Percebe-se que estruturas mais esbeltas têm seu comportamento mais diretamente afetado pela redução na rigidez por fissuração, já que seus efeitos de segunda ordem tendem a ser maiores. Aqui, propõe-se analisar a redução da rigidez da seção, conforme diagramas momento-curvatura construídos segundo a NBR 6118(ABNT, 2014), onde a partir da curvatura e momento atuante na seção, obtém-se a rigidez secante.

Em contrapartida, a NBR 6118 (ABNT, 2014) apresenta uma maneira aproximada para a consideração da não linearidade física do concreto na análise de estruturas com nós fixos. Em especial no item 15.7.3, são especificados os coeficientes para a redução da rigidez, para elementos de viga, pilar ou laje. Neste ponto, o trabalho propõe a comparação de seus resultados, desta vez com maior refinamento e considerando também seções de vigas.

\subsection{Objetivos}

O principal objetivo deste trabalho é inserir no programa base, o FTOOL, a análise não linear física do concreto armado. É considerada a rigidez como variável nas seções de concreto, sendo esta inserida a partir da metodologia da viga 
conjugada com base na rigidez secante calculada pelas relações momentocurvatura.

Propõe-se também a comparação com a análise aproximada sugerida pela NBR 6118 no seu item 15.7.3, além de um estudo para refinamento da análise com inércia variável, otimizando o custo computacional necessário para a convergência.

\subsection{Escopo}

O trabalho está organizado em 6 capítulos. O capítulo 2 faz uma revisão breve sobre os assuntos tratados neste trabalho, com base na literatura devidamente referenciada no capítulo 6. Descreve o processo adotado para a consideração da inércia variável ao longo das barras, a chamada analogia da viga conjugada. Faz também uma revisão sobre a maneira com que a NBR6118 e algumas normas internacionais lidam com a não linearidade física. Por fim, discorre-se sobre as curvas momento-curvatura e a sua relação com a não linearidade do material.

O capítulo 3 descreve todo o método implementado para que seja possível a consideração da não linearidade. Se apresenta a implementação computacional e como o usuário pode inserir os dados iniciais. Explica-se o processo numérico para a obtenção das curvas momento-curvatura e a integração numérica necessária para o uso da analogia da viga conjugada.

O capítulo 4 apresenta três exemplos para a análise da não linearidade física, mostrando nas aplicações o método e mostrando em gráficos, figuras e tabelas o impacto no dimensionamento. Todos os três exemplos são analisados em quatro tópicos. O primeiro descreve o modelo estrutural e a análise linear inicial necessária para o dimensionamento da seção. O segundo tópico mostra as iterações necessárias para a convergência do processo. O terceiro faz a análise dos deslocamentos e no quarto se insere a fluência, analisando seu impacto na redução de rigidez, recalculando-se tanto armaduras quanto deslocamentos.

O capítulo 5 traz as conclusões do trabalho, comentando os resultados obtidos, a comparação com a recomendação da Norma, comentários sobre o custo computacional da nova implementação e sugestões para próximos trabalhos.

O capítulo 6 traz as referências utilizadas para a construção deste trabalho. 


\section{2 \\ Revisão Bibliográfica}

Para desenvolvimento deste trabalho é necessário que se revisem alguns conceitos, ainda que estes já sejam amplamente conhecidos e discutidos na literatura. Os métodos utilizados foram brevemente citados na introdução deste trabalho, portanto, aqui se faz uma melhor explicação destes.

\subsection{Analogia da viga conjugada}

O programa base para desenvolvimento deste trabalho, o FTOOL, a partir do método dos deslocamentos faz a análise estrutural de pórticos planos, considerando a modelagem da estrutura por elementos de barra. A configuração final se dá pela superposição das barras isoladas.

Para a análise não linear das estruturas é necessário que seja conhecida a armadura das seções analisadas. Considerando uma viga em concreto armado de um edifício qualquer, dimensionado no estado limite último, a armadura da seção pode variar ao longo dos vãos conforme os diagramas de momentos fletores e forças normais e considerando a decalagem e a ancoragem das barras. Assim, a seção analisada no método dos deslocamentos não é necessariamente constante, sendo necessário definir um método que possa englobar a variação das propriedades seccionais nos elementos de barra.

No método dos deslocamentos, a seção dos elementos é considerada através do parâmetro de rigidez EI, onde E representa o módulo de deformação do material e I representa a inércia da seção; um parâmetro representa as características do material e outro a geometria da seção. O método sugerido pela NBR 6118, conforme seu item 15.3.1, que trata de momento-curvatura, implica considerar a rigidez secante da seção, mesmo parâmetro EI utilizado no método dos deslocamentos. Portanto, os valores obtidos nas curvas momento-curvatura podem ser diretamente aplicados no método dos deslocamentos. Em contrapartida, as soluções mais utilizadas no método envolvem elementos de barra com rigidez constante, o que não ocorre em estruturas de concreto armado, considerando a 
redução da rigidez pelo comportamento não linear e a variação da armadura ao longo do vão (para o caso de vigas). Desta forma, faz-se o uso da analogia da viga conjugada, também conhecida como processo de Mohr (Süssekind, 1977), para obtenção da solução de barras com rigidez variável, conforme Vilela (2008) e Martha (2015).

Na solução do método dos deslocamentos, os parâmetros principais são os coeficientes de rigidez locais, que são as forças e momentos que devem atuar nas extremidades da barra na direção das deslocabilidades, para equilibrá-la ao serem aplicados deslocamentos unitários. As deslocabilidades são os deslocamentos nas direções x e y ou a rotação em torno do eixo $z$, que devem ser conhecidos para a determinação da configuração final da estrutura.

A analogia da viga conjugada é baseada na comparação entre as equações diferenciais de equilíbrio e de compatibilidade. Essas equações são conhecidas da teoria das vigas de Navier, conforme a tabela 2.1.

Tabela 2.1 - Comparação: equações de equilíbrio e de compatibilidade

\begin{tabular}{|c|c|}
\hline Equações de Equilíbrio & Equações de Compatibilidade \\
\hline$\frac{d M}{d x}=Q(x)$ & $\frac{d v}{d x}=\theta(x)$ \\
\hline$\frac{d^{2} M}{d x^{2}}=q(x)$ & $\frac{d^{2} v}{d x^{2}}=\frac{M(x)}{E I(x)}$ \\
\hline
\end{tabular}

Conforme observa-se na tabela 2.1, o momento fletor $M(x)$ é análogo ao deslocamento $v(x)$, enquanto o cortante $Q(x)$ à rotação $\theta(x)$ e o carregamento $q(x)$ à $M(x) / E I(x)$. Assim, propõe-se a análise de uma viga utilizando as equações de compatibilidade de uma viga real, como se fossem as equações de equilíbrio de uma viga fictícia, sendo esta última a viga conjugada. Desta forma, adota-se como carregamento $M(x) / E I(x)$, como cortante $\theta(x)$ e momento fletor $v(x)$, conforme explicitado na tabela abaixo.

Tabela 2.2 - Analogia da Viga Conjugada

\begin{tabular}{|c|c|c|}
\cline { 2 - 3 } \multicolumn{1}{c|}{} & Viga Real & Viga Conjugada \\
\hline Carregamento & $q(x)$ & $q^{c}(x)=M(x) / E I(x)$ \\
\hline Esforço Cortante & $Q(x)$ & $Q^{c}(x)=\theta(x)$ \\
\hline Momento Fletor & $M(x)$ & $M^{c}(x)=v(x)$ \\
\hline Rotação & $\theta(x)$ & \multicolumn{1}{|c}{} \\
\hline Deslocamento Transversal & $v(x)$ &
\end{tabular}


Para a aplicação da analogia, devem-se converter as restrições de apoio da viga real para a conjugada. Na viga real, as condições de contorno são expressas como restrições de apoio, restringindo-se o deslocamento $v$ e a rotação $\theta$. Considerando a analogia proposta, na viga conjugada as restrições de deslocamentos são expressas em momentos $M(x)$ e as de rotação em cortantes $Q(x)$. A tabela 2.3 mostra todas as conversões de restrição de apoio da viga real para conjugada.

Conhecendo a conversão das restrições de apoio da viga real para a viga conjugada, pode-se fazer a análise com a seguinte sequência:

- Converter as restrições de apoio conforme a tabela 2.3;

- Determinar o diagrama de momentos fletores da viga real parametrizado pelos valores dos momentos nas extremidades das barras;

- Determinar o carregamento da viga conjugada. Neste ponto, insere-se a variação da rigidez da seção ao longo do vão da viga.

- Imposição das condições de equilíbrio da viga conjugada, equivalente às condições de compatibilidade da viga real.

É dado a seguir um exemplo para a determinação dos parâmetros de rigidez à rotação, sendo eles definidos por Süssekind (1977) como:

$K_{A}$ é o coeficiente de rigidez à rotação na extremidade inicial, sendo o momento que deve atuar na extremidade inicial de uma barra isolada para impor uma rotação unitária $\theta_{A}=1$ na extremidade inicial, enquanto todas as outras deslocabilidades são mantidas nulas;

$t_{A B}$ é o coeficiente de transmissão de momento da extremidade inicial para a extremidade final, sendo o parâmetro que estabelece a relação entre o coeficiente de rigidez $K_{A}$ e o momento que é necessário atuar na extremidade final para impor uma rotação $\theta_{A}=1$ na extremidade inicial enquanto todas as outras deslocabilidades são mantidas nulas. O momento da extremidade final sempre tem o mesmo sentido que $K_{A}$.

$K_{B}$ é o coeficiente de rigidez à rotação na extremidade final, sendo o momento que deve atuar na extremidade final de uma barra isolada para impor uma rotação unitária $\theta_{B}=1$ na extremidade final, enquanto todas as outras deslocabilidades são mantidas nulas; 
Tabela 2.3 - Conversão das restrições de apoio

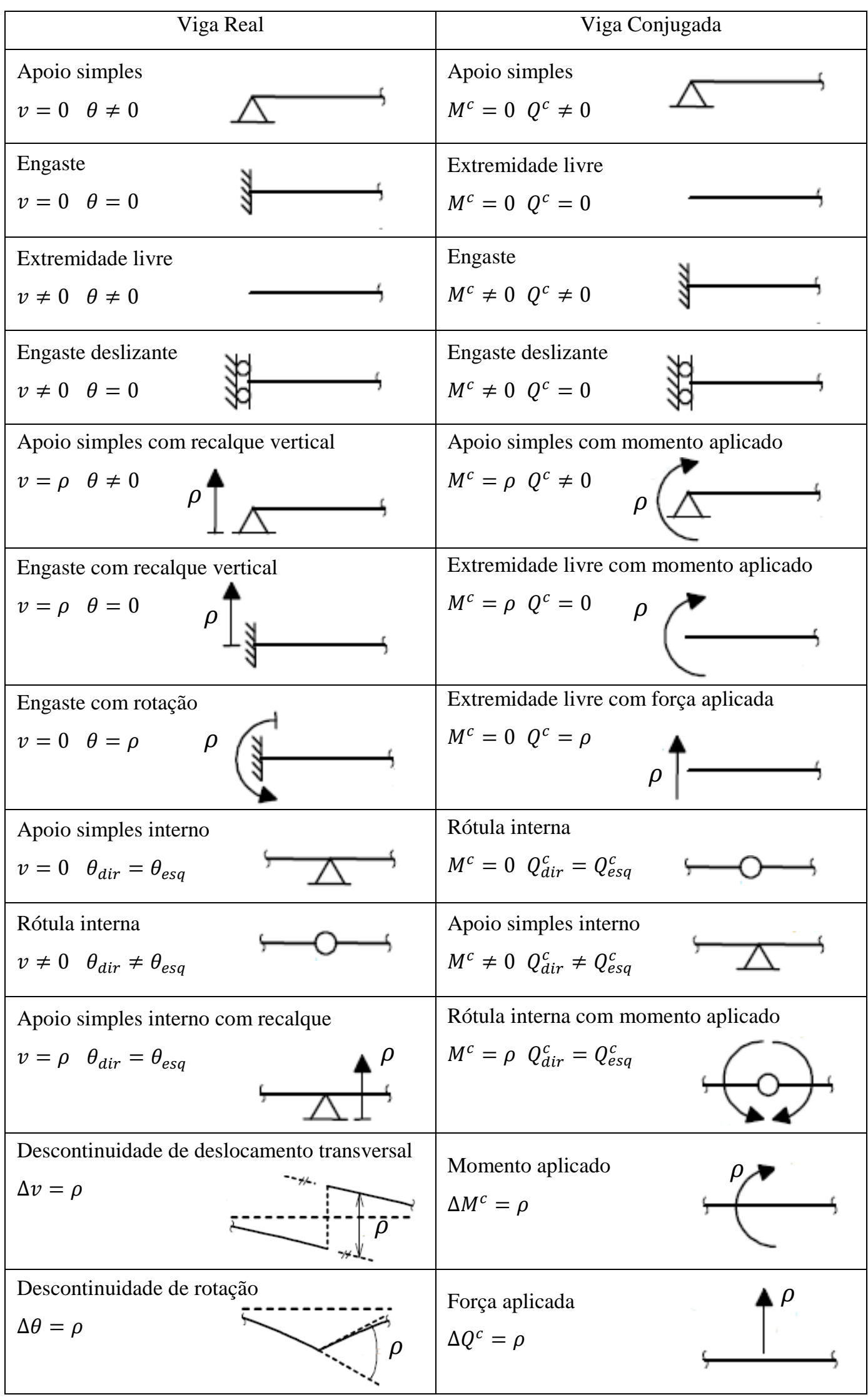


$t_{B A}$ é o coeficiente de transmissão de momento da extremidade final para a extremidade inicial, sendo o parâmetro que estabelece a relação entre o coeficiente de rigidez $K_{B}$ e o momento que é necessário atuar na extremidade inicial para impor uma rotação $\theta_{B}=1$ na extremidade final, enquanto todas as outras deslocabilidades são mantidas nulas. $\mathrm{O}$ momento da extremidade final sempre tem o mesmo sentido que $K_{B}$, conforme a figura 2.1 .
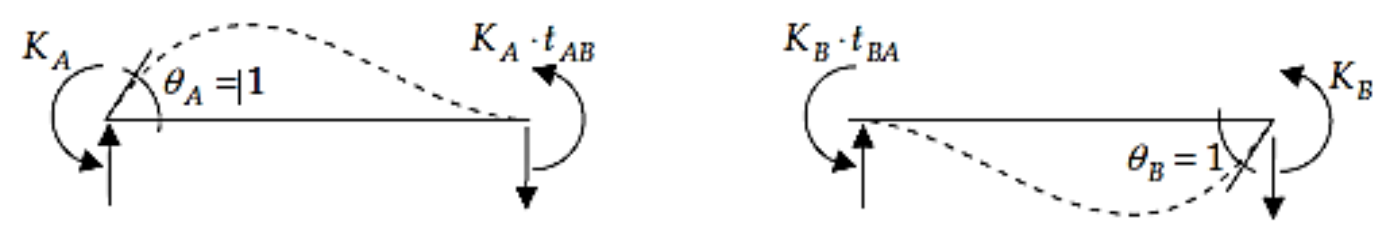

Figura 2.1- Parâmetros de rigidez à torção

Seja a viga biengastada, conforme a figura 2.2, em que se deseja obter os parâmetros de rigidez à rotação da viga $K_{A}$ e $t_{A B}$ referentes à extremidade inicial, a partir da determinação dos momentos atuantes nas extremidades $M_{A}$ e $M_{B}$. Portanto, aplica-se a rotação $\theta_{A}=\rho$. Para a conversão das restrições de apoio, observa-se na extremidade inicial um engaste com rotação aplicada; portanto, converte-se a extremidade livre com aplicação de força, enquanto a extremidade final é convertida de um engaste para extremidade livre, conforme a figura 2.2:
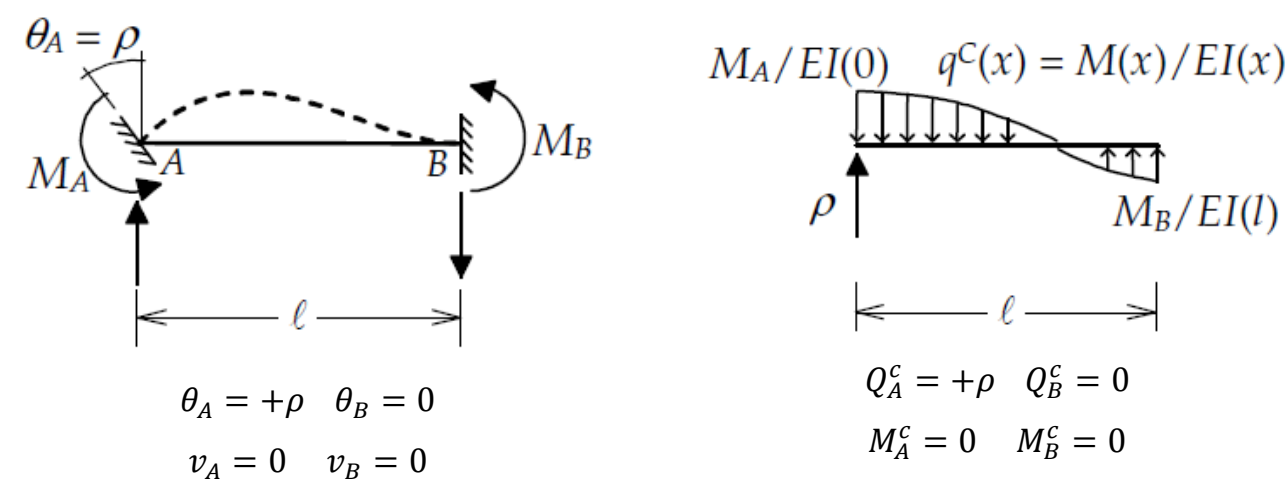

Figura 2.2 - Viga real e viga conjugada

A partir dos momentos de engastamento $M_{A}$ e $M_{B}$ na viga real, na figura 2.3 constrói-se o diagrama de momento fletores:

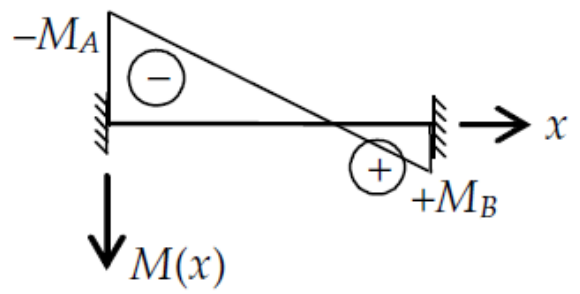

Figura 2.3 - Diagrama de momentos fletores da viga real 
Por conveniência, a figura 2.4 mostra a decomposição do diagrama de momentos fletores em duas parcelas lineares, uma referente a $M_{A}$ e outra a $M_{B}$.
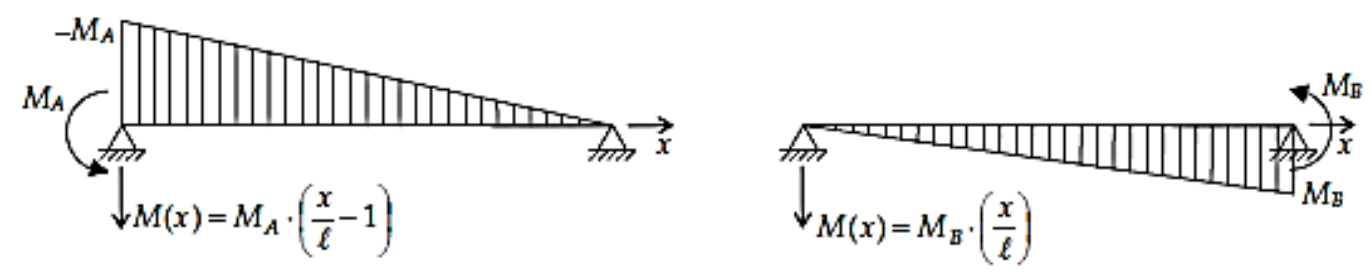

Figura 2.4 - Diagrama de momentos fletores decomposto em duas parcelas referentes aos momentos aplicados nas extremidades

Deve-se determinar o carregamento da viga conjugada, que conforme explicitado é calculado a partir do diagrama de momentos fletores da viga real e da rigidez da seção. É neste ponto que se insere a variação da rigidez da seção $E I(x)$. Desta forma o carregamento da seção é dado pela equação (2.1):

$$
q^{c}(x)=\frac{M(x)}{E I(x)}=\frac{M_{A} \cdot(x / l-1)+M_{B} \cdot x / l}{E I(x)}
$$

Considerando a viga conjugada obtida, devem-se aplicar as equações de equilíbrio, como um carregamento autoequilibrado, calculando-se o somatório das forças em y e o momento em torno do nó $\mathrm{A}$ - extremidade inicial, conforme as duas equações (2.2) e (2.3):

$$
\begin{aligned}
& \sum F_{y}^{c}=0 \rightarrow \int_{0}^{l} q^{c}(x) d x+\rho=0 \\
& \sum M_{A}^{c}=0 \rightarrow \int_{0}^{l} q^{c}(x) \cdot x d x=0
\end{aligned}
$$

Considerando as parcelas do momento para a expressão do carregamento atuante, as equações (2.2) e (2.3) se tornam:

$$
\begin{gathered}
\sum F_{y}^{c}=0 \rightarrow M_{A} \cdot \int_{0}^{l} \frac{x / l-1}{E I(x)} d x+M_{B} \cdot \int_{0}^{l} \frac{x / l}{E I(x)} d x+\rho=0 \\
\sum M_{A}^{c}=0 \rightarrow M_{A} \cdot \int_{0}^{l} \frac{x^{2} / l-x}{E I(x)} d x+M_{B} \cdot \int_{0}^{l} \frac{x^{2} / l}{E I(x)} d x=0
\end{gathered}
$$

Com as equações (2.4) e (2.5), forma-se um sistema e fica possível calcular os valores de $M_{A}$ e $M_{B}$. Com os valores conhecidos, calculam-se com as equações (2.6) e (2.7) os parâmetros de rigidez $K_{A}$ e $t_{A B}$ : 


$$
\begin{gathered}
K_{A}=\frac{M_{A}}{\rho} \\
t_{A B}=\frac{M_{B}}{M_{A}}
\end{gathered}
$$

De maneira análoga, obtêm-se os valores de $K_{B}$ e $t_{B A}$ conforme as equações (2.8) e (2.9), impondo uma rotação $\theta_{B}=\rho$ na extremidade final B e repetindo os passos conforme descrito anteriormente.

$$
\begin{aligned}
K_{B} & =\frac{M_{B}}{\rho} \\
t_{B A} & =\frac{M_{A}}{M_{B}}
\end{aligned}
$$

Observe-se que em alguns casos as integrais envolvidas nas equações (2.4) e (2.5) não tem solução analítica fechada, pois elas envolvem a divisão de polinômios. Desta forma, as integrais são resolvidas numericamente.

A metodologia para determinação de cargas equivalentes nodais em barras de inércia variável é análoga ao que foi descrito nesta seção, conforme Vilela (2008) e Martha (2015).

\subsection{Análise Não Linear}

A fim de simplificar análises mais complexas, utiliza-se a análise linear aproximando o comportamento das estruturas e dos materiais. Assim, criam-se hipóteses para esse comportamento, para tentar se aproximar da realidade. Em alguns casos, a análise linear apresenta resultados aceitáveis que são suficientes para uma análise estrutural e posterior dimensionamento. Por outro lado, em alguns casos faz-se necessária uma análise mais complexa, seja com referência ao material ou à estrutura.

A não linearidade é classificada em dois grupos. O primeiro chama-se não linearidade física, o que faz referência ao comportamento não linear do material, impossibilitando uma análise elástica-linear. O concreto é um exemplo de um material com comportamento não linear, em se tratando de sua relação tensãodeformação. Conforme se observa na NBR6118 (ABNT, 2014), seu item 8.2.10.1 define a relação entre tensão e deformação pela equação (2.10) onde a deformação é elevada a uma potência $n$ - referente à classe do concreto, com gráfico conforme a figura 2.5. 


$$
\sigma_{c}=0,85 f_{c d}\left[1-\left(1-\frac{\varepsilon_{c}}{\varepsilon_{c 2}}\right)^{n}\right]
$$

Onde,

$\sigma_{c}$ é a tensão de compressão no concreto;

$f_{c d}$ é a tensão resistente de cálculo do concreto;

$f_{c k}$ é a tensão resistente característica do concreto;

$\varepsilon_{c}$ é a deformação em uma dada fibra do concreto;

$\varepsilon_{c 2}$ é a deformação limite de encurtamento no concreto no patamar plástico.

$\varepsilon_{c u}$ é a deformação de encurtamento do concreto na ruptura.

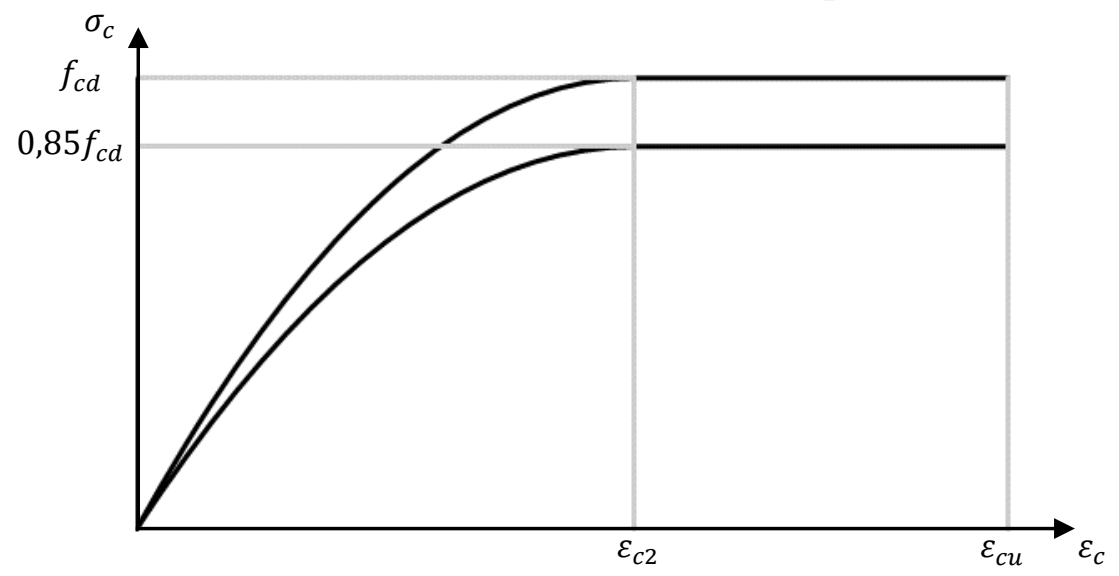

Figura 2.5 - Diagrama tensão-deformação - Adaptada da figura 8.2 da NBR 6118(ABNT, 2014)

Observa-se que para tensões inferiores à 0,5 $f_{c}$, a Norma permite a análise elástica-linear com o módulo de deformação do concreto com o valor secante, conforme seu item 8.2.8.

A fim de simplificar o comportamento não linear do concreto, a NBR 6118 (ABNT, 2014) fornece as hipóteses básicas definidas em seu item 17.2.2, onde em uma delas permite-se que o diagrama tensão-deformação parábola-retângulo seja substituído por um retângulo de profundidade $\lambda x$ com tensão constante de valor igual a $a_{c} f_{c d}$, conforme a figura 2.6. Os parâmetros $\lambda$ e $a_{c}$ dependem da classe do concreto. 


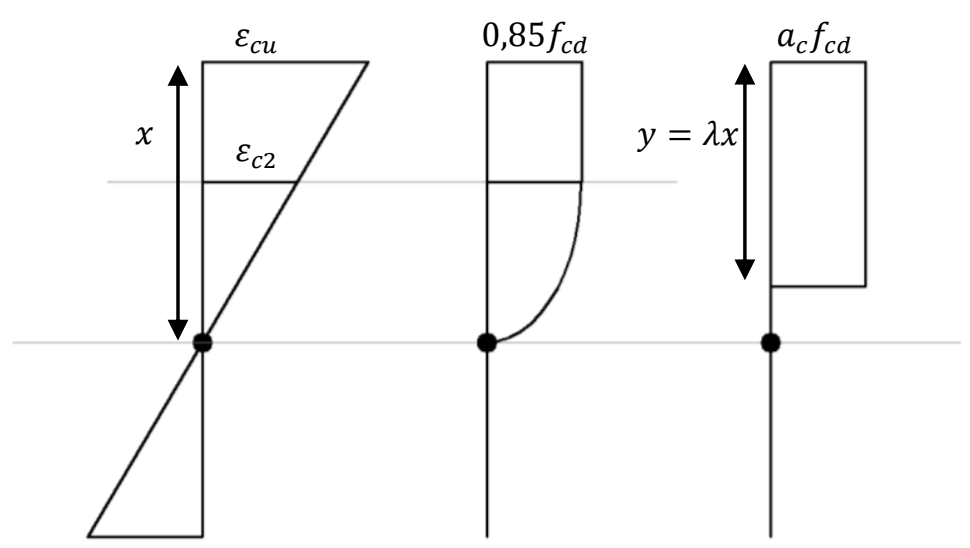

Figura 2.6 - Diagramas da tensão e deformação no concreto

Observa-se que o comportamento não linear não é substituído por um comportamento linear, já que a relação de tensão-deformação se torna uma constante. Porém esta é uma das hipóteses básicas definidas pela NBR 6118 para que se simplifique o comportamento não linear do material.

O segundo grupo é chamado de não linearidade geométrica, referente aos esforços causados pelos deslocamentos da estrutura, ou seja, quando os esforços internos, por exemplo, devem ser obtidos considerando-se a estrutura deformada. O método P-delta é uma forma de consideração simplificada da não linearidade geométrica da estrutura; com a estrutura deformada considera-se o efeito dos momentos gerados pelas forças verticais vezes o deslocamento do nó de aplicação desta força. Para a consideração deste efeito, substitui-se a análise não linear, por várias análises lineares aplicando-se cargas horizontais fictícias que produzam o mesmo efeito que o momento gerado pelo deslocamento da força vertical. Consultando a figura 2.7, no nó 1 , o binário de forças fictícias aplicadas $H_{1}$ deverá produzir no nó 2 , o mesmo momento que a força $N_{1}$ produz com o braço de alavanca da diferença entre os deslocamentos dos nós 1 e 2 . Assim, as forças fictícias são dadas pela equação (2.11):

$$
H_{1}=\frac{N_{1}\left(a_{1}-a_{2}\right)}{h_{1}}
$$



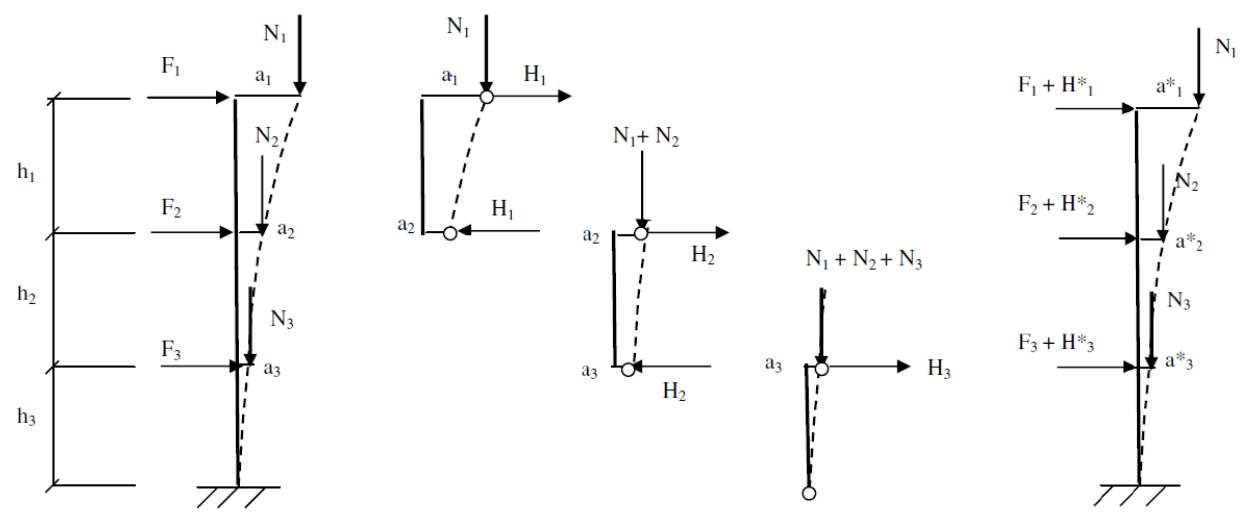

Figura 2.7 - Método P-Delta

Estes são apenas dois exemplos de como, no geral, a não linearidade pode ser simplificada, permitindo que se façam as análises aplicando as hipóteses básicas e sobrepondo resultados conhecidos de problemas mais simples.

Este trabalho trata da não linearidade do concreto gerada pela fissuração, que é uma não linearidade física. Sabe-se que ao fissurar, parte da seção perde sua capacidade de resistência e rigidez, o que leva a não linearidade neste trabalho ser traduzida por um fator de redução localizada da rigidez.

\subsubsection{Abordagem da Norma Brasileira}

A NBR 6118 (ABNT, 2014), faz observações sobre a consideração da não linearidade física e geométrica. Quanto à não linearidade física, foco principal deste trabalho, seu item 14.5.5 define que:

- Na análise não linear deve-se considerar o comportamento não linear geométrico e dos materiais (físico).

- Toda a geometria da estrutura, bem como todas as suas armaduras, precisam ser conhecidas, pois a resposta da estrutura depende de como ela foi armada.

- As condições de equilíbrio, de compatibilidade e de ductilidade devem ser necessariamente satisfeitas. Pode-se adotar análise não linear tanto para verificações de estados limites últimos como de estados limites de serviço.

Para a análise dos esforços solicitantes no estado limite último, pode-se adotar procedimentos aproximados definidos conforme o item 15 da Norma. Com relação ao comportamento físico, seu item 15.3 define que "a não linearidade física, presente nas estruturas de concreto armado, deve ser obrigatoriamente considerada". 
O item 15.3.1 define que "o principal efeito da não linearidade física pode em geral, ser considerado através da construção da relação momento-curvatura para cada seção, com armadura suposta conhecida, e para o valor da força normal atuante". Desta forma, adota-se a relação momento-curvatura como base nas análises feitas neste trabalho.

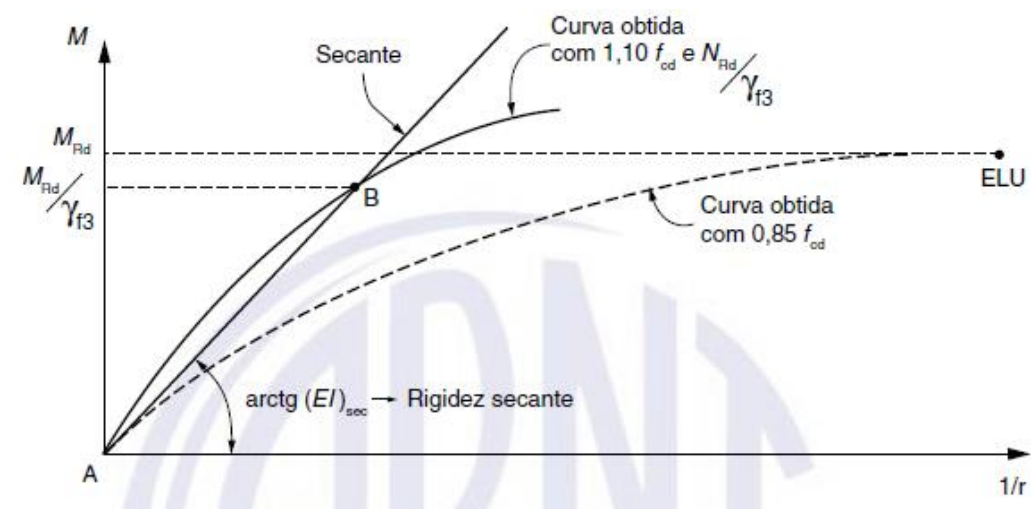

Figura 2.8 - Diagrama momento-curvatura - Figura 15.1 da NBR 6118 (ABNT, 2014)

A curva $\mathrm{AB}$ da figura 2.8 é obtida considerando-se o valor da força normal $N_{R d} / \gamma_{f 3}$, onde $N_{R d}$ é a força resistente normal última e $\gamma_{f 3}$ a parte do coeficiente de ponderação das ações $\gamma_{f}$, que considera os desvios gerados nas construções e as aproximações feitas em projeto do ponto de vista das solicitações. $\gamma_{f 3}$ é definido no referido item da Norma como $\gamma_{f 3}=1,1$. De maneira conservadora, a norma sugere a linearização da curva $\mathrm{AB}$ para a reta $\mathrm{AB}$, caracterizando a rigidez secante da seção $E I_{s e c}$, que pode ser utilizada em processos aproximados para flexão composta normal ou oblíqua.

Neste trabalho, adotam-se estes conceitos de momento-curvatura, porém considerando que o referido item trata de efeitos de $2^{\mathrm{a}}$ ordem, serão utilizadas curvas obtidas com a tensão máxima no concreto de $0,85 f_{c d}$ e a força normal atuante de cálculo. Observa-se que neste trabalho os efeitos de $2^{\mathrm{a}}$ ordem não são tratados, mas no exemplo 4.3 faz-se uma breve consideração do efeito P-Delta.

Além disto, adota-se o diagrama tensão-deformação do concreto conforme o item 8.2.10 da NBR 6118, o que será melhor explicado no item 3.2.3 deste trabalho. 


\subsubsection{Abordagem das Normas Internacionais}

\subsubsection{ACl - American Concrete Institute}

Consultando o Building Code e o Building Code Commantary (ACI, 2015), em seu item 22.2.2 discorre-se sobre a relação não linear entre tensões e deformações do concreto. Diferentemente dos valores da NBR 6118 (ABNT, 2014), é recomendada a adoção de 0,003 para a máxima deformação de compressão no concreto. Os comentários afirmam que a deformação específica do concreto, na ruptura à compressão obtida em diferentes tipos de testes, varia de 0,003 até valores superiores a 0,008 em determinadas condições especiais. Entretanto, para elementos de proporções normais, a deformação onde a resistência máxima é obtida fica entre 0,003 e 0,004 .

Para o desenvolvimento de projetos, a ACI (2015) permite, no item 22.2.2.3, que a relação tensão-deformação à compressão tenha a representação aproximada de retângulo, parábola, trapézio ou outra forma em que a resistência resultante esteja em concordância com os resultados dos ensaios à compressão. No item 22.2.2.4, recomenda-se a adoção do formato retangular, mesmo formato simplificado da NBR 6118, desde que:

- A tensão de compressão no concreto seja igual a $0,85 f^{\prime}{ }_{c}$, onde $f^{\prime}{ }_{c}$ é a resistência característica do concreto à compressão, e uniforme em toda a região comprimida da seção, região esta limitada pelas bordas da seção e uma linha paralela à linha neutra a distância $a$ da fibra mais comprimida, calculada pela equação (2.12):

$$
a=\beta_{1} c
$$

- A distância $c$ da fibra mais comprimida da seção até a linha neutra deve ser medida perpendicularmente à linha neutra;

- O fator $\beta_{1}$ é obtido de acordo com a resistência do concreto, conforme a tabela 2.4 : 
Tabela 2.4 - Valores de $\beta_{1}$ para distribuição retangular de tensão no concreto -Tabela 22.2.2.4.3 do Building Code - ACI (2015)

\begin{tabular}{|c|c|c|}
\hline$f^{\prime}{ }_{c}, M P a$ & $\beta_{1}$ & \\
\hline $17 \leq{f^{\prime}}^{\prime} \leq 28$ & 0.85 & (a) \\
\hline $28<{f^{\prime}}^{\prime}<55$ & $0.85-\frac{0.05\left(f^{\prime}{ }_{c}-28\right)}{7}$ & (b) \\
\hline$f^{\prime}{ }_{c} \geq 55$ & 0.65 & (c) \\
\hline
\end{tabular}

É dada na figura 2.9 a distribuição das tensões de compressão no concreto conforme a ACI (2015):

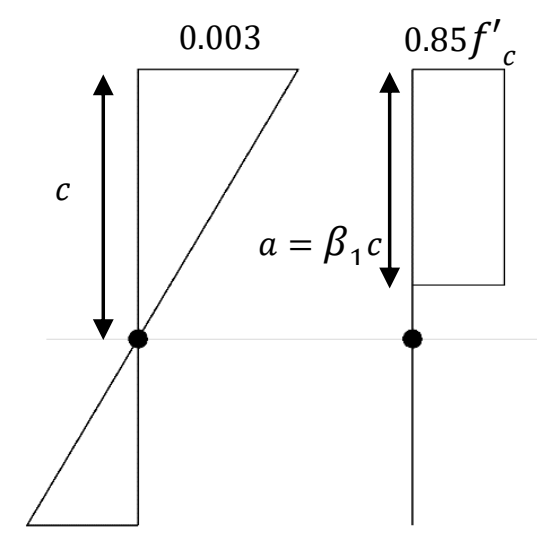

Figura 2.9 - Diagramas da tensão e deformação no concreto - ACI (2015)

O item 6.7 discorre sobre análises de segunda ordem elásticas. Neste item, faz-se referência ao uso de rigidez reduzida para consideração da fissuração e fluência, sendo estas as não linearidades físicas principais do concreto. Observa-se que neste mesmo item, trata-se da não linearidade geométrica, definindo como considerar os efeitos de segunda ordem da estrutura deformada.

Nos comentários, explica-se que a rigidez EI usada na análise deve representar a rigidez do elemento imediatamente antes da falha. O método exposto é válido para análises de segunda ordem, onde se deve prever a deflexão ao se aproximar do carregamento último para a ruptura da seção. Porém, observa-se que o valor da rigidez EI não deve ser baseado apenas na relação momento-curvatura para a seção mais carregada de um vão. Recomenda-se um fator de redução da rigidez $\phi_{K}$ para a análise, que deve ser menor do que 1 . Observa-se que as propriedades da seção calculadas conforme o item 6.6.3.1 já consideram esta redução. 
No item 6.6.3.1 são fornecidas duas tabelas com os valores dos coeficientes de redução recomendados, devendo-se escolher uma delas, conforme reproduzido nas tabelas 2.5 e 2.6 .

Tabela 2.5 - Momento de inercia e área da seção permitida para análise elástica - Tabela 6.6.3.1.1(a) do Building Code - ACI (2015)

\begin{tabular}{|l|l|c|c|}
\hline \multicolumn{2}{|c|}{ Member and condition } & Moment of Inertia & Cross-sectional area \\
\hline \multirow{2}{*}{ Columns } & Uncracked & $0.7 I_{g}$ & \\
\cline { 2 - 3 } & Cracked & $0.7 I_{g}$ & \multirow{2}{*}{$1.0 A_{g}$} \\
\hline Beams & $0.35 I_{g}$ & \\
\cline { 1 - 2 } Flat plates and flat slabs & $0.35 I_{g}$ & \\
\hline
\end{tabular}

Tabela 2.6 - Momento de inercia alternativo para análise elástica - Tabela 6.6.3.1.1(b) do

Building Code - ACI (2015)

\begin{tabular}{|c|c|c|c|}
\hline \multirow{2}{*}{ Member } & \multicolumn{3}{|c|}{ Alternative value of I for elastic analysis } \\
\cline { 2 - 4 } & Minimum & I & Maximum \\
\hline $\begin{array}{c}\text { Columns and } \\
\text { Walls }\end{array}$ & $0.35 I_{g}$ & $\left(0.8+25 \frac{A_{s t}}{A_{g}}\right)\left(1-\frac{M_{u}}{P_{u} h}-0.5 \frac{P_{u}}{P_{0}}\right) I_{g}$ & $0.875 I_{g}$ \\
\hline $\begin{array}{c}\text { Beams, flat } \\
\text { plates and flat } \\
\text { slabs }\end{array}$ & $0.25 I_{g}$ & $(0.10+25 \rho)\left(1.2-0.2 \frac{b_{w}}{d}\right) I_{g}$ & $0.5 I_{g}$ \\
\hline
\end{tabular}

Onde,

$h$ é a altura da seção;

$b_{w}$ é a largura da mesa;

$d$ é a altura útil da seção;

$\rho$ é a taxa de armadura calculada pela razão entre a área de aço total e a área útil da seção;

$I_{g}$ é o momento de inércia da seção bruta;

$A_{s t}$ é a área total de armadura passiva na seção;

$A_{g}$ é a área da seção bruta de concreto;

$M_{u}$ é o momento de cálculo atuante na seção;

$P_{u}$ é a força normal de cálculo atuante na seção;

$P_{0}$ é a normal resistente nominal da seção, sem excentricidade.

O item 6.8, intitulado "Análise de segunda ordem inelástica", descreve que deve-se considerar a não linearidade do material, recomendando a adoção dos mesmos fatores de redução das tabelas 6.6.3.1.1(a) e (b). 


\subsubsection{EN-1992-2-2 - Eurocode 2}

A norma europeia, no seu item 3.1.5, apresenta a definição da relação tensãodeformação para análises estruturais não lineares, válida para tensões de compressão e deformações de encurtamento, conforme as equações (2.13) e (2.14):

$$
\begin{gathered}
\frac{\sigma_{c}}{f_{c m}}=\frac{k \eta-\eta^{2}}{1+(k-2) \eta} \\
\eta=\frac{\varepsilon_{c}}{\varepsilon_{c 1}} \quad k=1,05 E_{c m} \frac{\left|\varepsilon_{c 1}\right|}{f_{c m}}
\end{gathered}
$$

Onde,

$\sigma_{c}$ é a tensão de compressão no concreto;

$\varepsilon_{c}$ é a deformação específica de encurtamento no concreto;

$\varepsilon_{c 1}$ é a deformação específica no pico de tensão do diagrama;

$E_{c m}$ é o módulo de elasticidade do concreto, determinado de maneira aproximada com a secante no diagrama de tensão-deformação à tensão $0,4 f_{c m}$;

$f_{c m}$ é a resistência média à compressão ao final de 28 dias.

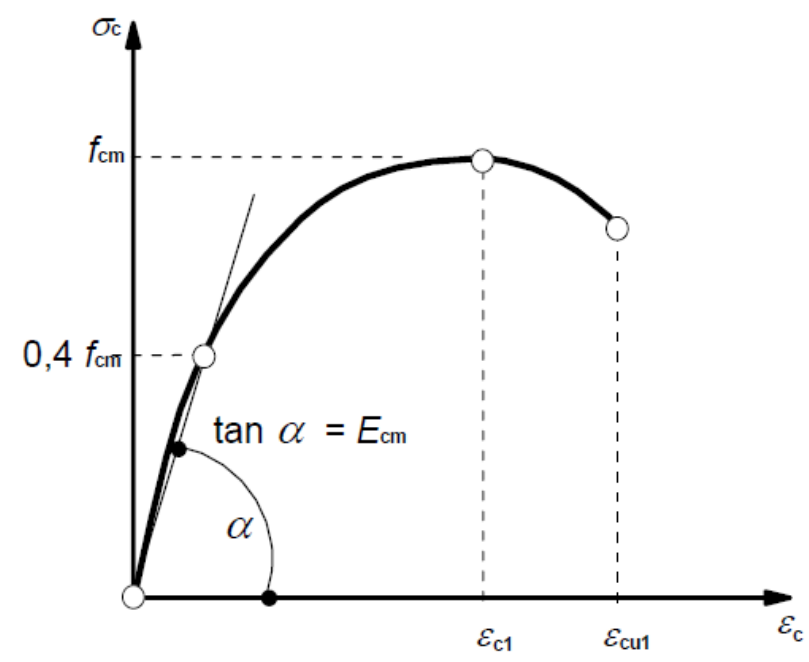

Figura 2.10 - Diagrama tensão-deformação - Figura 3.2 do EN 1992-1-1:2004

Seja $f_{c k}$ a resistência característica do concreto a compressão, os valores de $\varepsilon_{c 1}, E_{c m}$ e $f_{c m}$ podem ser obtidos na tabela 3.1 da referida norma ou calculados pelas equações (2.15), (2.16) e (2.17):

$$
\begin{gathered}
\varepsilon_{c 1}(\% 0)=0,7 f_{c m}^{0,31}<2,8 \\
E_{c m}=22\left[\frac{f_{c m}[M P a]}{10}\right]^{0,3}
\end{gathered}
$$




$$
f_{c m}=f_{c k}+8[\mathrm{MPa}]
$$

Para o dimensionamento de seções de concreto armado, o item 3.1.7 apresenta algumas simplificações para a relação tensão-deformação, ilustrada na figura 2.11. Semelhantemente às simplificações da norma brasileira, o diagrama tensãodeformação pode ser reduzido ao digrama parábola-retângulo dado pelas equações (2.18) e (2.19):

$$
\begin{gathered}
\sigma_{c}=f_{c d}\left[1-\left(1-\frac{\varepsilon_{c}}{\varepsilon_{c 2}}\right)^{n}\right], \text { se } 0 \leq \varepsilon_{c} \leq \varepsilon_{c 2} \\
\sigma_{c}=f_{c d}, \text { se } \varepsilon_{c 2} \leq \varepsilon_{c} \leq \varepsilon_{c u}
\end{gathered}
$$

O coeficiente $n$, a deformação específica para máxima tensão $\varepsilon_{c 2}$ e a deformação específica última $\varepsilon_{c u}$ são calculados da mesma forma apresentada pela NBR 6118.

Observa-se que a tensão máxima de resistência, diferentemente da NBR 6118, é dada por $\alpha_{c c}$. $f_{c d}$, quando na NBR 6118 ela é dada por $0,85 f_{c d}$. O coeficiente $\alpha_{c c}$, definido no item 3.1.6 desta norma, considera os efeitos da perda de resistência com carregamentos de longa duração e os efeitos desfavoráveis da maneira que o carregamento é aplicado. Este coeficiente, que deve estar entre 0,8 e 1,0, deve ser definido no National Annex de cada país.

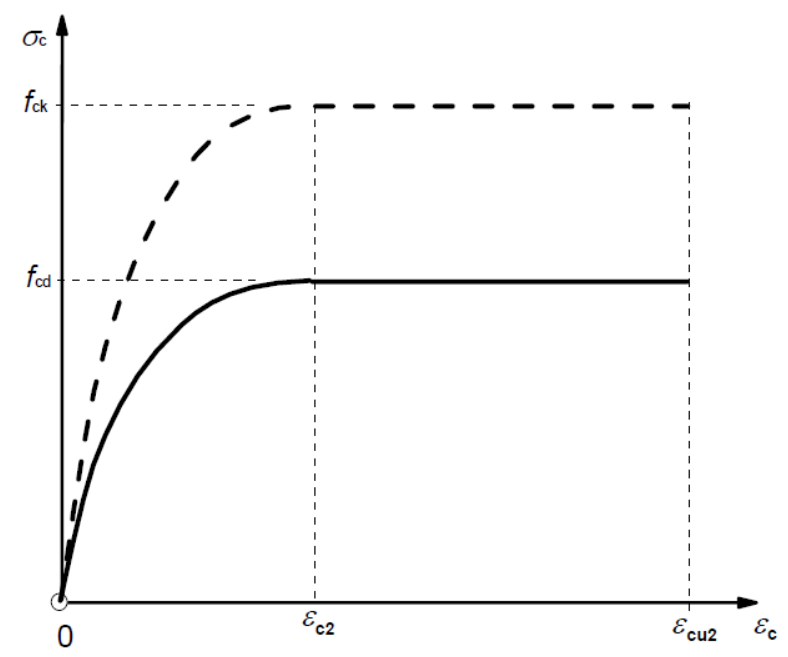

Figura 2.11 - Diagrama parábola-retângulo da tensão-deformação - Figura 3.3 do EN 1992-1-

$1: 2004$

No mesmo item, também permite-se assumir a distribuição retangular das tensões mostrada na figura 2.12, aplicando-se um fator $\lambda$ para o cálculo da altura efetiva na região comprimida e um fator $\eta$ para a resistência efetiva, apresentados nas equações (2.20) e (2.21). 
Se $f_{c k} \leq 50 M P a$,

$$
\lambda=0,8 \text { e } \eta=1 \text {, }
$$

Se $50<f_{c k} \leq 90 M P a$,

$$
\lambda=0,8-\left(\frac{f_{c k}-50}{400}\right) \text { e } \eta=1,0-\left(\frac{f_{c k}-50}{200}\right)
$$

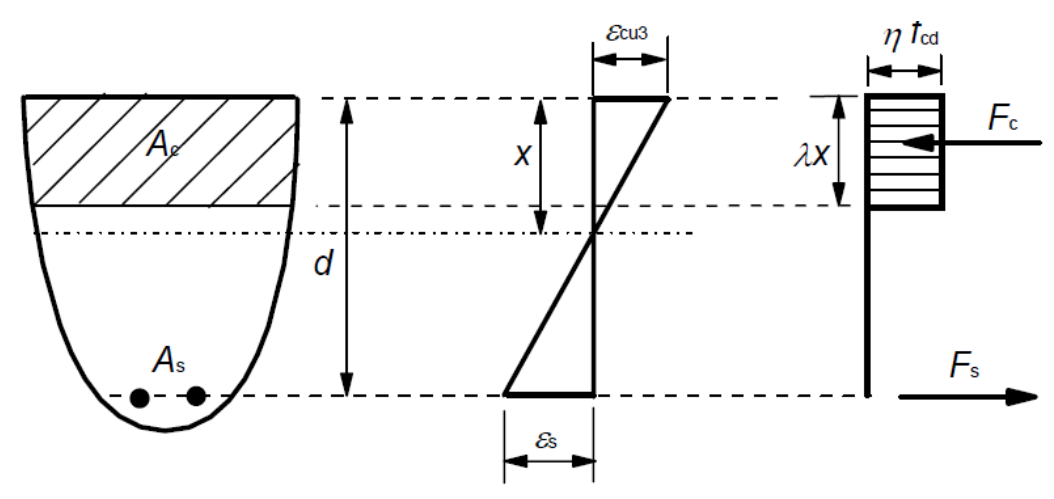

Figura 2.12 - Distribuição retangular da seção - Figura 3.5 do EN 1992-1-1:2004

Observa-se que a NBR 6118(ABNT, 2014) permite a mesma simplificação, com o mesmo cálculo para $\lambda$. O coeficiente $\eta$ apresenta valores diferentes nas normas, porque as normas calculam de maneira diferente a resistência de cálculo do concreto à compressão.

O Eurocode (CEN, 2004), no seu item 5.7, fala especificamente sobre a análise não linear:

- Os métodos de análise não linear podem ser utilizados no estado limite último e no estado limite de serviço, desde que o equilíbrio e a compatibilidade sejam satisfeitos e que o comportamento não linear físico dos materiais seja considerado adequadamente. A análise pode ser de primeira ou segunda ordem;

- No estado limite último, a capacidade de seções críticas locais de resistirem a qualquer deformação não elástica dada pela análise, deve ser verificada, considerando adequadamente as incertezas;

- Para estruturas predominantemente sujeitas a carregamentos estáticos, os efeitos de aplicação de carregamentos anteriores podem, no geral, serem ignorados, e o crescimento monotônico da intensidade das ações pode ser utilizado;

- As características do material utilizadas a serem adotadas para a análise não linear devem representar a rigidez de uma forma realista, considerando as incertezas na ruptura. 
- Em estruturas esbeltas, onde os efeitos de segunda ordem não podem ser ignorados, deve-se utilizar o método de dimensionamento do item 5.8.6 da referida norma intitulado General Method.

Para análises de segunda ordem, o Eurocode (CEN, 2004) fornece dois métodos para a análise não linear. Observa-se que para efeitos de segunda ordem, a não linearidade deve ser obrigatoriamente considerada, tanto a física quanto a geométrica. Desta forma, os métodos de análise não linear referentes ao material, assim como na NBR 6118, são explicitados nos itens referentes a análise de segunda ordem.

O primeiro método proposto, intitulado Método Baseado na Rigidez Nominal, é definido no item 5.8.7, onde se define uma rigidez nominal considerando os efeitos de fissuração, não linearidade física e fluência no comportamento geral da estrutura. Calcula-se o momento de cálculo resultante, resultado da amplificação do momento de primeira ordem, que deve ser adotado no dimensionamento das seções.

A rigidez nominal é calculada com a equação (2.22):

$$
E I=K_{c} E_{c d} I_{c}+K_{s} E_{s} I_{s}
$$

Onde,

$E_{c d}$ é o módulo de elasticidade do concreto de cálculo;

$I_{C}$ é o momento de inércia da seção;

$E_{S}$ é o módulo de elasticidade do aço;

$I_{S}$ é o momento de inércia da armadura em relação ao centro da área de concreto;

$K_{C}$ é um fator para consideração dos efeitos da fissuração;

$K_{S}$ é um fator para consideração da contribuição das armaduras.

Desta forma, com o valor da rigidez nominal, utiliza-se a equação (2.23) para calcular o fator de amplificação do momento a ser aplicado ao momento de primeira ordem:

$$
M_{E d}=M_{0 E d}\left[1+\frac{\beta}{\left(N_{B} / N_{E d}\right)-1}\right]
$$

Onde,

$M_{0 E d}$ é o momento fletor de primeira ordem;

$\beta$ é um fator relativo à distribuição do momento fletor (constante, parabólico, triangular, etc); 
$N_{B}$ é a força normal crítica de flambagem obtida com a rigidez nominal;

$N_{E d}$ é a força normal atuante de cálculo.

O segundo método, intitulado Método Baseado na Curvatura Nominal, não faz referência à não linearidade do material. Sendo descrito no item 5.8.8, neste método, calcula-se um momento fletor adicional baseado na deflexão, que por sua vez é calculada pela máxima curvatura aproximada.

\subsubsection{3. fib - Model Code 2010}

O Model Code 2010 (FIB, 2013) faz referência à não linearidade da relação tensão-deformação, porém de forma diferente da NBR6118 e semelhante à do Eurocode.

No item 5.1.8, a relação tensão-deformação, mostrada na figura 2.13, para carregamentos de compressão é dada pelas equações (2.24) e (2.25):

$$
\begin{gathered}
\sigma_{c}=f_{c m}\left[\frac{k \cdot \eta-\eta^{2}}{1+(k-2) \cdot \eta}\right], \text { se }\left|\varepsilon_{c}\right|<\left|\varepsilon_{c, l i m}\right| \\
\eta=\frac{\varepsilon_{c}}{\varepsilon_{c 1}} \quad k=\frac{E_{c i}}{E_{c 1}}
\end{gathered}
$$

Onde,

$\varepsilon_{c 1}$ é a deformação específica máxima de encurtamento;

$E_{c 1}$ é o módulo secante partindo da origem até o pico de tensão de compressão;

$k$ é o número de plasticidade.

Os valores de $\varepsilon_{c 1}, E_{c 1}$ e $k$ são dados pela tabela 5.1-8 do Model Code 2010.

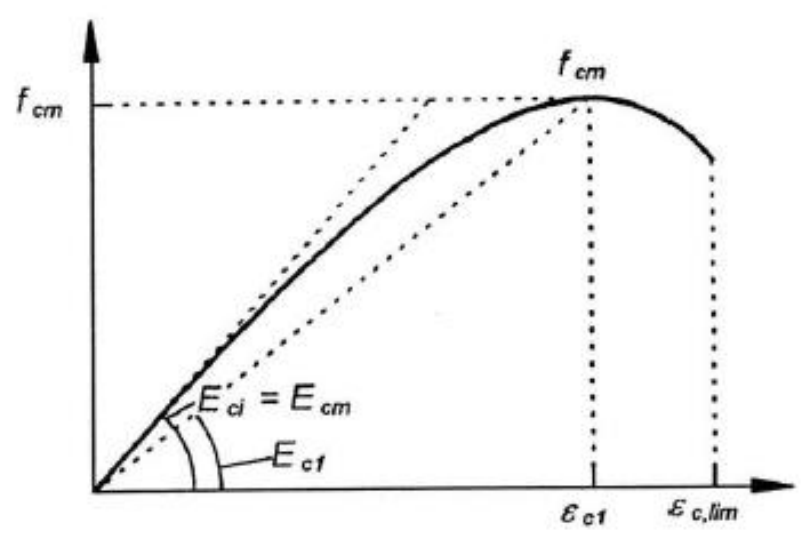

Figura 2.13 - Diagrama tensão-deformação - Figura 5.1-3 do Model Code 2010 
O Model Code 2010 (FIB, 2013) não faz referência a não linearidade física do material, porém adota o mesmo método da curvatura nominal do Eurocode (CEN, 2004) para o cálculo dos momentos de segunda ordem a serem adicionados ao momento obtido na análise de primeira ordem.

\subsection{Relação Momento-Curvatura}

Conforme citado nas recomendações das normas no item anterior, a relação momento-curvatura deve ser utilizada para a consideração da não linearidade dos materiais. Observa-se que, em análises de estruturas em geral, os materiais são considerados com comportamento elástico-linear. Porém, é sabido que os materiais aço e concreto não se comportam linearmente. Portanto, a rigidez destes materiais também não terá comportamento linear.

A relação momento-curvatura põe em evidência a não linearidade das relações tensão-deformação do aço e do concreto. Segundo a NBR 6118, o concreto possui comportamento elástico até alcançar a deformação específica $\varepsilon_{c 2}$, quando entra em um patamar plástico e sofre aumento de deformação sem acréscimo de tensão, fixada em $0,85 f_{c d}$, até atingir o limite último de deformação $\varepsilon_{c u}$. O mesmo ocorre com o aço, que atinge o patamar plástico na deformação $\varepsilon_{y d}$ com tensão fixada em $f_{y d}$ até atingir o valor último de deformação.

Para construção dos diagramas momento-curvatura é necessário que algumas hipóteses sejam admitidas:

- As seções permanecem planas após a deformação. Logo, é possível fazer a relação da curvatura com as deformações da seção, sendo aquela o gradiente destas;

- Considera-se a aderência entre as barras de aço e o concreto, não havendo deslizamento na região de contato entre os materiais;

- Considera-se que a força normal e o momento fletor atuantes são aplicados no centroide da seção;

- Despreza-se completamente a resistência do concreto à tração, logo, todo o esforço de tração é resistido pelas armaduras.

Como exemplo, seja um pilar em concreto armado com seção de $20 \times 50 \mathrm{~cm}$ com carregamento normal de compressão de $1500 k N$ e armadura conhecida, ilustrada na figura 2.14 com suas características descritas na tabela 2.7. Constrói-se a curva momento-curvatura com o código desenvolvido para o FTOOL. 


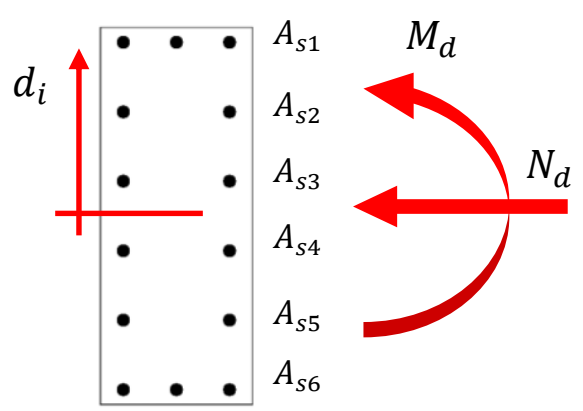

Figura 2.14 - Seção de exemplo para construção do momento-curvatura

Tabela 2.7 - Propriedades da seção

\begin{tabular}{|c|c|c|c|}
\hline Concreto & $f_{c k}=30$ & & $\gamma_{c}=1,4$ \\
\hline Aço & $f_{y}=500$ & & $v_{s}=1,15$ \\
\hline Seção & \multicolumn{3}{|c|}{$20 \times 50 \mathrm{~cm}$} \\
\hline Normal Atuante & \multicolumn{3}{|c|}{$-1500 k N$} \\
\hline Armadura & $d_{i}$ & \multicolumn{2}{|c|}{$\overline{A_{s i}}$} \\
\hline$A_{s 1}$ & $23,0 \mathrm{~cm}$ & $3 \emptyset 10 \mathrm{~mm}$ & $2,3562 \mathrm{~cm}^{2}$ \\
\hline$A_{s 2}$ & $13,8 \mathrm{~cm}$ & $2 \emptyset 10 \mathrm{~mm}$ & $1,5708 \mathrm{~cm}^{2}$ \\
\hline$A_{s 3}$ & $4,6 \mathrm{~cm}$ & $2 \emptyset 10 \mathrm{~mm}$ & $1,5708 \mathrm{~cm}^{2}$ \\
\hline$A_{s 4}$ & $-4,6 \mathrm{~cm}$ & $2 \emptyset 10 \mathrm{~mm}$ & $1,5708 \mathrm{~cm}^{2}$ \\
\hline$A_{s 5}$ & $-13,8 \mathrm{~cm}$ & $2 \emptyset 10 \mathrm{~mm}$ & $1,5708 \mathrm{~cm}^{2}$ \\
\hline$A_{s 6}$ & $-23,0 \mathrm{~cm}$ & $3 \emptyset 10 \mathrm{~mm}$ & $2,3562 \mathrm{~cm}^{2}$ \\
\hline
\end{tabular}

Com o processo de obtenção da relação momento-curvatura, detalhado no item 3, o diagrama obtido para a seção é demonstrado na figura 2.15:

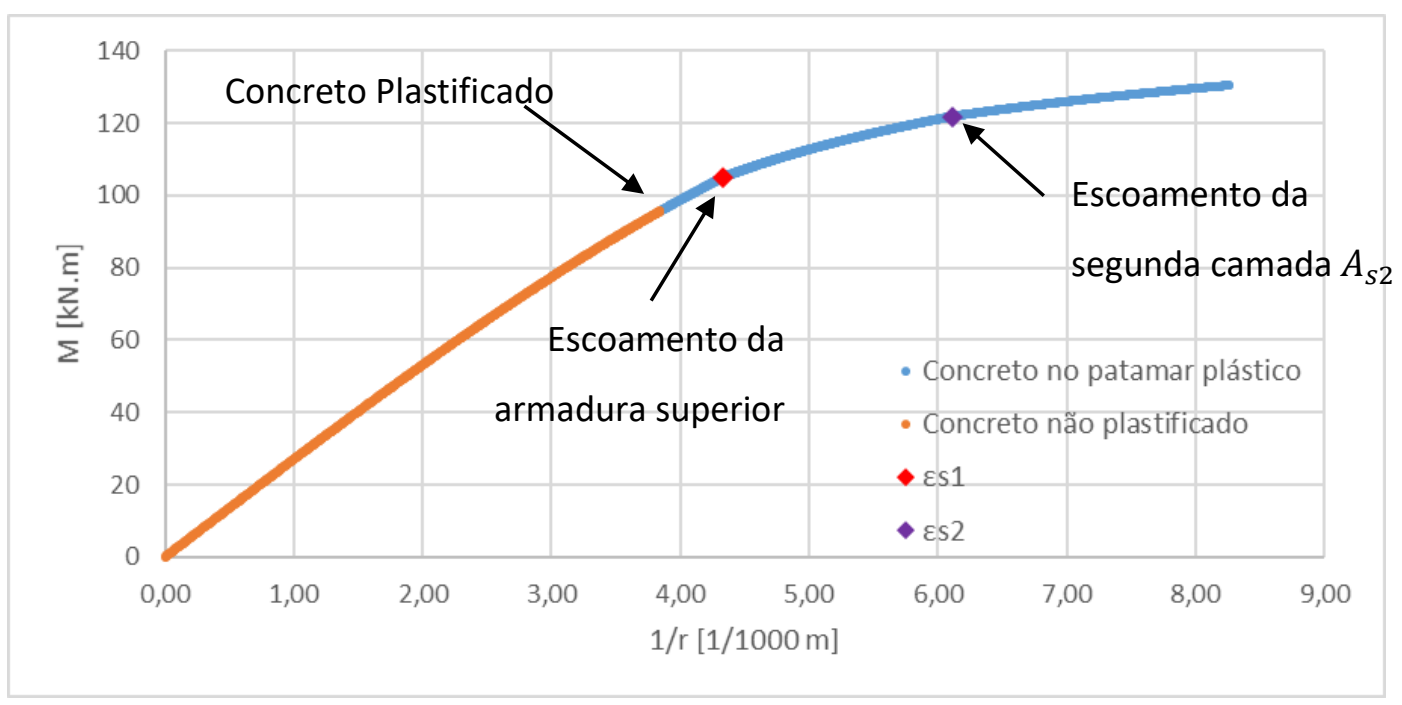

Figura 2.15 - Momento curvatura do pilar dado

Observam-se três pontos importantes no gráfico, onde há mudança na inclinação da curva, pondo em evidência o comportamento não linear dos materiais. 
As primeiras duas legendas do gráfico são referentes às configurações de seção em que a deformação da fibra mais comprimida da seção está acima do limite do patamar plástico e abaixo, portanto, não plastificado. Este ponto, obtido de maneira numérica pelo programa apresenta momento fletor de 95,69 kN.m e curvatura de $3,84810^{-3} / \mathrm{m}$.

Conforme aumenta-se a curvatura da seção, o aumento do momento fletor resistente da seção é menor que em regime elástico quando a fibra mais comprimida ainda não está em regime plástico.

A mesma queda é observada quando as armaduras superiores escoam. A camada superior $A_{s 1}$ escoa com o momento fletor de $105,04 \mathrm{kN} . \mathrm{m}$ e a segunda camada $A_{s 2}$ escoa em $121,84 \mathrm{kN}$. m.

A seguir, apresenta-se a tabela 2.8 com as configurações das seções em cada um destes nós de plastificação e o momento resistente final da seção.

Tabela 2.8 - Pontos de alteração na inclinação da curva momento-curvatura.

\begin{tabular}{|c|c|c|c|c|c|c|}
\hline & $\begin{array}{c}M_{d} \\
{[k N . m]}\end{array}$ & $\begin{array}{c}k \\
{\left[1 / 1000 m^{-1}\right]}\end{array}$ & $\begin{array}{c}\varepsilon_{c} \\
{[m / m]}\end{array}$ & $\begin{array}{c}L N \\
{[m]}\end{array}$ & $\begin{array}{c}\varepsilon_{s 1} \\
{[m / m]}\end{array}$ & $\begin{array}{c}\varepsilon_{s 2} \\
{[m / m]}\end{array}$ \\
\hline $\begin{array}{c}\text { Plastificação } \\
\text { do Concreto }\end{array}$ & 95,694 & 3,848 & $-2,001$ & 0,520 & $-1,924$ & $-1,570$ \\
\hline $\begin{array}{c}\text { Escoamento } \\
A_{s 1}\end{array}$ & 105,039 & 4,335 & $-2,157$ & 0,498 & $-2,070$ & $-1,671$ \\
\hline $\begin{array}{c}\text { Escoamento } \\
A_{s 2}\end{array}$ & 121,839 & 6,111 & $-2,755$ & 0,451 & $-2,632$ & $-2,070$ \\
\hline $\begin{array}{c}\text { Momento } \\
\text { Máximo }\end{array}$ & 130,409 & 8,263 & $-3,498$ & 0,423 & $-3,333$ & $-2,573$ \\
\hline
\end{tabular}

A verificação das curvas geradas foi feita com o auxílio de dois programas desenvolvidos por alunos da UFRJ em projeto de graduação e dissertação de mestrado. O primeiro programa, M-k UFRJ (Castro, 2011), tem uma interface em que o usuário define as características do material, da seção e o carregamento normal. Com isso o programa gera o diagrama momento-curvatura na mesma tela de inserção de informações. A extração dos valores de momento-curvatura é feita por arquivo de texto. A figura 2.16 mostra a interface e o diagrama obtido. 


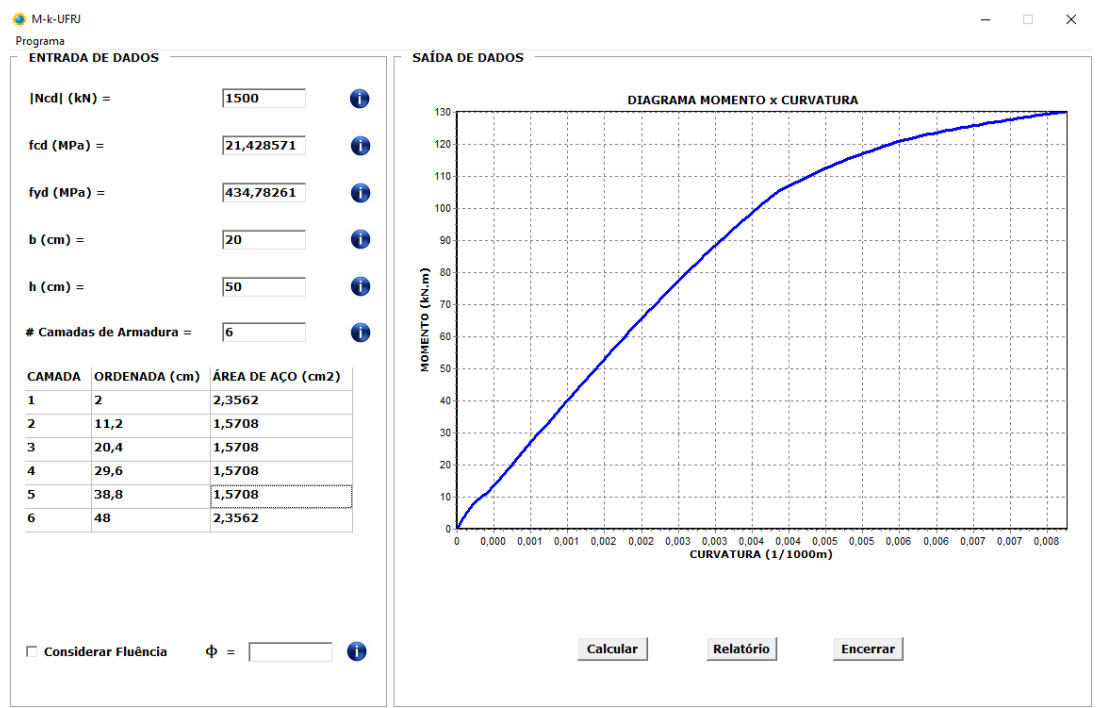

Figura 2.16 - Diagrama momento-curvatura obtido pelo M-k UFRJ (Castro, 2011).

O segundo programa, Capiba (Souza Júnior, 2012), apresenta a interface de inserção das informações da seção, material e carregamento, que ao calcular o diagrama gera uma pré-visualização. Entretanto, por ser desenvolvido VBA para Excel, gera a tabela com os valores de momento-curvatura e o diagrama em planilhas no Excel. A figura 2.17 apresenta a interface inicial e a figura 2.18 apresenta o diagrama obtido pelo Capiba.

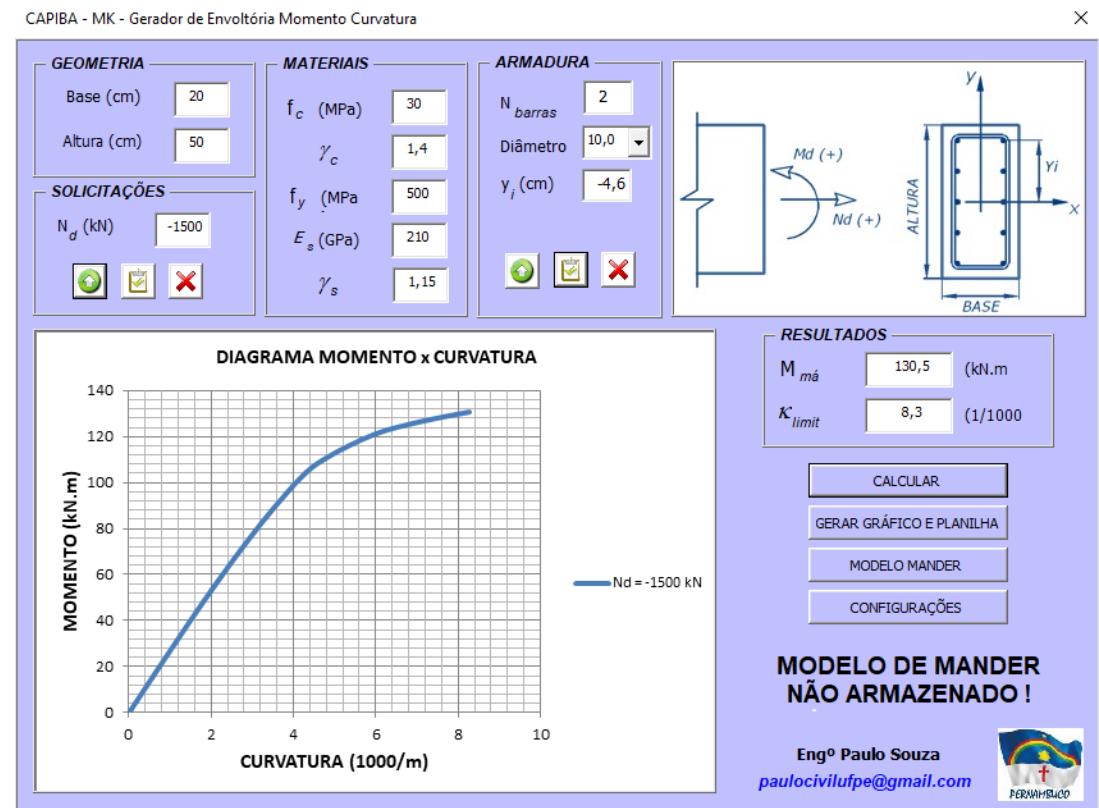

Figura 2.17 - Interface com pré-visualização - Capiba (Souza Júnior, 2012). 


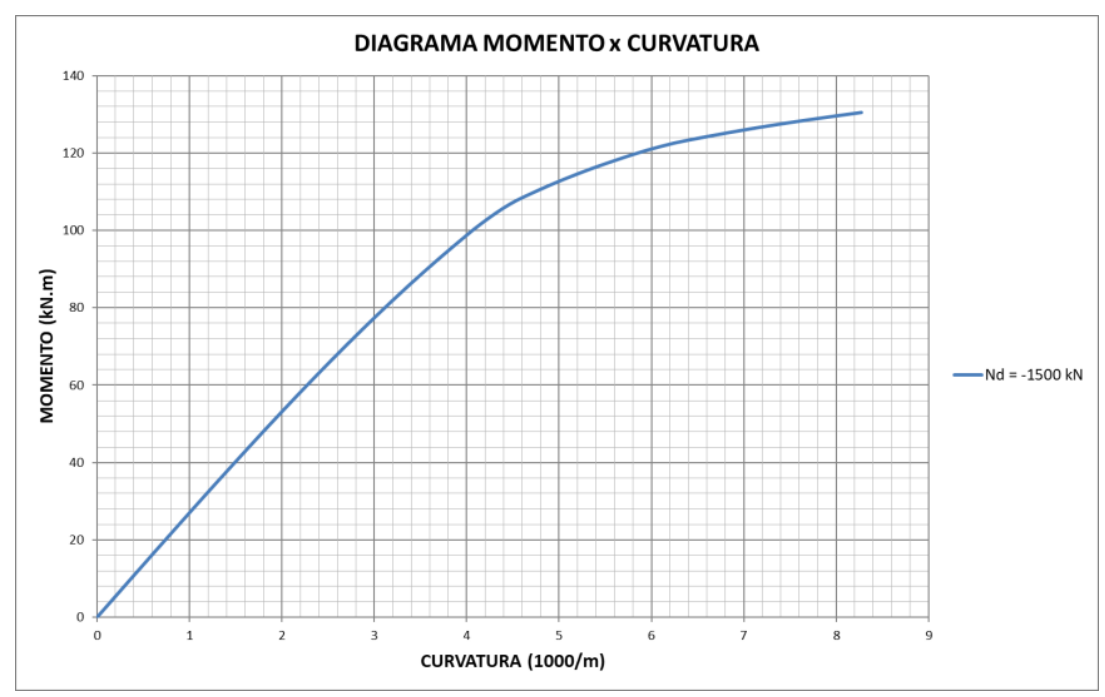

Figura 2.18 - Diagrama momento-curvatura obtido pelo Capiba (Souza Júnior, 2012).

As figuras 2.16, 2.17 e 2.18 foram geradas com a mesma seção de pilar conforme a tabela 2.7. Ao plotar as três curvas geradas, observa-se que se sobrepõem e os valores para momento máximo e curvatura limite são similares, conforme a figura 2.19 .

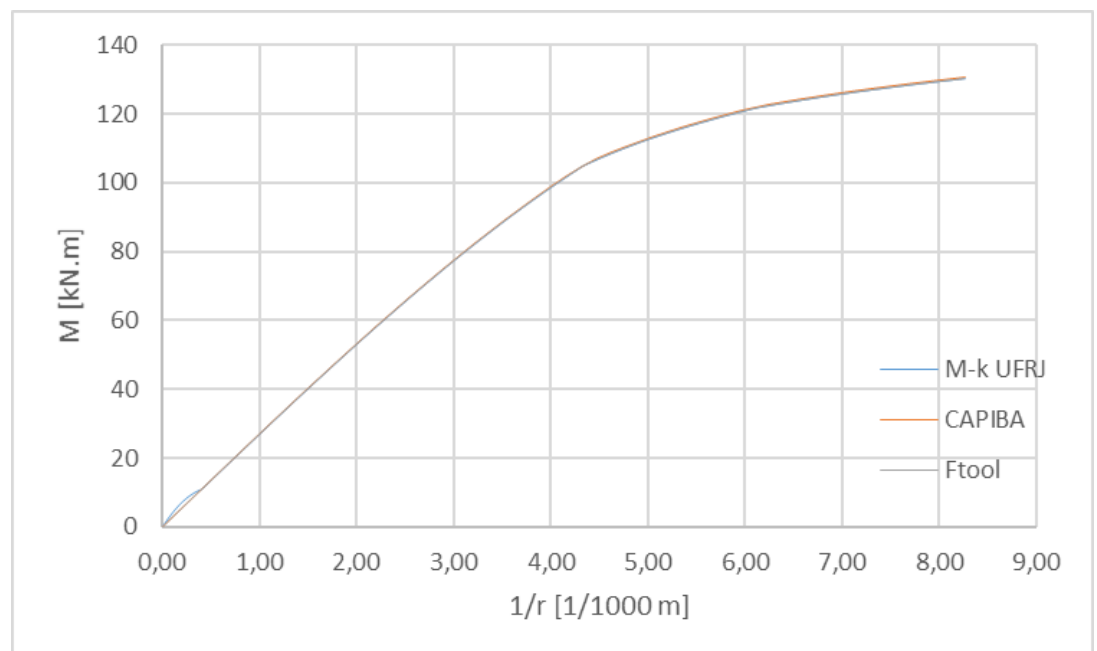

Figura 2.19 - Sobreposição dos diagramas obtidos pelos três programas.

Na tabela 2.9 os valores de momento máximo e curvatura limite obtidos:

Tabela 2.9 - Valores de momento máximo e curvatura limite.

\begin{tabular}{|l|c|c|}
\cline { 2 - 3 } \multicolumn{1}{c|}{} & $\begin{array}{c}M_{\text {máx }} \\
{[k N . m]}\end{array}$ & $\begin{array}{c}k_{\text {limite }} \\
{\left[1 / 1000 m^{-1}\right]}\end{array}$ \\
\hline Ftool & 130,409 & 8,263 \\
\hline M-k UFRJ & 130,420 & 8,268 \\
\hline Capiba & 130,469 & 8,269 \\
\hline
\end{tabular}




\section{3 \\ Metodologia}

Neste capítulo são apresentadas as considerações e metodologias para as análises apresentadas.

\subsection{Definição da Estrutura}

Para análise da estrutura, é necessário que o usuário defina o modelo estrutural analisado, bem como os materiais e os carregamentos atuantes. É responsabilidade do usuário que o modelo criado seja coerente com a estrutura analisada.

\subsubsection{Definição dos Materiais}

As informações referentes aos materiais são "inputs" que o usuário insere na interface do FTOOL, que devem estar de acordo com as classes de concreto que a NBR 6118 (ABNT, 2014) contempla, ou seja, entre as classes C20 e C90, além das classes de aço que devem ser selecionadas pelo usuário, entre as contempladas pela norma citada, com características geométricas de acordo com a NBR 7480 (ABNT, 2007).

Conforme o menu de definição do material da figura 3.1, o usuário define a resistência característica do concreto $\left(f_{c k}\right)$, a classe do aço, o coeficiente de fluência $(\varphi)$, o coeficiente de ponderação das resistências para o concreto $\left(\gamma_{c}\right)$ e para o aço $\left(\gamma_{s}\right)$. O programa não impede que o usuário escolha uma classe de concreto que não esteja dentro do intervalo C20-C90, porém adverte ao usuário de que os cálculos podem ser imprecisos e não confiáveis. 


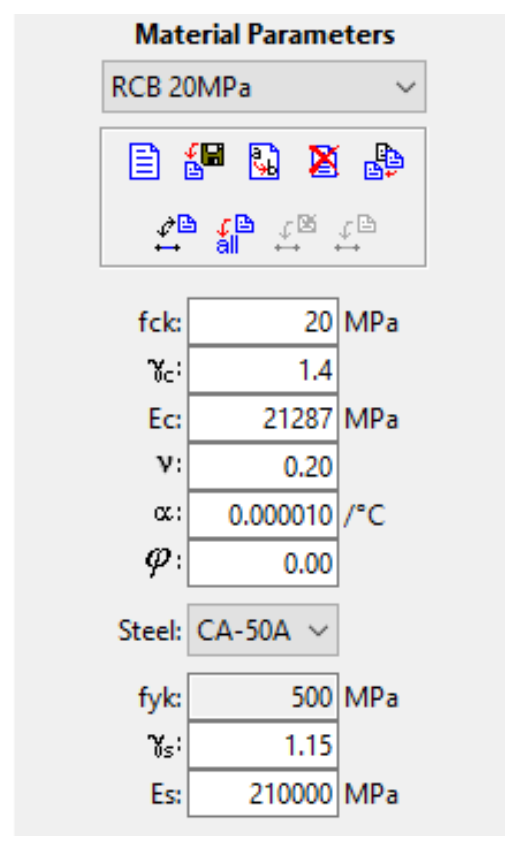

Figura 3.1 - Menu para definição do material - FTOOL

Observa-se que o usuário possui a liberdade de alterar os valores manualmente, porém o FTOOL já considera características com valores ou cálculos pré-definidos conforme a NBR 6118 (ABNT, 2014). Ao se inserir a resistência característica da seção, o programa calcula o módulo de deformação secante segundo o item 8.2.8, que define a equação (3.1):

$$
E_{c s}=\alpha_{i} \cdot E_{c i}
$$

Onde

$$
\alpha_{i}=0,8+0,2 \cdot \frac{f_{c k}}{80} \leq 1,0
$$

A variável $E_{c i}$ é o módulo de elasticidade inicial, definido no mesmo item da referida norma. Para concretos de classe C20 até C50, definido pela equação (3.3):

$$
E_{c i}=\alpha_{E} \cdot 5600 \sqrt{f_{c k}}
$$

Para concretos de classe C55 até C90, pela equação (3.4):

$$
E_{c i}=21,5 \cdot 10^{3} \cdot \alpha_{E} \cdot\left(\frac{f_{c k}}{10}+1,25\right)^{1 / 3}
$$

O parâmetro $\alpha_{E}$ é definido pelo agregado utilizado no concreto, que no programa é definido, como padrão, como granito ou gnaisse; assim, este parâmetro assume o valor de 1,0 .

O Coeficiente de Poisson, referente às deformações transversais, é definido segundo o item 8.2.9, como: 


$$
v=0,20
$$

O coeficiente de dilatação térmica, conforme o item 8.2.3, é admitido como:

$$
\alpha=10^{-5} /{ }^{\circ} \mathrm{C}
$$

Para definição do aço empregado, o programa oferece as opções de classe CA-25, CA-50 e CA-60, conforme a NBR 6118 (ABNT, 2014). A tensão limite de escoamento do aço é definida automaticamente conforme a classe. O módulo de elasticidade do aço, apesar de também poder ser alterado pelo usuário, é definido inicialmente com o valor padrão, conforme o item 8.3.5:

$$
E_{s}=210 G P a
$$

Por fim, para a definição dos materiais, o usuário deve inserir os coeficientes de ponderação das resistências, do aço $\left(\gamma_{s}\right)$ e do concreto $\left(\gamma_{c}\right)$. Observe-se que a NBR 6118 (ABNT, 2014) define estes valores para os casos de estado limite da análise. Para o estado limite último, o item 12.4.1, define os valores para coeficientes considerando a combinação do carregamento, conforme a tabela 3.1 extraída da referida norma:

Tabela 3.1 - Coeficientes de ponderação das resistências no estado-limite último (ELU) - Tabela 12.1 da NBR 6118(ABNT, 2014)

\begin{tabular}{|c|c|c|}
\hline Combinaçōes & $\begin{array}{c}\text { Concreto } \\
\gamma_{\mathrm{c}}\end{array}$ & $\begin{array}{c}\text { Aço } \\
\gamma_{\mathrm{s}}\end{array}$ \\
\hline Normais & 1,4 & 1,15 \\
\hline Especiais ou de construção & 1,2 & 1,15 \\
\hline Excepcionais & 1,2 & 1,0 \\
\hline
\end{tabular}

Para os estados limites de serviço (ELS), não é necessária minoração da resistência, portanto, conforme o item 12.4.2 admite-se:

$$
\gamma_{c}=\gamma_{s}=1,0
$$

\subsubsection{Definição da Estrutura}

O FTOOL tem a capacidade de analisar estruturas em duas dimensões, portanto, o usuário pode modelar vigas e pórticos planos, sendo responsável por definir a geometria das seções e da estrutura global.

A estrutura é modelada com barras e nós. A cada barra deve corresponder uma seção e cada seção terá sua geometria própria e definição do material utilizado, conforme explicitado no item anterior. Os nós são criados para delimitarem a 
estrutura, podendo também dividir e delimitar as barras, serem pontos de aplicação de carregamento, delimitar os carregamentos e definirem os apoios das estruturas. Portanto, as barras são utilizadas para definição das seções, podendo ser alteradas ao longo do vão, desde que se criem nós para transição.

Ao se modelar uma seção com material em concreto armado, o usuário deve definir se a seção representada é um pilar ou uma viga. O pilar possui apenas como opção a seção retangular, definida como $R C$-Column Rectangle. Abre-se o menu para definição da seção do pilar conforme a figura 3.2:

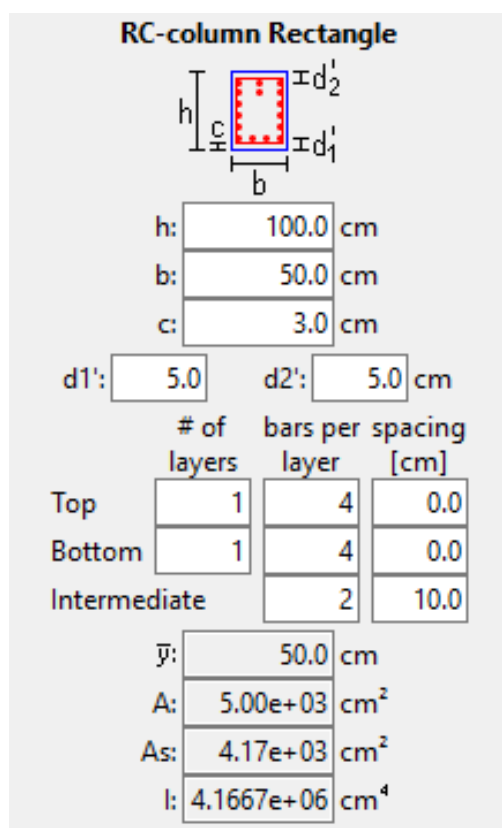

Figura 3.2 - Menu para definição da geometria do pilar com seção retangular - FTOOL

O usuário deve definir as dimensões, altura $h$, largura $b$ e cobrimento $c$ da seção, dados em centímetros, além das distâncias $d 1$ ' e $d 2$ ', que representam, respectivamente, a distância do centro da armadura inferior até a base da seção e a distância do centro da armadura superior até o topo da seção. Observa-se que o FTOOL dá a opção para o usuário definir os valores de $d 1$ ' e $d 2$ ' de acordo com o momento atuante, sendo este positivo ou negativo. No caso de pilares, recomendase que estas distâncias sejam iguais, independentemente do sinal do momento, tanto pela montagem das armaduras na prática quanto para evitar excentricidades, garantindo a simetria da seção. Para o dimensionamento de pilares, o usuário deve definir o posicionamento das armaduras, com o número de camadas, o número de barras por camada e o espaçamento entre as camadas, dentro de três situações de camada, a superior, a inferior e as intermediárias. O espaçamento dado nas camadas intermediárias é o espaçamento entre elas, que será utilizado para calcular o total 
de camadas intermediárias, mantando o espaçamento entre elas o mais próximo possível do valor dado pelo usuário. Observa-se que o dimensionamento de pilares fornece a armadura total calculada, indicando a bitola que deve ser adotada, dadas as informações de disposição das armaduras.

As características geométricas da seção são calculadas automaticamente, sendo elas a posição do centroide da seção $\bar{y}$, a área total da seção transversal $A$, a área de cisalhamento da seção $A_{s}$ e o momento de inércia em relação ao eixo principal $I$. Observa-se que estas características são em relação à seção de concreto, sem considerar a armadura, que neste ponto ainda não foi definida.

Conforme recomendação da NBR 6118 (ABNT, 2014), no seu item 18.4, que se refere ao dimensionamento de pilares, quando a maior dimensão do pilar exceder cinco vezes a menor, o pilar deve ser tratado como pilar-parede. Esta situação não está englobada no dimensionamento do FTOOL. O programa adverte ao usuário para redimensionar a seção. Assim como, por motivos práticos, o FTOOL adverte o usuário ao selecionar uma seção com menor lado inferior a $19 \mathrm{~cm}$, dado que no item 13.2.3, a Norma permite adoção de tais dimensões (entre 14 e 19 cm) apenas em casos especiais. Assim, o programa adverte para o redimensionamento da seção.

Para as vigas, o programa oferece quatro opções de modelagem das seções: $R C$ - beam Rectangle (figura 3.3), RC - beam T-shape (figura 3.4), $R C$ - beam $L$ shape (figura 3.4) e $R C$ - beam I-shape (figura 3.4). Abaixo são apresentados os menus para a configuração das seções. 


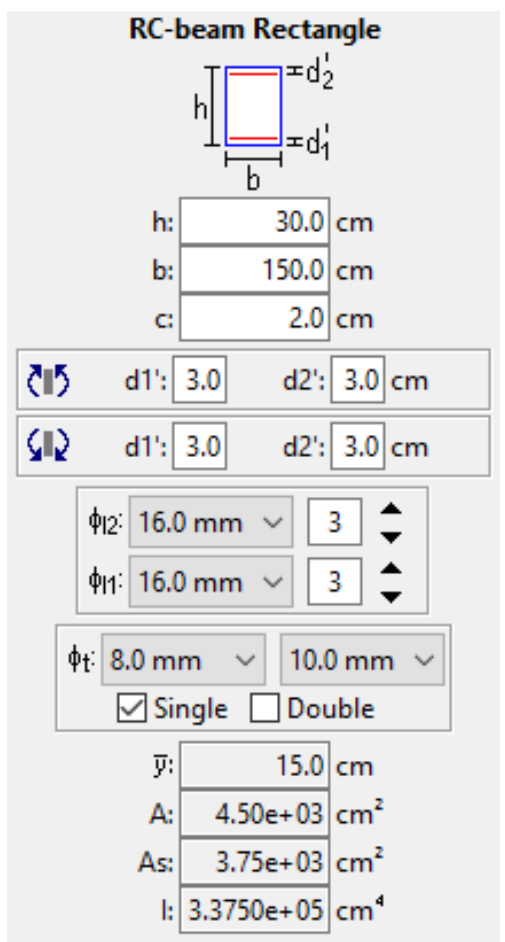

Figura 3.3 - Menu para definição da geometria da viga com seção retangular - FTOOL

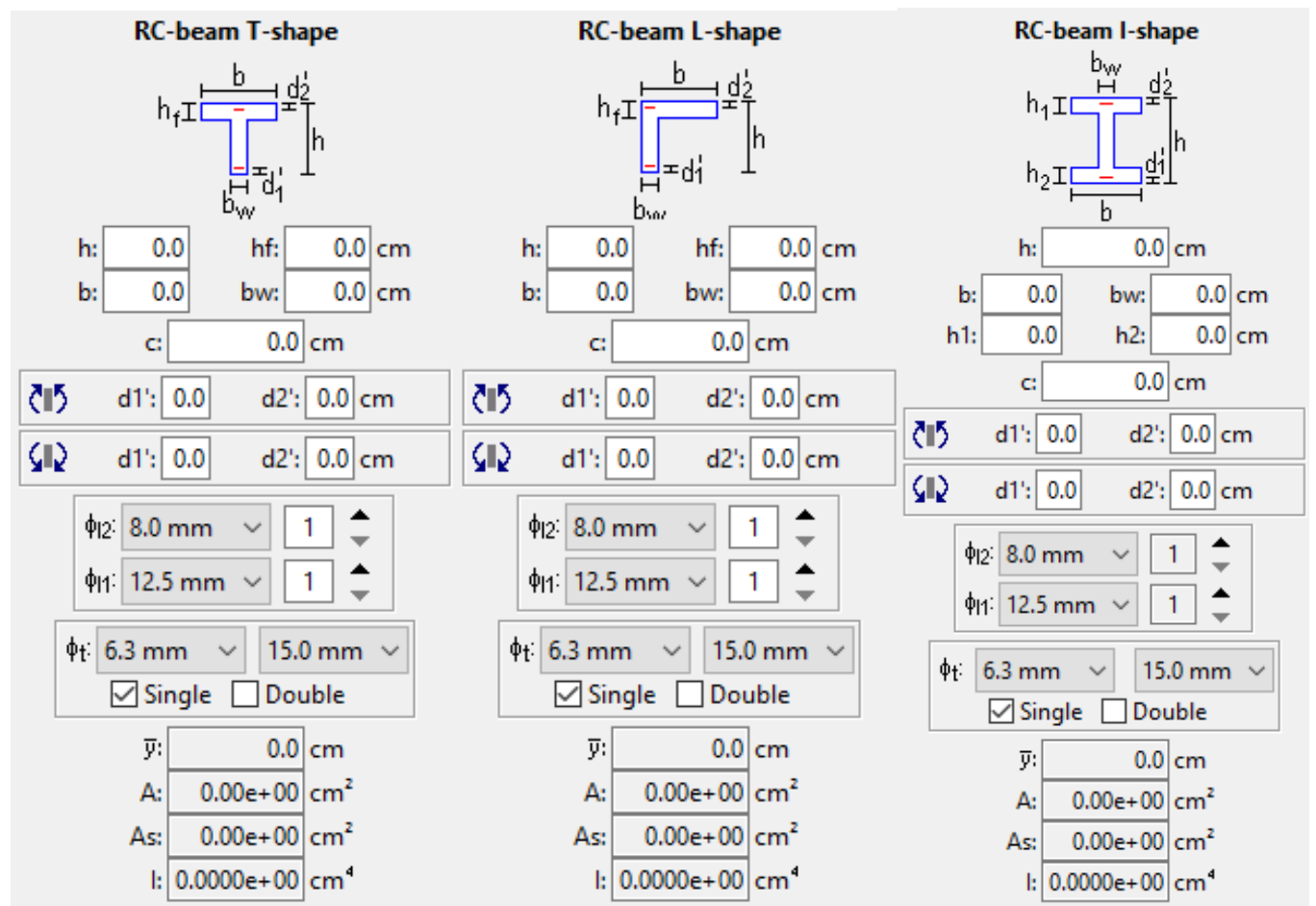

Figura 3.4 - Menus para definição da geometria da viga com seções T, L e I - FTOOL

Assim como para os pilares, o usuário deve definir toda a geometria da seção. No caso de vigas retangulares, define-se a altura $h$, a largura $b$, o cobrimento $c$ da seção e as distâncias $d 1^{\prime}$ e $d 2^{\prime}$, respectivamente, distância do centro da armadura inferior até a base da seção e distância do centro da armadura superior até o topo da seção. Assim como no caso de pilares, o usuário pode definir valores distintos para 
$d 1$ ' e $d 2$ ', o que é o usual na prática. Observa-se que também há a opção de definir valores distintos em função do sinal do momento atuante, positivo ou negativo. Dentro da rotina do programa, utiliza-se o momento em módulo, portanto, para os casos de momento negativo, a seção é invertida e a armadura superior é adotada como principal, enquanto que a inferior é a armadura secundária.

Diferentemente do dimensionamento de pilares, onde o programa determina a bitola a ser adotada dada a disposição das armaduras, para o dimensionamento de vigas, o programa calcula o número necessário de barras em cada camada, dada a bitola a ser utilizada. Desta forma, o usuário deve definir a bitola a ser utilizada na armadura superior e inferior, definidas como $\phi_{l 2}$ e $\phi_{l 1}$, respectivamente.

Observa-se que, pela maneira de cálculo do programa, que rotaciona a seção de acordo com o sinal do momento atuante, a fim de realizar o cálculo adotando sinal positivo, as armaduras podem ser definidas como principal $\phi_{l 1}$ e secundária $\phi_{l 2}$, sendo que em caso de momento negativo, $\phi_{l 1}$ será utilizada na armadura superior. Sobre a armadura transversal, o usuário deve definir a bitola $\phi_{t}$ a ser utilizada e o espaçamento, definindo se o estribo é duplo ou simples, com quatro ou dois ramos, respectivamente. No dimensionamento da armadura transversal, o FTOOL testa se a bitola e espaçamento dados são suficientes. Quando não forem, o usuário recebe uma mensagem para diminuir o espaçamento. Quando forem maiores que a armadura necessária, o FTOOL ajusta o espaçamento, porém mantendo a bitola selecionada.

Para as vigas com seção não retangular, sejam elas T, I ou L, o usuário deve inserir as informações da alma e da mesa da seção. Observa-se que para o dimensionamento, o formato da seção é indiferente, pois será considerada uma seção vazada, mas para facilitar a entrada da seção pelo usuário, são dadas as três opções. Portanto, o usuário deve definir a altura total $h$ da seção, a altura $h_{1}$ da mesa superior, a altura $h_{2}$ da mesa inferior, a largura $b$ das mesas superior e inferior e a largura $b_{w}$ da alma.

Assim, como no caso dos pilares, as informações geométricas da seção transversal são calculadas automaticamente, como a posição do centroide da seção $\bar{y}$, a área total da seção transversal $A$, a área de cisalhamento da seção $A_{s} \mathrm{e}$ o momento de inércia em relação ao eixo principal $I$. 


\subsubsection{Carregamentos Atuantes}

A definição dos carregamentos atuantes na estrutura é feita pelo usuário, que tem como opções de entrada, carga concentrada, momento, carga distribuída e variação de temperatura, todos exemplificados na figura 3.5.

(a)

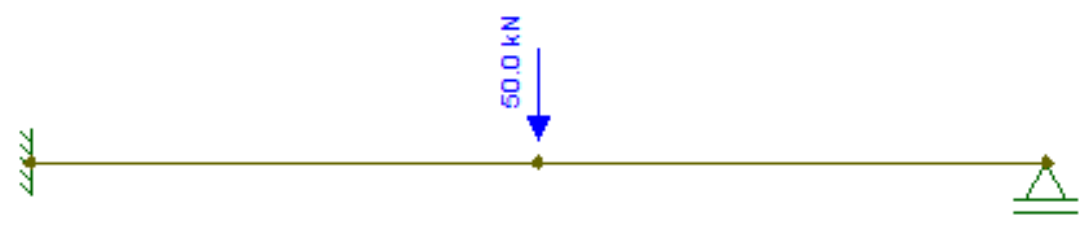

(b)

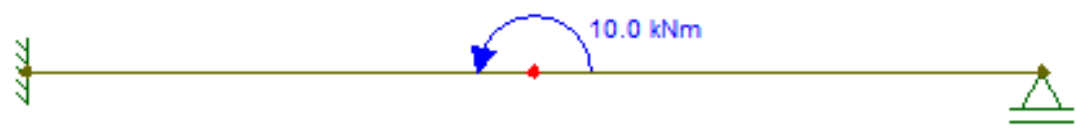

(c)

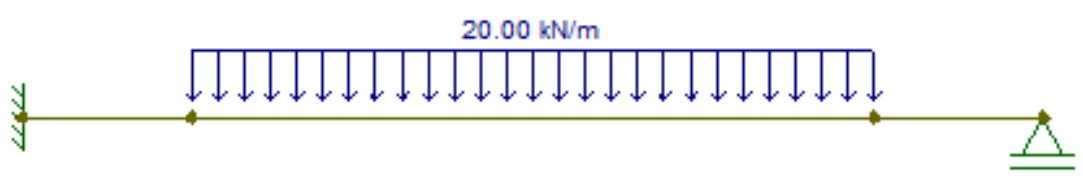

(d)

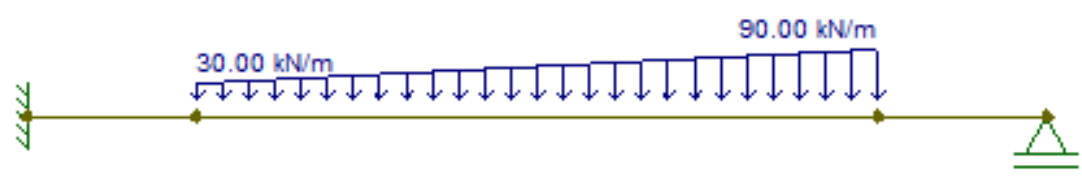

(e)

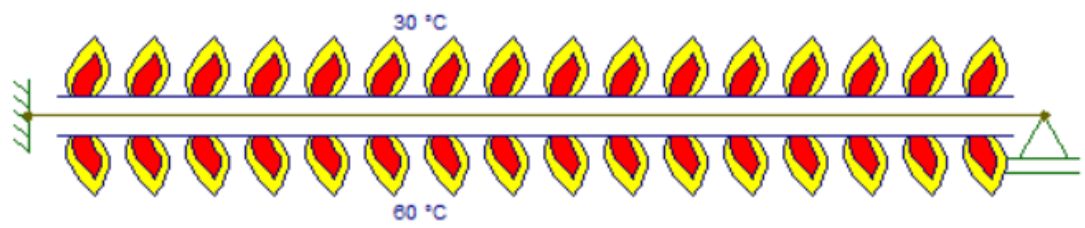

Figura 3.5 - Opções de inserção de carregamento: (a) carga pontual; (b) momento pontual; (c) carga uniformemente distribuída; (d) carga linearmente variável; (e) temperatura - FTOOL

Observe-se que o usuário deve inserir o carregamento com os coeficientes de ponderação das ações e a combinação adequada, de acordo com a probabilidade de que as ações ocorram simultaneamente. Para isto, devem-se seguir os itens $11.7 \mathrm{e}$ 11.8 da NBR 6118 (ABNT, 2014), que se referem, respectivamente, aos coeficientes de ponderação das ações e combinações de ações.

\subsection{Obtenção da Curva Momento-Curvatura}

A curva momento-curvatura é obtida de maneira numérica, com um código inserido no programa FTOOL em linguagem C. Para cada seção dimensionada, é necessário que, a partir das características do material utilizado, da seção adotada e do carregamento, se construa a curva momento-curvatura para análise da rigidez 
secante da seção, que é adotada na nova análise para verificação dos esforços e dimensionamento, considerando-se assim a não linearidade física.

Como cada seção tem um carregamento atuante, é necessário que se encontre a combinação de posição da linha neutra e curvatura em que haja equilíbrio entre o par de esforços aplicados e os esforços resistentes - momento fletor e força normal. Portanto, para cada posição de linha neutra dada, busca-se a curvatura que resulte na força normal atuante na seção. Com isso calcula-se o momento resistente da seção e constrói-se o gráfico momento-curvatura apresentando os pares de momento e curvatura na seção em equilíbrio, como exemplificado na figura 3.6.

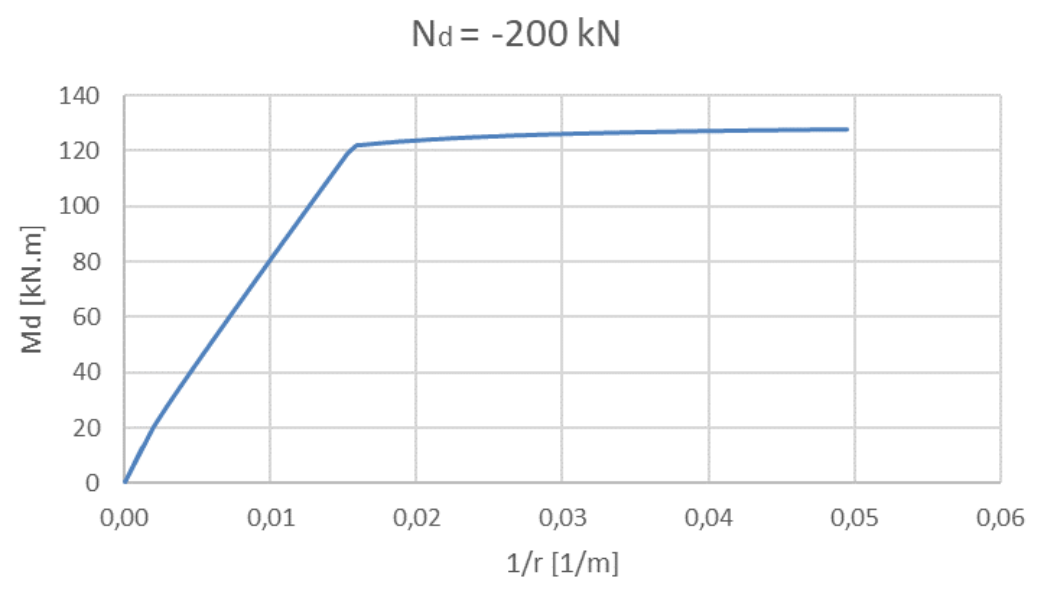

Figura 3.6 - Exemplo de Curva Momento-Curvatura obtida pelo programa

Observa-se que o programa não disponibiliza para o usuário os diagramas de momento-curvatura das seções, portanto, o diagrama não é construído até o momento máximo, parando ao convergir com o momento atuante e calculando a rigidez secante. Opta-se pela não disponibilização dado o alto número de seções, à exemplo do pórtico do item 4.3 que tem 365 nós de integração, portanto 365 seções com diagramas de momento-curvatura.

\subsubsection{Processo Iterativo - Variação da Linha Neutra e Curvatura}

Conforme explicitado anteriormente, deve-se buscar um par de linha neutra e curvatura para o equilíbrio da seção, dados os carregamentos de normal e momento atuantes. Opta-se por construir dois "loops", o primeiro variando a posição da linha neutra e o segundo a curvatura, portanto, para cada iteração da linha neutra, será feito um "loop" para encontrar a curvatura para a seção em equilíbrio com a normal. Com os valores da posição da linha neutra e da curvatura, faz-se o cálculo do 
momento resistente da seção e compara-se com o momento atuante. Caso a diferença esteja dentro da tolerância, considera-se convergido o processo, caso contrário passa-se para a próxima iteração de posição da linha neutra, a fim de encontrar a curvatura em equilíbrio com a normal e testar o momento fletor, e assim sucessivamente.

O dimensionamento de elementos lineares em concreto armado sujeitos a solicitações normais, segundo a NBR 6118 (ABNT, 2014) é feito no estado limite último com base nos domínios de deformação definidos no item 17.2.2 da referida norma, conforme a figura 3.7 ilustra. A ruína da seção transversal é definida quando um dos materiais, ou ambos, atingem os valores últimos de deformação.

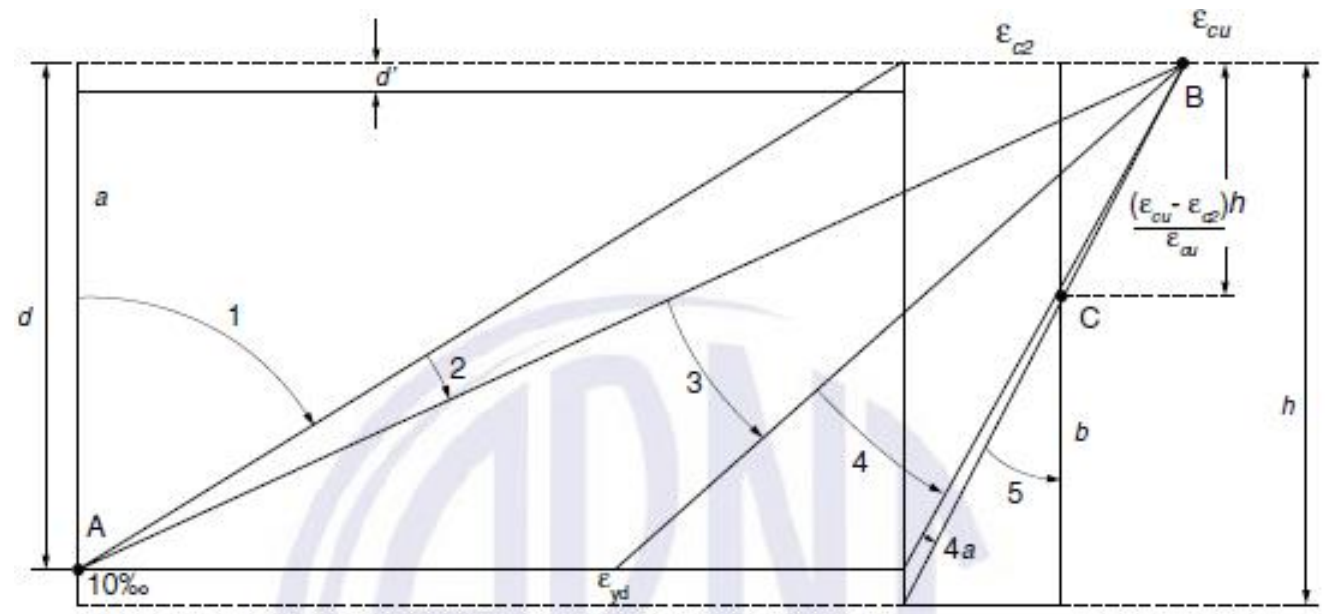

Figura 3.7 - Domínios de ELU de uma seção transversal - Figura 17.1 da NBR 6118 (ABNT, 2014)

A fim de cercar todas as possibilidades de ruína nas seções analisadas, não deixando o programa assumir uma configuração de uma seção que não esteja rompida, é feita uma analogia com os domínios de deformação. A variação da posição da linha neutra e curvatura ocorre dentro dos limites impostos pelos domínios, portanto, as iterações ocorrem sempre considerando as deformações limites. Observa-se que o programa busca o par linha neutra-curvatura começando pelas hipóteses da linha neutra estar acima da seção; caso não encontre o par que resulte no equilíbrio da seção, considera-se a hipótese da linha neutra estar dentro da seção, e por fim, a hipótese da linha neutra estar abaixo da seção.

Para as situações de carregamento com tração no concreto, uniforme ou não, adotam-se os limites dados no domínio 1 , sendo a deformação limite no concreto e no aço de alongamento $10 \%$. São as situações em que a linha neutra está acima da seção, variando de zero ao infinito negativo. É inviável variar a linha neutra entre 
valores considerando o infinito, portanto, opta-se por variar a deformação do concreto no topo da seção, que terá valor entre zero e 10\%, equações (3.9) e (3.10), definindo os valores máximos e mínimos para a deformação no concreto:

$$
\begin{gathered}
\varepsilon_{c, \text { mín,1 }}=0,00 \mathrm{~m} / \mathrm{m} \\
\varepsilon_{c, \text { máx }, 1}=0,010 \mathrm{~m} / \mathrm{m}
\end{gathered}
$$

O primeiro "loop" do processo iterativo é feito com uma varredura de todos os valores no intervalo dado para a variável, assim, a deformação no concreto na iteração $i$ é dada pela equação (3.11).

$$
\varepsilon_{c i}=\varepsilon_{c, \text { máx }}-\frac{i}{N_{i t}} \cdot\left(\varepsilon_{c, \text { máx }}-\varepsilon_{c, \text { mín }}\right)
$$

Onde

$\varepsilon_{c, m a ́ x}$ é a deformação máxima no concreto;

$\varepsilon_{c, m i ́ n}$ é a deformação mínima no concreto;

$i$ é o número da iteração;

$N_{i t}$ é o número total máximo de iterações para $\varepsilon_{c i}$.

Logo, utilizando a equação (3.11) com os limites expostos análogos ao domínio 1, esta se reduz à equação (3.12):

$$
\varepsilon_{c i, 1}=0,010-\frac{i}{N_{i t}} \cdot 0,010
$$

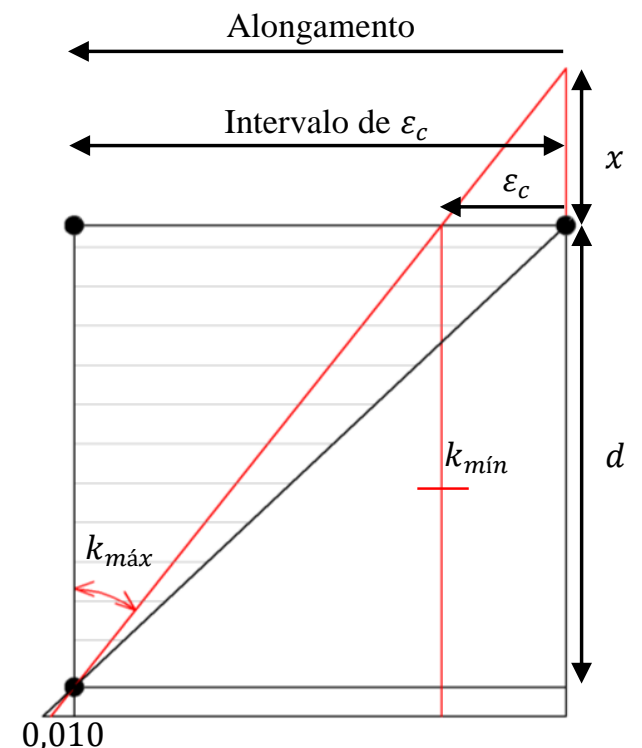

Figura 3.8 - Diagrama de deformações - Analogia ao domínio 1

As relações definidas conforme a figura 3.8, são baseadas em uma das hipóteses básicas da NBR 6118 (ABNT, 2014), que define no item 14.6.1 que as 
seções permanecem planas após a deformação. Com a aproximação da tangente da curvatura para a própria curvatura, faz-se a relação entre a curvatura $(k)$, posição da linha neutra $(x)$ e a deformação na fibra mais comprimida da seção $\left(\varepsilon_{c}\right)$ considerada no topo na convenção de momentos positivos. Portanto, para o caso análogo ao domínio 1, com a linha neutra acima da seção, dado que as iterações ocorrem na deformação, para a obtenção da linha neutra, utiliza-se a seguinte equação (3.13):

$$
x=\frac{\varepsilon_{c}}{k}
$$

Em todos os casos de domínios e deformações, as relações entre curvatura, deformação e linha neutra são obtidas pela hipótese de seções planas e calculadas por semelhança de triângulos.

Conforme a figura 3.8, para uma dada deformação $\varepsilon_{c}$, a curvatura pode variar de zero - situação com tração pura, até a curvatura que configure a deformação limite de $10 \%$ no aço da armadura inferior, que define a ruptura do aço. Desta forma, para a dada deformação $\varepsilon_{c}$, as curvaturas limite máxima e mínima são definidas pelas equações (3.14) e (3.15):

$$
\begin{gathered}
k_{\text {mín,1 }}=0,00 m^{-1} \\
k_{\text {máx,1 }}=\frac{\left(0,010-\varepsilon_{c}\right)}{d}
\end{gathered}
$$

Os domínios de deformação das regiões hachuradas são delimitados pelos centros de rotação de cada domínio, definidos pelas deformações de estado limite último, como por exemplo o domínio 1 que o centro de rotação é na deformação 10\%o na armadura inferior. Como este trabalho considera o estado limite de serviço, as peças não estão no limite da ruptura, portanto, exploram-se todas as configurações de curvatura e linha neutra, ainda que fora da região hachurada.

Para diversas situações de carregamento com flexão simples e composta, a linha neutra está dentro da seção. Conforme os domínios definidos, faz-se a analogia com os domínios 2, 3 e 4. No primeiro caso, para o domínio 2, o centro de rotação também é a deformação 10\% na armadura inferior. Portanto, considera-se a ruína da seção com a deformação excessiva no aço sem que o concreto rompa. $\mathrm{Na}$ figura 3.9 os limites de deformação, curvatura e linha neutra: 


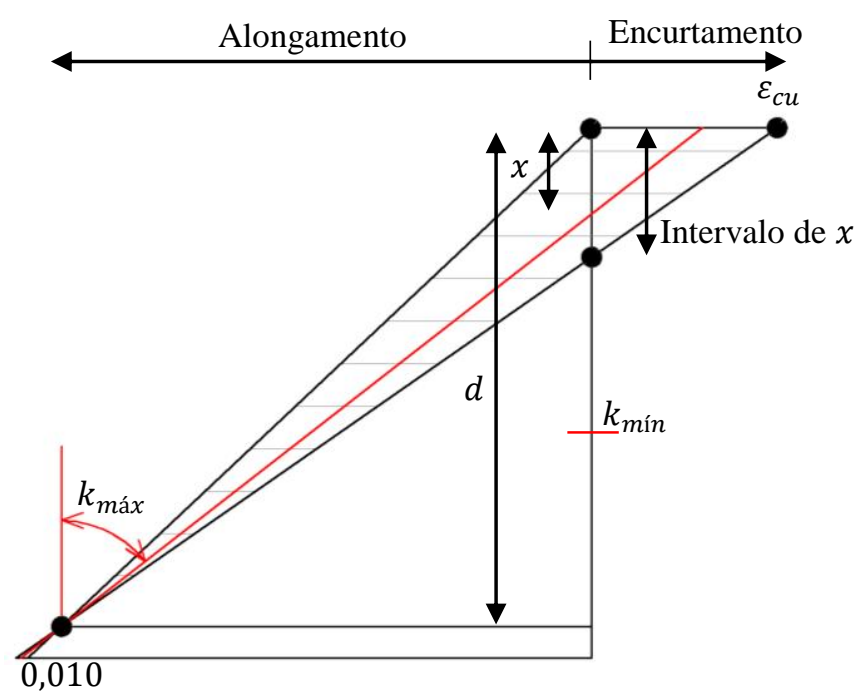

Figura 3.9 - Diagrama de deformações - Analogia ao domínio 2

Desta forma, considera-se a variação da linha neutra dentro dos limites, considerando que a fibra superior do concreto tenha encurtamento, sem atingir a deformação limite $\varepsilon_{c u}$, girando em torno da deformação limite do aço. A linha neutra, portanto, tem os limites dados pelas equações (3.16) e (3.17).

$$
\begin{gathered}
x_{\text {mín,2 }}=0,00 m \\
x_{\text {máx,2 }}=\frac{\varepsilon_{c u} \cdot d}{\left(0,010+\varepsilon_{c u}\right)}
\end{gathered}
$$

Onde,

$d$ é a altura útil da seção;

$\varepsilon_{c u}$ é a deformação específica de encurtamento do concreto na ruptura.

Assim, analogamente ao cálculo da deformação no concreto da iteração $i$, segundo a equação (3.11), calcula-se a posição da linha neutra da iteração $i$, obtendo a equação (3.18):

$$
x_{i}=x_{\min }+\frac{i}{N_{i t}} \cdot\left(x_{\text {máx }}-x_{\text {mín }}\right)
$$

Onde

$x_{m a ́ x}$ é a posição máxima da linha neutra do concreto;

$x_{m i n}$ é a posição mínima da linha neutra;

$i$ é o número da iteração;

$N_{i t}$ é o número total máximo de iterações para $x_{i}$.

Desta forma, aplicando limites análogos ao do domínio 2, a equação (3.18) se torna: 


$$
x_{i, 2}=\frac{i}{N_{i t}} \cdot \frac{\varepsilon_{c u} \cdot d}{\left(0,010+\varepsilon_{c u}\right)}
$$

Para uma dada posição da linha neutra $x$, a curvatura pode variar de zero caso sem carregamento, até a curvatura máxima com a ruptura do aço por deformação excessiva. Logo, as equações (3.20) e (3.21) definem os valores máximos:

$$
\begin{gathered}
k_{\text {mín,2 }}=0,00 m^{-1} \\
k_{\text {máx }, 2}=\frac{0,010}{(d-x)}
\end{gathered}
$$

A partir do limite da posição da linha neutra para o domínio 2, inicia-se o 3. Conforme a NBR 6118, este tem por característica a ruptura de ambos os materiais, com o concreto atingindo $\varepsilon_{c u}$ e o aço, escoado, atingindo a deformação máxima, sendo ilustrado na figura 3.10. Esta é a situação ideal para o dimensionamento da seção subarmada, com aproveitamento dos dois materiais e com sinais de aviso da ruptura. Desta forma, a rotação no domínio ocorre com o concreto em $\varepsilon_{c u}$ e o aço com deformações superiores à deformação limite para o escoamento. Assim, determinam-se os limites para posição da linha neutra pelas equações (3.22) e (3.23):

$$
\begin{gathered}
x_{\text {min }, 3}=x_{\text {máx }, 2}=\frac{\varepsilon_{c u} \cdot d}{\left(0,010+\varepsilon_{c u}\right)} \\
x_{\text {máx,3}}=\frac{\varepsilon_{c u} \cdot d}{\left(\varepsilon_{y d}+\varepsilon_{c u}\right)}
\end{gathered}
$$




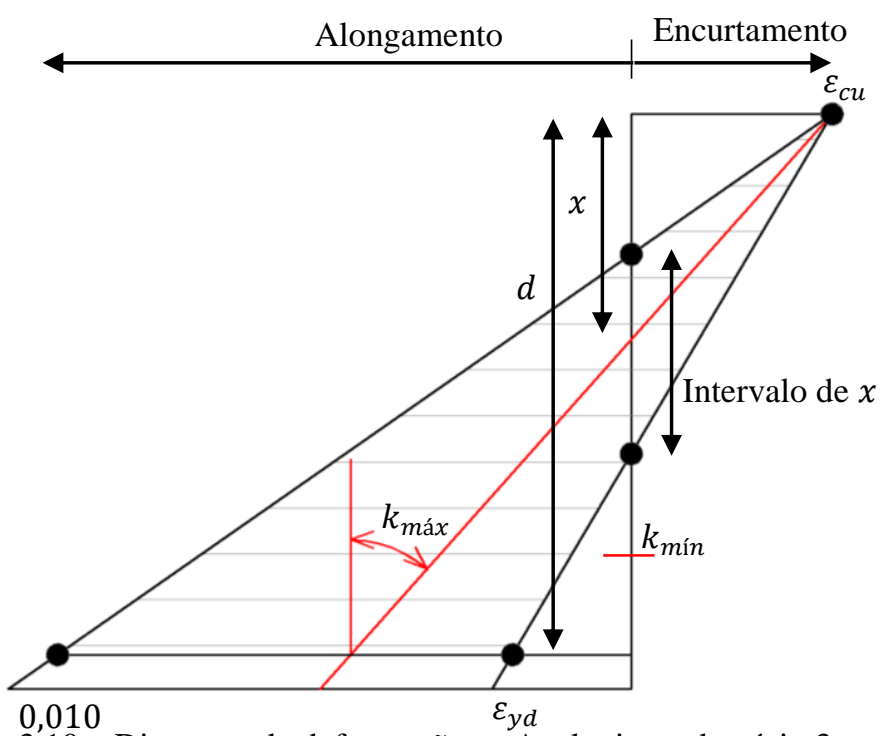

Figura 3.10 - Diagrama de deformações - Analogia ao domínio 3

Desta forma, a variação da posição da linha neutra, de acordo com a equação (3.18), se dá com:

$$
x_{i, 3}=\frac{\varepsilon_{c u} \cdot d}{\left(0,010+\varepsilon_{c u}\right)} \cdot\left[1+\frac{i}{N_{i t}} \cdot \frac{\left(0,010-\varepsilon_{y d}\right)}{\left(\varepsilon_{y d}+\varepsilon_{c u}\right)}\right]
$$

Para uma dada posição da linha neutra de uma iteração $i$, a curvatura varia de zero, da mesma forma que os demais domínios, para situações sem carregamento, até a deformação de ruptura da seção, quando o concreto atinge $\varepsilon_{c u}$. Desta forma, define-se com as equações (3.25) e (3.26) o intervalo de variação da curvatura:

$$
\begin{gathered}
k_{\text {mín,3}}=0,00 m^{-1} \\
k_{\text {máx,3 }}=\frac{\varepsilon_{c u}}{x}
\end{gathered}
$$

A última hipótese para a linha neutra dentro da seção é o limite do domínio 4, conforme a figura 3.11, que corresponde ao dimensionamento da seção superarmada, com a ruptura sem que o aço entre em escoamento, ocorrendo apenas no concreto, o que corresponde a uma ruptura frágil e sem aviso. Para a analogia, unem-se os domínios 4 e 4a, este último com a linha neutra abaixo da armadura inferior e, portanto, com todas as armaduras comprimidas. Assim, o intervalo da posição da linha neutra se dá, desde o ponto com deformações $\varepsilon_{c u}$ no concreto e $\varepsilon_{y d}$ no aço, até a face inferior da seção:

$$
\begin{gathered}
x_{m i ́ n, 4}=x_{m a ́ x, 3}=\frac{\varepsilon_{c u} \cdot d}{\left(\varepsilon_{y d}+\varepsilon_{c u}\right)} \\
x_{\text {máx,4 }}=h
\end{gathered}
$$




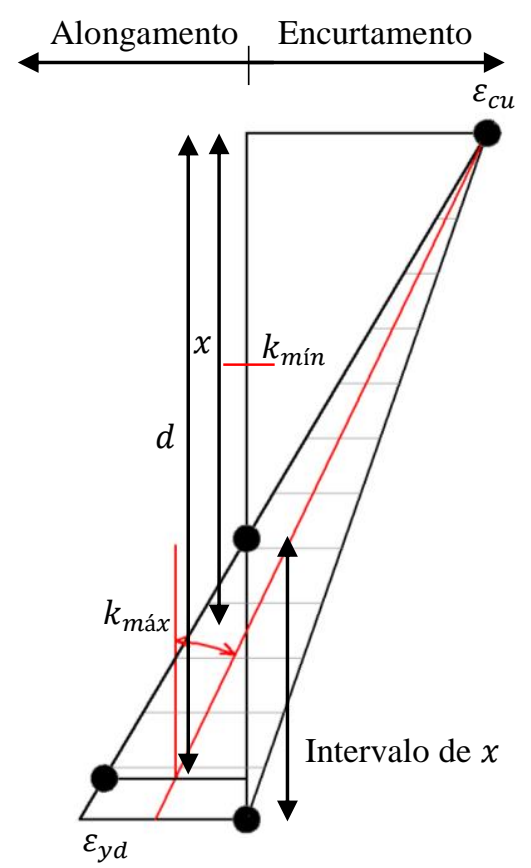

Figura 3.11 - Diagrama de deformações - Analogia ao domínios 4 e 4a

A equação (3.18) para o intervalo análogo aos domínios 4 e 4a se torna:

$$
x_{i, 4}=\frac{\varepsilon_{c u} \cdot d}{\left(\varepsilon_{y d}+\varepsilon_{c u}\right)}+\frac{i}{N_{i t}} \cdot\left(h-\frac{\varepsilon_{c u} \cdot d}{\left(\varepsilon_{y d}+\varepsilon_{c u}\right)}\right)
$$

Pelo critério de ruptura dos domínios 4 e 4a, as curvaturas máximas serão sempre as que combinadas com a dada linha neutra $x$, resultem na deformação $\varepsilon_{c u}$ do concreto. A curvatura mínima é o valor nulo para os casos sem carregamento:

$$
\begin{gathered}
k_{\text {mín,4}}=0,00 m^{-1} \\
k_{\text {máx } x, 4}=\frac{\varepsilon_{c u}}{x}
\end{gathered}
$$

A última hipótese de configuração da seção é com a linha neutra abaixo da seção, análogo ao domínio 5. Nesta configuração a seção está totalmente comprimida e os limites últimos são definidos com a deformação $\varepsilon_{c 2}$ para compressão uniforme e $\varepsilon_{c u}$ para flexo-compressão. 
(a)

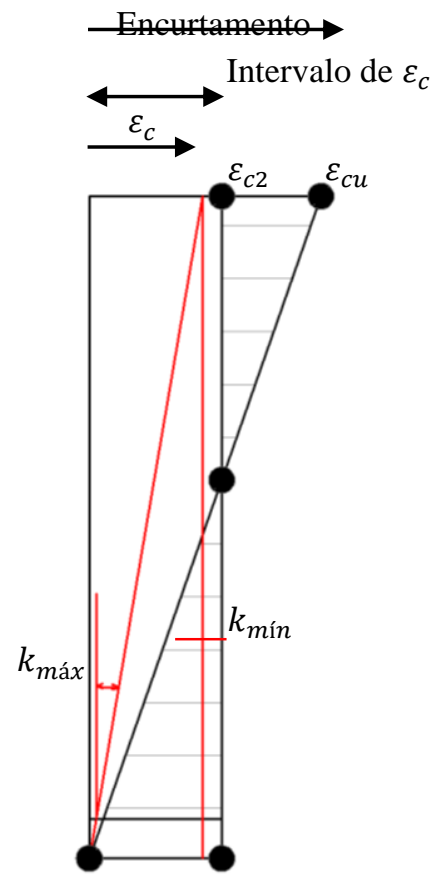

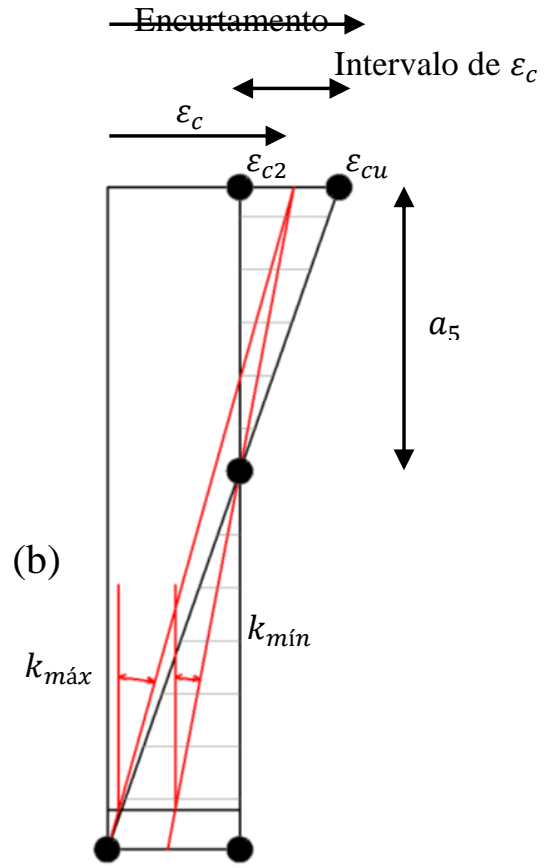

Figura 3.12 - Diagrama de deformações - Analogia ao domínio 5

Conforme a figura 3.12, observam-se as duas situações para o domínio 5. A primeira, Figura 3.12a, com a fibra mais comprimida da seção com deformação abaixo de $\varepsilon_{c 2}$, portanto, não plastificada, e a segunda, figura $3.12 \mathrm{~b}$, com deformação acima de $\varepsilon_{c 2}$ no patamar plástico. Assim como na hipótese da linha neutra estar acima da seção, para tratar a hipótese da linha neutra abaixo da seção opta-se por variar a deformação na fibra mais comprimida do concreto, que por convenção de momento positivo é a fibra superior. A linha neutra neste caso varia da altura total da seção até o infinito positivo. Desta forma, a deformação no concreto varia de zero até a deformação limite de encurtamento do concreto $\varepsilon_{c u}$, obtendo as equações (3.32) e (3.33):

$$
\begin{gathered}
\varepsilon_{c, \text { mín }, 5}=0,00 \mathrm{~m} / \mathrm{m} \\
\varepsilon_{c, \text { máx }, 5}=\varepsilon_{c u}
\end{gathered}
$$

Desta forma, a deformação no concreto para a iteração $i$, calculada conforme a equação (3.11) é dada por:

$$
\varepsilon_{c i, 5}=\varepsilon_{c u}-\frac{i}{N_{i t}} \cdot \varepsilon_{c u}
$$

Para a definição das curvaturas limites deve-se atentar às deformações limites em ambas as situações. Para o caso (a), observa-se que pela convenção de momento positivo, não há como a seção atingir nenhuma das deformações limites dos 
materiais. O concreto não rompe à compressão uniforme nem à flexo-compressão, já que a deformação $\varepsilon_{c}$ é inferior ao limite do patamar plástico. Portanto, o único limite imposto é a curvatura máxima que iguala a linha neutra à altura da seção, pois caso a curvatura passe deste limite, a linha neutra entra na seção e se retorna às situações de configuração de linha neutra-curvatura já tratadas nos intervalos análogos aos domínios 2, 3 e 4. Logo, para o caso (a), as equações (3.35) e (3.36) definem os limites de curvatura para uma deformação $\varepsilon_{c}$ no topo da seção.

$$
\begin{gathered}
k_{\text {mín, } 5 a}=0,00 m^{-1} \\
k_{\text {máx }, 5 a}=\frac{\varepsilon_{c}}{h}
\end{gathered}
$$

Para o caso (b), deve-se observar que a deformação no concreto é superior ao patamar plástico, deformação limite para ruptura em compressão uniforme. Desta forma a curvatura não pode assumir valor mínimo zero, pois configura uma seção rompida por esmagamento do concreto. Logo, a curvatura mínima deve ser a que passa exatamente pelo ponto distante de $a_{5}$ da fibra mais comprimida da seção, ponto este centro da rotação da região do domínio 5, conforme a NBR 6118 (ABNT, 2014). Assim, definem-se os limites pelas equações (3.37) e (3.38) para o caso (b), para uma dada deformação $\varepsilon_{c}$ no topo da seção.

$$
\begin{gathered}
k_{\text {mín, } 5 b}=\frac{\varepsilon_{c}-\varepsilon_{c 2}}{\varepsilon_{c u}-\varepsilon_{c 2}} \cdot \frac{\varepsilon_{c u}}{h} \\
k_{\text {máx }, 5 b}=\frac{\varepsilon_{c}}{h}
\end{gathered}
$$

\subsubsection{Convergência da Força Normal}

No item anterior, apresentaram-se os valores limites para as iterações de linha neutra, de deformação do concreto e da curvatura. Porém, adota-se um outro método numérico para obtenção da curvatura que convirja com a força normal e encontre a seção em equilíbrio. Dado o custo computacional de se fazer uma varredura por todos os valores, tendo o conhecimento dos valores limites para curvatura e objetivando o maior controle entre os valores obtidos sem que se configure uma seção rompida, opta-se pelo método da bisseção.

O método da bisseção encontra a raiz de uma dada equação, dentro de um dado intervalo, dividindo o intervalo ao meio, testando em qual dos dois novos intervalos encontra-se a raiz e partindo o novo intervalo novamente. O processo é 
repetido até que se encontre um intervalo tão pequeno quanto a tolerância e considera-se então que o processo tenha convergido, encontrando-se assim a raiz da equação.

Na figura 3.13, apresenta-se uma ilustração do processo iterativo do método da bisseção:

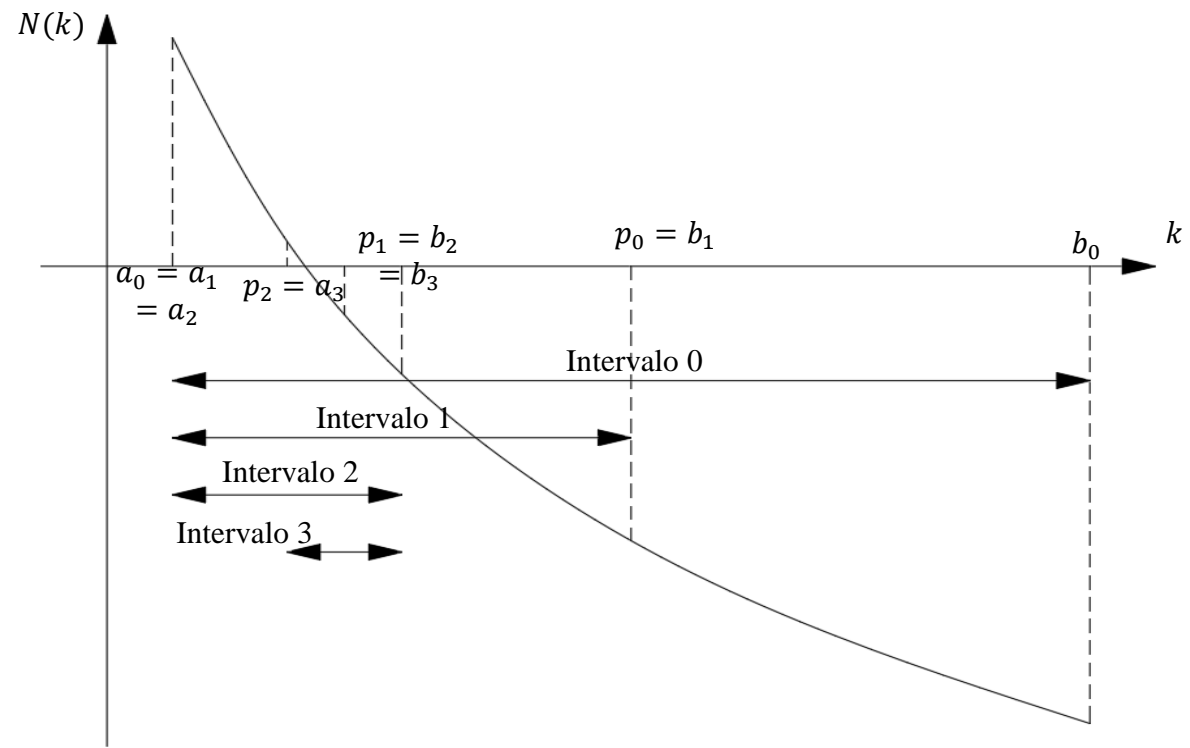

Figura 3.13 - Método da Bisseção

Observa-se que a raiz a ser encontrada é a curvatura $k$, função da força normal $N$. A raiz desejada é o valor em que a força normal resistente da seção tem o mesmo valor que a força normal atuante. Observa-se, também, que o método da bisseção é adotado para funções contínuas, o que não ocorre com a função $N(k)$ - normal resistente, em função da curvatura. A função apresenta descontinuidade em sua derivada nos pontos de escoamento das armaduras, dado que a armadura ao escoar continua a se deformar sem aumento da tensão resistente. Logo, a curva da função $N(k)$ tem uma queda no crescimento, ou seja, diminuição da sua derivada. Durante o desenvolvimento do trabalho, observou-se este comportamento nos intervalos análogos aos domínios 2 e 3, onde a seção pode estar sobre efeito de tração ou compressão. Com o escoamento das armaduras, a derivada da função troca de sinal e a função $N(k)$ tem valores de resistência tanto de tração quanto de compressão.

Abaixo apresenta-se uma curva normal-curvatura construída para uma dada seção de pilar para dois valores fixados de posição da linha neutra. 


\section{Domínio 2 - N vs 1/R}

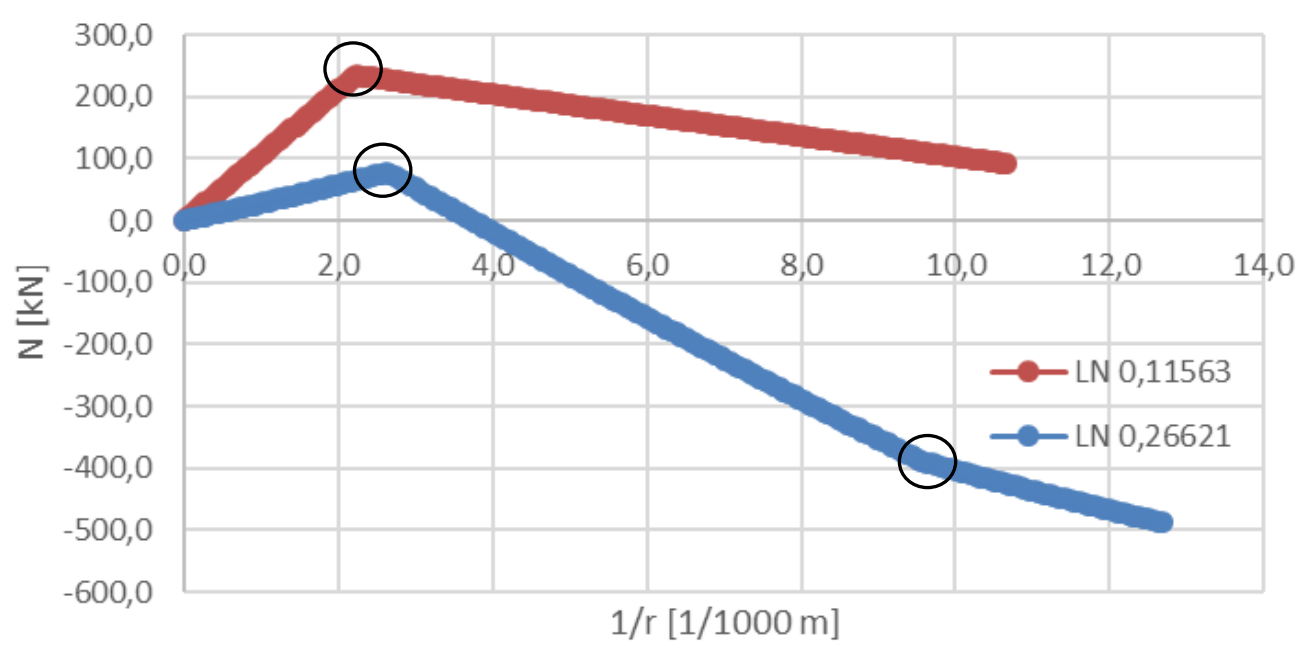

Figura 3.14 - Gráfico Normal-Curvatura para uma seção genérica - Pontos de descontinuidade da derivada em destaque

No gráfico da figura 3.14, é possível observar a variação da força normal conforme a variação da curvatura. A primeira curva, onde é considerada a profundidade de linha neutra de $0,11563 \mathrm{~m}$, possui um ponto de descontinuidade da derivada, que representa o escoamento da camada inferior de aço, porém não apresenta resistência à normal de compressão em nenhuma configuração. Já a segunda curva, com linha neutra a $0,26621 \mathrm{~m}$, ou seja, com uma linha neutra mais abaixo na seção, ao escoar a camada mais inferior, surge uma inversão no sinal da derivada e a resistência cresce no sentido da compressão. Após o escoamento da armadura inferior, há uma nova descontinuidade na função, com uma nova queda no crescimento da resistência. É de se esperar que a resistência à compressão aumente com o aumento da curvatura, pois existe uma maior parcela de concreto comprimido; na situação da armadura de tração já escoada, mesmo com o aumento da deformação, não há ganho de resistência. Assim, como também é de se esperar, ocorre uma maior resistência à compressão com a linha neutra mais baixa na seção, pela maior parcela de concreto comprimido.

Sabendo-se da existência das descontinuidades devidas ao escoamento das armaduras, podendo duas curvaturas diferentes convergir para a mesma normal como o caso de ambas as curvas do gráfico na figura 3.14, opta-se por dividir os intervalos de curvatura do método da bisseção considerando as curvaturas em que as camadas de armadura escoam. Faz-se necessário, pois, a cada posição da linha 
neutra no primeiro "loop", que o programa busque a curvatura que convirja em normal para construção da curva momento-curvatura no segundo "loop". Portanto, apesar de se ter a mesma normal e mesma linha neutra, os dois pontos com valores diferentes de curvatura, têm momentos resistentes diferentes, e ao se considerar o intervalo total só com os valores mínimos e máximos de curvatura, poderia se convergir em um valor incorreto e excluir a segunda raiz para a curvatura, que pode ser a raiz que corresponda aos valores corretos de força normal e momento fletor.

Desta forma, para os casos dos intervalos análogos aos domínios 1 e 5, onde a variação se dá pela deformação no concreto, as curvaturas que definem o escoamento das camadas de armadura são dadas pelas equações (3.39) e (3.40):

$$
k_{\text {inter }, i}=\frac{\varepsilon_{s 1}-\varepsilon_{c}}{d_{i}}
$$

Onde

$k_{\text {inter }, i}$ é a curvatura de escoamento para a dada armadura;

$\varepsilon_{s 1}$ é a tensão limite para escoamento da armadura;

$\varepsilon_{c}$ é a deformação na fibra mais comprimida do concreto;

$d_{i}$ é a posição da armadura dada, contada a partir do topo da seção.

Para os casos de intervalos análogos aos domínios 2, 3 e 4, com a variação na linha neutra, as curvaturas com escoamento das camadas de armadura serão:

$$
k_{\text {inter }, i}=\frac{\varepsilon_{s 1}}{d_{i}-x}
$$

Onde

$x$ é a posição da linha neutra.

Assim, para cada iteração da linha neutra tem-se um vetor com os valores de curvatura mínima, máxima e os valores intermediários correspondentes ao escoamento das armaduras. Observa-se que nem todos os valores de $k_{\text {inter }}$ encontrados serão utilizados, já que podem estar fora do intervalo maior definido pelas deformações limites dos domínios $k_{\min }$ e $k_{\text {máx }}$.

Nas tabelas 3.2 e 3.3 apresentam-se os valores apresentados no item anterior para os intervalos de linha neutra, deformação no concreto e curvatura, com adição dos valores para as curvaturas intermediárias, conforme descrito neste item. 
Tabela 3.2 - Hipóteses análogas aos domínios 1 e 5 - Intervalos de deformação no concreto e curvatura.

\begin{tabular}{|l|c|c|c|c|c|}
\cline { 2 - 6 } \multicolumn{1}{c|}{} & \multicolumn{2}{c|}{ Primeiro "Loop" } & \multicolumn{3}{c|}{ Segundo "Loop" } \\
\cline { 2 - 6 } & $\varepsilon_{c, \text { mín }}$ & $\varepsilon_{c, \text { máx }}$ & $k_{\text {mín }}$ & $k_{\text {máx }}$ & $k_{\text {inter }}$ \\
\hline Domínio 1 & 0,0 & 0,010 & 0,0 & $\frac{0,010-\varepsilon_{c}}{d}$ & \\
\hline Domínio 5 & $-\varepsilon_{c u}$ & 0,0 & $\begin{array}{c}\text { Se } \varepsilon_{c} \leq \varepsilon_{c 2}, \\
\varepsilon_{c u}-\varepsilon_{c 2} \\
\text { Se } \varepsilon_{c}>\varepsilon_{c 2}, \\
h\end{array}$ & $\frac{\varepsilon_{c}}{h}$ & $\varepsilon_{c}$ \\
& & 0,0 & & \\
\hline
\end{tabular}

Tabela 3.3 - Hipóteses análogas aos domínios 2, 3 e 4 - Intervalos da linha neutra e curvatura

\begin{tabular}{|l|c|c|c|c|c|}
\cline { 2 - 6 } \multicolumn{1}{c|}{} & \multicolumn{2}{c|}{ Primeiro "Loop" } & \multicolumn{3}{c|}{ Segundo "Loop" } \\
\cline { 2 - 5 } & $x_{\text {mín }}$ & $x_{\text {máx }}$ & $k_{\text {mín }}$ & $k_{\text {máx }}$ & $k_{\text {inter }}$ \\
\hline Domínio 2 & 0,0 & $\frac{\varepsilon_{c u} \cdot d}{\varepsilon_{s 2}+\varepsilon_{c u}}$ & 0,0 & $\frac{\varepsilon_{s 2}}{d-x}$ & \\
\hline Domínio 3 & $\frac{\varepsilon_{c u} \cdot d}{\varepsilon_{s 2}+\varepsilon_{c u}}$ & $\frac{\varepsilon_{c u} \cdot d}{\varepsilon_{s 1}+\varepsilon_{c u}}$ & 0,0 & $\frac{\varepsilon_{c u}}{x}$ & $\frac{\varepsilon_{s 1}}{d_{i}-x}$ \\
\hline Domínio 4 & $\frac{\varepsilon_{c u} \cdot d}{\varepsilon_{s 1}+\varepsilon_{c u}}$ & $h$ & 0,0 & $\frac{\varepsilon_{c u}}{x}$ & \\
\hline
\end{tabular}

O processo numérico para se encontrar as raízes inicialmente adotado foi o método secante. Porém não foi possível com este método definir valores limites para a curvatura, devendo-se verificar se a seção está rompida ao longo do processo iterativo, além do método poder apresentar um resultado falso, devido às descontinuidades da função normal-curvatura. Se o valor inicial para o método não for escolhido adequadamente, o método pode não convergir, o que dificulta sua aplicação, já esta seria para situações distintas de configuração da seção. Pelos motivos anteriormente explicitados, optou-se pelo método da bisseção explicado no presente item, que é mais robusto e apresenta maior controle sobre os resultados.

\subsubsection{Força Resistente da Seção}

A força resistente total da seção é calculada com base nos pares dados de curvatura e posição da linha neutra ou curvatura e deformação no concreto, dados pela iteração. Com os dados da seção, material e estrutura definidos, a força total resistente da seção é calculada pelo somatório das parcelas do concreto e do aço. Para o cálculo da parcela do concreto, deve-se integrar a tensão na área da seção 
transversal sob compressão. Desconsidera-se a parcela do concreto sob tração. Logo, calcula-se a integral da equação (3.41):

$$
F_{c}=\iint \sigma_{c} d y d z
$$

Onde

$\sigma_{c}$ é a tensão de compressão atuante no concreto;

$d y$ é a unidade infinitesimal na largura da seção;

$d z$ é a unidade infinitesimal na altura da seção.

A tensão é calculada considerando o item 8.2.10.1 da NBR 6118 (ABNT, 2014), que adota o diagrama parábola-retângulo para o concreto, reproduzido na figura 3.15. Opta-se por esta consideração para uma melhor aproximação do modelo com a realidade, descartando o modelo simplificado sugerido pelo item 17.2.2, onde o diagrama é substituído por um retangular.

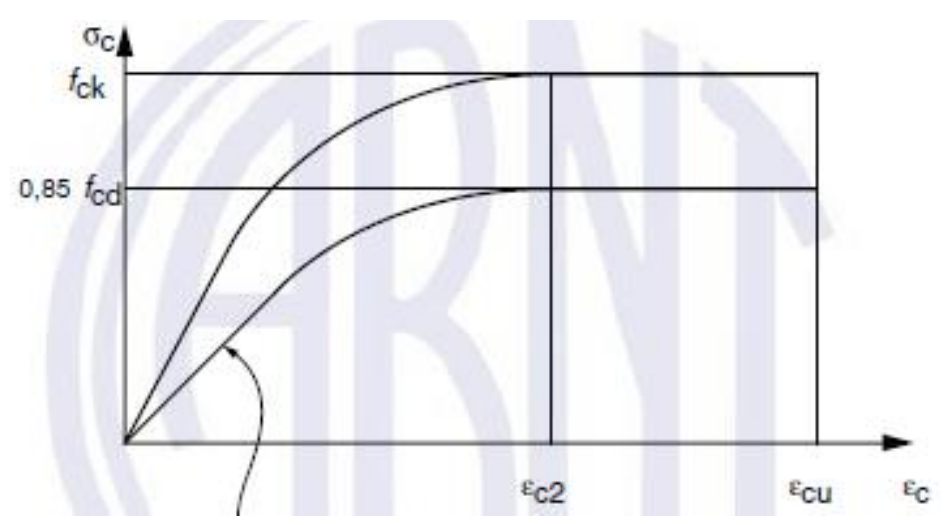

Figura 3.15 - Diagrama tensão-deformação - Figura 8.2 da NBR 6118 (ABNT, 2014)

A tensão é dada pela equação (3.42), segundo o mesmo item da NBR 6118:

$$
\sigma_{c}=0,85 f_{c d}\left[1-\left(1-\frac{\varepsilon_{c}}{\varepsilon_{c 2}}\right)^{n}\right]
$$

Onde:

$f_{c d}$ é a tensão resistente de cálculo do concreto;

$\varepsilon_{c}$ é a deformação específica da fibra do concreto;

$\varepsilon_{c 2}$ é a deformação específica de encurtamento do concreto no início do patamar plástico;

$\varepsilon_{c u}$ é deformação específica de encurtamento do concreto na ruptura;

$n$ é um parâmetro para a expressão de tensão. 
Definem-se os parâmetros abaixo, conforme a classe do concreto. Para concretos com resistência característica até $50 \mathrm{MPa}$, os limites de deformação e o parâmetro $n$ são definidos por:

$$
\begin{gathered}
\varepsilon_{c 2}=2,0 \% 0 \\
\varepsilon_{c u}=3,5 \% 0 \\
n=2
\end{gathered}
$$

Para concreto com resistência característica entre 55 e $90 \mathrm{MPa}$, os parâmetros tornam-se:

$$
\begin{gathered}
\varepsilon_{c 2}=2,0 \%+0,085 \% \cdot\left(f_{c k}-50\right)^{0,53} \\
\varepsilon_{c u}=2,6 \%+35 \% \cdot \cdot\left[\frac{\left(90-f_{c k}\right)}{100}\right]^{4} \\
n=1,4+23,4 \cdot\left[\frac{\left(90-f_{c k}\right)}{100}\right]^{4}
\end{gathered}
$$

Observe-se que a equação 3.42 , das tensões no concreto, é calculada em função da deformação $\varepsilon_{c}$ de encurtamento, enquanto que na equação 3.41 , a tensão é integrada ao longo da largura e altura da seção, variáveis y e $z$. Portanto, é necessário que se faça a mudança das variáveis da integral para o domínio da deformação específica. Observe-se, também, que a integração deve ser feita apenas na região comprimida do concreto. Portanto, exceto para os casos em que a linha neutra está abaixo da seção (figura 3.16b) e, portanto, toda a área transversal está comprimida, os limites de integração serão o topo da seção e a linha neutra (figura 3.16a). 
(a)

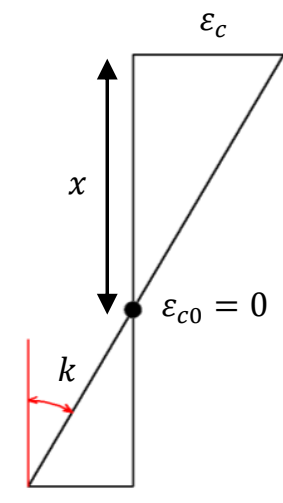

(b)

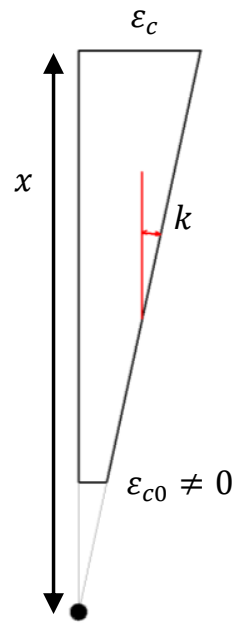

Figura 3.16 - Deformações dos limites de integração da tensão de compressão no concreto

Para a mudança de variáveis, utiliza-se a hipótese das seções planas, observada na figura 3.17 e conforme a equação (3.13), em que a posição da linha neutra está no domínio de $z$ e a deformação no concreto no domínio $\varepsilon_{x}$, sendo $z$ a posição de uma dada fibra, $\varepsilon_{x}$ a deformação específica nesta fibra e $k$ a curvatura da seção, assim se estabelece a equação (3.49).

$$
z=-\frac{\varepsilon_{x}}{k}+x
$$

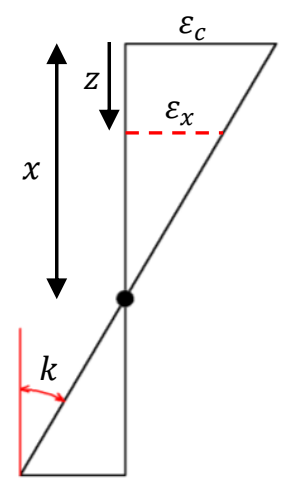

Figura 3.17 - Seção genérica com deformação $\varepsilon_{x}$ em uma fibra a distância $z$ do topo da seção

Derivando a equação (3.49) por $\varepsilon_{x}$, estabelece-se:

$$
\frac{d(z)}{d \varepsilon_{x}}=-\frac{d\left(\frac{\varepsilon_{x}}{k}\right)}{d \varepsilon_{x}}+\frac{d(x)}{d \varepsilon_{x}} \rightarrow d z=-\frac{d \varepsilon_{x}}{k}
$$

Desta forma, altera-se a integral da equação (3.41), redefinindo os limites de integração. Considerando que as seções tratadas neste trabalho são retangulares, e não havendo alteração da tensão ao longo da largura, chega-se a integral simples da equação (3.51). 


$$
F_{c}=-\frac{b}{k} \int_{\varepsilon_{c 0}}^{\varepsilon_{c}} \sigma_{c}\left(\varepsilon_{x}\right) d \varepsilon_{x}
$$

Logo,

$$
F_{c}=-0,85 f_{c d} \cdot \frac{b}{k} \int_{\varepsilon_{c 0}}^{\varepsilon_{c}}\left[1-\left(1-\frac{\varepsilon_{x}}{\varepsilon_{c 2}}\right)^{n}\right] d \varepsilon_{x}
$$

Observa-se que ao atingir a deformação $\varepsilon_{c 2}$ o concreto plastifica e não há aumento de tensão; assim, a resistência do concreto se mantém em $0,85 f_{c d}$. Portanto, para os casos em que a deformação no topo da seção for maior que o limite $\varepsilon_{c 2}$, a integral é definida pela equação (3.53).

$$
\begin{aligned}
F_{c}=-0,85 f_{c d} & \\
& \cdot \frac{b}{k}\left\{\int_{\varepsilon_{c 0}}^{\varepsilon_{c 2}}\left[1-\left(1-\frac{\varepsilon_{x}}{\varepsilon_{c 2}}\right)^{n}\right] d \varepsilon_{x}\right. \\
& \left.+\int_{\varepsilon_{c 2}}^{\varepsilon_{c}} 1 d \varepsilon_{x}\right\}
\end{aligned}
$$

O dimensionamento presente no FTOOL adota o método adimensional baseado no trabalho de Santos (1994). Desta forma, para o cálculo da parcela resistente do concreto, adota-se a variável adimensional $\eta$ da equação (3.54).

$$
\eta=\frac{F_{c}}{\sigma_{c d} \cdot A_{c}}
$$

Onde

$F_{C}$ é a força de compressão atuante no concreto;

$\sigma_{c d}$ é a tensão de cálculo no concreto, definida como $0,85 f_{c d}$ conforme o item 8.2.10.1 da NBR 6118 (ABNT, 2014);

$A_{c}$ é a área de concreto da seção bruta.

Assim, as integrais das equações (3.52) e (3.53) se tornam, respectivamente, as equações (3.55) e (3.56):

Para $\varepsilon_{c} \leq \varepsilon_{c 2}$

$$
\eta=\frac{1}{h \cdot k} \int_{\varepsilon_{c 0}}^{\varepsilon_{c}}\left[1-\left(1-\frac{\varepsilon_{x}}{\varepsilon_{c 2}}\right)^{n}\right] d \varepsilon_{x}
$$

Para $\varepsilon_{c}>\varepsilon_{c 2}$

$$
\eta=\frac{1}{h \cdot k}\left\{\int_{\varepsilon_{c 0}}^{\varepsilon_{c 2}}\left[1-\left(1-\frac{\varepsilon_{x}}{\varepsilon_{c 2}}\right)^{n}\right] d \varepsilon_{x}+\int_{\varepsilon_{c 2}}^{\varepsilon_{c}} 1 d \varepsilon_{x}\right\}
$$


Resolvendo as integrais para qualquer classe de concreto, sem especificar valores para $\varepsilon_{c 2}$ e $n$, as equações (3.55) e (3.56) se tornam as equações (3.57) e (3.58):

Para $\varepsilon_{c} \leq \varepsilon_{c 2}$

$\eta$

$$
=\frac{\left(\frac{\varepsilon_{c 2}-\varepsilon_{c}}{\varepsilon_{c 2}}\right)^{n+1} \cdot \varepsilon_{c 2}-\left(\frac{\varepsilon_{c 2}-\varepsilon_{c 0}}{\varepsilon_{c 2}}\right)^{n+1} \cdot \varepsilon_{c 2}+(n+1) \cdot\left(\varepsilon_{c}-\varepsilon_{c 0}\right)}{h \cdot k \cdot(n+1)}
$$

Para $\varepsilon_{c}>\varepsilon_{c 2}$

$$
\eta=\frac{\left(\varepsilon_{c 0}-\varepsilon_{c 2}\right) \cdot\left(\frac{\varepsilon_{c 2}-\varepsilon_{c 0}}{\varepsilon_{c 2}}\right)^{n}+(n+1) \cdot\left(\varepsilon_{c}-\varepsilon_{c 0}\right)}{h \cdot k \cdot(n+1)}
$$

Logo, para se obter a parcela da resistência à compressão do concreto, voltase a equação (3.54), aplicando o valor encontrado para $\eta$, conforme:

$$
F_{c}=-\eta \cdot \sigma_{c d} \cdot A_{c}
$$

A parcela da resistência do aço é calculada de acordo com a tensão e a área de armadura. As armaduras são dispostas ao longo das seções e cria-se o vetor $d_{i}$ com as posições das armaduras com referencial na fibra mais comprimida - o topo da seção, ilustrado na figura 3.18. A área de aço em cada camada é armazenada no vetor $A_{s}$ com o mesmo índice de $d_{i}$. Observa-se que a área de aço neste vetor é a área adotada na seção, portanto, calculada de acordo com o número de barras e a bitola adequada, após o dimensionamento.
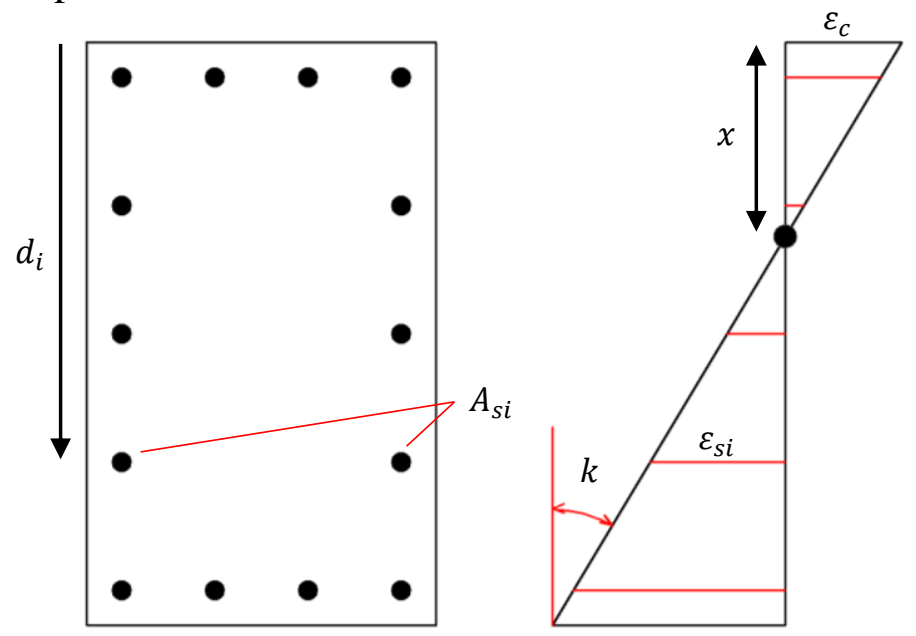

Figura 3.18 - Deformação das armaduras

Observa-se que o FTOOL possui duas maneiras de dimensionar a área de armadura adotada. Para o caso de vigas, o usuário define qual o diâmetro a ser 
utilizado na armadura superior e inferior e o FTOOL fornece ao final do dimensionamento o número de barras a ser utilizado para a dada bitola, separandoas por camadas. Já para o caso de pilares, o usuário fornece a disposição das barras e o FTOOL retorna qual o diâmetro deve ser adotado, dada a disposição fornecida pelo usuário.

Supondo uma seção genérica, independentemente de ser viga ou pilar, conforme a figura 3.18 , um outro vetor $\varepsilon_{s}$ armazena as deformações das barras em cada uma das camadas, que são calculadas de acordo com o hipótese de seções planas. Sendo a curvatura $k$ e a deformação $\varepsilon_{c}$ no topo da seção, na equação (3.60) encontra-se a deformação da camada $i$ de armadura conforme:

$$
\varepsilon_{s i}=\varepsilon_{c}+k \cdot d_{i}
$$

Observe-se que dentro da rotina de cálculo do programa, as deformações de encurtamento têm sinal negativo e as deformações de alongamento têm sinal positivo. Portanto, os sinais da deformação ficam iguais à convenção de sinais das forças para compressão, negativas e tração, positivas.

$\mathrm{Na}$ figura 3.19, mostra-se o diagrama tensão-deformação do aço, conforme definição do item 8.3.6 da NBR 6118 (ABNT, 2014). Até se atingir o patamar plástico, se tem variação linear de tensões. Após atingir a deformação $\varepsilon_{y d}$, o aço plastifica e não tem acréscimo de tensões, entrando no patamar plástico.

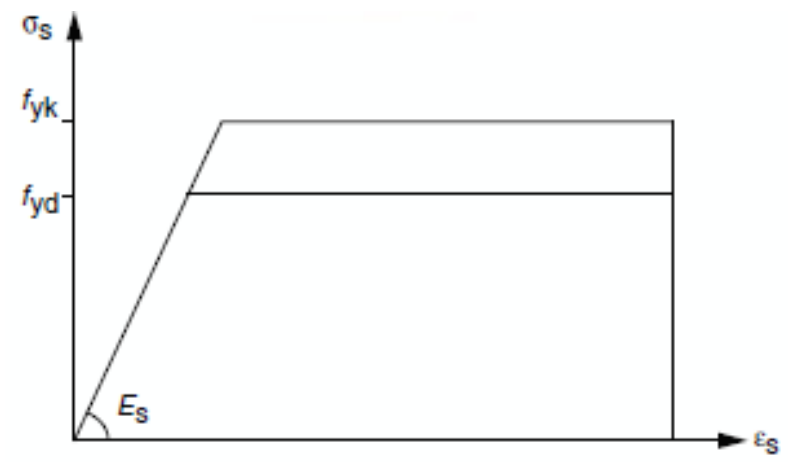

Figura 3.19 - Diagrama de tensão-deformação para aços de armaduras passivas -Figura 8.4 da NBR 6118(ABNT, 2014)

Para o cálculo da tensão atuante no aço, deve-se verificar se a armadura se encontra em comportamento elástico ou plástico. O diagrama acima, segundo a NBR 6118, pode ser aplicado para tração e compressão. Logo, o vetor $\sigma_{s}$ é calculado pelas equações (3.61), (3.62) e (3.63):

Se $\varepsilon_{s i} \leq-\varepsilon_{y d}$, patamar plástico à compressão: 


$$
\sigma_{s i}=-f_{y d}
$$

Se $-\varepsilon_{y d}<\varepsilon_{s i}<\varepsilon_{y d}$, comportamento elástico:

$$
\sigma_{s i}=\varepsilon_{s i} \cdot E_{s}
$$

Se $\varepsilon_{y d} \leq \varepsilon_{s i}$, patamar plástico à tração:

$$
\sigma_{s i}=f_{y d}
$$

Conhecidas a tensão atuante e a área total de aço em cada uma das camadas, com a equação (3.64) a parcela da resistência das armaduras é calculada pelo somatório do produto entre a tensão e área de aço:

$$
F_{s}=\Sigma \sigma_{s i} \cdot \varepsilon_{s i}
$$

Sendo o aço e o concreto os materiais resistentes da seção, a normal resistente total é dada pelo somatório das duas parcelas de resistência das equações (3.59) e (3.64):

$$
N_{r d}=F_{c}+F_{S}
$$

\subsubsection{Momento Resistente da Seção}

O momento fletor resistente da seção, assim como a força normal resistente, são calculados de acordo com o par de curvatura e linha neutra ou curvatura e deformação no concreto. O momento é considerado em relação ao topo da seção. Portanto, há três parcelas que contribuem: a normal resultante do concreto, a normal resultante em cada camada de armadura e a força normal atuante na seção, conforme a equação (3.66), que é aplicada no centro geométrico da seção:

$$
M_{r d}=M_{c}+M_{s}-M_{N d}
$$

Onde,

$M_{r d}$ é o momento total resistente da seção;

$M_{c}$ é a parcela resistente do concreto;

$M_{S}$ é a parcela resistente das camadas de armadura;

$M_{N d}$ é o momento resultante da normal atuante na seção.

Observe-se que o momento da normal atuante é calculado com a normal resistente obtida no item anterior. Desta forma, a parcela da normal entra com sinal negativo por ser uma força externa. Para cálculo da parcela da normal, usa-se a 
equação (3.67) que calcula o produto entre o valor da força e a distância de seu ponto de aplicação até o topo da seção:

$$
M_{N d}=N_{r d} \cdot c_{2}
$$

Onde,

$N_{r d}$ é a normal resistente da seção;

$c_{2}$ é a distância do centro geométrico da seção até o topo.

Seja a força do concreto obtida pela integral da região comprimida da seção. A parcela do momento fletor é obtida pela equação (3.68), que calcula a integral do produto das tensões de compressão pela distância até o eixo de referência para o momento fletor, sendo o topo da seção a origem do eixo z na convenção adotada.

$$
M_{c}=\iint z \cdot \sigma_{c} d y d z
$$

Analogamente ao cálculo da força normal, considerando-se que as seções de cálculo são retangulares e que, portanto, a integral em y será igual a $b$, além da mudança de variáveis para que se considere o domínio de deformação, a integral dupla da equação (3.68), se transforma em uma integral simples conforme equação (3.69):

$$
M_{c}=\frac{b}{k} \int_{\varepsilon_{c 0}}^{\varepsilon_{c}}\left(\frac{\varepsilon_{x}}{k}-x\right) \sigma_{c}\left(\varepsilon_{x}\right) d \varepsilon_{x}
$$

Logo,

$$
M_{c}=0,85 f_{c d} \cdot \frac{b}{k} \int_{\varepsilon_{c 0}}^{\varepsilon_{c}}\left(\frac{\varepsilon_{x}}{k}-x\right) \cdot\left[1-\left(1-\frac{\varepsilon_{x}}{\varepsilon_{c 2}}\right)^{n}\right] d \varepsilon_{x}
$$

Conforme observado no item anterior, para os casos em que a deformação no topo da seção for maior que o limite $\varepsilon_{c 2}$, a integral se divide em dois intervalos mostrados na equação (3.71):

$$
\begin{aligned}
M_{c}=0,85 f_{c d} & \cdot \frac{b}{k}\left\{\int_{\varepsilon_{c 0}}^{\varepsilon_{c 2}}\left(\frac{\varepsilon_{x}}{k}-x\right) \cdot\left[1-\left(1-\frac{\varepsilon_{x}}{\varepsilon_{c 2}}\right)^{n}\right] d \varepsilon_{x}\right. \\
& \left.+\int_{\varepsilon_{c 2}}^{\varepsilon_{c}}\left(\frac{\varepsilon_{x}}{k}-x\right) d \varepsilon_{x}\right\}
\end{aligned}
$$

A parcela do aço é calculada pelo somatório do produto entre a força e posição de cada uma das camadas de armadura, dado que a posição tem origem no topo da seção, referencial para o cálculo do momento. Portanto, utiliza-se a equação (3.72) para o cálculo da parcela do aço: 


$$
M_{s}=\Sigma F_{s i} \cdot d_{i}
$$

A figura 3.20 mostra em um fluxograma da maneira que o Ftool obtém a rigidez secante das seções após iniciar a análise não linear física da estrutura.

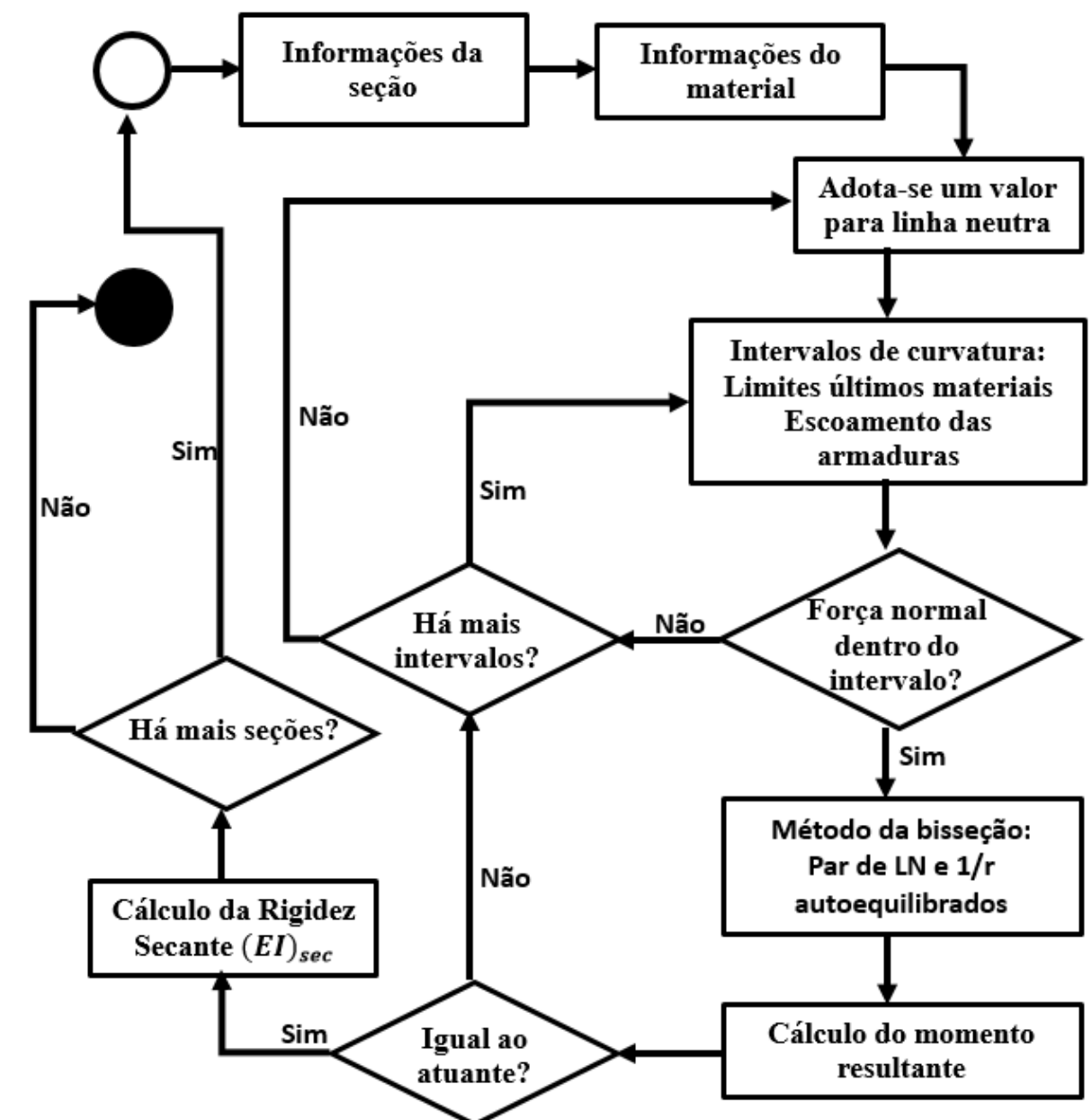

Figura 3.20 - Fluxograma do método de obtenção da rigidez secante

\subsection{Aplicação da Rigidez Secante no Modelo Estrutural}

Conforme discutido nos itens anteriores, aplica-se na análise a rigidez secante obtida com a relação momento-curvatura e então a análise é iterativamente refeita. Porém, conforme o item 2.1 deste trabalho, que discorre sobre a analogia da viga conjugada, método adotado para que se faça a análise considerando a variação da rigidez das seções ao longo do vão, é necessário um método numérico para que se obtenha o resultado da integração das equações (2.4) e (2.5).

$$
M_{A} \cdot \int_{0}^{l} \frac{x / l-1}{E I(x)} d x+M_{B} \cdot \int_{0}^{l} \frac{x / l}{E I(x)} d x+\rho=0
$$




$$
M_{A} \cdot \int_{0}^{l} \frac{x^{2} / l-x}{E I(x)} d x+M_{B} \cdot \int_{0}^{l} \frac{x^{2} / l}{E I(x)} d x=0
$$

As duas integrais formam um sistema para obtenção dos valores dos momentos de engastamento nas extremidades, $M_{A}$ e $M_{B}$. Com a solução do sistema, consequentemente com os valores de momento conhecidos, é possível calcular os valores dos coeficientes de rigidez à rotação $K_{A}$ e $K_{B}$ e os coeficientes de transmissão de momento $t_{A B}$ e $t_{B A}$, conforme as equações (2.6), (2.7), (2.8) e (2.9), observando a viga com deslocamento imposto mostrada na figura 3.21.

$$
\begin{gathered}
K_{A}=\frac{M_{A}}{\rho} \\
t_{A B}=\frac{M_{B}}{M_{A}} \\
K_{B}=\frac{M_{B}}{\rho} \\
t_{B A}=\frac{M_{A}}{M_{B}}
\end{gathered}
$$

Onde,

$\rho$ é o deslocamento imposto;

$K_{A}$ e $K_{B}$ são os coeficientes de rigidez à rotação;

$t_{A B}$ e $t_{B A}$ são os coeficientes de transmissão de momento;

$M_{A}$ e $M_{B}$ são os momentos de engastamento.

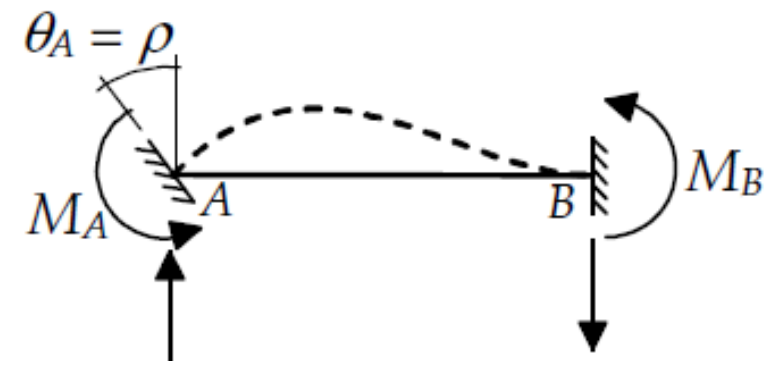

Figura 3.21 - Viga biengastada com rotação $\rho$ na extremidade inicial.

Desta forma, fica evidente a necessidade da implementação de um método para a integração numérica.

No Ftool, também é necessário determinar as reações de engastamento provocadas por solicitações externas atuantes em barras isoladas. Para barras com inércia variáveis, Vilela (2008) e Martha (2015) apresentam expressões semelhantes para o cálculo de reações de engastamento provocadas por forças linearmente distribuídas e variação de temperatura. 


\subsubsection{Nós de Integração}

A integral a ser resolvida é a divisão de um polinômio por uma função dada por pontos. O numerador é dado pelo polinômio de grau um ou dois que envolve a posição do nó em relação ao vão, vão este definindo o domínio da integração. O denominador é dado pelos valores de $E I(x)$, sendo estes últimos obtidos pela curva momento-curvatura, na forma de um vetor com pares de valores de posição relativa e rigidez secante obtida.

Os domínios de integração são definidos por trechos no código, que por sua vez podem ter uma maior discretização conforme o usuário defina o passo da estrutura, limitando a distância máxima entre os nós de integração. Cada elemento de barra no programa representa um trecho e, se ao longo deste elemento houver alteração na armadura, divide-se o trecho.

Nos apoios já há obrigatoriamente a divisão dos trechos, já que os apoios limitam elementos de barra, assim como no caso de alterações de carregamento. Observe-se que na análise não linear a armadura deve ser conhecida, e a alteração nas seções é dada pela alteração na armadura, situação comum no caso de vigas, onde a armadura é escalonada ao longo do vão. Portanto, os vãos das vigas apresentam variações de armadura, ou seja, vários trechos diferentes. Deve-se ressaltar que, para o cálculo da redução da inércia, a variação de armadura não considera o comprimento de ancoragem, apenas o diagrama escalonado. Esta situação não ocorre no caso de pilares, pois os pilares têm armadura constante ao longo do vão, sendo a discretização do pilar dada apenas pelos nós de integração definidos pelo passo do usuário.

A importância da divisão em trechos dos vãos se dá por que a curva momentocurvatura é construída a partir das características das seções e do carregamento, portanto, deve-se dividir os vãos em trechos com alteração de seção. Cria-se a seguir um exemplo genérico de viga para ilustrar a divisão de trechos e nós.

Seja uma viga com seção $20 x 45 \mathrm{~cm}$, em concreto C20, com altura útil de $42 \mathrm{~cm}$. Apresenta-se na figura 3.22 o modelo, o diagrama de momentos fletores e a armadura adotada. 
(a)

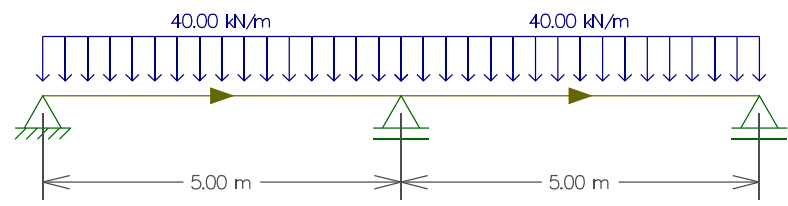

(b)

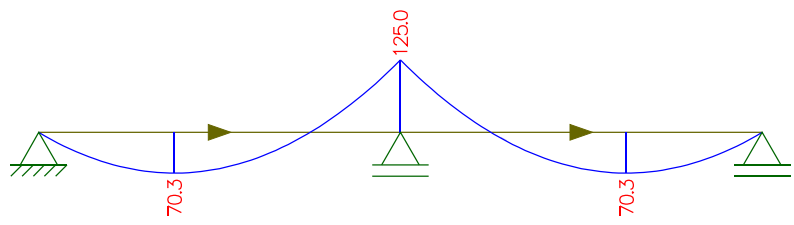

(c)

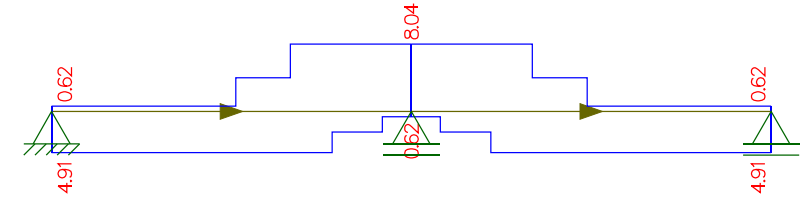

Figura 3.22 - (a) Modelo estrutural; (b) Diagrama de Momento Fletor; (c) Diagrama de armadura adotada.

Na figura 3.23 se apresentam três situações de discretização do vão. A primeira considera apenas os trechos, sem inserir nós dentro dos trechos. Desta forma cada trecho tem apenas dois nós de integração. A segunda tem passo de 0,2 $\mathrm{m}$; assim dentro de cada trecho adiciona-se um nó de integração a cada $0,2 \mathrm{~m}$. A última não considera a alteração de armadura ao longo do vão e considera seções espaçadas de aproximadamente $0,5 \mathrm{~m}$.

(a)

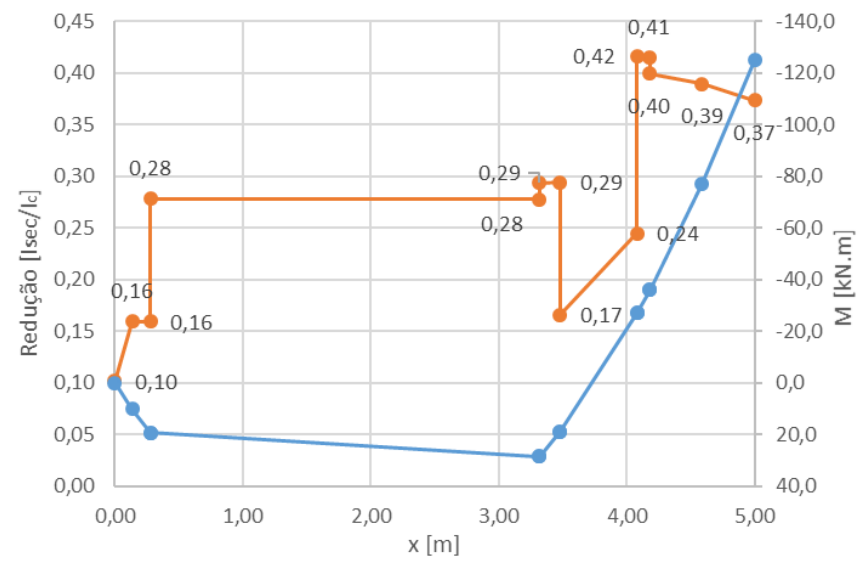


(b)

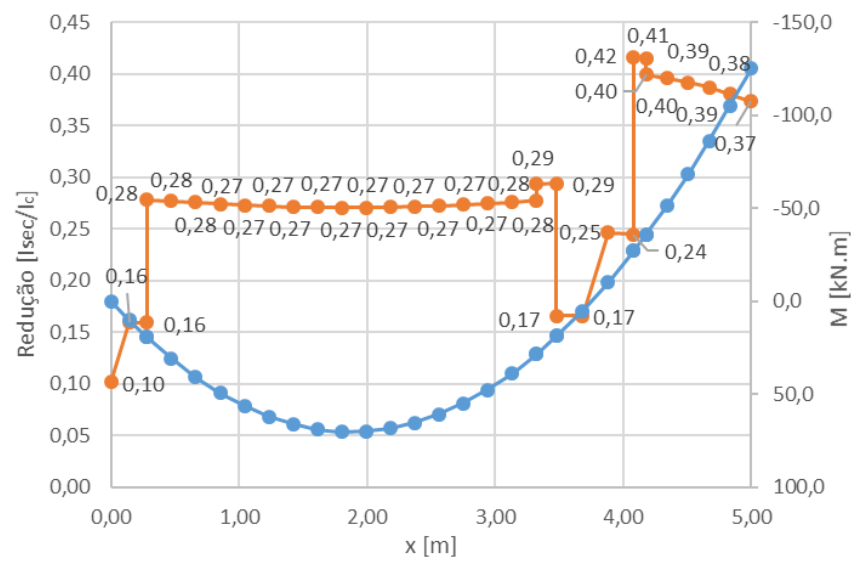

(c)

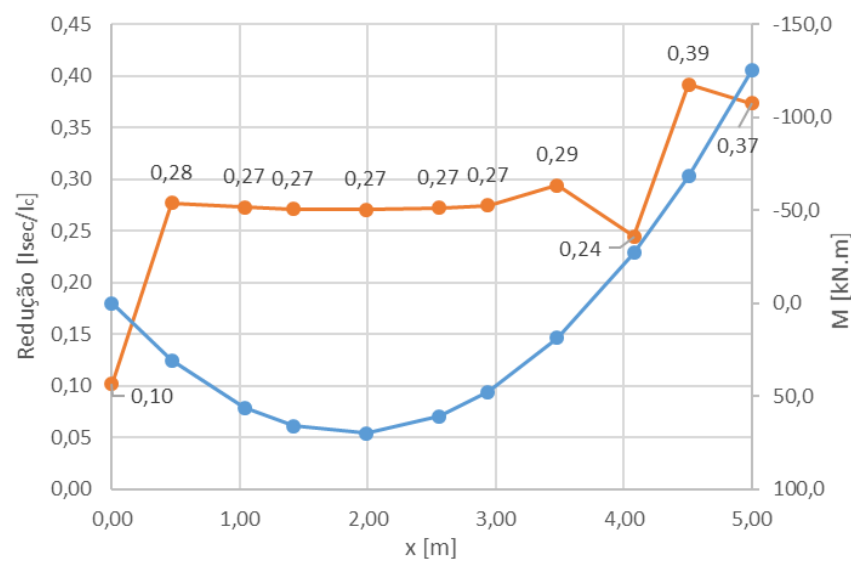

Figura 3.23 - Sobreposição do diagrama de momentos fletores com a redução da rigidez (a) Por trechos com 0,0 m; (b) Por trechos com 0,2 m; (c) Passo 0,5 m ao longo do vão.

Primeiro, observa-se que a armadura utilizada para a análise da redução da rigidez difere do diagrama de armadura adotada, pois não é considerado o comprimento de ancoragem, dado que esse comprimento não tem função estrutural. Por isso, há um trecho inicial que aparece na figura 3.23 (b) e não há um degrau correspondente no diagrama de armaduras.

A comparação entre os passos 0,0 e $0,2 \mathrm{~m}$ será melhor desenvolvida no capítulo 4 ao aplicar o método em exemplos. Mas percebe-se que ao se desconsiderar a alteração de seções e considerar um único trecho ao longo do vão, alguns valores de rigidez são negligenciados, observando a figura 3.23 (c), como a queda de rigidez entre as posições 3,0 e 4,0 m, assim como o degrau logo antes de 4,0 $\mathrm{m}$ e o pico logo depois de $4,0 \mathrm{~m}$.

Para pilares, cria-se um elemento genérico de $30 \times 75 \mathrm{~cm}$ com altura útil de $70 \mathrm{~cm}$ em concreto C30, com 18 barras distribuídas em 6 camadas, 3 barras nas 
camadas superior e inferior e 2 barras nas camadas intermediárias. Na figura 3.24 mostra-se o carregamento aplicado:

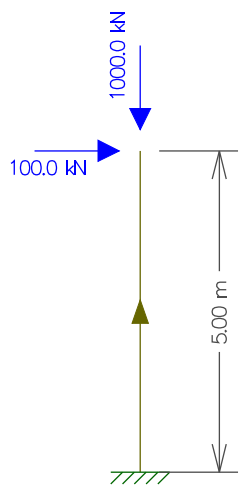

(a)

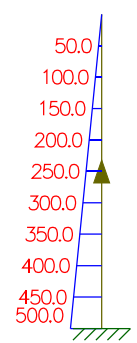

(b)

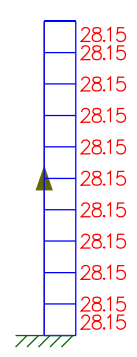

(c)

Figura 3.24 - (a) Modelo estrutural; (b) Diagrama de Momentos Fletores; (c) Diagrama de armadura adotada.

Na figura 3.25, analisa-se a variação da redução da rigidez do pilar ao longo do vão. Utiliza-se o passo de $0,0 \mathrm{~m}$ e $0,2 \mathrm{~m}$.

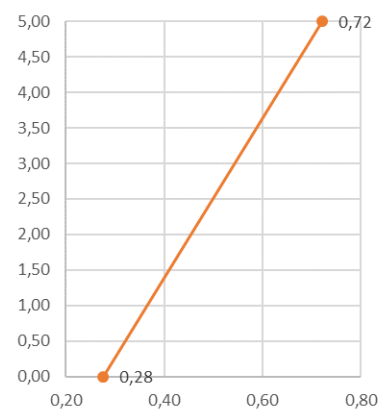

(a)

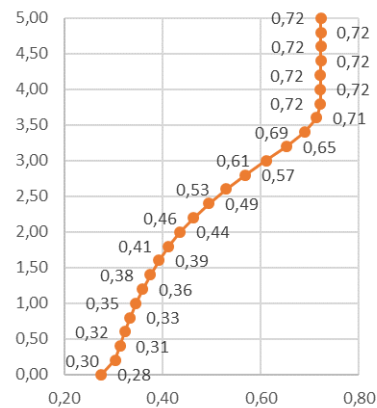

(b)

Figura 3.25 - Redução da rigidez ao longo do pilar (a) Passo 0,0 m; (b) Passo 0,2 m.

Observa-se que ao utilizar o passo $0,0 \mathrm{~m}$, considera-se a redução da rigidez linear ao longo do vão, mas ao aplicar uma maior discretização percebe-se uma curva diferente na redução. No topo da seção, onde o momento se aproxima de zero, a rigidez é quase constante até o ponto de altura 3,8 $\mathrm{m}$ que registra momento fletor de $-120 k N$. m. Observa-se que este valor é próximo ao momento de fissuração da seção, conforme pode ser confirmado pelo cálculo do item 17.3.1 da NBR 6118 (ABNT, 2014), que pela equação (3.73) define o momento de fissuração. 


$$
M_{r}=\frac{\alpha \cdot f_{c t, m} \cdot I_{c}}{y_{t}}
$$

Onde,

$\alpha$ é o fator que correlaciona aproximadamente a resistência à tração na flexão com a resistência à tração direta;

$y_{t}$ é a distância do centro de gravidade da seção à fibra mais tracionada;

$I_{c}$ é o momento de inércia da seção bruta do concreto;

$f_{c t}$ é a resistência à tração direta do concreto.

Seja a seção do exemplo. Na seção retangular, $\alpha$ assume valor de 1,5 e $y_{t}$ assume o valor da meia altura, 0,375 m. A inércia bruta da seção é calculada com a equação (3.74).

$$
\begin{gathered}
I_{c}=\frac{b \cdot h^{3}}{12} \\
I_{c}=\frac{0,30 \cdot 0,75^{3}}{12}=0,0105469 \mathrm{~m}^{4}
\end{gathered}
$$

A resistência à tração direta pode ser calculada pela equação (3.75), segundo o item 8.2.5 da Norma, com o valor da resistência à tração média.

$$
\begin{gathered}
f_{c t, m}=0,3 \cdot f_{c k}^{2 / 3} \\
f_{c t, m}=0,3 \cdot 30^{2 / 3}=2,8965 \mathrm{MPa}
\end{gathered}
$$

Obtidos estes valores, com a equação (3.73) calcula-se o momento de fissuração da seção:

$$
M_{r}=122,195 \mathrm{kN} \cdot \mathrm{m}
$$

Observa-se, portanto, que o material mantém a inércia secante constante até que o momento de fissuração seja atingido, o que é esperado, dado que após a fissuração o concreto se comporta de maneira não linear e deixa de contribuir para as forças internas. Acrescenta-se às variações da rigidez ao longo do vão, a não linearidade do concreto e do aço quanto a relação tensão-deformação.

Observar que esta comparação tem efeito apenas qualitativo, já que a expressão é válida para a flexão simples e não para a flexão composta.

O pilar é um bom exemplo para evidenciar a variação da rigidez pela curva momento-curvatura, dado que a armadura é igual em toda a altura do pilar e, portanto, apresenta a mesma curva, passando por grande parte dos valores do domínio dos momentos. 


\subsubsection{Método de Integração}

A integração numérica é feita pela regra dos trapézios, portanto, dentro de cada trecho, faz-se a integração da razão entre o polinômio do numerador e a função de pontos o denominador em todos os nós de integração, dada a malha do usuário. É importante a divisão de trechos pela descontinuidade da armadura, já que os nós iniciais e finais de trecho terão valores diferentes de armadura.

O sistema é composto por duas equações, dentro delas no total há quatro integrais. No lugar de se calcular as quatro integrais, é possível reduzir esse número a três integrais e com os resultados, montar as equações. A equação (2.4) pode ser alterada para:

$$
M_{A}\left[\frac{1}{l} \int_{0}^{l} \frac{x}{E I(x)} d x-\int_{0}^{l} \frac{1}{E I(x)} d x\right]+M_{B}\left[\frac{1}{l} \int_{0}^{l} \frac{x}{E I(x)} d x\right]+\rho=0
$$

Similarmente, a equação (2.5) também é alterada:

$$
M_{A}\left[\frac{1}{l} \int_{0}^{l} \frac{x^{2}}{E I(x)} d x-\int_{0}^{l} \frac{x}{E I(x)} d x\right]+M_{B} \cdot \frac{1}{l} \int_{0}^{l} \frac{x^{2}}{E I(x)} d x=0
$$

Desta forma, reduz-se o número de integrais para três, sendo elas as seguintes:

$$
\int_{0}^{l} \frac{1}{E I(x)} d x \quad \int_{0}^{l} \frac{x}{E I(x)} d x \quad \int_{0}^{l} \frac{x^{2}}{E I(x)} d x
$$

Observa-se que as integrais são calculadas a cada passo dado pelo usuário, portanto, o processo é iterativo e as equações do sistema são montadas ao final da solução de todas as integrais ao longo do elemento, num processo acumulativo.

Observa-se que dentro de cada passo há apenas dois valores conhecidos de EI. Portanto, dentro do passo, a variação da rigidez é calculada linearmente com a interpolação dos valores. Entretanto, dentro do passo, para as funções do numerador, a variação não é linear e utilizar apenas os dois pontos para cálculo da integral pela regra do trapézio geraria erros nos resultados. Desta forma, cada passo é discretizado em intervalos com tamanho igual ao comprimento do elemento de barra dividido por 1000, sendo o numerador calculado conforme a posição $x$ e o denominador com interpolação linear dos valores iniciais e finais de $(E I)_{\text {sec }}$ daquele passo.

Considera-se o mesmo exemplo do pilar do item anterior. O primeiro passo está entre a base e 0,2 m acima. Conforme visto no item anterior, a redução da 
rigidez na base foi na ordem de 0,28 e no passo 0,2 de 0,30 . Isso equivale, mais precisamente retirando-se os dados do programa, à rigidez secante de $78046,89 k N . m^{2}$ e $85940,87 k N . m^{2}$, respectivamente. Geram-se gráficos na figura 3.26 com cada uma das curvas a serem integradas.

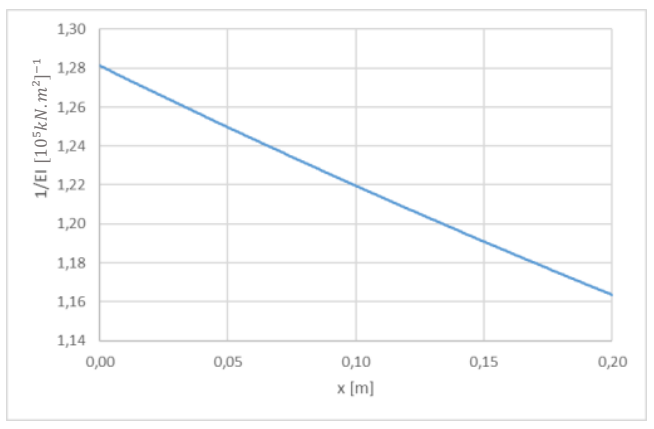

(a)

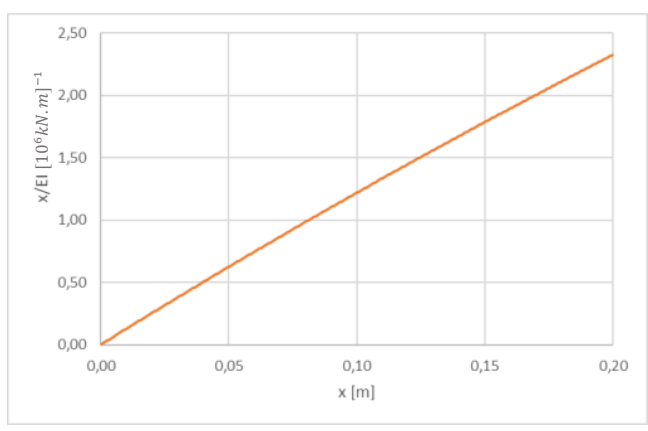

(b)

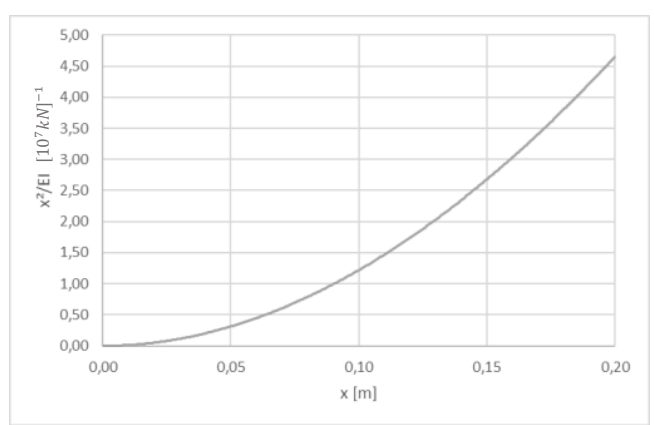

(c)

Figura 3.26 - Gráficos das funções de integração (a) Função de grau zero; (b) Função de grau um;

(c) Função de grau dois.

Para todos os casos de função, a equação (3.76) define a integral pela regra do trapézio.

$$
I=\sum_{1}^{n} \frac{F\left(a_{i}\right)+F\left(b_{i}\right)}{2} \cdot\left(b_{i}-a_{i}\right)
$$

Onde,

$F\left(a_{i}\right)$ e $F\left(b_{i}\right)$ são os valores da função nos pontos iniciais e finais do intervalo da integração;

$a_{i}$ e $b_{i}$ são as posições iniciais e finais do intervalo;

$n$ é o número de intervalos dentro do passo.

O valor da rigidez secante dentro do passo é calculado pela interpolação conforme a equação (3.77).

$$
E I_{s e c, i}=E I_{s e c, 0}+\frac{E I_{s e c, f}-E I_{s e c, 0}}{x_{f}-x_{0}} \cdot\left(x_{i}-x_{0}\right)
$$


Onde,

$E I_{s e c, f} e E I_{s e c, 0}$ são as rijezas finais e iniciais no passo;

$x_{f}$ e $x_{0}$ são as posições iniciais e finais do passo;

$x_{i}$ é a posição da seção onde deseja-se calcular a rigidez secante.

\subsection{Consideração da Fluência}

Sendo a fluência o aumento gradual da deformação de uma estrutura de concreto a partir de um carregamento constante ao longo do tempo, esta tem seu aumento acentuado logo após a aplicação do carregamento e tende a se estabilizar, ou seja, considerando uma análise em que o tempo tende a infinito, a deformação por fluência assume um valor assintótico máximo. Portanto, divide-se a deformação por fluência em duas partes, a rápida e a lenta. A deformação rápida ocorre nas primeiras 24 h após aplicação do carregamento e é irreversível. Já a lenta, possui uma parcela reversível e outra irreversível, sendo a deformação total dada pela equação (3.78), onde faz-se o somatório destas três parcelas.

$$
\varepsilon_{c c}=\varepsilon_{c c a}+\varepsilon_{c c f}+\varepsilon_{c c d}
$$

Onde

$\varepsilon_{c c a}:$ Deformação rápida irreversível;

$\varepsilon_{c c f}$ : Deformação lenta irreversível;

$\varepsilon_{c c d}$ : Deformação lenta reversível.

Desta forma, calcula-se a deformação total no concreto, num determinado tempo $t$, considerando as três parcelas por fluência mais a parcela da deformação imediata do carregamento, esta última ocorrendo no tempo $t_{0}$ :

$$
\varepsilon_{c}(t)=\varepsilon_{c}\left(t_{0}\right)+\varepsilon_{c c}(t)+\varepsilon_{c s}(t)
$$

Onde

$\varepsilon_{c}\left(t_{0}\right):$ Deformação imediata;

$\varepsilon_{c c}(t)$ : Deformação por fluência;

$\varepsilon_{c s}(t)$ : Deformação por retração, que neste trabalho não será considerada na análise.

Segundo a NBR 6118 (ABNT, 2014) no item A.2.2.1 de seu apêndice A, a deformação total do concreto, considerando a fluência, pode ser dada pela equação (3.80). 


$$
\varepsilon_{c, t o t}=\varepsilon_{c}\left(t_{0}\right)+\varepsilon_{c c}(t)=\varepsilon_{c}(1+\varphi)
$$

Logo, para consideração da fluência é necessário definir o coeficiente de fluência $\varphi$; e $\varepsilon_{c}$ é a deformação no concreto obtida a partir da teoria das vigas de Euler-Bernoulli, com deformações com distribuição linear na seção transversal.

A definição do coeficiente de fluência pode ser feita de duas formas recomendadas pela NBR 6118(ABNT, 2014). Quando não houver, por ensaios, dados precisos sobre o concreto a ser utilizado e o primeiro carregamento aplicado não gerar tensões superiores à $0,5 f_{c}$, podem ser utilizados os valores recomendados na tabela 8.2 do item 8.2.11 da Norma, podendo-se interpolar linearmente os valores. Havendo ensaios com o concreto considerado, com dados sobre a resistência do concreto de acordo com a idade fictícia, pode-se utilizar a metodologia como detalhado no item A.2.2.3 da Norma.

Para o desenvolvimento deste trabalho, optou-se por utilizar o método simplificado, porém observe-se que o usuário do programa terá a liberdade e a responsabilidade de adotar o valor de coeficiente de fluência correspondente à estrutura em análise. Na tabela 3.4, reproduz-se a tabela 8.2 da Norma.

Tabela 3.4 - Coeficientes de fluência e retração - Tabela 8.2 da NBR 6118: (ABNT, 2014)

\begin{tabular}{|c|c|c|c|c|c|c|c|c|c|c|}
\hline \multicolumn{3}{|c|}{$\begin{array}{c}\text { Umidade média } \\
\text { ambiente } \\
\%\end{array}$} & \multicolumn{2}{|c|}{40} & \multicolumn{2}{|c|}{55} & \multicolumn{2}{|c|}{75} & \multicolumn{2}{|c|}{90} \\
\hline \multicolumn{3}{|c|}{$\begin{array}{l}\text { Espessura fictícia } \\
22 A_{\mathrm{c}} / u \\
\mathrm{~cm}\end{array}$} & 20 & 60 & 20 & 60 & 20 & 60 & 20 & 60 \\
\hline \multirow{3}{*}{$\begin{array}{c}\varphi\left(t_{\infty}, t_{0}\right) \\
\text { Concreto } \\
\text { das classes } \\
\text { C20 a C45 }\end{array}$} & \multirow{9}{*}{$\begin{array}{c}t_{0} \\
\text { dias }\end{array}$} & 5 & 4,6 & 3,8 & 3,9 & 3,3 & 2,8 & 2,4 & 2,0 & 1,9 \\
\hline & & 30 & 3,4 & 3,0 & 2,9 & 2,6 & 2,2 & 2,0 & 1,6 & 1,5 \\
\hline & & 60 & 2,9 & 2,7 & 2,5 & 2,3 & 1,9 & 1,8 & 1,4 & 1,4 \\
\hline$\varphi\left(t_{\infty}, t_{0}\right)$ & & 5 & 2,7 & 2,4 & 2,4 & 2,1 & 1,9 & 1,8 & 1,6 & 1,5 \\
\hline $\begin{array}{l}\text { Concreto } \\
\text { das classes }\end{array}$ & & 30 & 2,0 & 1,8 & 1,7 & 1,6 & 1,4 & 1,3 & 1,1 & 1,1 \\
\hline C50 a C90 & & 60 & 1,7 & 1,6 & 1,5 & 1,4 & 1,2 & 1,2 & 1,0 & 1,0 \\
\hline \multirow{3}{*}{$\varepsilon_{\mathrm{cs}}\left(t_{\infty}, t_{0}\right) \%$} & & 5 & $-0,53$ & $-0,47$ & $-0,48$ & $-0,43$ & $-0,36$ & $-0,32$ & $-0,18$ & $-0,15$ \\
\hline & & 30 & $-0,44$ & $-0,45$ & $-0,41$ & $-0,41$ & $-0,33$ & $-0,31$ & $-0,17$ & $-0,15$ \\
\hline & & 60 & $-0,39$ & $-0,43$ & $-0,36$ & $-0,40$ & $-0,30$ & $-0,31$ & $-0,17$ & $-0,15$ \\
\hline
\end{tabular}

Na tabela 3.4, observa-se que quatro fatores que influenciam na fluência serão utilizados para definir o coeficiente. O primeiro é a umidade média do ambiente, também relacionada com a perda de água no processo de cura. Quanto maior a umidade do ambiente, menor a perda de água e menor a deformação por fluência. 
O segundo fator é o tempo $t_{0}$, que representa a idade fictícia em dias do concreto para na aplicação do carregamento. O terceiro é a relação $2 A_{c} / u$, sendo $A_{c}$ a área da seção de concreto e $u$ o perímetro da seção. Quanto menor for essa relação, maior é o perímetro e maior a superfície de contato com o ambiente, podendo gerar maior perda de água. Por fim, o quarto fator é a classe do concreto, seja ela de concreto C20 à C45 ou C50 à C90.

Para consideração da fluência na análise, adota-se a recomendação do Eurocode (CEN, 2004) no seu item 5.8.6, que determina que na ausência de modelo mais refinado, a fluência pode ser considerada multiplicando-se todos os valores das deformações do diagrama de tensão-deformação pelo fator $(1+\varphi)$ utilizando as equações (3.81) e (3.82), o que altera as deformações limites do concreto, tanto a deformação específica de encurtamento no início do patamar plástico, quanto a deformação específica na ruptura.

$$
\begin{aligned}
& \varepsilon_{c 2}=\varepsilon_{c 2}(1+\varphi) \\
& \varepsilon_{c u}=\varepsilon_{c u}(1+\varphi)
\end{aligned}
$$

A mesma metodologia é adotada por Ceccon (2008). 


\section{4}

\section{Aplicação do Método - Exemplos e Resultados}

Neste capítulo são apresentados alguns exemplos de vigas e pórticos para validação do método apresentado no item anterior. Propõem-se, para fins comparativos de resultados, as seguintes análises das estruturas aqui exemplificadas:

- Variação dos esforços internos;

- Variação da armadura calculada;

- Variação da armadura adotada;

- Variação dos deslocamentos.

Para a análise do impacto no dimensionamento da consideração da não linearidade física dos materiais, é necessário que a seção de concreto e as armaduras sejam conhecidas. Portanto, uma análise inicial para dimensionamento da armadura é feita conforme o método usual implementado no FTOOL. Após conhecida a seção, avaliam-se os diagramas momento-curvatura de todas as seções e obtém-se as novas rijezas. Observe-se que o processo é iterativo, portanto, aqui são apresentadas todas as iterações até que a estrutura convirja para um valor final. O diagrama de momentos fletores é utilizado como parâmetro para convergência. Não havendo mais alteração significativa nos valores do diagrama, considera-se convergida a análise. As comparações entre as armaduras e os deslocamentos são feitas após a convergência, conhecidas as configurações finais da estrutura.

\subsection{Exemplo 1 - Viga Contínua}

O primeiro exemplo é retirado do livro de Chust e Figueredo Filho (2015).

\subsubsection{Modelo Estrutural - Análise Inicial}

Propõe-se o cálculo e detalhamento das seções transversais mais solicitadas da viga central V101 na estrutura da figura 4.1: 


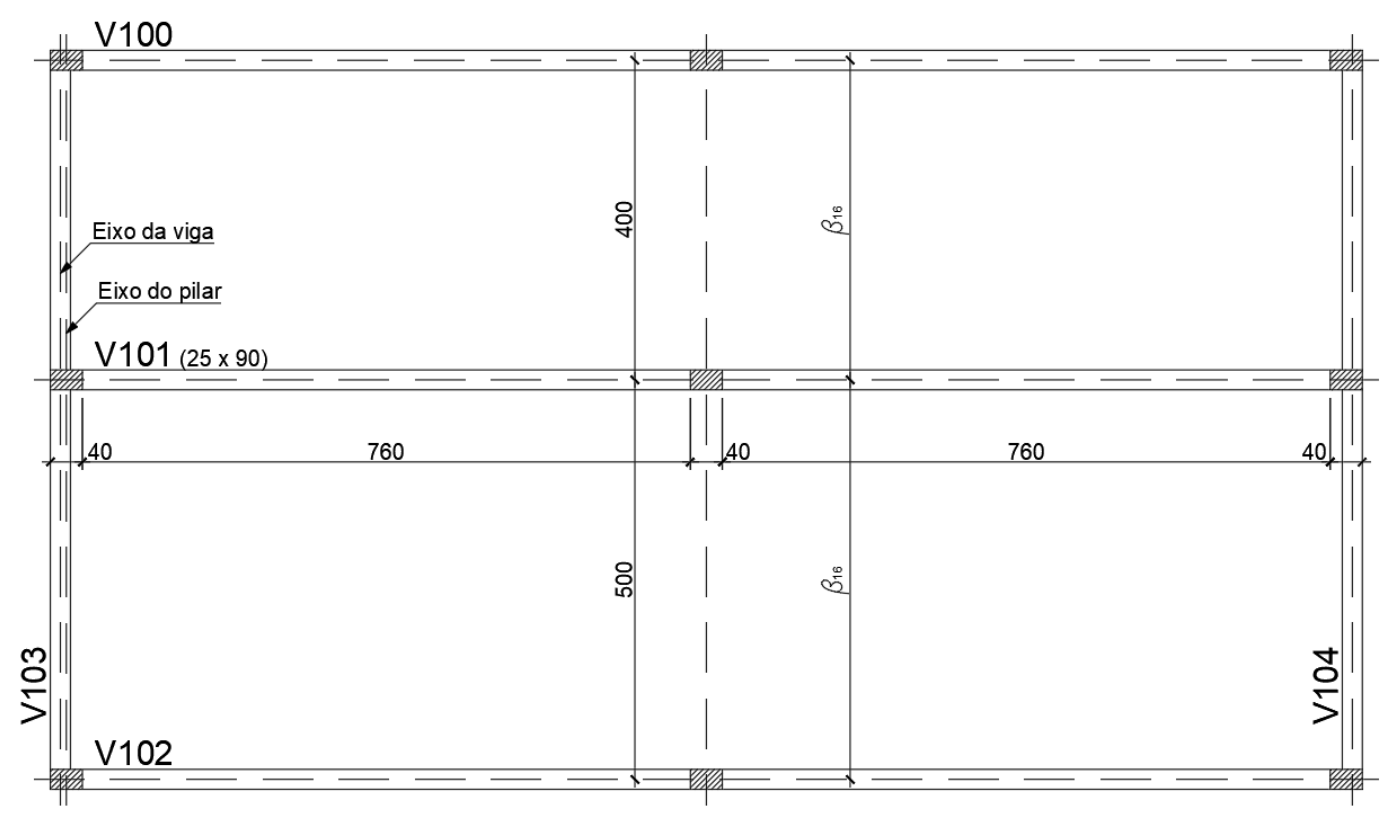

Figura 4.1 - Planta da formas da estrutura - Adaptada da Figura 4.11 de Chust e Figueiredo (2015)

Para se definir os dados necessários para o cálculo da armadura longitudinal, considera-se na viga a existência de uma parede de tijolos maciços com espessura de $25 \mathrm{~cm}$, assim como uma sobrecarga permanente de $1,5 \mathrm{kN} / \mathrm{m}^{2}$ e acidental de $4,0 \mathrm{kN} / \mathrm{m}^{2}$. A laje é pré-moldada com altura $h$ de $16 \mathrm{~cm}$ e peso próprio de $1,61 \mathrm{kN} / \mathrm{m}^{2}$. O concreto utilizado para a viga é C20 e aço CA50, e o cobrimento da viga é de $3 \mathrm{~cm}$. Considerando-se a altura mínima, já estimada no exemplo, a seção da viga será de $25 \times 90 \mathrm{~cm}$ com altura útil $\mathrm{d}$ de $80 \mathrm{~cm}$.

Para o cálculo do carregamento atuante na viga, deve-se considerar o carregamento da laje transferido para a viga. As cargas permanentes atuantes na laje são o seu peso próprio e a carga que engloba o revestimento e argamassa do piso. A equação (4.1) define a carga permanente total da laje.

$$
\begin{gathered}
g_{\text {laje }}=g_{1}+g_{2} \\
g_{\text {laje }}=3,11 \mathrm{kN} / \mathrm{m}^{2}
\end{gathered}
$$

A equação (4.2) define a única carga variável atuante na laje, que é a acidental.

$$
\begin{gathered}
q_{\text {laje }}=q_{1} \\
q_{\text {laje }}=4,0 \mathrm{kN} / \mathrm{m}^{2}
\end{gathered}
$$

Observa-se que só há apenas um carregamento variável, portanto, conforme recomendação da NBR 6118 (ABNT, 2014), todos os carregamentos serão 
majorados pelo mesmo coeficiente $\gamma_{f} 1,4$, para ações permanentes ou variáveis em combinações de ações normais.

Logo, pela equação (4.3), calcula-se o carregamento característico atuante na laje.

$$
\begin{aligned}
& f_{\text {laje }, k}=g_{\text {laje }}+q_{\text {laje }} \\
& f_{\text {laje }, k}=7,11 \mathrm{kN} / \mathrm{m}^{2}
\end{aligned}
$$

Na viga, devem-se considerar os carregamentos permanentes de peso próprio e da parede de tijolo maciço, portanto, a equação (4.4) define os carregamentos permanentes da viga.

$$
g_{v i g a}=g_{1}+g_{2}
$$

O peso próprio da viga considera o peso específico do concreto de $25 \mathrm{kN} / \mathrm{m}^{3}$ :

$$
\begin{gathered}
g_{1}=b \cdot h \cdot \gamma_{\text {conc }}=0,25 \cdot 0,90 \cdot 25 \\
g_{1}=5,625 \mathrm{kN} / \mathrm{m}
\end{gathered}
$$

A carga da parede considera o peso específico da alvenaria de tijolo maciço de $18 \mathrm{kN} / \mathrm{m}^{3}$, a altura da parede de $3,0 \mathrm{~m}$ e a largura de $25 \mathrm{~cm}$ :

$$
\begin{gathered}
g_{2}=b \cdot h \cdot \gamma_{a l v}=0,25 \cdot 3,0 \cdot 18 \\
g_{2}=13,5 \mathrm{kN} / \mathrm{m}
\end{gathered}
$$

Logo,

$$
g_{v i g a}=19,125 \mathrm{kN} / \mathrm{m}
$$

Como a viga V101 é a viga central da estrutura, considera-se simplificadamente que a metade do carregamento da laje de piso seja transferido para a viga. Portanto, para a determinação do carregamento atuante na viga, devese considerar além das cargas permanentes já calculadas, a carga transferida para a viga. Seja a distância entre os eixos das vigas V100 e V101 de 4,0 m e entre as vigas V101 e V102 de 5,0 m. Logo, área referente à viga V101 tem extensão de 4,5 $m$ e é calculada conforme a equação (4.5).

$$
\begin{gathered}
f_{\text {viga }, k}=g_{\text {viga }}+f_{\text {laje }, k} \cdot l \\
f_{\text {viga }, k}=19,125+7,11 \cdot 4,5 \\
f_{\text {viga }, k}=51,1 \mathrm{kN} / \mathrm{m}
\end{gathered}
$$


Considerando-se o vão efetivo a distância livre entre os apoios internos e externos, mais a metade da extensão dos apoios, obtém-se o vão efetivo de 8,0 $\mathrm{m}$. Mostra-se na figura 4.2 o modelo estrutural para o cálculo da viga.

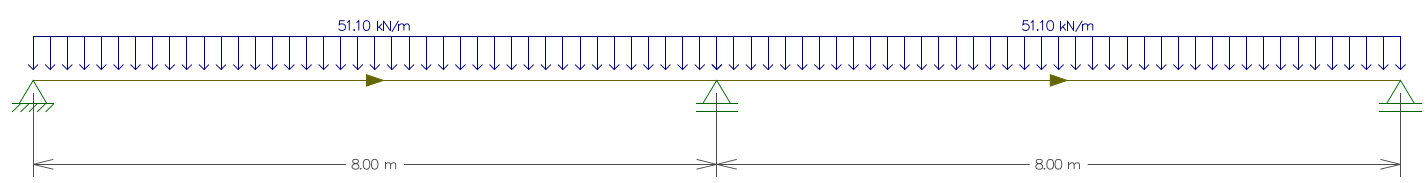

Figura 4.2 - Esquema estrutural com valor característico do carregamento de V101

No programa FTOOL, cria-se uma combinação única com fator de majoração de carregamentos $\gamma_{f}$ de 1,4 , resultando na carga distribuída de $71,54 \mathrm{kN} / \mathrm{m}$, aplicada na estrutura na figura 4.3.

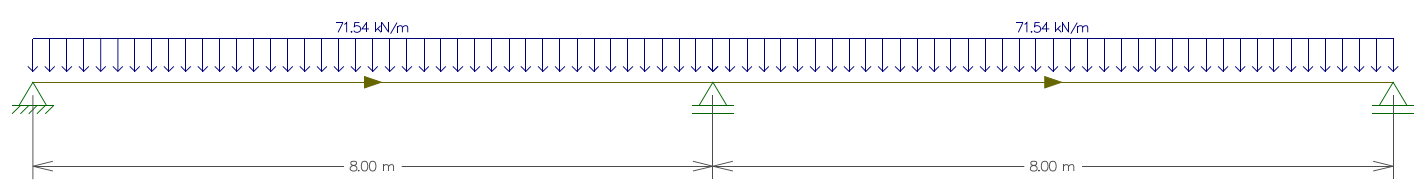

Figura 4.3 - Esquema estrutural com valor de cálculo do carregamento de V101.

Conforme explicitado, uma primeira análise para conhecimento da armadura da seção é feita. Consideram-se as seções com maiores momentos de cálculo, ou seja, as de máximo negativo no apoio central e máximo positivo no vão. Na figura 4.4 o diagrama de momento fletor de cálculo da estrutura.

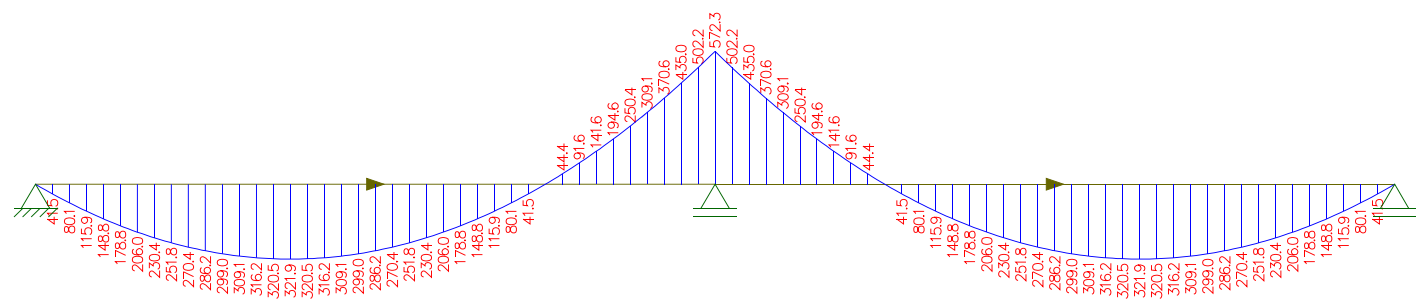

Figura 4.4 - Diagrama de momento fletor com valores de cálculo [kN.m].

Pelo o dimensionamento usual com fórmulas adimensionais para o cálculo das armaduras, calcula-se a armadura necessária, a equação (4.6) determina o momento adimensional de cálculo.

$$
K_{m d}=\frac{M_{d}}{b \cdot d^{2} \cdot f_{c d}}
$$

Momento máximo negativo:

Momento máximo positivo:

$$
\begin{gathered}
K_{m d}=\frac{572,32}{0,25 \cdot 0,80^{2} \cdot 20000 / 1,4} \quad K_{m d}=\frac{322,00}{0,25 \cdot 0,80^{2} \cdot 20000 / 1,4} \\
=0,25
\end{gathered}
$$

Fator adimensional da linha neutra, equação (4.7). 


$$
K_{x}=\frac{1-\sqrt{1-\frac{2 \cdot K_{m d}}{0,85}}}{0,8}
$$

Momento máximo negativo:

Momento máximo positivo:

$$
K_{x}=\frac{1-\sqrt{1-\frac{2 \cdot 0,25}{0,85}}}{0,8}=0,4479 \quad K_{x}=\frac{1-\sqrt{1-\frac{2 \cdot 0,14}{0,85}}}{0,8}=0,2264
$$

Equação (4.8) para cálculo do fator adimensional do braço de alavanca da seção.

$$
K_{z}=1-0,4 K_{x}
$$

Momento máximo negativo:

Momento máximo positivo:

$$
K_{z}=1-0,4 \cdot 0,4479=0,8208 \quad K_{z}=1-0,4 \cdot 0,2264=0,9094
$$

Cálculo da força de tração pela equação (4.9).

$$
T_{d}=\frac{M_{d}}{K_{z} \cdot d}
$$

Momento máximo negativo:

$$
T_{d}=\frac{572,32}{0,8208 \cdot 0,8}=871,59 \mathrm{kN} \quad T_{d}=\frac{322,00}{0,9094 \cdot 0,8}=442,60 \mathrm{kN}
$$

A armadura necessária pela equação (4.10).

$$
A_{s}=\frac{T_{d}}{f_{y d}}
$$

Momento máximo negativo:

Momento máximo positivo:

$$
A_{s}=\frac{871,59}{50 / 1,15}=20,05 \mathrm{~cm}^{2} \quad A_{s}=\frac{442,60}{50 / 1,15}=10,18 \mathrm{~cm}^{2}
$$

Adota-se a barra com diâmetro de 12,5 mm, com área de 1,227 cm². Logo, na região de momento máximo negativo são necessárias 17 barras, resultando em $20,86 \mathrm{~cm}^{2}$ e na região de momento máximo positivo 9 barras, portanto com armadura principal adotada de $11,04 \mathrm{~cm}^{2}$.

A partir da modelagem no FTOOL, obtêm-se as armaduras inferior e superior necessárias calculadas, diagrama na figura 4.5, considerando a decalagem do diagrama de momento fletor. Observa-se que o resultado é em $\mathrm{cm}^{2}$ e os valores são compatíveis com os obtidos no exemplo de Chust e Figueredo Filho (2015), conforme mostrado na tabela 4.1. 


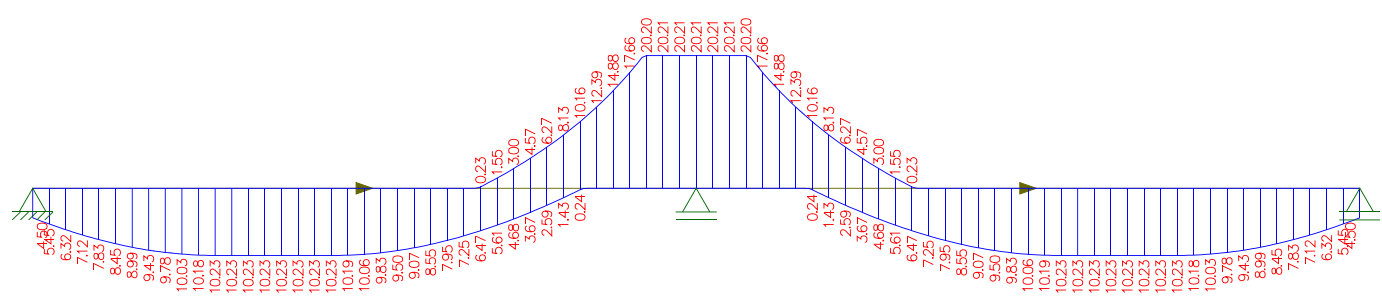

Figura 4.5 - Diagrama de armaduras necessárias $\left[\mathrm{cm}^{2}\right]$.

Tabela 4.1 - Resultado do cálculo das armaduras pelos dois métodos

\begin{tabular}{|c|c|c|}
\hline Armadura Calculada & Momento máximo negativo: & Momento máximo positivo: \\
\hline Resultado numérico & $20,05 \mathrm{~cm}^{2}$ & $10,18 \mathrm{~cm}^{2}$ \\
\hline FTOOL & $20,21 \mathrm{~cm}^{2}$ & $10,23 \mathrm{~cm}^{2}$ \\
\hline
\end{tabular}

No programa, ao se configurar a seção utilizada, o usuário escolhe o diâmetro da barra a ser adotada na armadura principal. Neste exemplo, opta-se pelo mesmo diâmetro de 12,5 mm, resultando no diagrama de armadura adotada da figura 4.6. Observa-se que este diagrama inclui o comprimento de ancoragem.

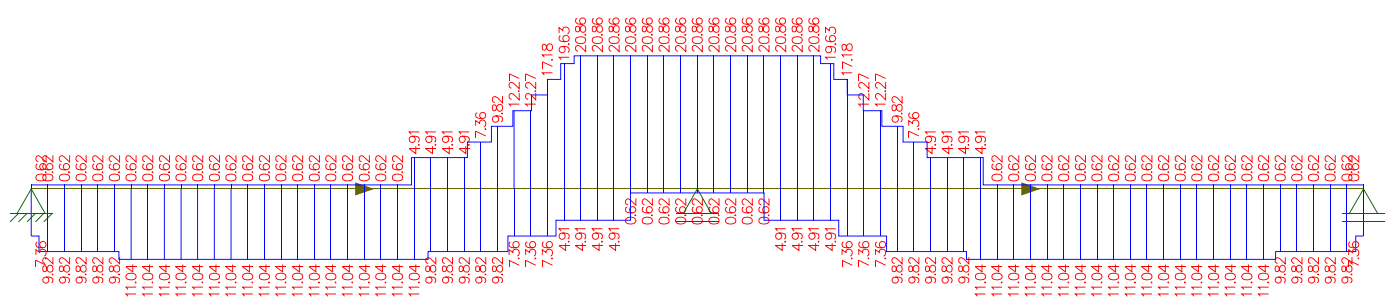

Figura 4.6 - Diagrama de armaduras adotadas $\left[\mathrm{cm}^{2}\right]$.

\subsubsection{Redução da Rigidez - Convergência do Modelo}

Com a armadura conhecida, faz-se a análise não linear com a rigidez reduzida. O programa permite que o usuário escolha qual o intervalo de pontos para a análise. Porém, conforme explicitado no item anterior, a cada mudança de seção - o que inclui mudança na armadura inferior ou superior - é inserido compulsoriamente um nó. Sabe-se que quanto mais pontos se inserem na análise, mais o tempo de processamento aumenta, por isso é importante que se faça uma análise do número de nós ideal para convergência do modelo. Aqui faz-se um estudo da convergência variando os valores de intervalo entre pontos.

Observe-se que cada estrutura necessita do seu próprio estudo de convergência. Aqui tenta-se mostrar o impacto no resultado final, que para o usuário é a área de armadura do dimensionamento, da alteração da malha de pontos na integração. O diagrama de momento fletores e o dimensionamento são montados com a malha refinada do FTOOL e a armadura é calculada em todos estes pontos. 
O que difere para a análise com a inércia reduzida é que o usuário determina o passo para a alteração da rigidez.

Com o dimensionamento inicial da armadura, é possível observar os trechos da estrutura fazendo a leitura dos dados, obtendo a figura 4.7 com a divisão de trechos:

Trecho 15

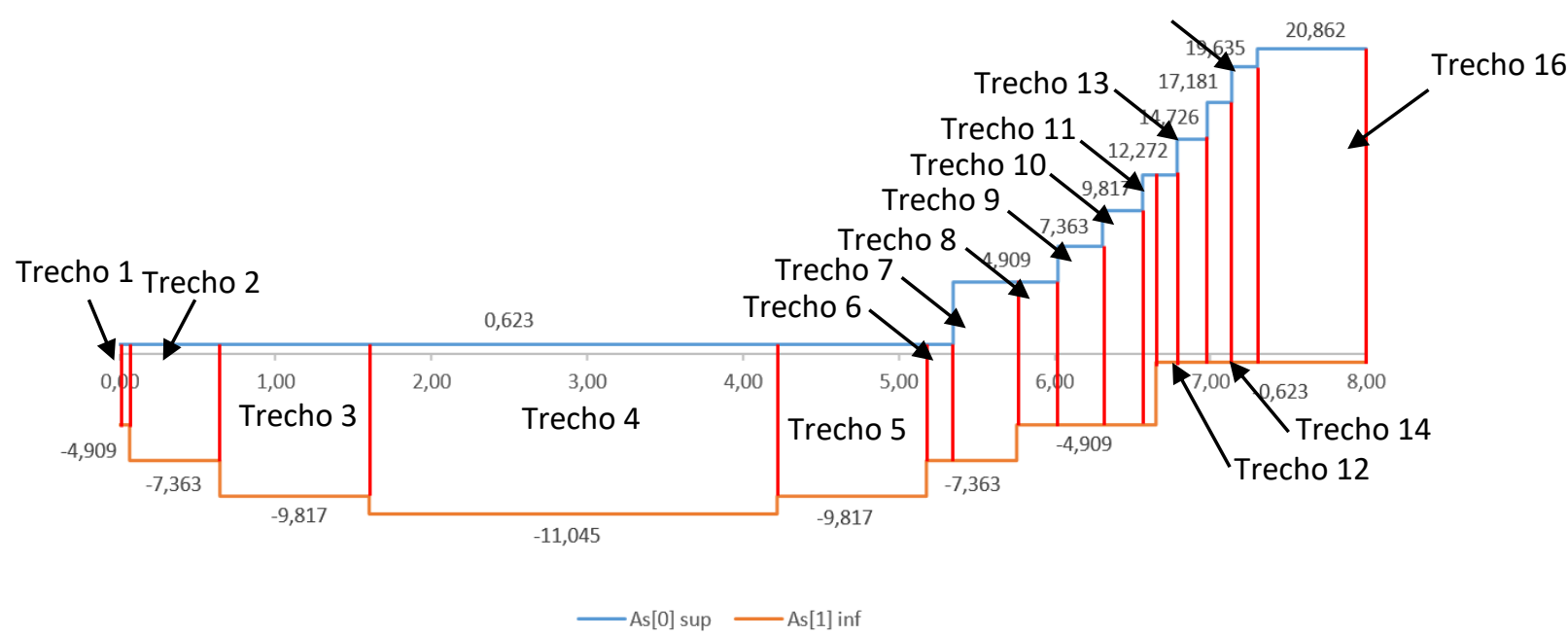

Figura 4.7 - Trechos para integração da estrutura - Meio vão por simetria

Assim, é possível observar os 16 trechos limitados pelas linhas verticais. O passo é determinado pelo usuário e serão criados nós adicionais dentro dos trechos. Os passos propostos para este estudo são de $0,2 \mathrm{~m}, 0,5 \mathrm{~m}, 1,0 \mathrm{~m}$ e $0,0 \mathrm{~m}$. Com o passo $0,0 \mathrm{~m}$ o programa calcula as rijezas apenas nos nós iniciais e finais de cada trecho.

Os gráficos da figura 4.8 mostram a armadura adotada em cada seção e o diagrama de momento fletor sobreposto. $\mathrm{O}$ eixo da direita é referente ao momento fletor [kN.m] e o da esquerda à armadura adotada $\left[\mathrm{cm}^{2}\right]$.

(a)

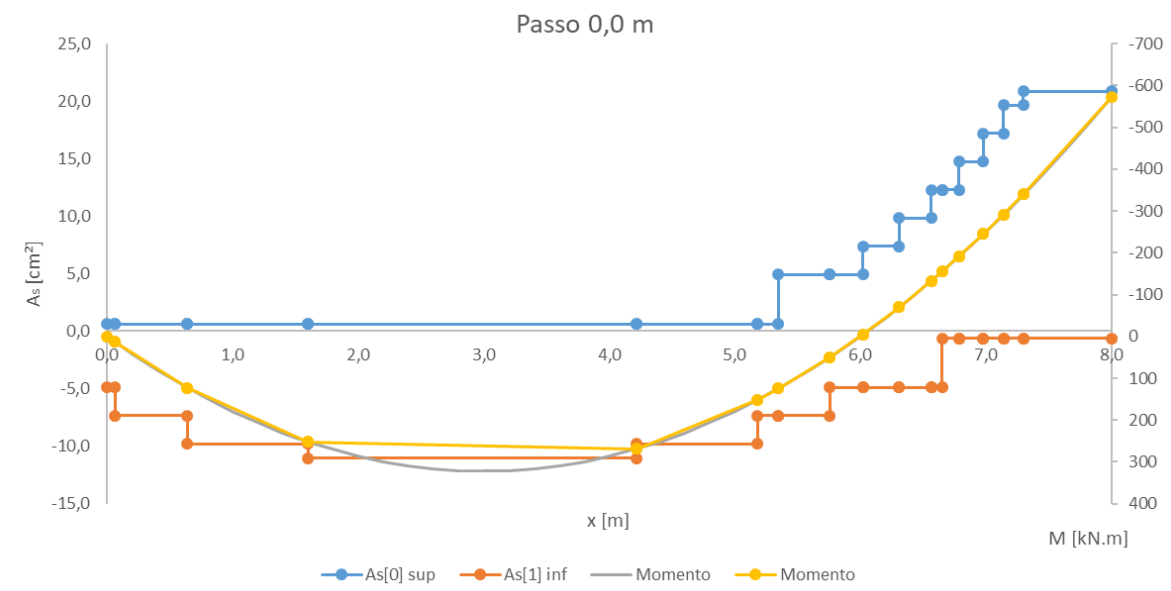


(b)

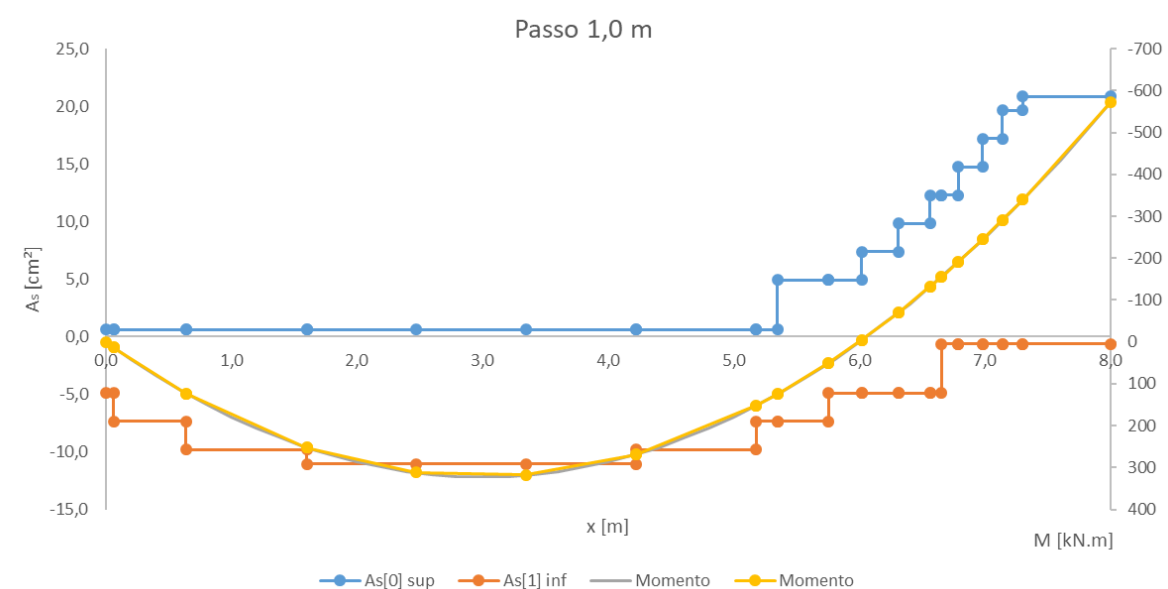

(c)

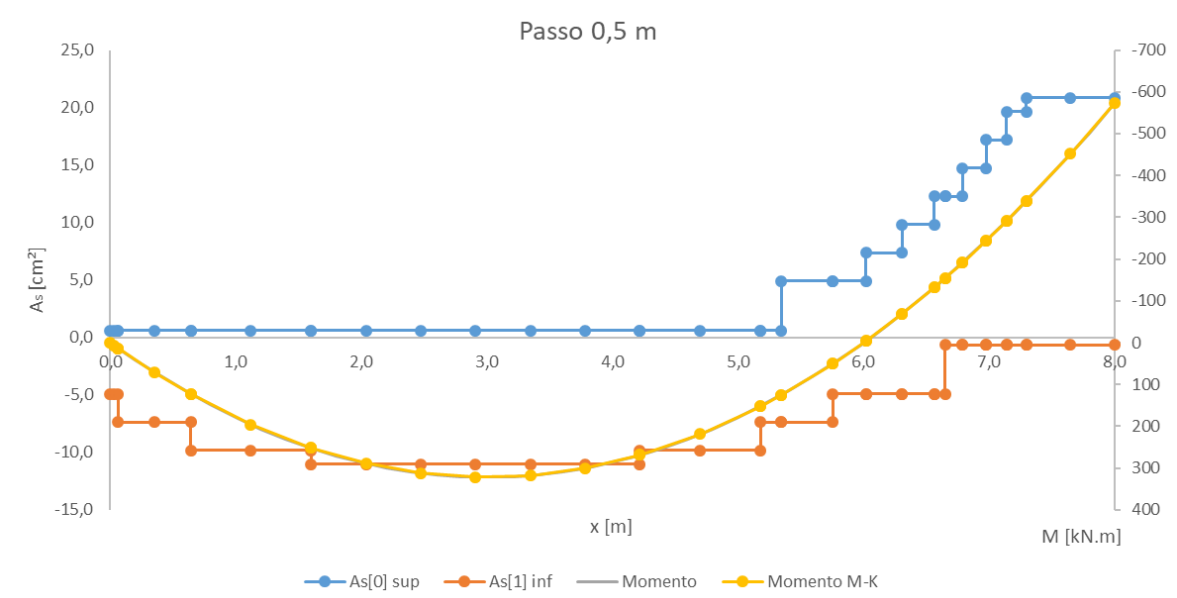

(d)

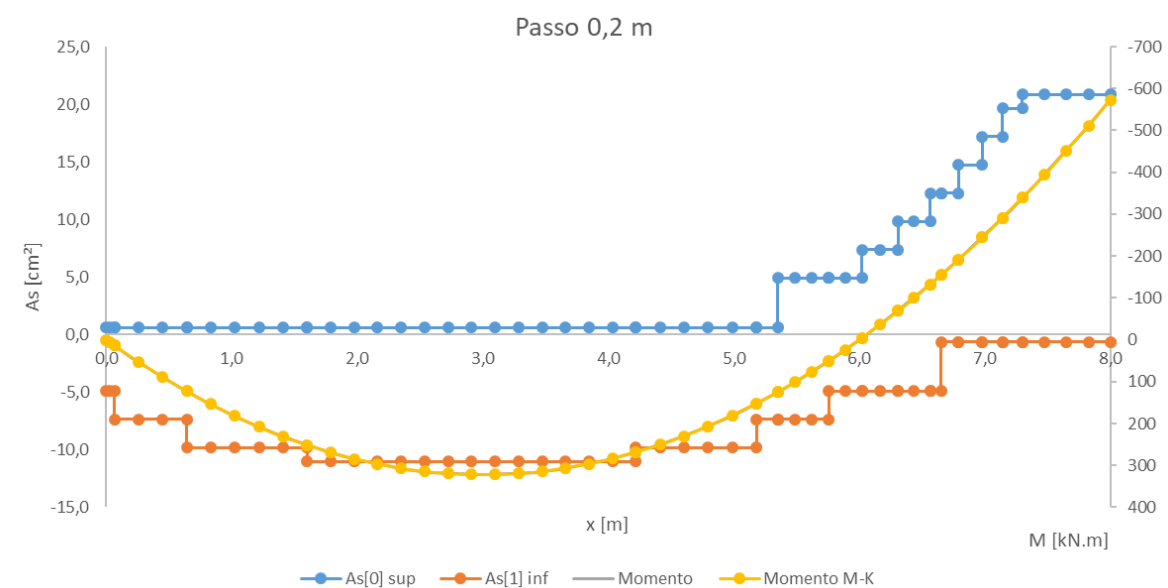

Figura 4.8 - Nós de integração considerando os passos propostos: (a) 0,0 m; (b) 1,0 m; (c) 0,5 m;

(d) $0,2 \mathrm{~m}$.

Conforme a legenda da figura 4.8, as armaduras superior e inferior são marcadas na parte superior e inferior do gráfico, respectivamente. Há duas curvas de momento, a curva cinza denominada "Momento" representa o momento refinado default do FTOOL, já a curva "Momento M-K" marca os momentos nos nós utilizados para a integração. 
Observa-se que o momento máximo negativo no apoio central da viga sempre terá um nó, pois trata-se de um apoio que separa os elementos de barra da estrutura, por consequência é o último nó de um trecho. Já o momento máximo positivo fica no vão e dependendo do passo dado pelo usuário, pode não ser computado na análise do momento-curvatura. Dado que cada trecho tem a mesma armadura e seção, a curva momento-curvatura é a mesma, considerando-se que não há alteração do esforço normal dentro deste trecho. Portanto, o ponto de momento máximo seria o ponto com maior redução na rigidez da seção.

Para demonstração do processo, acompanha-se a variação do diagrama de momentos fletores nas iterações até a convergência. Considera-se o passo de $0,5 \mathrm{~m}$ como demonstrativo para as iterações da figura 4.9 até 4.16 .

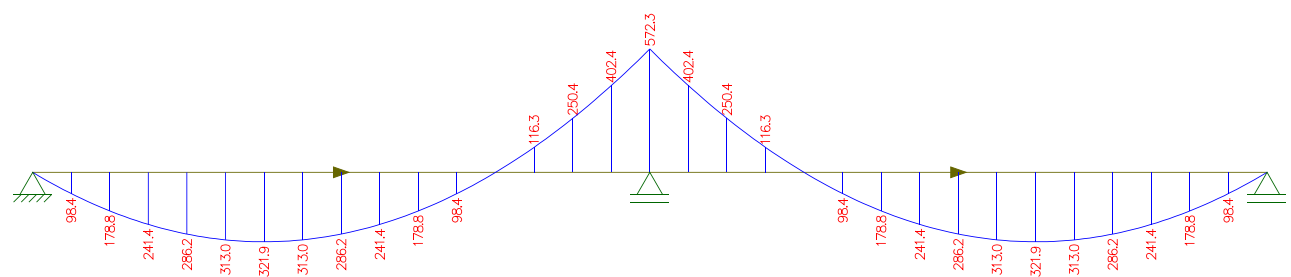

Figura 4.9 - Iteração 0 - Diagrama de Momento Fletor [kN.m]- Análise Linear

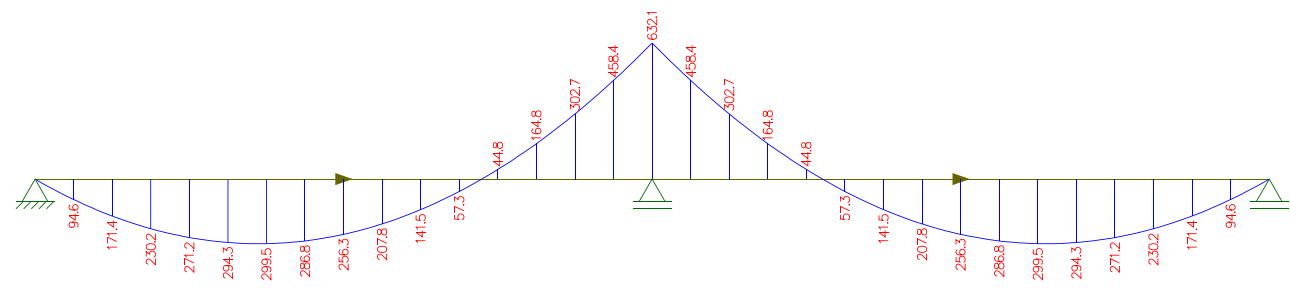

Figura 4.10 - Iteração 1 - Diagrama de Momento Fletor [kN.m].

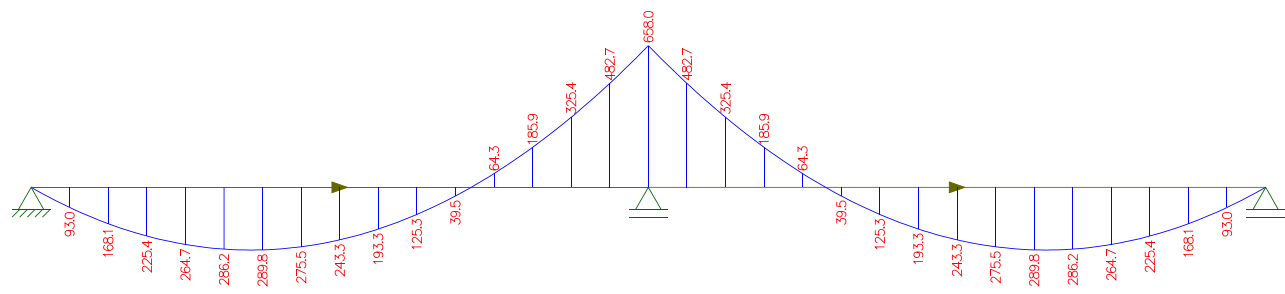

Figura 4.11 - Iteração 2 - Diagrama de Momento Fletor [kN.m].

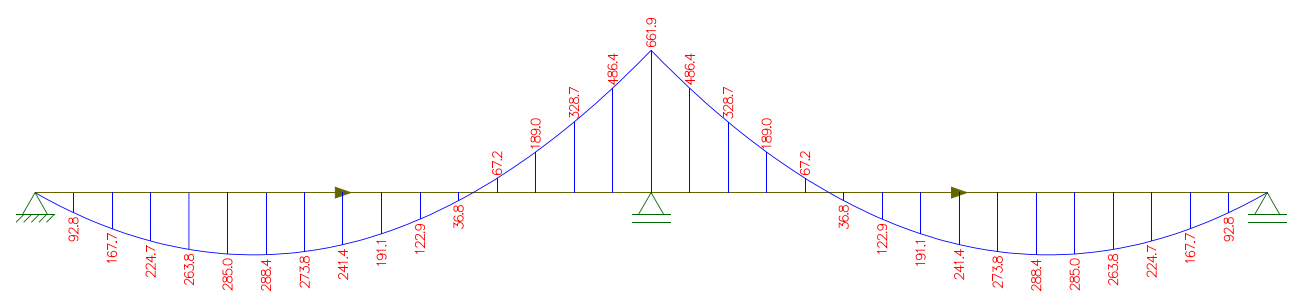

Figura 4.12 - Iteração 3 - Diagrama de Momento Fletor [kN.m]. 


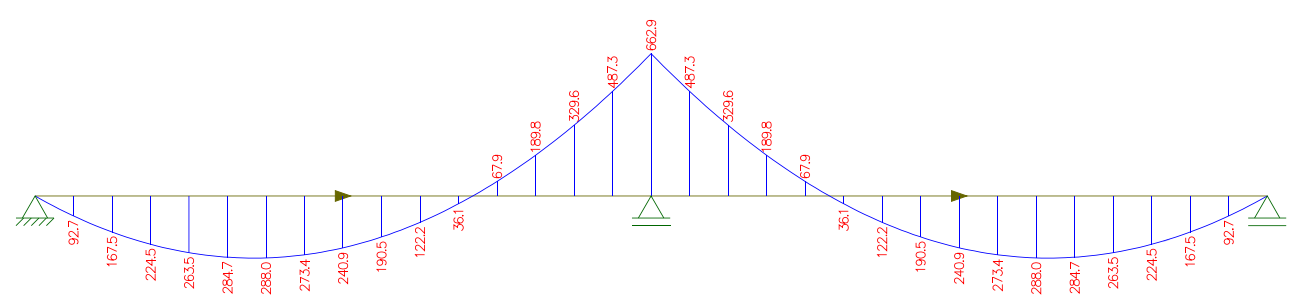

Figura 4.13 - Iteração 4 - Diagrama de Momento Fletor $[k N . m]$.

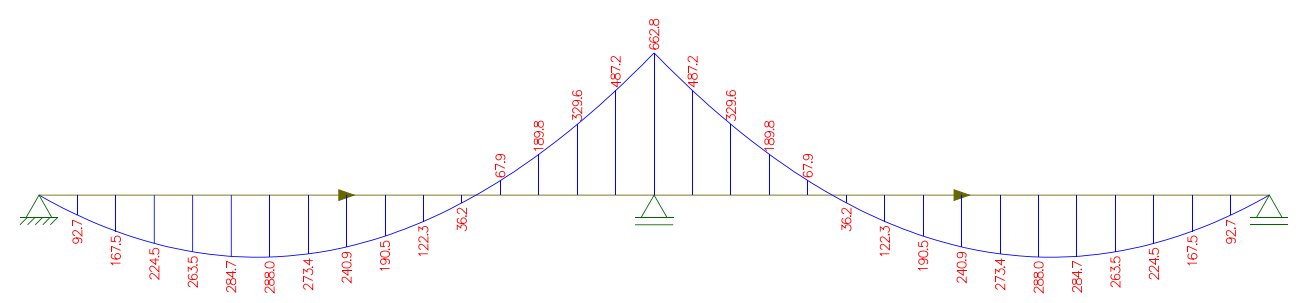

Figura 4.14 - Iteração 5 - Diagrama de Momento Fletor [kN.m].

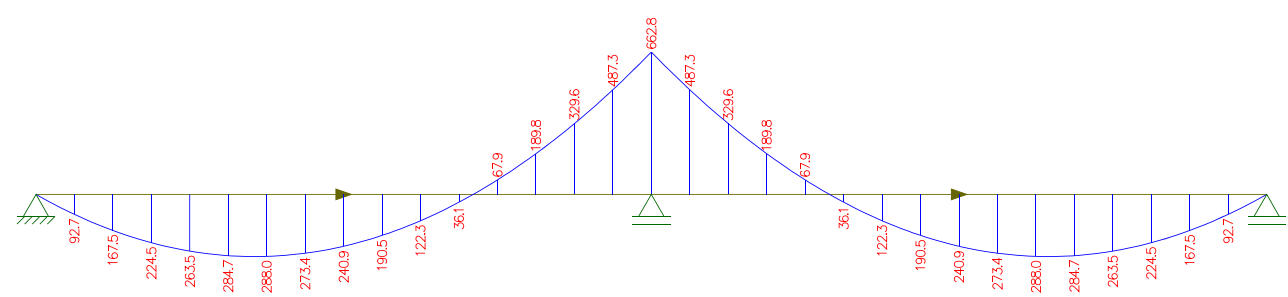

Figura 4.15 - Iteração 6 - Diagrama de Momento Fletor [kN.m].

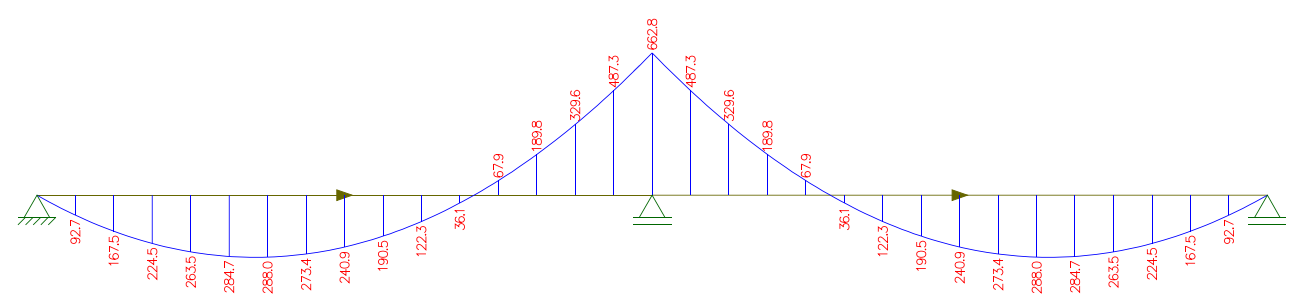

Figura 4.16 - Iteração 7 - Diagrama de Momento Fletor [kN.m].

A iteração 7 da figura 4.16 apresenta os mesmos valores que a iteração 6, portanto, considera-se a convergência em 6 iterações.

Faz-se o processo iterativo até a convergência dos quatro modelos. Conforme dito anteriormente, o parâmetro para convergência são os momentos fletores mostrados nos diagramas da interface gráfica. Na tabela 4.2 é mostrada a relação entre os nós de integração e o momento de convergência:

Tabela 4.2 - Convergência dos modelos - Relação dos nós de integração

\begin{tabular}{|c|c|c|c|c|c|c|}
\hline \multirow{2}{*}{$\begin{array}{c}\text { Passo } \\
{[\mathrm{m}]}\end{array}$} & \multirow{2}{*}{$\begin{array}{c}\text { Nós para } \\
\text { Integração }\end{array}$} & \multirow{2}{*}{ Iterações } & \multicolumn{4}{|c|}{ Momento de Convergência [kN.m] } \\
\cline { 4 - 7 } & & Máximo Negativo & $\Delta \mathrm{Md}[\%]$ & Máximo Positivo & $\Delta \mathrm{Md} \mathrm{[ \% ]}$ \\
\hline 0,2 & 130 & 6 & $-663,3$ & $15,90 \%$ & 288,7 & $-10,31 \%$ \\
\hline 0,5 & 84 & 6 & $-662,8$ & $15,81 \%$ & 288,0 & $-10,53 \%$ \\
\hline 1,0 & 72 & 6 & $-662,8$ & $15,81 \%$ & 288,0 & $-10,53 \%$ \\
\hline 0,0 & 68 & 6 & $-658,9$ & $15,13 \%$ & 290,3 & $-9,82 \%$ \\
\hline
\end{tabular}


O comparativo dos momentos fletores é em referência aos valores obtidos com a análise linear, que foram usados no dimensionamento inicial conforme o item anterior, sendo de $321,9 \mathrm{kN} . \mathrm{m}$ para momento positivo e de $572,3 \mathrm{kN} . \mathrm{m}$ para negativo. Observa-se que a variação do momento máximo negativo fica no patamar de $15 \%$ e o positivo de $10 \%$. Observa-se também, que o momento negativo tem seu módulo aumentado, o que requer maior área de aço, enquanto o momento positivo decresce e demanda menor armadura. Isso se deve ao fato da região de momentos negativos apresentar maior rigidez em relação à de momento positivo. Isso pode ser observado pelo diagrama momento-curvatura de cada uma das seções, conforme as figuras 4.17 e 4.18 .

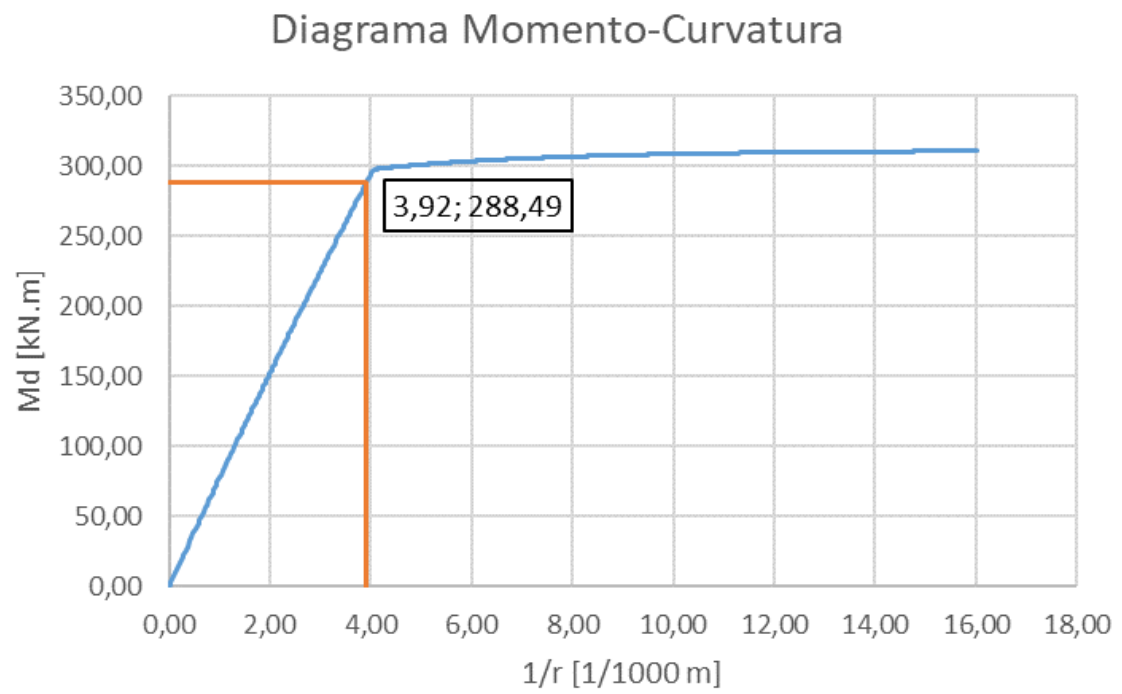

Figura 4.17 - Diagrama Momento-Curvatura - Seção com Momento Positivo

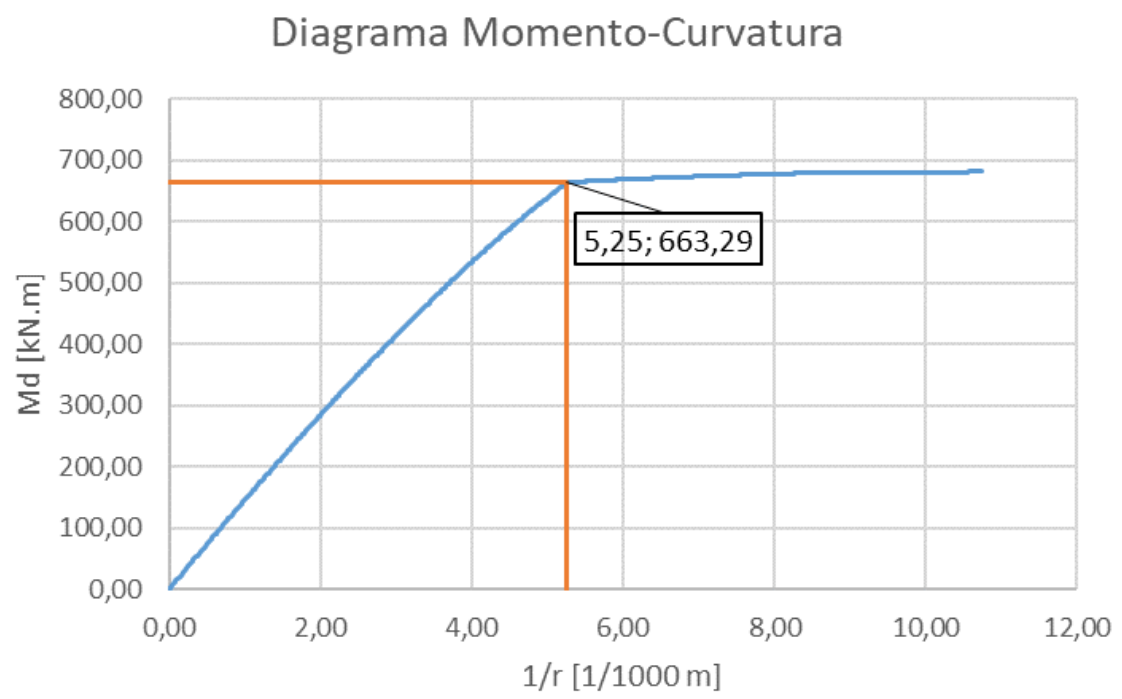

Figura 4.18- Diagrama Momento-Curvatura - Seção com Momento Negativo 
Utilizando-se os dados obtidos para a convergência do modelo considerando a maior discretização da estrutura, com passo de $0,2 \mathrm{~m}$, são dadas nas tabelas $4.3 \mathrm{e}$ 4.4 as seções iniciais e finais obtidas para momento máximo positivo e negativo.

Tabela 4.3 - Armadura final da seção de momento positivo com passo de $0,2 \mathrm{~m}$.

\begin{tabular}{|c|c|c|c|c|c|c|c|c|}
\hline \multicolumn{9}{|c|}{ Momento Máximo Positivo } \\
\hline \multirow{2}{*}{ 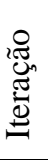 } & \multirow{2}{*}{$\begin{array}{c}\text { Posição } \\
x[\mathrm{~m}] \\
\end{array}$} & \multirow{2}{*}{$\begin{array}{c}\begin{array}{c}\text { Momento } \\
\text { Fletor }\end{array} \\
\text { Md [kN.m] }\end{array}$} & \multirow{2}{*}{$\begin{array}{c}\text { Inércia } \\
\text { Secante }\end{array}$} & \multirow{2}{*}{$\begin{array}{c}\text { Redução } \\
\text { Isec/Ic }\end{array}$} & \multicolumn{2}{|c|}{$\begin{array}{c}\text { Superior As }[0] \\
{\left[\mathrm{cm}^{2}\right]}\end{array}$} & \multicolumn{2}{|c|}{$\begin{array}{l}\text { Inferior As }[1] \\
\quad\left[\mathrm{cm}^{2}\right]\end{array}$} \\
\hline & & & & & Calculada & Adotada & Calculada & Adotada \\
\hline 0 & 2,910 & 321,639 & 0,00373253 & 0,246 & 0,00 & 0,62 & 10,23 & 11,04 \\
\hline 6 & 2,760 & 288,485 & 0,00345465 & 0,227 & 0,00 & 0,62 & 9,08 & 9,82 \\
\hline
\end{tabular}

Tabela 4.4- Armadura final da seção de momento negativo com passo de 0,2 m.

\begin{tabular}{|c|c|c|c|c|c|c|c|c|}
\hline \multicolumn{9}{|c|}{ Momento Máximo Negativo } \\
\hline \multirow{2}{*}{ 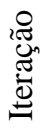 } & \multirow{2}{*}{$\begin{array}{c}\text { Posição } \\
x[\mathrm{~m}]\end{array}$} & \multirow{2}{*}{$\begin{array}{c}\text { Momento } \\
\text { Fletor }\end{array}$} & \multirow{2}{*}{$\begin{array}{c}\text { Inércia } \\
\text { Secante }\end{array}$} & \multirow{2}{*}{$\begin{array}{c}\text { Redução } \\
\text { Isec/Ic }\end{array}$} & \multicolumn{2}{|c|}{$\begin{array}{c}\text { Superior As }[0] \\
{\left[\mathrm{cm}^{2}\right]}\end{array}$} & \multicolumn{2}{|c|}{$\begin{array}{c}\text { Inferior As[1] } \\
{\left[\mathrm{cm}^{2}\right]}\end{array}$} \\
\hline & & & & & Calculada & Adotada & Calculada & Adotada \\
\hline 0 & 8,000 & $-572,320$ & 0,00513547 & 0,338 & 20,21 & 20,86 & 0,00 & 0,62 \\
\hline 6 & 8,000 & $-663,293$ & 0,00593408 & 0,391 & 23,24 & 23,32 & 2,89 & 4,91 \\
\hline
\end{tabular}

Como foi definido que as barras adotadas são de $12,5 \mathrm{~mm}$, na região de momento positivo subtraiu-se uma barra e na região de momento negativo adicionaram-se duas barras na armadura tracionada e quatro barras na armadura comprimida. Observa-se que a armadura adotada de $0,62 \mathrm{~cm}^{2}$ é referente ao portaestribos de $6,3 \mathrm{~mm}$.

A coluna da tabela denominada "Redução" faz a relação entre o momento de inércia secante obtido pelo momento-curvatura e a seção bruta. Trata-se da mesma seção 25x90; a diferença fica na armadura adotada e consequentemente no diagrama momento-curvatura.

Em todos os passos utilizados na análise, obteve-se o mesmo resultado final para a armadura adotada. Portanto, com relação à armadura para o dimensionamento, não houve grande impacto em relação ao passo adotado. Entretanto, independentemente do passo, houve grande variação da armadura adotada, tendo a taxa de armadura na região de momento positivo variando de $0,52 \%$ para $0,46 \%$, decrescendo $13 \%$, e na região de momento negativo de $0,95 \%$ para $1,25 \%$, tendo aumento de $32 \%$. 


\subsubsection{Deslocamentos}

No item anterior, observou-se que independentemente do passo para o cálculo da inércia fissurada ao longo do vão da viga, o resultado da seção adotada é indiferente. Portanto, este item é desenvolvido considerando o passo 0,0 $\mathrm{mm}$ com nós de integração no início e no final de cada trecho. Os deslocamentos, assim como os momentos e as armaduras, são alterados a cada iteração até a convergência e também converge na iteração 6.

O cálculo de deslocamentos e rotações ao longo de um elemento de barra com inércia variável também é feito com base na analogia da viga conjugada. De acordo com Martha[2015], o deslocamento transversal é determinado pelo diagrama de momento fletor na viga conjugada, o que é feito por integração numérica.

A primeira configuração deformada da viga é obtida com a análise linear da iteração 0 , portanto, ainda sem armadura conhecida e sem qualquer redução da rigidez. Na figura 4.19 é mostrada a deformada da viga:

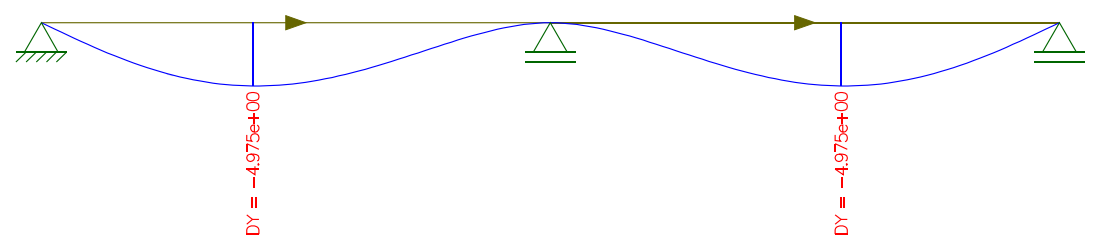

Figura 4.19 - Iteração 0 - Deslocamento vertical da viga $[\mathrm{mm}]$

Como parte o processo iterativo, da figura 4.20 até 4.25 mostram-se as deformadas obtidas em cada iteração:

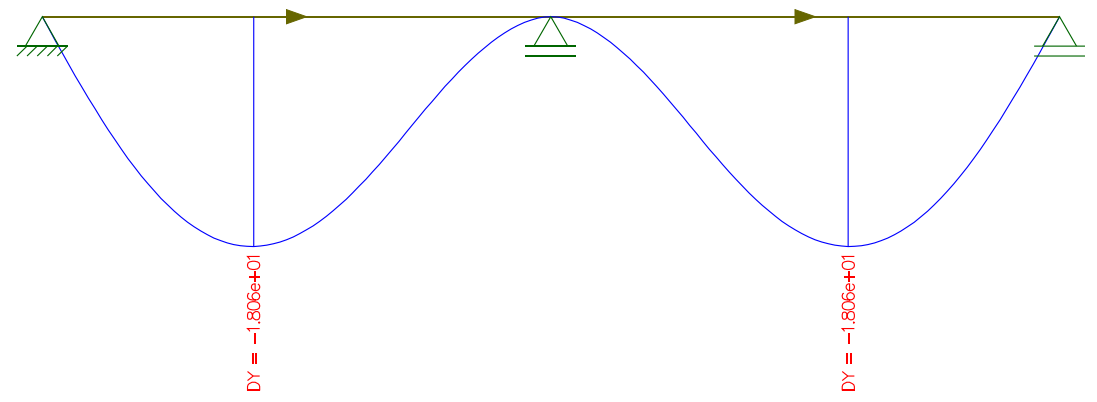

Figura 4.20 - Iteração 1 - Deslocamento vertical da viga $[\mathrm{mm}]$. 


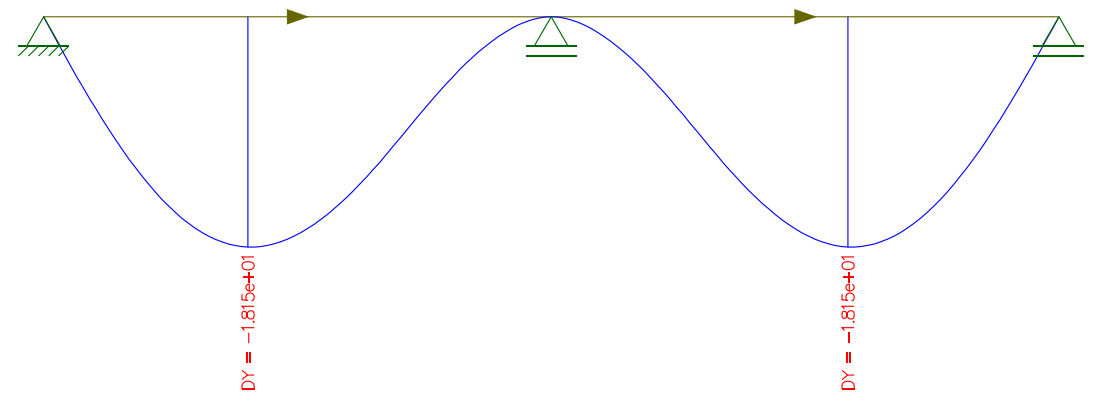

Figura 4.21 - Iteração 2 - Deslocamento vertical da viga $[\mathrm{mm}]$.

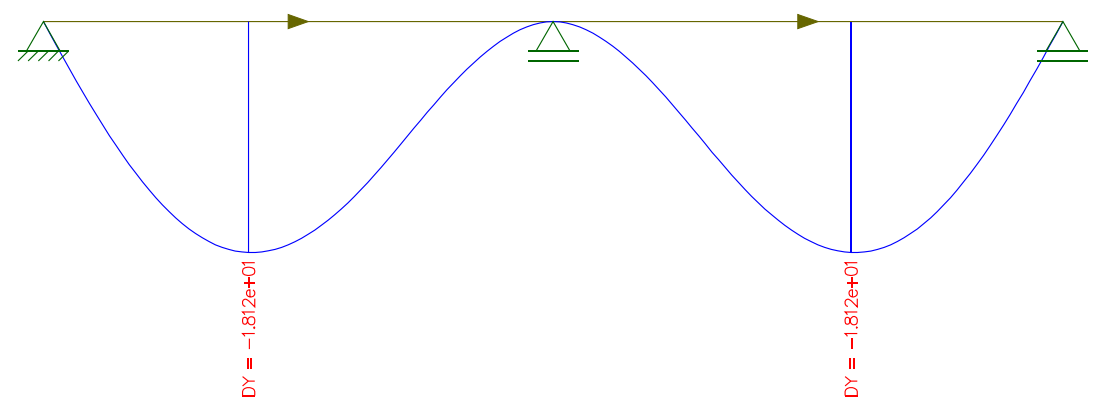

Figura 4.22 - Iteração 3 - Deslocamento vertical da viga $[\mathrm{mm}]$.

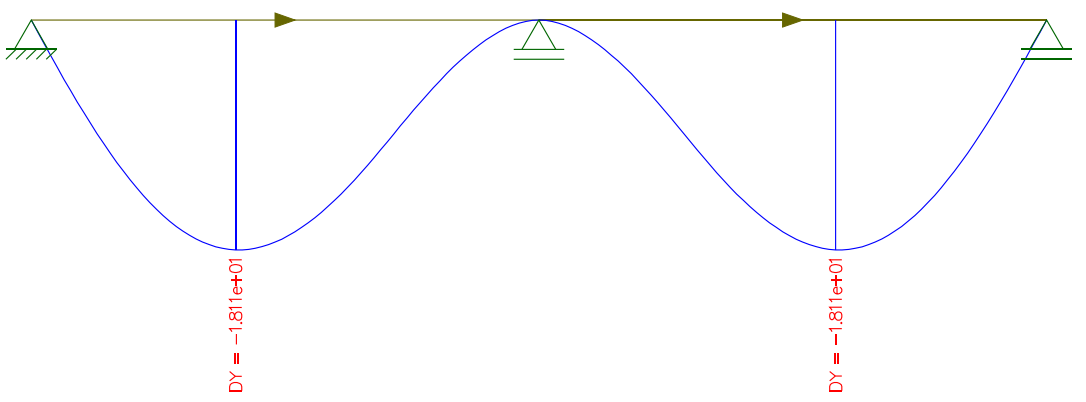

Figura 4.23 - Iteração 4 - Deslocamento vertical da viga $[\mathrm{mm}]$.

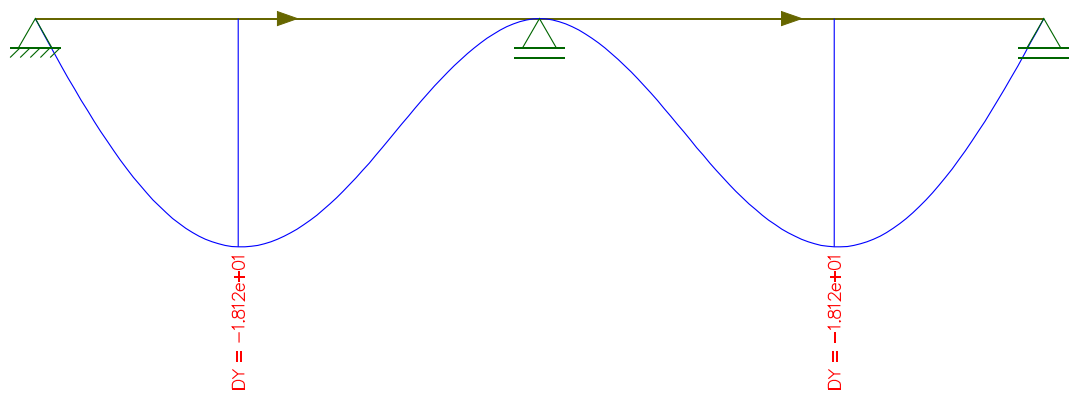

Figura 4.24 - Iteração 5 - Deslocamento vertical da viga $[\mathrm{mm}]$. 


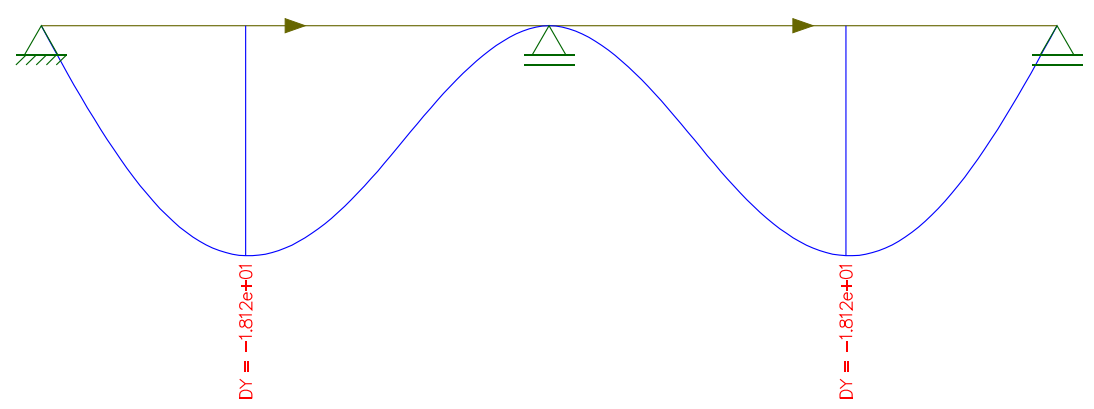

Figura 4.25 - Iteração 6 - Deslocamento vertical da viga $[\mathrm{mm}]$.

Na tabela 4.5 é dada o resumo os valores obtidos em cada iteração, para a flecha máxima, a posição no eixo da viga e o fator de amplificação calculado pela razão entre o deslocamento obtido na iteração e na iteração 0 .

Tabela 4.5 - Valores dos deslocamentos obtidos com a redução da inércia

\begin{tabular}{|l|r|r|r|r|r|r|r|}
\cline { 2 - 8 } \multicolumn{1}{l|}{} & Iteração 0 & Iteração 1 & Iteração 2 & Iteração 3 & Iteração 4 & Iteração 5 & Iteração 6 \\
\hline Posição [m] & 3,38 & 4,71 & 3,29 & 4,71 & 3,29 & 3,29 & 3,29 \\
\hline $\begin{array}{l}\text { Flecha } \\
\begin{array}{l}\text { Máxima } \\
\text { [mm] }\end{array}\end{array}$ & 4,98 & 18,07 & 18,16 & 18,12 & 18,11 & 18,13 & 18,13 \\
\hline Amplificação & - & 3,63 & 3,65 & 3,64 & 3,64 & 3,64 & 3,64 \\
\hline
\end{tabular}

Observa-se que, após a primeira iteração, o valor do deslocamento máximo não sofre grandes alterações, estabilizando-se no valor aproximado de $18,1 \mathrm{~mm}$, já que as alterações seguintes ficam na ordem de centésimos de milímetro, o que é mais que a precisão utilizada para a verificação de flechas.

A NBR 6118 (ABNT, 2014) recomenda a verificação em estado limite de serviço de deformações excessivas. Tomando como parâmetro, conforme a tabela 13.3 da referida norma, o deslocamento limite para "Aceitabilidade sensorial" do usuário, faz-se a verificação para limites visuais e para vibrações sentidas, a primeira tendo limite de $\ell / 250$, calculada com todos os carregamentos aplicados e a segunda com limite de $\ell / 350$, calculada com as cargas acidentais.

É necessária verificar a combinação quase permanente de carregamentos para a verificação do estado limite de serviço de deformações excessivas. Portanto, conforme o item 11.8.3.2, a solicitação deve ser calculada conforme a equação (4.11).

$$
F_{d, s e r}=\Sigma F_{g i, k}+\Sigma \Psi_{2 j} F_{q j, k}
$$

Para a verificação de efeitos visuais, faz-se a combinação com todos os carregamentos atuantes, portanto: 


$$
F_{d, s e r}=\left[\left(g_{1}+g_{2}\right)_{v i g a, k}+\left(g_{1}+g_{2}\right)_{l a j e, k} \cdot \ell\right]+\psi_{2} q_{l a j e, k} \cdot \ell
$$

$\mathrm{O}$ valor do fator de redução de combinação quase permanente $\Psi_{2}$ é retirado da tabela 11.2 da Norma. Considerou-se que o valor de $4,0 \mathrm{kN} / \mathrm{m}^{2}$ adotado corresponda ao carregamento recomendado para bibliotecas, portanto, o valor de $\Psi_{2}$ é definido como 0,6.

$$
\begin{gathered}
F_{d, \text { ser }}=[(5,625+13,5)+(1,61+1,5) \cdot 4,5]+0,6 \cdot 4,0 \cdot 4,5 \\
F_{d, \text { ser }}=43,92 \mathrm{kN} / \mathrm{m}
\end{gathered}
$$

Aplicando o carregamento na estrutura, nas figuras 4.26 e 4.27 são apresentadas as deformadas na iteração inicial 0 com análise linear e na iteração 6 com a convergência do modelo.

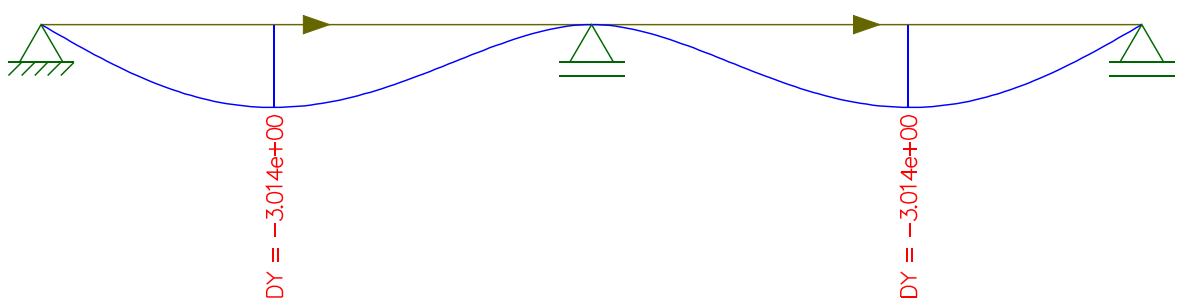

Figura 4.26 - Iteração 0 - Deslocamento vertical da viga - ELS - Aceitação visual [mm].

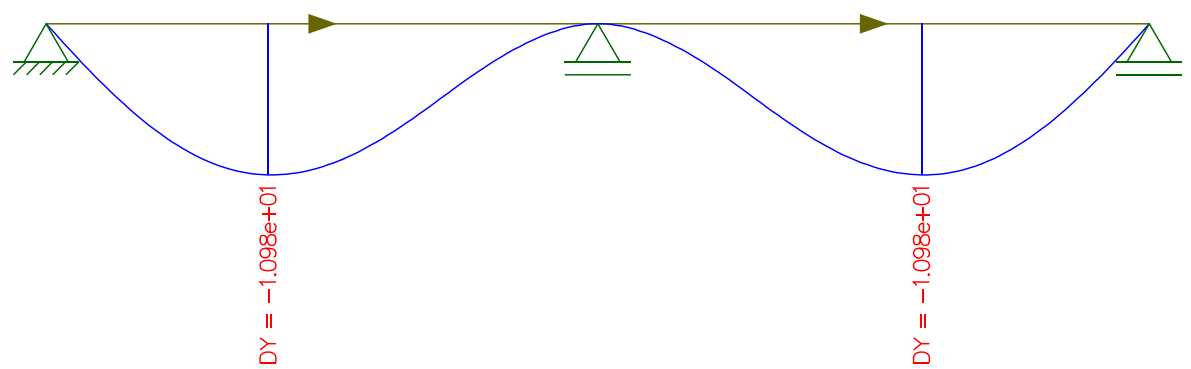

Figura 4.27 - Iteração 6 - Deslocamento vertical da viga - ELS - Aceitação visual [mm].

Para a verificação de vibrações sentidas pelo usuário, utilizam-se apenas os carregamentos acidentais da estrutura, logo, a combinação é calculada pela equação (4.12).

$$
\begin{gathered}
F_{d, s e r}=\Sigma \Psi_{2 j} F_{q j, k} \\
F_{d, \text { ser }}=0,6 \cdot 4,0 \cdot 4,5=10,8 \mathrm{kN} / \mathrm{m}
\end{gathered}
$$

Aplica-se o carregamento na estrutura, e são dadas nas figuras 4.28 e 4.29 as deformadas na iteração 0 e na convergência do modelo. 


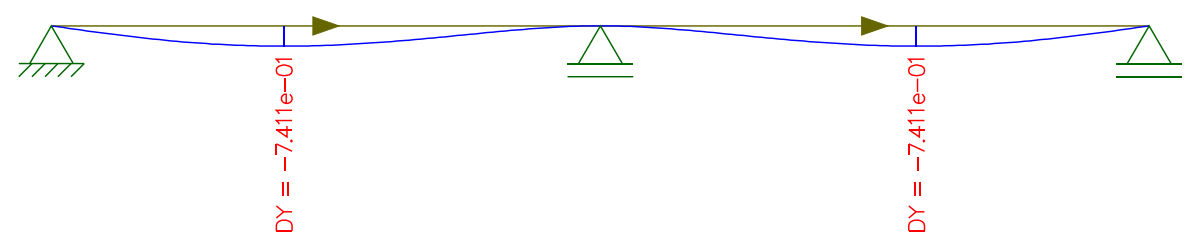

Figura 4.28 - Iteração 0 - Deslocamento vertical da viga - ELS - Vibrações [mm].

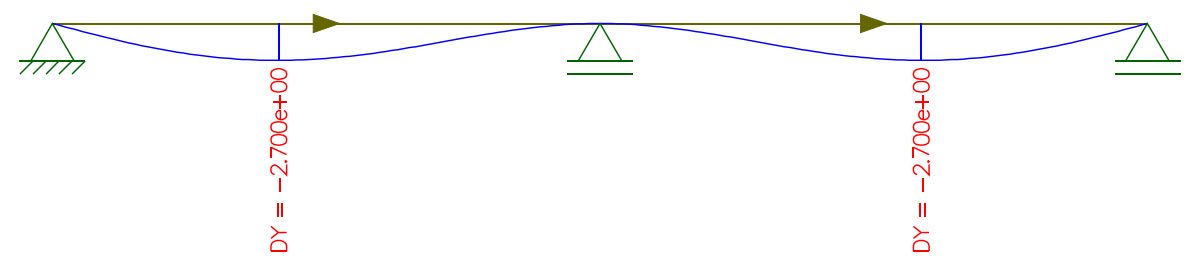

Figura 4.29 - Iteração 6 - Deslocamento vertical da viga - ELS - Vibrações [mm].

Considerando o vão simétrico da viga de $8,0 \mathrm{~m}$, na tabela 4.6, faz-se a comparação com a flecha limite e os valores obtidos na análise.

Tabela 4.6 - Resultado das flechas obtidas para verificação ELS

\begin{tabular}{|l|c|c|c|c|}
\hline & \multicolumn{2}{|c|}{ Flecha Limite [mm] } & Linear [mm] & Não Linear [mm] \\
\hline ELS - Visuais & $\ell / 250$ & 32,00 & 3,01 & 10,98 \\
\hline ELS - Vibraçõos & $\ell / 350$ & 22,86 & 0,74 & 2,70 \\
\hline
\end{tabular}

Observa-se que apesar da redução da rigidez e de um fator de amplificação de aproximadamente 3,6 no deslocamento, os valores ainda se encontram dentro da flecha limite de verificação em serviço. Neste exemplo, portanto, a redução não impacta na verificação em serviço, estando a estrutura em conformidade com o recomendado.

\subsubsection{Fluência do Concreto}

Sabendo-se que a fluência do concreto é considerada nas deformações específicas limite do concreto $e_{c 2}$ e $e_{c u}$, como definido no método apresentado no capítulo anterior, sabe-se que a fluência impacta na rigidez da seção obtida nos diagramas momento-curvatura. Desta forma, insere-se aqui a fluência do concreto na estrutura analisada.

Opta-se por um único valor de fluência para o concreto. O primeiro parâmetro de entrada na tabela 8.2 da NBR 6118 (ABNT, 2014) é a umidade média do ambiente. Para a cidade do Rio de Janeiro, utiliza-se o valor de referência 75\%. A espessura fictícia da seção é calculada conforme equação (4.13).

$$
e_{f i c}=2 A_{c} / u
$$


Para a seção com largura de $25 \mathrm{~cm}$ e altura de $90 \mathrm{~cm}$ tem-se o valor de:

$$
e_{f i c}=2 \cdot 25 \cdot 90 /(2 \cdot 25+2 \cdot 90)=19,56 \mathrm{~cm}
$$

O concreto do exemplo tem resistência característica de 20MPa e opta-se pela idade fictícia de 5 dias. Consultando a tabela, adota-se o valor para o coeficiente:

$$
\varphi=2,8
$$

\begin{tabular}{|c|c|c|c|c|c|c|c|c|c|c|}
\hline \multicolumn{3}{|c|}{$\begin{array}{c}\text { Umidade média } \\
\text { ambiente } \\
\%\end{array}$} & \multicolumn{2}{|c|}{40} & \multicolumn{2}{|c|}{55} & \multicolumn{2}{|c|}{75} & \multicolumn{2}{|c|}{90} \\
\hline \multicolumn{3}{|c|}{$\begin{array}{l}\text { Espessura fictícia } \\
22 A_{\mathrm{c}} / u \\
\mathrm{~cm}\end{array}$} & 20 & 60 & 20 & 60 & 20 & 60 & 20 & 60 \\
\hline \multirow{3}{*}{$\begin{array}{c}\varphi\left(t_{\infty}, t_{0}\right) \\
\text { Concreto } \\
\text { das classes } \\
\text { C20 a C45 }\end{array}$} & \multirow{9}{*}{$\begin{array}{c}t_{0} \\
\text { dias }\end{array}$} & 5 & 4,6 & 3,8 & 3,9 & 3,3 & 2,8 & 2,4 & 2,0 & 1,9 \\
\hline & & 30 & 3,4 & 3,0 & 2,9 & 2,6 & 2,2 & 2,0 & 1,6 & 1,5 \\
\hline & & 60 & 2,9 & 2,7 & 2,5 & 2,3 & 1,9 & 1,8 & 1,4 & 1,4 \\
\hline$\varphi\left(t_{\infty}, t_{0}\right)$ & & 5 & 2,7 & 2,4 & 2,4 & 2,1 & 1,9 & 1,8 & 1,6 & 1,5 \\
\hline $\begin{array}{l}\text { Concreto } \\
\text { das classes }\end{array}$ & & 30 & 2,0 & 1,8 & 1,7 & 1,6 & 1,4 & 1,3 & 1,1 & 1,1 \\
\hline C50 a C90 & & 60 & 1,7 & 1,6 & 1,5 & 1,4 & 1,2 & 1,2 & 1,0 & 1,0 \\
\hline \multirow{3}{*}{$\varepsilon_{c s}\left(t_{\infty}, t_{0}\right) \%$} & & 5 & $-0,53$ & $-0,47$ & $-0,48$ & $-0,43$ & $-0,36$ & $-0,32$ & $-0,18$ & $-0,15$ \\
\hline & & 30 & $-0,44$ & $-0,45$ & $-0,41$ & $-0,41$ & $-0,33$ & $-0,31$ & $-0,17$ & $-0,15$ \\
\hline & & 60 & $-0,39$ & $-0,43$ & $-0,36$ & $-0,40$ & $-0,30$ & $-0,31$ & $-0,17$ & $-0,15$ \\
\hline
\end{tabular}

Tabela 4.7 - Coeficientes de fluência e retração - Tabela 8.2 da NBR 6118(ABNT, 2014)

Inserindo o coeficiente de fluência na análise, o diagrama momento-curvatura será alterado e, portanto, os diagramas de momentos fletores finais serão diferentes. Conforme o item anterior, considerou-se que neste exemplo o passo escolhido pouco altera o resultado final; logo, para a análise da fluência, escolhe-se o passo 0,0 m. Com este passo, são mostrados nas figuras 4.30 e 4.31 os diagramas iniciais e finais do processo iterativo, assim como os iniciais e finais de armadura calculada e adotada para o carregamento definido em ELU com carga distribuída de $71,54 \mathrm{kN} / \mathrm{m}$. Com a consideração da fluência, o modelo convergiu em 5 iterações, nas figuras 4.30 e 4.31 mostram-se as iterações inicial e final.

(a)

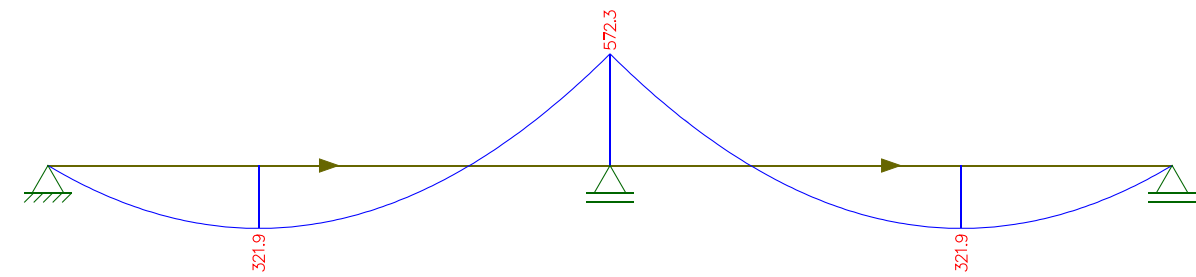


(b)

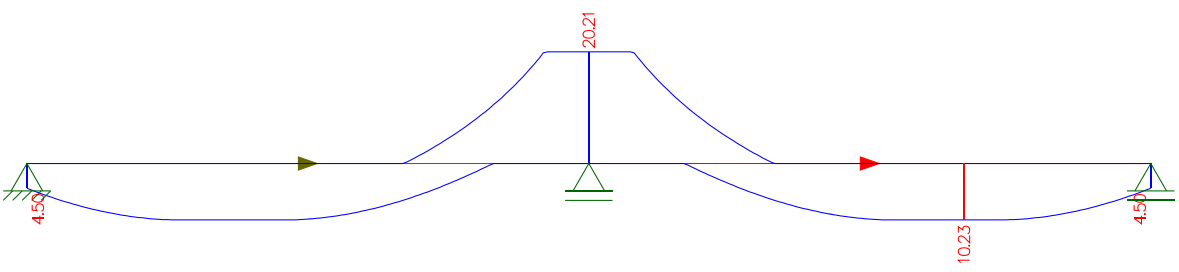

(c)

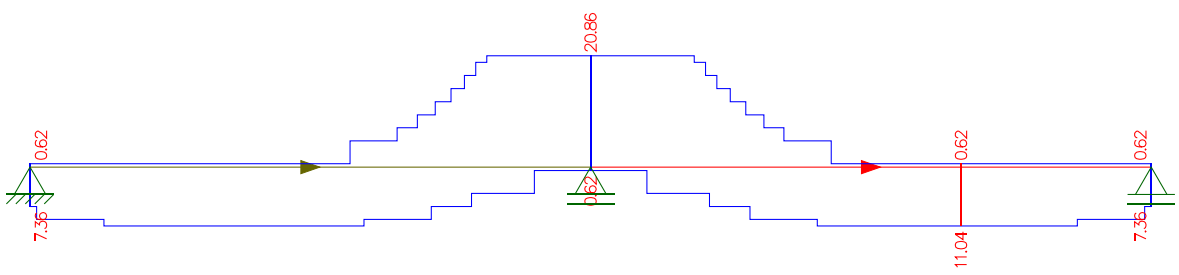

Figura 4.30 - Iteração 0 (a) Diagrama de momento fletor [kN.m]; (b) Armadura calculada [ $\left.\mathrm{cm}^{2}\right]$;

(c) Armadura adotada $\left[\mathrm{cm}^{2}\right]$.

(a)

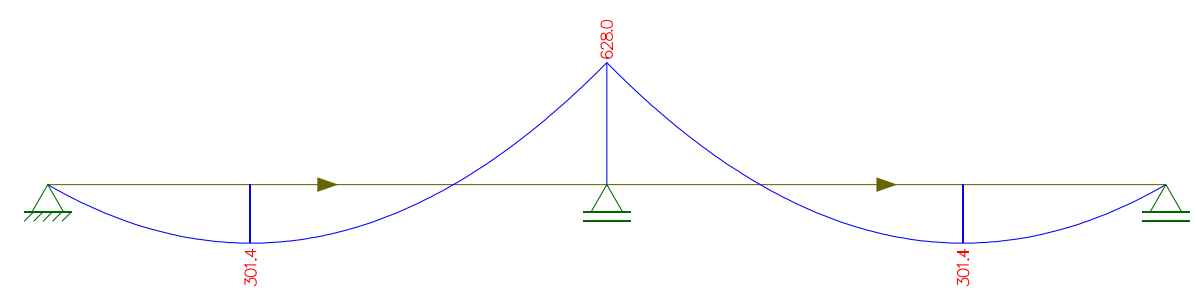

(b)

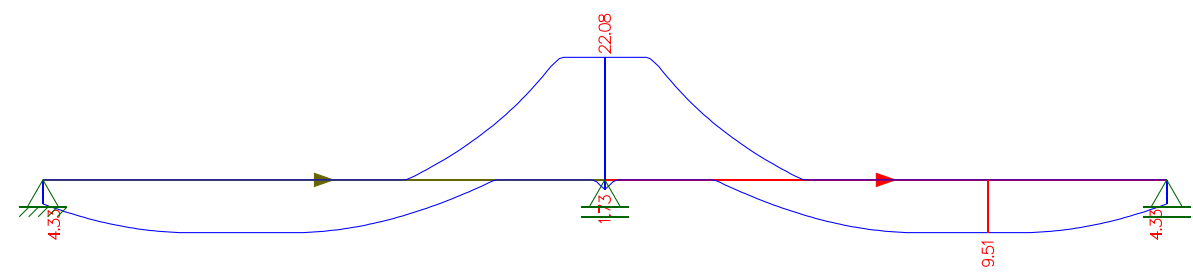

(c)

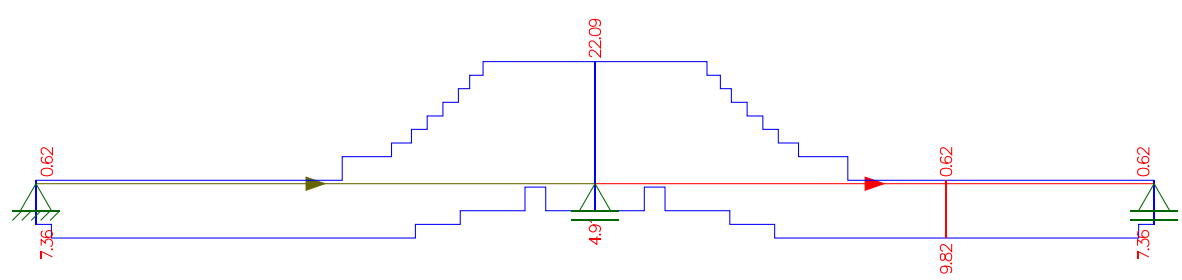

Figura 4.31 - Iteração 5 (a) Diagrama de momento fletor [kN.m]; (b) Armadura calculada [cm²];

(c) Armadura adotada $\left[\mathrm{cm}^{2}\right]$.

Nas tabelas 4.8 e 4.9 é dado o resumo dos valores com a comparação com os da inércia inicial. Observa-se que na tabela 4.8 os valores de momento fletor são inferiores aos observados nos diagramas de momento fletor das figuras 4.30 e 4.31 , isso se deve ao fato do momento fletor presente na tabela ser referente ao máximo momento positivo dos nós de integração utilizados para o cálculo da redução da rigidez, que, dependendo do passo adotado, não inclui o momento máximo do vão. Além disso, observa-se que a posição do momento máximo positivo também varia, 
dado que é o momento máximo dos nós de integração, portanto, dependendo do escalonamento da armadura e do passo dado pelo usuário, pode variar a posição.

Tabela 4.8 - Armadura final da seção de momento positivo com passo de $0,0 \mathrm{~m}$ considerando a

$$
\text { fluência: } \varphi=2,8
$$

\begin{tabular}{|c|c|c|c|c|c|c|c|c|}
\hline \multicolumn{9}{|c|}{ Momento Máximo Positivo } \\
\hline \multirow{2}{*}{ 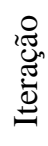 } & \multirow{2}{*}{$\begin{array}{c}\text { Posição } \\
x[\mathrm{~m}]\end{array}$} & \multirow{2}{*}{$\begin{array}{c}\text { Momento } \\
\text { Fletor }\end{array}$} & \multirow{2}{*}{$\begin{array}{c}\text { Inércia } \\
\text { Secante }\end{array}$} & \multirow{2}{*}{$\begin{array}{c}\text { Redução } \\
\text { Isec/Ic }\end{array}$} & \multicolumn{2}{|c|}{$\begin{array}{c}\text { Superior As }[0] \\
{\left[\mathrm{cm}^{2}\right]}\end{array}$} & \multicolumn{2}{|c|}{$\begin{array}{l}\text { Inferior As[1] } \\
\qquad\left[\mathrm{cm}^{2}\right]\end{array}$} \\
\hline & & & & & Calculada & Adotada & Calculada & Adotada \\
\hline 0 & 4,220 & 268,716 & 0,00241291 & 0,159 & 0,00 & 0,62 & 10,23 & 11,04 \\
\hline 5 & 4,885 & 160,881 & 0,00231546 & 0,152 & 0,00 & 0,62 & 9,51 & 9,82 \\
\hline
\end{tabular}

Já o momento máximo negativo da tabela 4.9 tem sua posição constante e momentos fletores máximos iguais aos diagramas das figuras 4.30 e 4.31, dado que está no apoio, portanto, no final de um elemento de barra e consequentemente tem seu momento utilizado na redução da rigidez.

Tabela 4.9 - Armadura final da seção de momento negativo com passo de $0,0 \mathrm{~m}$ considerando a fluência: $\varphi=2,8$

\begin{tabular}{|c|c|c|c|c|c|c|c|c|}
\hline \multicolumn{9}{|c|}{ Momento Máximo Negativo } \\
\hline \multirow{2}{*}{ 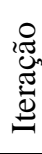 } & \multirow{2}{*}{$\begin{array}{c}\text { Posição } \\
\text { x [m] }\end{array}$} & \multirow{2}{*}{$\begin{array}{l}\text { Momento } \\
\text { Fletor }\end{array}$} & \multirow{2}{*}{$\begin{array}{c}\begin{array}{c}\text { Inércia } \\
\text { Secante }\end{array} \\
\text { Isec [m4] }\end{array}$} & \multirow{2}{*}{$\begin{array}{c}\text { Redução } \\
\text { Isec/Ic }\end{array}$} & \multicolumn{2}{|c|}{$\begin{array}{c}\text { Superior As }[0] \\
{\left[\mathrm{cm}^{2}\right]}\end{array}$} & \multicolumn{2}{|c|}{$\begin{array}{l}\text { Inferior As[1] } \\
\qquad\left[\mathrm{cm}^{2}\right]\end{array}$} \\
\hline & & & & & Calculada & Adotada & Calculada & Adotada \\
\hline 0 & 8,000 & $-572,320$ & 0,00185642 & 0,122 & 20,21 & 20,86 & 0,00 & 0,62 \\
\hline 5 & 8,000 & $-628,005$ & 0,00231494 & 0,152 & 22,08 & 22,09 & 1,73 & 4,91 \\
\hline
\end{tabular}

Observa-se que a armadura obtida considerando a fluência é alterada, devido à mudança na rigidez das seções e à redistribuição dos esforços internos. Comparando-se as análises linear, não linear e não linear com fluência, observa-se que, com a consideração da fluência, a rigidez das seções diminui consideravelmente, gerando a diminuição da armadura superior na região com momento máximo negativo, que neste exemplo, se aproxima da redução na região de máximo momento positivo. Assim, o resultado considerando a fluência, devido à grande diminuição da rigidez ao longo do vão, tende a redistribuir os esforços internos de maneira mais uniforme, apresentando valores entre a análise linear e a não linear sem fluência. As tabelas 4.10 e 4.11 apresentam estes resultados. 
Tabela 4.10 - Comparação entre momentos, armadura calculada e adotada com as três análises Seção com momento máximo positivo.

\begin{tabular}{|c|c|c|c|c|c|c|c|}
\hline \multirow{3}{*}{ Análise } & \multicolumn{7}{|c|}{ Momento Máximo Positivo } \\
\hline & \multirow{2}{*}{\begin{tabular}{|c|} 
Convergência \\
Md [kN.m]
\end{tabular}} & \multicolumn{2}{|c|}{ Superior As $[0]\left[\mathrm{cm}^{2}\right]$} & \multicolumn{2}{|c|}{ Inferior As[1] $\left[\mathrm{cm}^{2}\right]$} & \multirow{2}{*}{$\begin{array}{c}\text { Inércia Secante } \\
\text { Isec }[\mathrm{m} 4]\end{array}$} & \multirow{2}{*}{$\begin{array}{c}\text { Redução } \\
\text { Isec/Ic }\end{array}$} \\
\hline & & Calculada & Adotada & Calculada & Adotada & & \\
\hline Linear & 321,90 & 0,00 & 0,62 & 10,23 & 11,04 & 0,0151875 & 1,0000 \\
\hline $\begin{array}{l}\text { Não } \\
\text { Linear }\end{array}$ & 290,30 & 0,00 & 0,62 & 9,13 & 9,82 & 0,0035611 & 0,2345 \\
\hline $\begin{array}{l}\text { Não } \\
\text { Linear - } \\
\text { Fluência }\end{array}$ & 301,40 & 0,00 & 0,62 & 9,51 & 9,82 & 0,0023155 & 0,1525 \\
\hline
\end{tabular}

Tabela 4.11 - Comparação entre momentos, armadura calculada e adotada com as três análises -

Seção com momento máximo negativo

\begin{tabular}{|l|r|r|r|r|r|r|r|}
\hline \multirow{3}{*}{ Análise } & \multicolumn{7}{|c|}{ Momento Máximo Negativo } \\
\cline { 2 - 8 } & Convergência & \multicolumn{1}{|c|}{ Superior As[0] $\left[\mathrm{cm}^{2}\right]$} & \multicolumn{2}{|c|}{ Inferior As[1] $\left[\mathrm{cm}^{2}\right]$} & Inércia Secante & Redução \\
\cline { 2 - 8 } & Md [kN.m] & Calculada & Adotada & Calculada & Adotada & Isec [m4] & Isec/Ic \\
\hline Linear & $-572,30$ & 20,21 & 20,86 & 0,00 & 0,62 & 0,0151875 & 1,00000 \\
\hline $\begin{array}{l}\text { Não } \\
\text { Linear }\end{array}$ & $-658,90$ & 23,10 & 23,32 & 2,75 & 4,91 & 0,0059483 & 0,39166 \\
\hline $\begin{array}{l}\text { Não } \\
\text { Linear- } \\
\text { Fluência }\end{array}$ & $-628,00$ & 22,08 & 22,09 & 1,73 & 4,91 & 0,0023149 & 0,15242 \\
\hline
\end{tabular}

Note-se que a recomendação da NBR 6118 (ABNT, 2014), item 15.7.3, para consideração aproximada da não linearidade física do concreto é a aplicação de fatores de redução de 0,4 na rigidez, para seções de vigas com armaduras superior e inferior diferentes. No exemplo apresentado, na região de momento negativo, o fator obtido com a curva momento-curvatura tem valor de 0,39 e na região de momento máximo positivo, 0,23. Observa-se que ao considerar a fluência na construção da curva, a estrutura fica menos rígida e os fatores obtidos são de 0,15 para as duas seções analisadas. Observa-se que a Norma recomenda tal aproximação para estruturas reticuladas com pelo menos quatro andares, o que não é o caso da estrutura deste exemplo.

Para mostrar essa distribuição mais uniforme dos deslocamentos, com os dados das iterações finais, plota-se um gráfico da redução da rigidez ao longo do vão da viga. A redução é calculada pela razão entre o momento de inércia obtido e a inércia bruta da seção. 


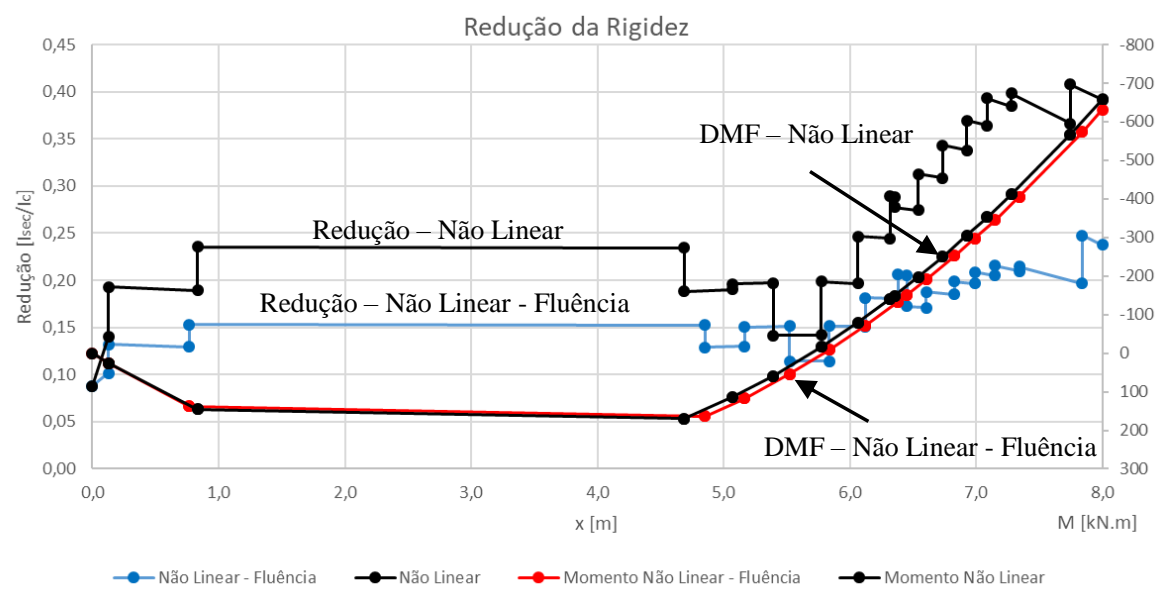

Figura 4.32 - Gráfico de redução da rigidez com sobreposição do diagrama de momentos fletores no eixo secundário

Observa-se na figura 4.32, que os diagramas de momento construídos com os valores dos momentos nos nós de integração são próximos, porém não coincidem, conforme esperado, dados os valores dos momentos de convergência. Porém a grande diferença fica na redução da rigidez, que conforme se observa no gráfico, com a consideração a fluência tem valores menores. Entretanto, a variação ao longo do vão é menor que na análise não linear sem fluência. Assim, a inércia adotada na análise tem valores mais próximos, o que faz com que os momentos fletores se aproximem do resultado linear, onde todas as seções têm mesma inércia bruta.

Assim como no item anterior, agora se faz a análise dos deslocamentos considerando a fluência do concreto. Utilizam-se as mesmas combinações ELS para verificação das flechas máximas pelos dois critérios: visual e vibração.

Considerando a combinação ELS para aceitação visual, com todos os carregamentos atuantes, resultando numa única carga distribuída de 43,92 kN/m, mostram-se na figura 4.34 as flechas obtidas.

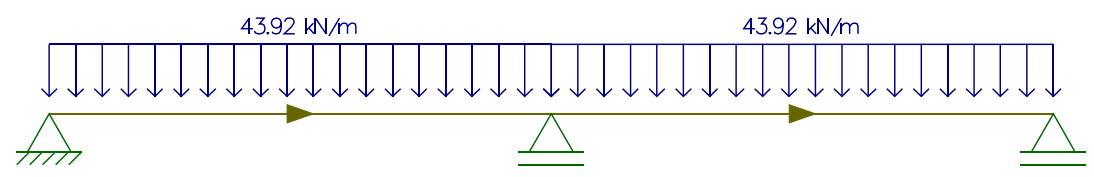

Figura 4.33 -Combinação de ações - ELS - Aceitação visual 


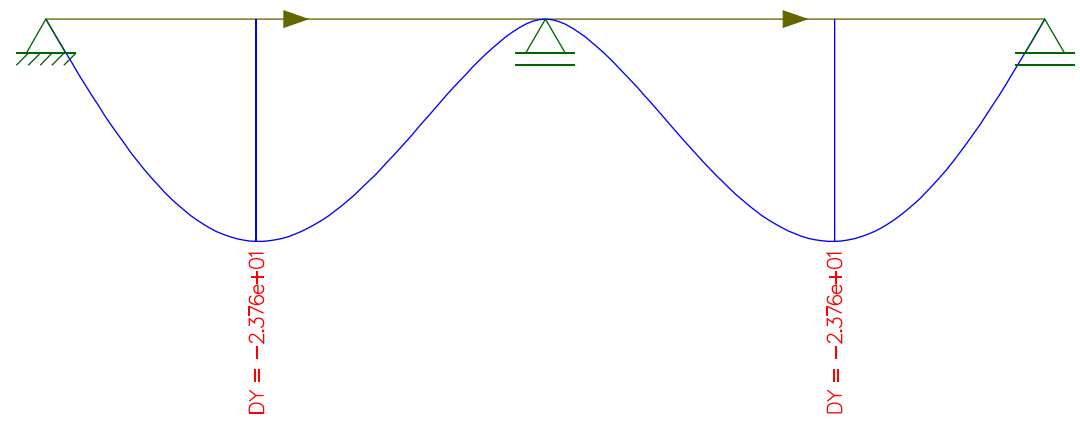

Figura 4.34 -Deslocamento vertical da viga - ELS - Aceitação visual [mm]

A combinação ELS para vibrações é feita com as cargas acidentais, resultando numa única carga distribuída de $10,80 \mathrm{kN} / \mathrm{m}$, mostrando-se na figura 4.36 as flechas obtidas:

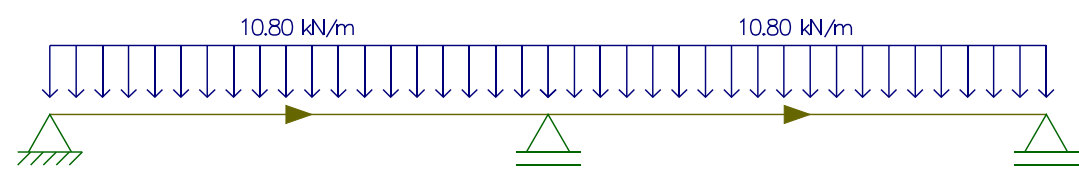

Figura 4.35 -Combinação de ações - ELS - Vibrações

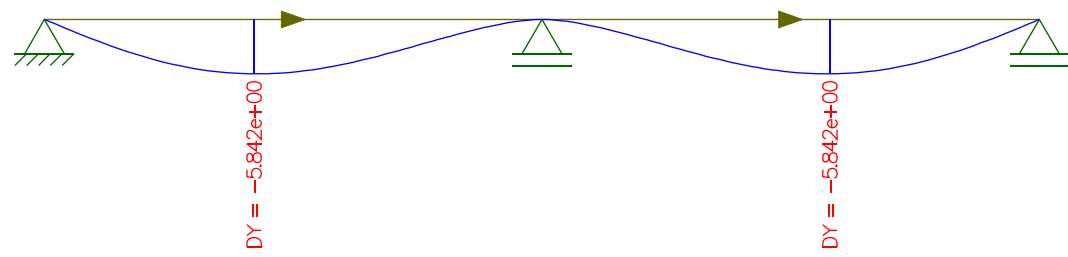

Figura 4.36 -Deslocamento vertical da viga - ELS - Vibrações [mm]

Tabela 4.12 - Resultado das flechas obtidas para verificação ELS

\begin{tabular}{|l|c|c|c|c|c|}
\hline & \multicolumn{2}{|c|}{$\begin{array}{c}\text { Flecha Limite } \\
{[\mathrm{mm}]}\end{array}$} & $\begin{array}{c}\text { Linear } \\
{[\mathrm{mm}]}\end{array}$ & $\begin{array}{c}\text { Não Linear } \\
{[\mathrm{mm}]}\end{array}$ & $\begin{array}{c}\text { Não Linear - } \\
\text { Fluência [mm] }\end{array}$ \\
\hline ELS - Visuais & $\ell / 250$ & 32,00 & 3,01 & 10,98 & 23,76 \\
\hline ELS - Vibrações & $\ell / 350$ & 22,86 & 0,74 & 2,70 & 5,84 \\
\hline
\end{tabular}

Como esperado, o deslocamento vertical é maior ao se considerar a fluência, observado na tabela 4.12, devido à menor rigidez da seção. Porém para o dado exemplo, o deslocamento ainda está dentro do limite estabelecido. Observa-se que, ao considerar a fluência, o deslocamento aumenta com um fator de amplificação de 7,89 para ambas as combinações de aceitação visual e vibrações. Enquanto que sem a fluência, estes fatores eram de 3,6.

Para fins de demonstração, na figura4.37 plota-se o gráfico momentocurvatura para a seção de momento negativo máximo para os valores de coeficiente de fluência 0,0 e para três valores de idade fictícia do concreto com coeficientes 1,$9 ; 2,2$ e 2,8 . 


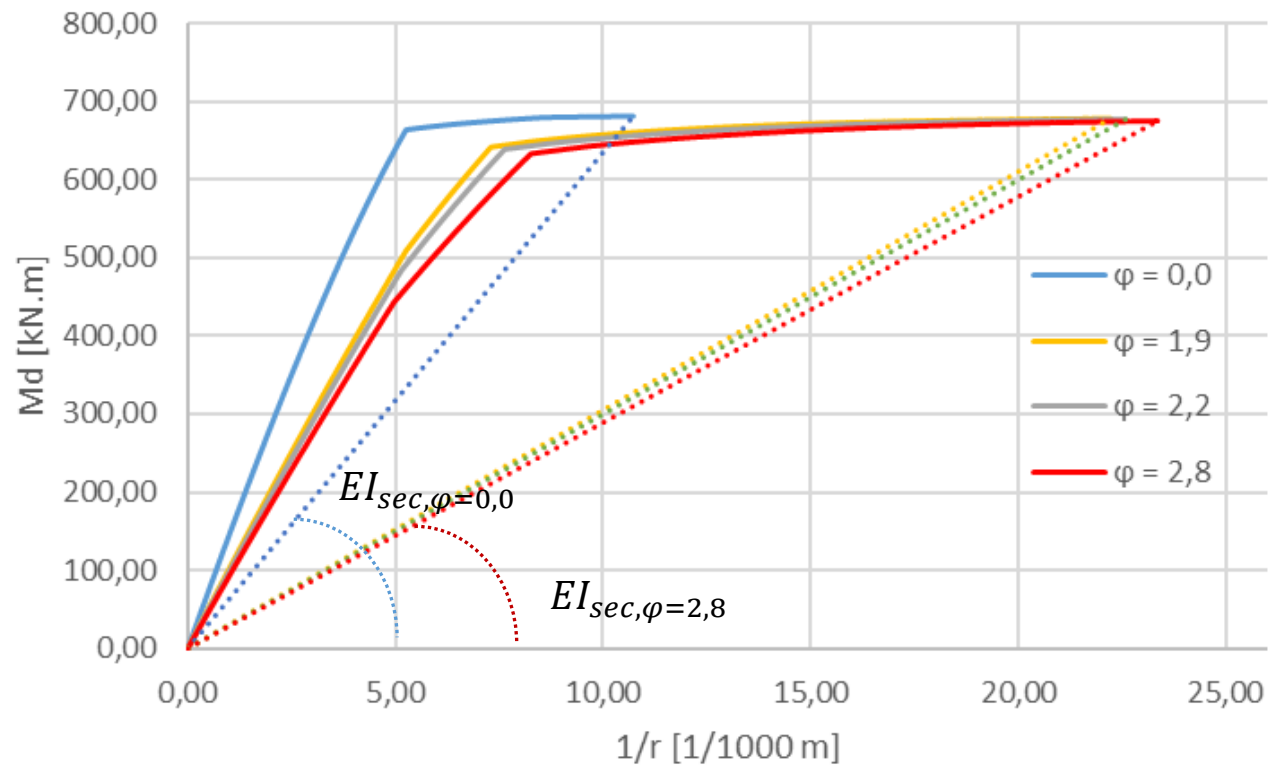

Figura 4.37 - Curva Momento-Curvatura para os dados valores de fluência.

Considerando o momento máximo em cada uma das quatro curvas, faz-se o cálculo das rijezas críticas e da redução da inércia da seção, mostrado na tabela 4.13 .

Tabela 4.13 - Valores de redução da rigidez na seção crítica para cada curva considerando os coeficientes de fluência.

\begin{tabular}{|c|r|r|c|c|r|}
\cline { 2 - 6 } \multicolumn{1}{c|}{} & $\begin{array}{c}\text { Curvatura } \\
{\left[1 / 1000 m^{-1}\right]}\end{array}$ & $\begin{array}{c}\text { Momento } \\
{[k N . m]}\end{array}$ & $\begin{array}{c}\text { EIsec } \\
{\left[k N . m^{2}\right]}\end{array}$ & $\begin{array}{c}\text { Isec } \\
{\left[m^{4}\right]}\end{array}$ & $\left.\begin{array}{c}\text { Redução } \\
{\left[I_{\text {sec }} I_{c}\right.}\end{array}\right]$ \\
\hline$\varphi=0,0$ & 10,732 & 681,235 & 63477,58 & 0,002982 & 0,1963 \\
\hline$\varphi=1,9$ & 22,234 & 678,426 & 30512,59 & 0,001433 & 0,0944 \\
\hline$\varphi=2,2$ & 22,594 & 677,399 & 29981,76 & 0,001408 & 0,0927 \\
\hline$\varphi=2,8$ & 23,361 & 675,240 & 28904,34 & 0,001358 & 0,0894 \\
\hline
\end{tabular}

Conforme o cálculo do momento de fissuração da equação (3.73), a seção deste exemplo tem momento de fissuração de 111,90 kN.m. Desta forma, extraemse os valores da redução da rigidez para momentos inferiores ao de fissuração para cada um dos valores de fluência, o que é mostrado na tabela 4.14. 
Tabela 4.14 - Valores de redução da rigidez em seção com momento abaixo de fissuração para cada curva considerando os coeficientes de fluência.

\begin{tabular}{|c|r|r|r|r|r|}
\cline { 2 - 6 } \multicolumn{1}{c|}{} & $\begin{array}{c}\text { Curvatura } \\
{\left[1 / 1000 \mathrm{~m}^{-1}\right]}\end{array}$ & $\begin{array}{c}\text { Momento } \\
{[k N . m]}\end{array}$ & $\begin{array}{c}\text { EIsec } \\
{\left[k N . m^{2}\right]}\end{array}$ & $\begin{array}{c}\text { Isec } \\
{\left[\mathrm{m}^{4}\right]}\end{array}$ & $\begin{array}{c}\text { Redução } \\
{\left[I_{\text {sec }} / I_{c}\right]}\end{array}$ \\
\hline$\varphi=0,0$ & 0,681 & 100,00 & 146806,10 & 0,006896 & 0,4541 \\
\hline$\varphi=1,9$ & 0,976 & 100,00 & 102443,12 & 0,004812 & 0,3169 \\
\hline$\varphi=2,2$ & 1,012 & 100,00 & 98854,14 & 0,004644 & 0,3058 \\
\hline$\varphi=2,8$ & 1,077 & 100,00 & 92875,29 & 0,004363 & 0,2873 \\
\hline
\end{tabular}

Observa-se que na seção com momento atuante inferior ao de fissuração, a redução da rigidez apresenta o fator 0,45 , que se aproxima do 0,4 recomendado pela NBR 6118. Porém, conforme a tabela anterior, a redução na seção crítica de momento máximo é de 0,20 .

\subsection{Exemplo 2 - Pilar}

O segundo exemplo é retirado da dissertação de mestrado de Silva (2017), sendo um pilar submetido a flexão composta reta com grande excentricidade.

\subsubsection{Modelo Estrutural - Análise Inicial}

O pilar proposto tem seção de $50 \times 100 \mathrm{~cm}$, em concreto $35 \mathrm{MPa}$ e altura útil de $95 \mathrm{~cm}$. A estrutura é considerada engastada na base e livre na outra extremidade, com carregamento normal no topo de $1200 \mathrm{kN}$ e uma força na horizontal de $250 \mathrm{kN}$, com vão de 5,00 m. A seção transversal possui 10 camadas de armadura, tendo as camadas externas 4 barras e as intermediárias 2 barras, com espaçamento de $10 \mathrm{~cm}$.

Considera-se a seção submetida a flexão composta reta com grande excentricidade, pela excentricidade , calculado conforme a equação (4.14),exceder o limite $h / 6$.

$$
\begin{gathered}
e=M_{d} / N_{d} \\
e=250 \cdot 5 / 1200=1,04 \mathrm{~m} \\
h / 6=1,00 / 6=0,17 \mathrm{~m}
\end{gathered}
$$




$$
e>h / 6
$$

Modela-se a estrutura no FTOOL e obtêm-se os mesmos resultados que o exemplo do trabalho referido, como mostrado na figura 4.38.

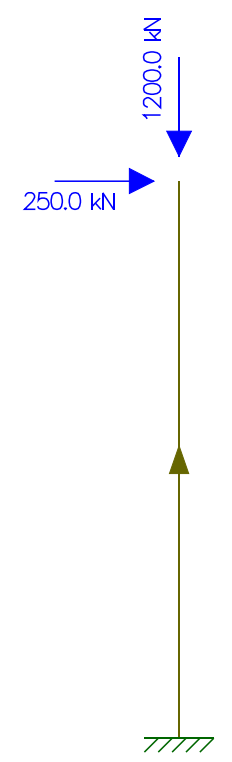

(a)

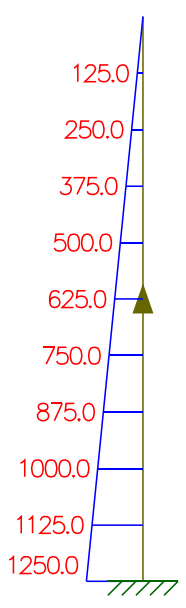

(b)

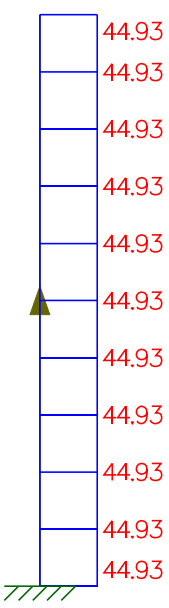

(c)

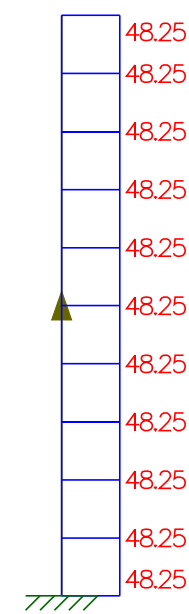

(d)

Figura 4.38 - (as) Esquema estrutural do pilar com o carregamento dado; (b) Diagrama de momento fletor $[\mathrm{kN} . \mathrm{m}]$; (c) Armadura calculada $\left[\mathrm{cm}^{2}\right]$; (d) Armadura adotada $\left[\mathrm{cm}^{2}\right]$.

O método de dimensionamento do FTOOL fornece como resultado a área total de aço da seção, portanto, sabendo-se que são 24 barras na seção, a bitola adotada é de $16 \mathrm{~mm}$.

\subsubsection{Redução da Rigidez - Convergência do Modelo}

Seja o pilar analisado neste exemplo, com uma extremidade engastada e outra livre, sendo a estrutura isostática. Desta forma, a inércia não interfere no diagrama de momentos fletores, logo, não causa alteração na seção dimensionada. Sendo assim, em todo este exemplo a seção do pilar tem $24 \emptyset 16 \mathrm{~mm}$ e uma única curva momento-curvatura. A figura 4.39 apresenta-se a relação momento-curvatura da seção dada sob carregamento normal de compressão $1200 \mathrm{kN}$. 


\section{Diagrama Momento-Curvatura}

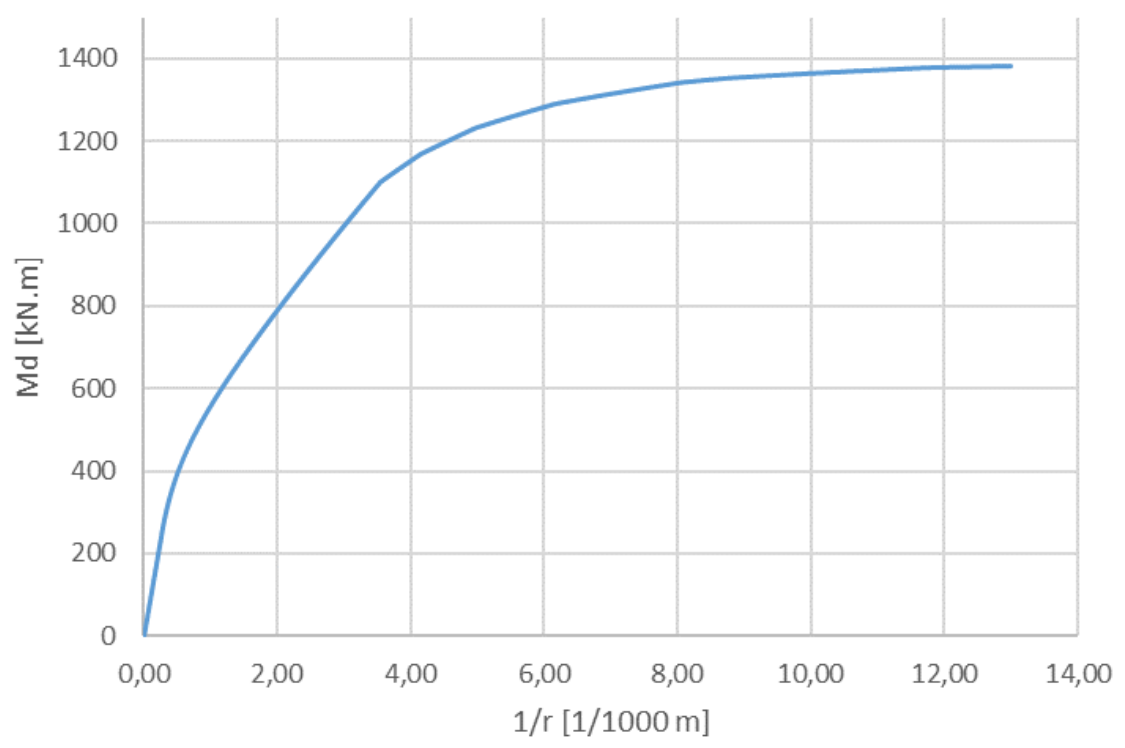

Figura 4.39 - Exemplo 2 - Diagrama Momento Curvatura

Independentemente do passo adotado, a armadura calculada será a mesma. A principal diferença será nos valores da rigidez adotada para a seção, que geram impacto nos deslocamentos. É importante ressaltar a diferença entre a análise em vigas e em pilares, dado que em vigas existe o escalonamento do diagrama e a área de aço varia ao longo do vão. Já no caso de pilares a armadura é constante. Este fato gera dois impactos na análise da rigidez:

- Sendo o domínio de integração dividido em trechos, estes são definidos nas seções com mudança de armadura ou no início e fim de um elemento de barra. Dado o escalonamento da armadura da viga, um mesmo elemento de barra possui vários trechos, e dentro desses trechos são inseridos nós de integração, dado o passo escolhido pelo usuário. No caso de pilares, o elemento de barra terá apenas um trecho, sendo os nós de integração ao longo do vão do pilar inseridos apenas de acordo com o passo dado.

- Os pilares não têm mudança de armadura ao longo do vão, portanto, têm uma mesma curva momento-curvatura e têm maior variação ao longo do vão da rigidez secante das seções. Já no caso de vigas, pelo escalonamento da armadura, cada alteração de armadura gera alteração na seção e consequentemente uma nova curva momentocurvatura e desta forma a rigidez de elementos de viga sofre menor variação ao longo do vão. Ao se plotar a redução da rigidez ao longo do vão da viga, devido ao escalonamento da armadura, a gráfico apresenta degraus nos limites entre trechos. Já em pilares, este gráfico apresenta uma curva contínua. 
Utilizam-se os mesmos passos do exemplo anterior para mostrar a variação da rigidez ao longo do vão do pilar. Na figura 4.40 mostra-se o diagrama de momento fletor para cada passo e na figura 4.41 a variação da rigidez.

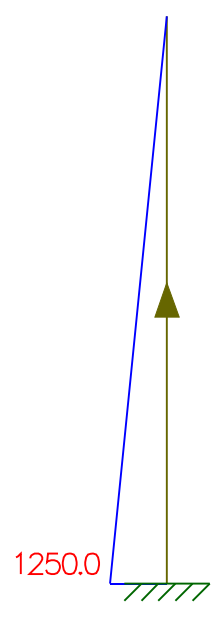

(a)

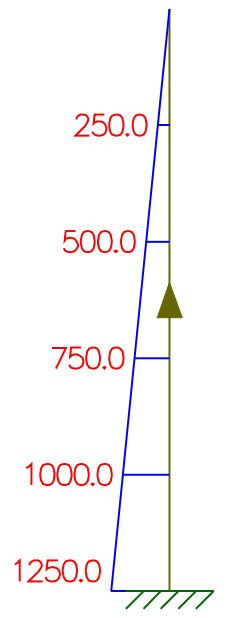

(b)

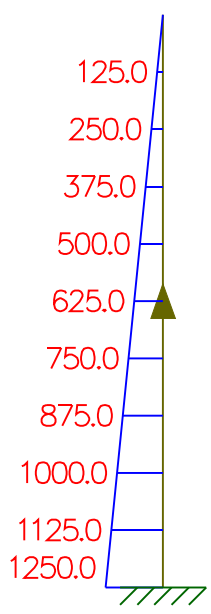

(c)

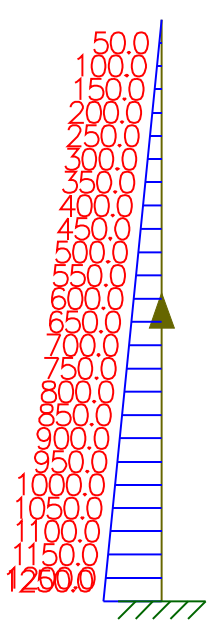

(d)

Figura 4.40 - Diagrama de momento fletor [kN.m] com os valores de momento utilizados na

integração dos nós (a) Passo 0,0 m; (b) Passo 1,0 m; (c) Passo 0,5 m; (d) Passo 0,2 m;

Observa-se na figura 4.41 que no topo do pilar, onde os momentos tem valores menores, até o nó de momento $300 \mathrm{kN} . \mathrm{m}, 1,0 \mathrm{~m}$ abaixo do topo, o valor da redução é quase constante, no patamar de 76,9\%. Abaixo desse nó, há uma grande variação nos valores, até se chegar à base do pilar com momento de $1250 \mathrm{kN}$. m e com redução de $12,9 \%$. Isso equivale à aplicação de um fator de redução de 0,769 no topo e 0,129 na base do pilar. Segundo o item 15.7.3 da NBR 6118 (ABNT, 2014), a recomendação é de aplicação de fatores de redução de 0,8 para pilares. Observase que a redução obtida se aproxima da recomendada nas regiões de comportamento linear da curva-momento curvatura.

O valor constante da rigidez no topo do pilar se dá pelo comportamento elástico dos materiais concreto e aço. Conforme a fibra mais comprimida do concreto plastifica e as camadas de armadura escoam, a curva momento-curvatura muda sua inclinação e, portanto, percebe-se a variação da rigidez ao longo do vão. 


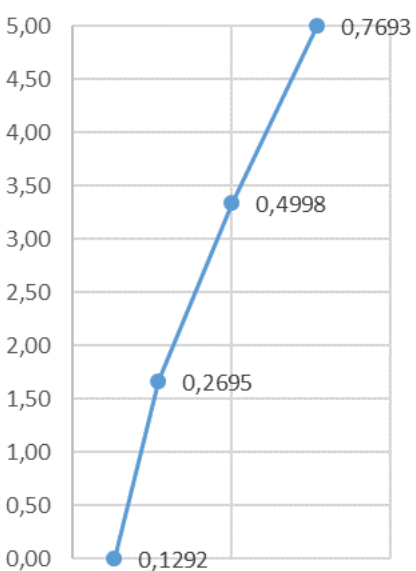

(a)

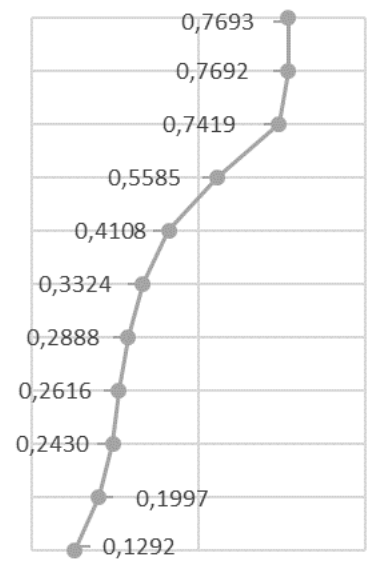

(c)

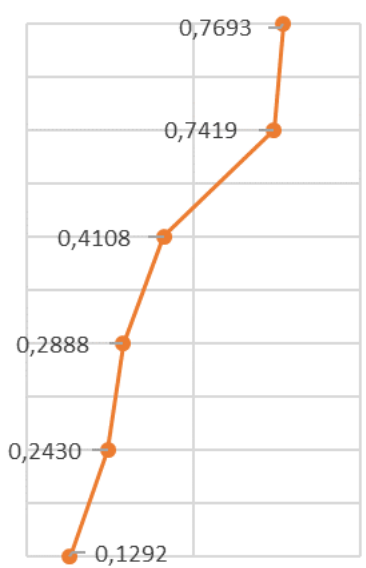

(b)

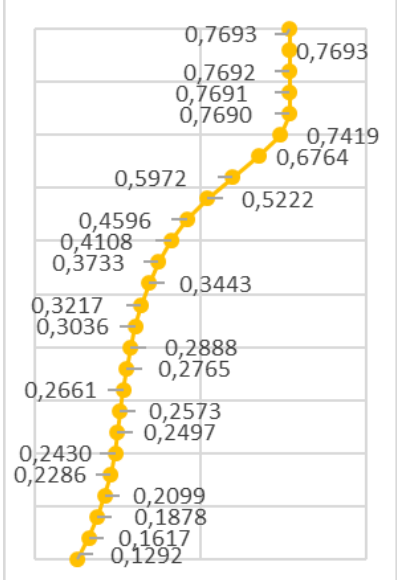

(d)

Figura 4.41 - Redução na rigidez ao longo do vão do pilar (a) Passo 0,0 m; (b) Passo 1,0 m; (c) Passo 0,5 m; (d) Passo 0,2 m;

\subsubsection{Deslocamentos}

Sabendo que para o pilar, o passo adotado impacta mais no resultado que para vigas, aqui se faz a análise dos deslocamentos do pilar com todos os passos sugeridos. Sabe-se que a armadura $24 \emptyset 16 \mathrm{~mm}$ e os valores de redução da rigidez apresentados no item anterior são constantes, dado que a estrutura é isostática, portanto, são os mesmos aplicados para o cálculo dos deslocamentos.

Com o carregamento aplicado, mostrado na figura 4.42, faz-se uma análise linear para obtenção da deformada. 


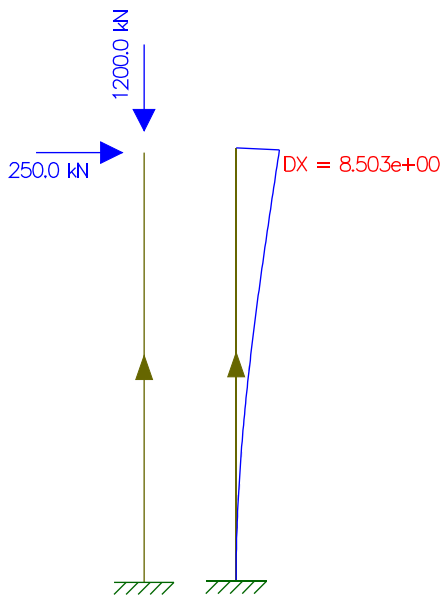

Figura 4.42 - Deformada do pilar - Análise Linear [ $\mathrm{mm}]$.

Aqui, se insere a redução da rigidez para cálculo dos deslocamentos da estrutura, tomando-se como referência o deslocamento no topo do pilar. Observese que, como a estrutura é isostática, só há necessidade de uma iteração para a deformada. Portanto, para cada um dos passos do item anterior, faz-se uma iteração para obter o deslocamento no topo do pilar, com resultado da deformada na figura 4.43 .

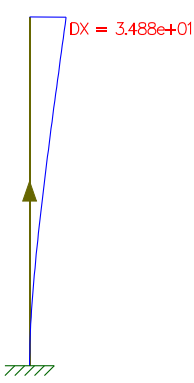

(a)

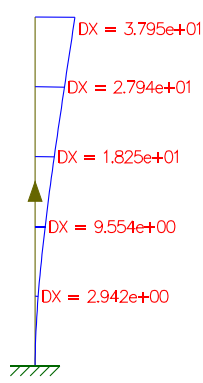

(b)

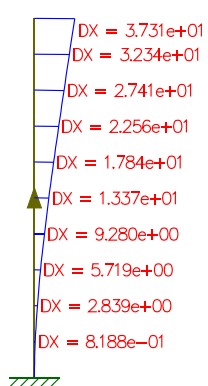

(c)

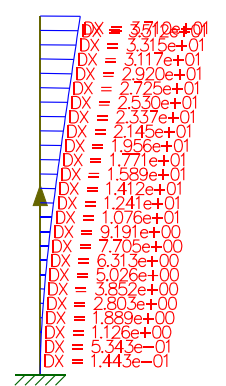

(d)

Figura 4.43 - Deslocamento horizontal [mm] para análise não linear (a) Passo 0,0 m; (b) Passo 1,0 m; (c) Passo 0,5 m; (d) Passo 0,2 m;

Com os valores obtidos nas análises, faz-se a tabela 4.15 com um resumo e calcula-se o valor de amplificação, razão do deslocamento obtido com a rigidez reduzida e do deslocamento obtido na análise não linear.

Tabela 4.15 - Resumos dos valores de deslocamento no topo da seção para os passos dados.

\begin{tabular}{|l|r|r|r|r|r|}
\cline { 3 - 6 } \multicolumn{1}{c|}{} & \multirow{2}{c|}{\begin{tabular}{c} 
Análise \\
\multicolumn{1}{c|}{}
\end{tabular}} & \multicolumn{4}{c|}{ Análise não linear - Passo } \\
\cline { 3 - 7 } \multicolumn{1}{c|}{} & \multicolumn{1}{c|}{$0,0 \mathrm{~m}$} & $1,0 \mathrm{~m}$ & \multicolumn{1}{c|}{$0,5 \mathrm{~m}$} & \multicolumn{1}{c|}{$0,2 \mathrm{~m}$} \\
\hline $\begin{array}{l}\text { Deslocamento } \\
\text { Topo [mm] }\end{array}$ & 8,503 & 34,88 & 37,95 & 37,31 & 37,10 \\
\hline Amplificação & - & 4,10 & 4,46 & 4,39 & 4,36 \\
\hline
\end{tabular}

Com base na tabela de resumo dos resultados, observa-se que os passos inferiores a 1,0 $\mathrm{m}$ apresentam diferença no resultado final inferior a 1,0 $\mathrm{mm}$. 


\subsubsection{Fluência do Concreto}

Assim como no exemplo anterior, considera-se a fluência do concreto na análise utilizando um único valor para o coeficiente. Seja a umidade média do ambiente do Rio de Janeiro o valor de referência 75\%. A espessura fictícia da seção é calculada por:

$$
e_{f i c}=2 A_{c} / u
$$

Este para a seção com largura de $50 \mathrm{~cm}$ e altura de $100 \mathrm{~cm}$ tem valor de:

$$
e_{\text {fic }}=2 \cdot 50 \cdot 100 /(2 \cdot 50+2 \cdot 100)=33,33 \mathrm{~cm}
$$

O concreto do exemplo tem resistência característica de 35MPa e opta-se pela idade fictícia de 5 dias. Consultando a tabela, é necessário que se faça a interpolação entre os valores de espessura fictícia de 20 e $60 \mathrm{~cm}$, adotando-se:

$$
\varphi=2,67
$$

\begin{tabular}{|c|c|c|c|c|c|c|c|c|c|c|}
\hline \multicolumn{3}{|c|}{$\begin{array}{c}\text { Umidade média } \\
\text { ambiente } \\
\%\end{array}$} & \multicolumn{2}{|c|}{40} & \multicolumn{2}{|c|}{55} & \multicolumn{2}{|c|}{75} & \multicolumn{2}{|c|}{90} \\
\hline \multicolumn{3}{|c|}{$\begin{array}{l}\text { Espessura fictícia } \\
2 A_{\mathrm{c}} / u \\
\mathrm{~cm}\end{array}$} & 20 & 60 & 20 & 60 & 20 & 60 & 20 & 60 \\
\hline \multirow{3}{*}{$\begin{array}{c}\varphi\left(t_{\infty}, t_{0}\right) \\
\text { Concreto } \\
\text { das classes } \\
\text { C20 a C45 }\end{array}$} & \multirow{9}{*}{$\begin{array}{c}t_{0} \\
\text { dias }\end{array}$} & 5 & 4,6 & 3,8 & 3,9 & 3,3 & 2,8 & 2,4 & 2,0 & 1,9 \\
\hline & & 30 & 3,4 & 3,0 & 2,9 & 2,6 & 2,2 & 2,0 & 1,6 & 1,5 \\
\hline & & 60 & 2,9 & 2,7 & 2,5 & 2,3 & 1,9 & 1,8 & 1,4 & 1,4 \\
\hline$\varphi\left(t_{\infty}, t_{0}\right)$ & & 5 & 2,7 & 2,4 & 2,4 & 2,1 & 1,9 & 1,8 & 1,6 & 1,5 \\
\hline Concreto & & 30 & 2,0 & 1,8 & 1,7 & 1,6 & 1,4 & 1,3 & 1,1 & 1,1 \\
\hline C50 a C90 & & 60 & 1,7 & 1,6 & 1,5 & 1,4 & 1,2 & 1,2 & 1,0 & 1,0 \\
\hline \multirow{3}{*}{$\varepsilon_{c s}\left(t_{\infty 00}, t_{0}\right) \%_{0}$} & & 5 & $-0,53$ & $-0,47$ & $-0,48$ & $-0,43$ & $-0,36$ & $-0,32$ & $-0,18$ & $-0,15$ \\
\hline & & 30 & $-0,44$ & $-0,45$ & $-0,41$ & $-0,41$ & $-0,33$ & $-0,31$ & $-0,17$ & $-0,15$ \\
\hline & & 60 & $-0,39$ & $-0,43$ & $-0,36$ & $-0,40$ & $-0,30$ & $-0,31$ & $-0,17$ & $-0,15$ \\
\hline
\end{tabular}

Tabela 4.16 - Coeficientes de fluência e retração - Tabela 8.2 da NBR 6118(ABNT, 2014)

Pela estrutura ser isostática, a fluência na curva momento-curvatura não gera qualquer alteração nos momentos fletores ou na armadura, portanto, busca-se apenas analisar o impacto nos deslocamentos. Considerando o menor passo de 0,2 m, para que entre na análise o maior número de nós, colocando em evidência a grande variação da rigidez, faz-se a análise dos deslocamentos. 
Comparam-se na figura 4.44 os valores de redução obtidos na análise anterior com os valores agora obtidos com a redução da inércia considerando a fluência.

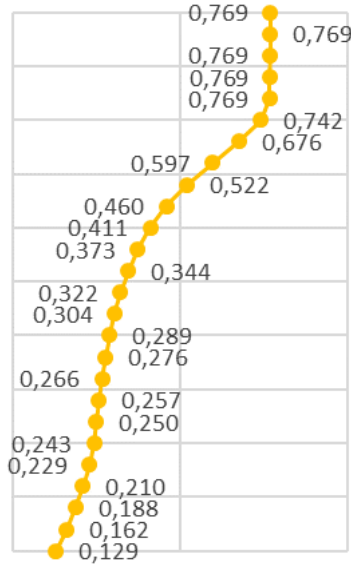

(a)

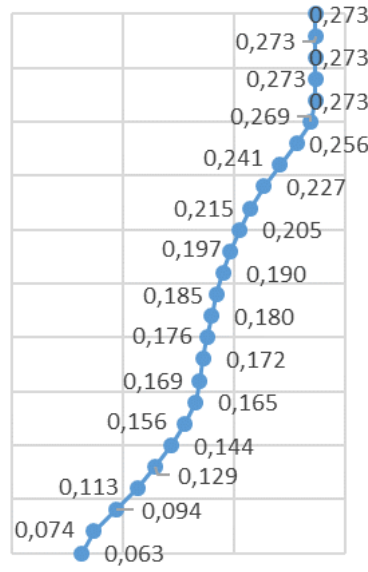

(b)

Figura 4.44 - Redução na rigidez ao longo do vão do pilar com passo 0,2m (a) Análise não linear;

(b) Análise não linear com fluência.

$\mathrm{Na}$ figura 4.45, a deformada obtida em comparação com as obtidas anteriormente pela análise linear e não linear:

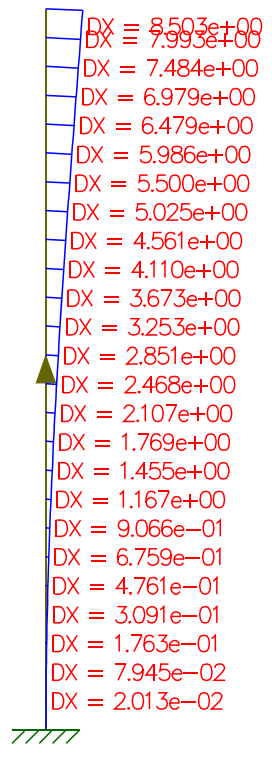

(a)

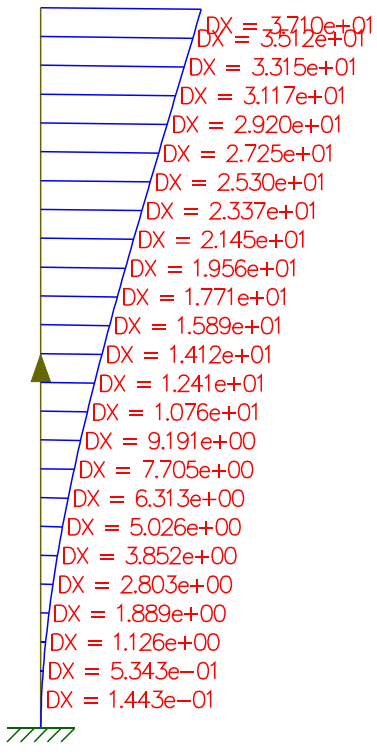

(b)

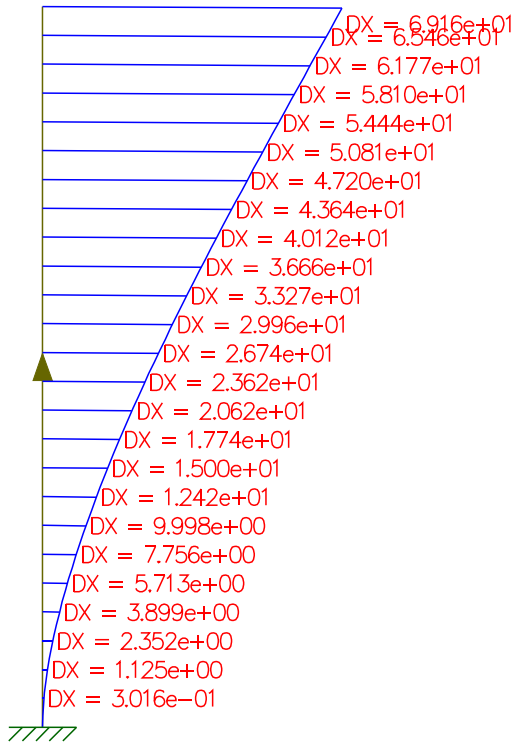

(c)

Figura 4.45 - Deformada do pilar [mm] obtida com passo 0,2m para (a) Análise linear; (b) Análise não linear; (c) Análise não linear com fluência.

Com as análises, faz-se a tabela 4.17 comparativa com os resultados e inércia secante, redução e deslocamento. 
Tabela 4.17 - Comparação entre os valores de inércia secante, redução e deslocamento.

\begin{tabular}{|l|c|c|c|c|c|c|}
\hline \multirow{2}{*}{ Análise } & \multicolumn{2}{|c|}{ Base do Pilar } & \multicolumn{4}{c|}{ Topo do Pilar } \\
\cline { 2 - 7 } & $\begin{array}{c}\text { Inércia } \\
\text { Secante } \\
\text { Isec [m4] }\end{array}$ & $\begin{array}{c}\text { Redução } \\
\text { Isec/Ic }\end{array}$ & $\begin{array}{c}\text { Inércia } \\
\text { Secante } \\
\text { Isec [m4] }\end{array}$ & $\begin{array}{c}\text { Redução } \\
\text { Isec/Ic }\end{array}$ & $\begin{array}{c}\text { Deslocamento } \\
{[\mathrm{mm}]}\end{array}$ & Amplificação \\
\hline Linear & 0,04167 & 1,0000 & 0,04167 & 1,0000 & 8,503 & 1,000 \\
\hline $\begin{array}{l}\text { Não } \\
\text { Linear }\end{array}$ & 0,005382 & 0,1292 & 0,03206 & 0,7693 & 37,10 & 4,363 \\
\hline $\begin{array}{l}\text { Não } \\
\text { Linear - } \\
\text { Fluência }\end{array}$ & 0,002634 & 0,0632 & 0,01139 & 0,2733 & 69,16 & 8,134 \\
\hline
\end{tabular}

Para esta estrutura, com estas condições de carregamento, sem a fluência a redução obtida no topo do pilar é de 0,77 , valor que se aproxima da recomendação da NBR 6118 para a consideração aproximada da não linearidade física de 0,8. Já na base, onde o momento é máximo, a redução é de 0,13 . Ao se considerar a fluência, esses valores são ainda menores, com fatores de redução de 0,06 e 0,27, respectivamente, na base e no topo do pilar.

\subsection{Exemplo 3 - Pórtico}

O terceiro exemplo também é retirado da dissertação de mestrado de Silva (2017), sendo um pórtico plano.

\subsubsection{Modelo Estrutural - Análise Inicial}

O pórtico do exemplo é composto por vigas e pilares, tendo três andares, sendo o primeiro com altura de 4,70 $\mathrm{m}$ e os demais 3,0 $\mathrm{m}$, um vão de $10,0 \mathrm{~m}$ e um balanço de 3,0 $\mathrm{m}$.

Ele é composto por vigas e pilares, sendo a seção das vigas de $30 \times 150 \mathrm{~cm}$ com cobrimento de $2,0 \mathrm{~cm}$ e altura útil de $27 \mathrm{~cm}$. Opta-se pelo detalhamento com barras de $16 \mathrm{~mm}$ de diâmetro e decalagem de duas em duas barras. A armadura transversal escolhida é de $8 \mathrm{~mm}$ com espaçamento de $10 \mathrm{~cm}$. Os pilares têm seção de $40 \times 150 \mathrm{~cm}$ com altura útil de $37 \mathrm{~cm}$ e cobrimento de 2,5 cm. A seção do pilar terá 4 camadas de armadura: as camadas superior e inferior terão 11 barras, enquanto as camadas intermediárias 2 barras, com espaçamento de $11 \mathrm{~cm}$.

Em todo pórtico é utilizado o concreto C30 com resistência característica de $30 \mathrm{MPa}$ e aço CA-50. Na figura 4.46 apresenta-se o modelo estrutural do pórtico, com os carregamentos de cálculo aplicados, já majorados: 


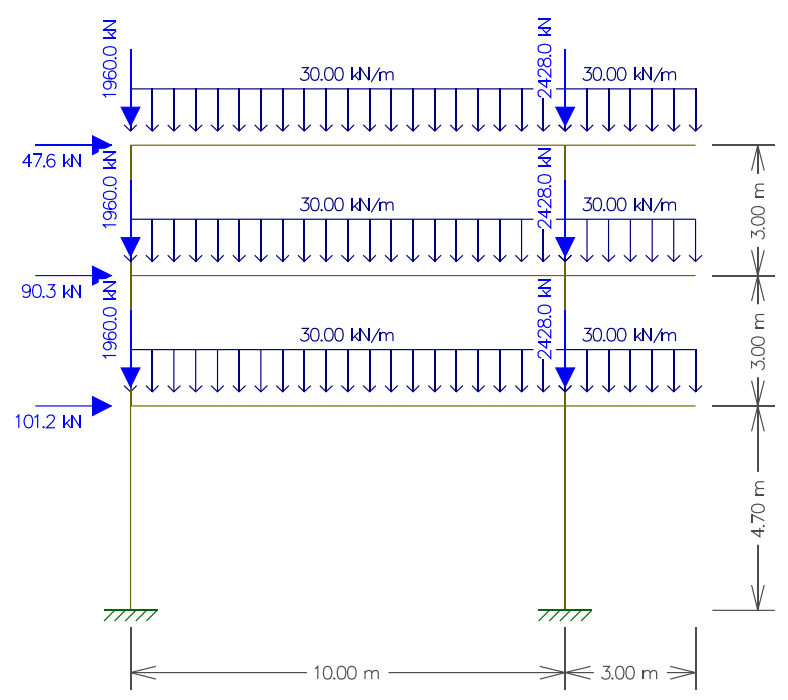

Figura 4.46 - Pórtico plano.

Com a primeira análise linear, na figura 4.47 fazem-se os diagramas de momentos fletores e força normal.

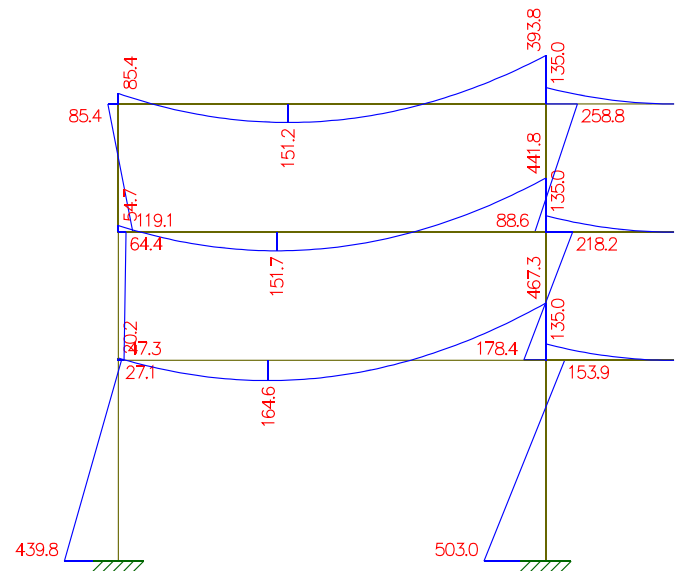

(a)

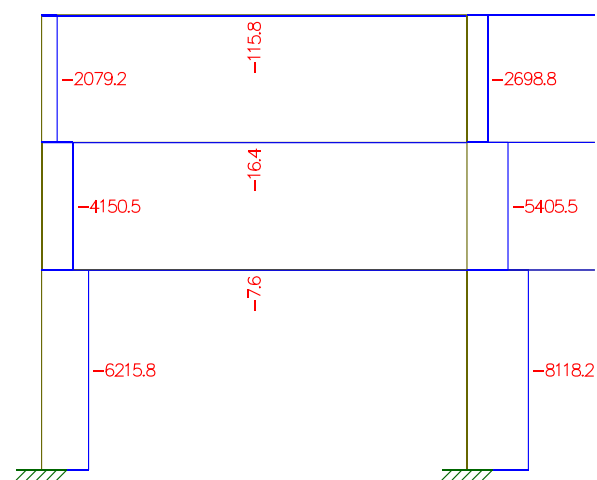

(b)

Figura 4.47 - Diagramas de análise do pórtico (a) Momento Fletor [kN.m] ; (b) Normal [kN].

Baseado nesses diagramas, a figura 4.48 mostra o dimensionamento das seções de vigas e pilares. 


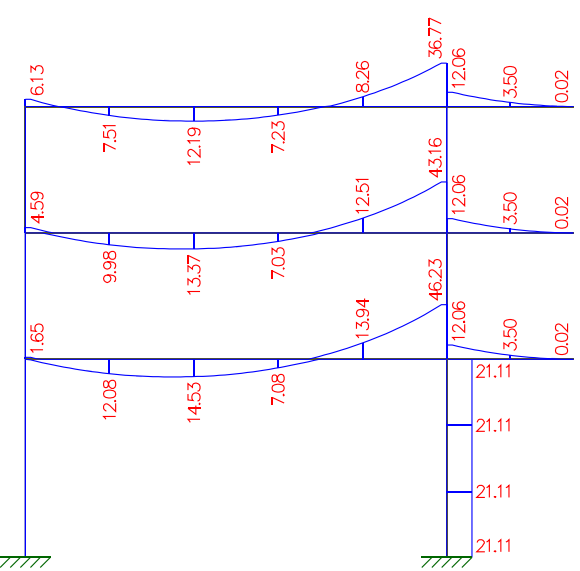

(a)

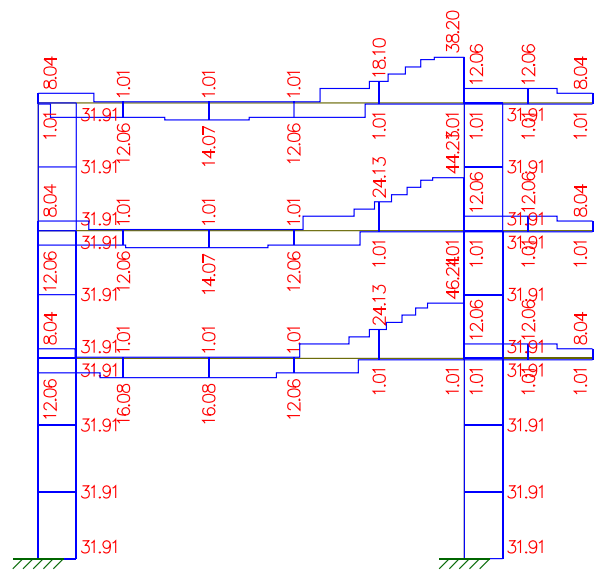

(b)

Figura 4.48 - Diagramas de análise do pórtico (a) Armadura calculada [ $\left.\mathrm{cm}^{2}\right]$; (b) Armadura adotada $\left[\mathrm{cm}^{2}\right]$.

Para ficar mais claro qual armadura foi adotada nas seções, na figura 4.49 amplia-se o diagrama de armadura e anota-se o número e o diâmetro das barras adotadas:

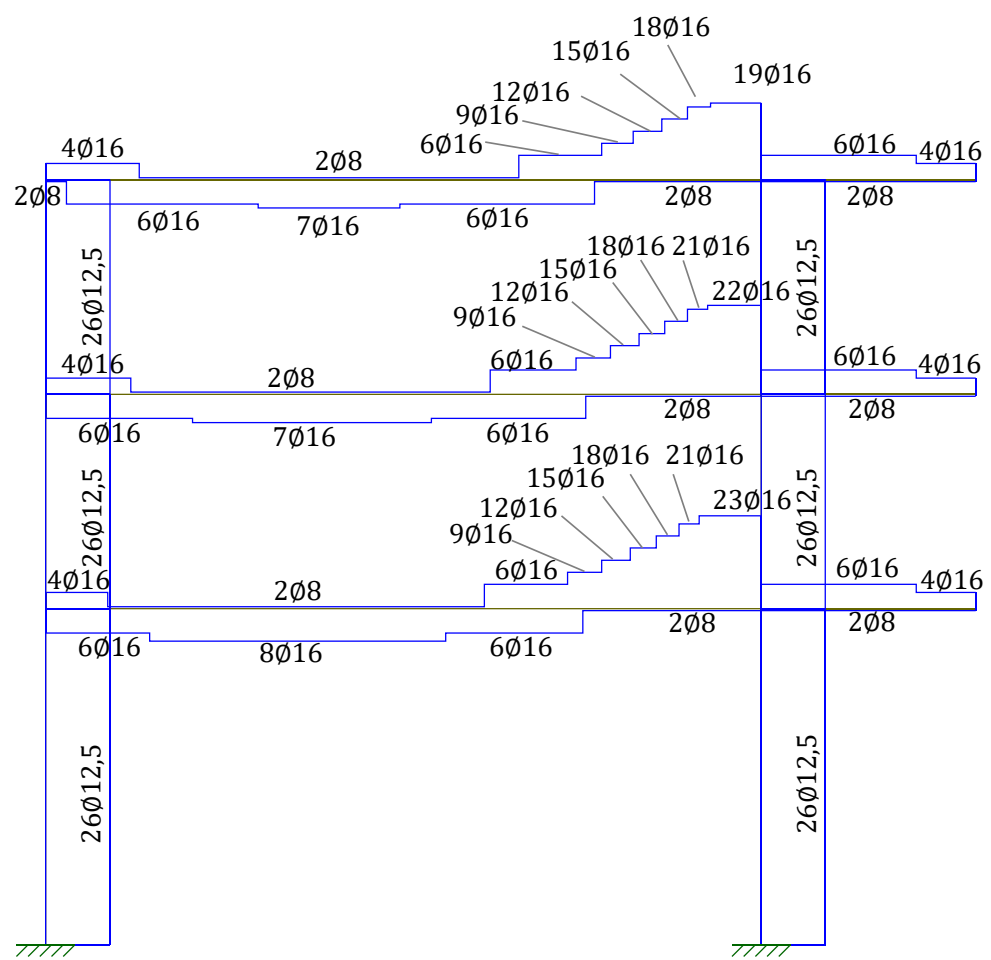

Figura 4.49 - Diagrama de armadura adotadas

\subsubsection{Redução da Rigidez - Convergência do Modelo}

Após o dimensionamento inicial da seção, faz-se a análise não linear. Assim como nos exemplos anteriores, são adotados os mesmos valores de passo $0,0 \mathrm{~m}$; 
$1,0 m ; 0,5 m$ e $0,2 m$. Para melhor clareza na apresentação dos resultados, na figura 4.50 as vigas e os pilares são nomeados.

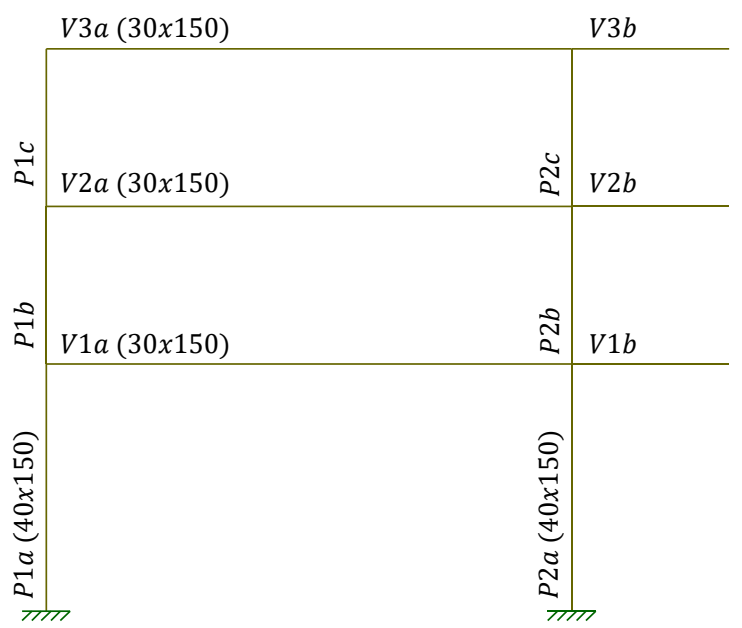

Figura 4.50 - Pórtico plano com nome das vigas e pilares analisados.

Observa-se nos diagramas de momentos fletores e força normal, que o pilar mais solicitado é o $P 2 a$ e a viga mais solicitada a $V 1 a$. Portanto, neste exemplo serão estes os elementos estruturais analisados. Com a primeira iteração, a partir das armaduras obtidas com o dimensionamento linear, são calculadas as reduções de inércia obtidas no pilar $P 2 a$ e na viga $V 1 a$, como mostrado na figura 4.51 .

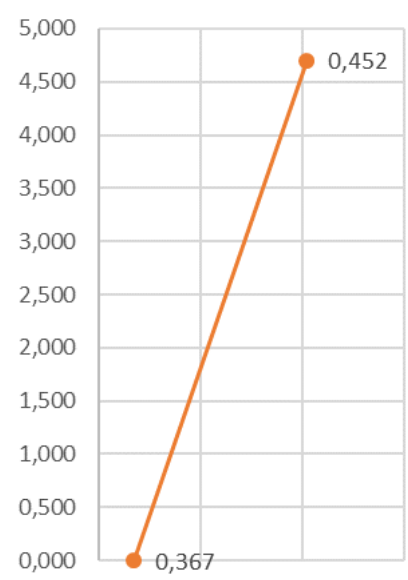

(a)

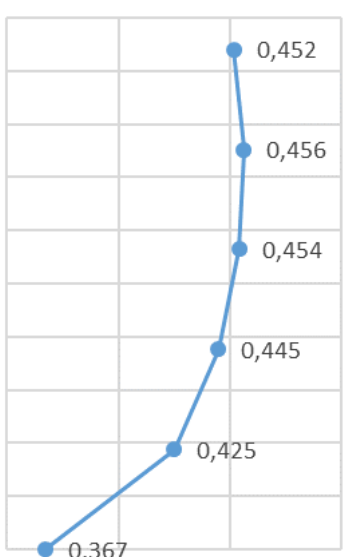

(b) 


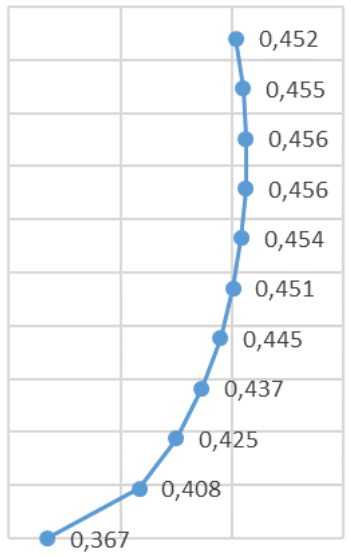

(c)

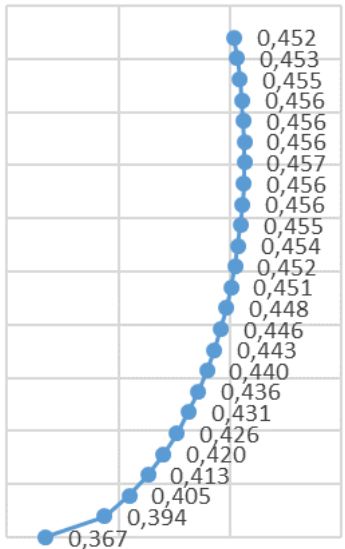

(d)

Figura 4.51 - Redução na rigidez ao longo do vão de P2a (a) Passo 0,0 m; (b) Passo 1,0 m; (c) Passo 0,5 m; (d) Passo 0,2 m;

Observa-se que para este pilar P2a não há grandes variações na redução da rigidez dentro do vão, apesar de ser uma redução maior que no exemplo anterior. Isso se deve a dois fatores. O primeiro é que a curva momento-curvatura deste pilar para o carregamento normal de compressão $-8118,3 k N$ é mais suave que a apresentada no exemplo anterior, portanto, não apresenta um patamar. O segundo é que a armadura adotada, é superior em $51,2 \%$ da calculada. Na figura 4.52 mostrase a curva momento-curvatura da seção do pilar para o dado carregamento normal.

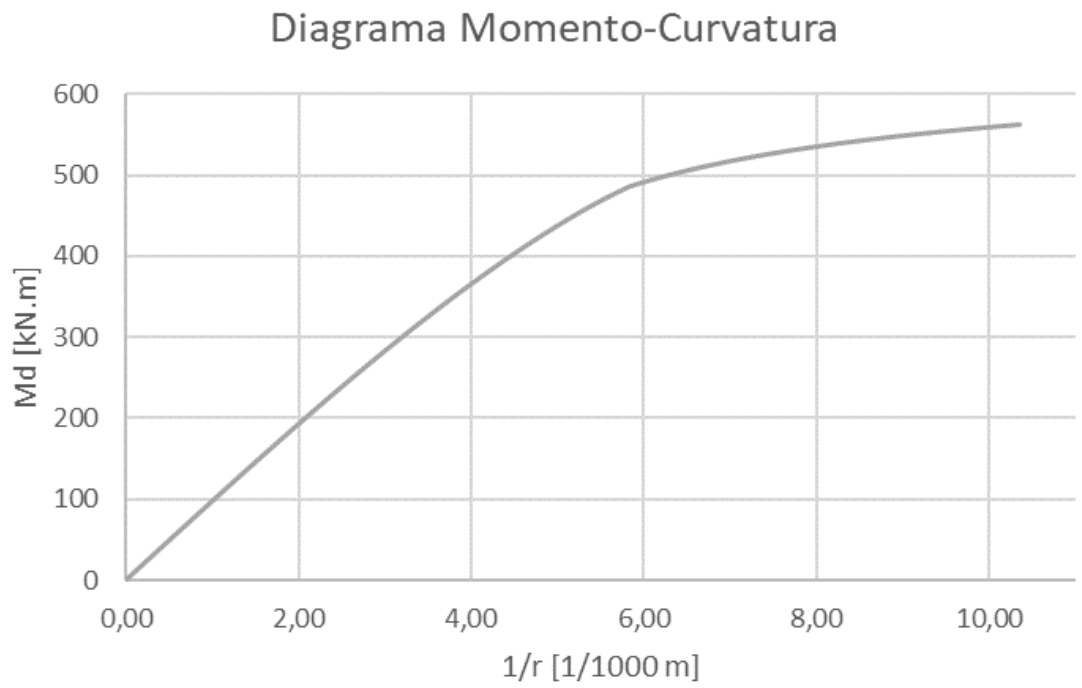

Figura 4.52 - Diagrama momento-curvatura para a seção do pilar P2a com carregamento normal de $-8118,3 k N$ 
(a)

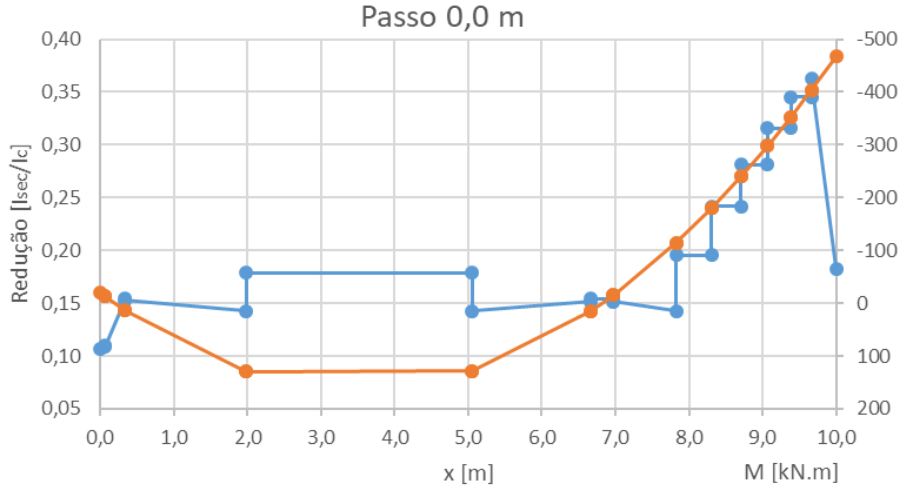

(b)

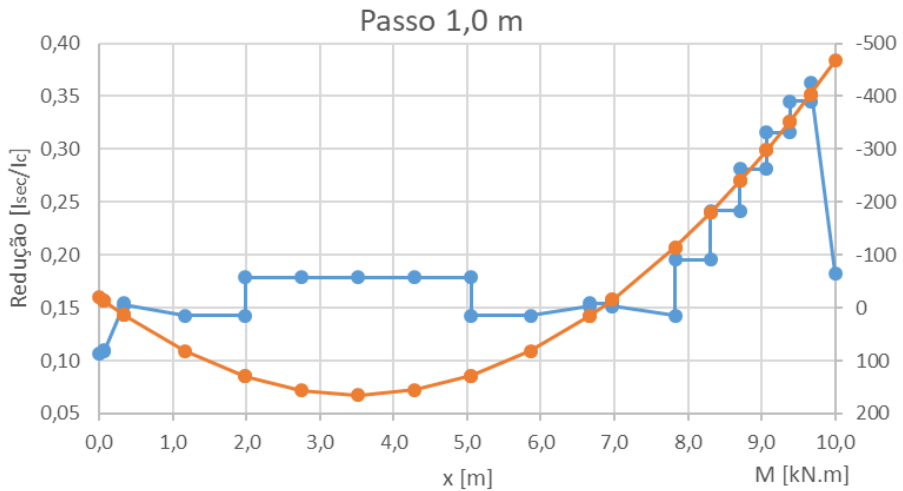

(c)

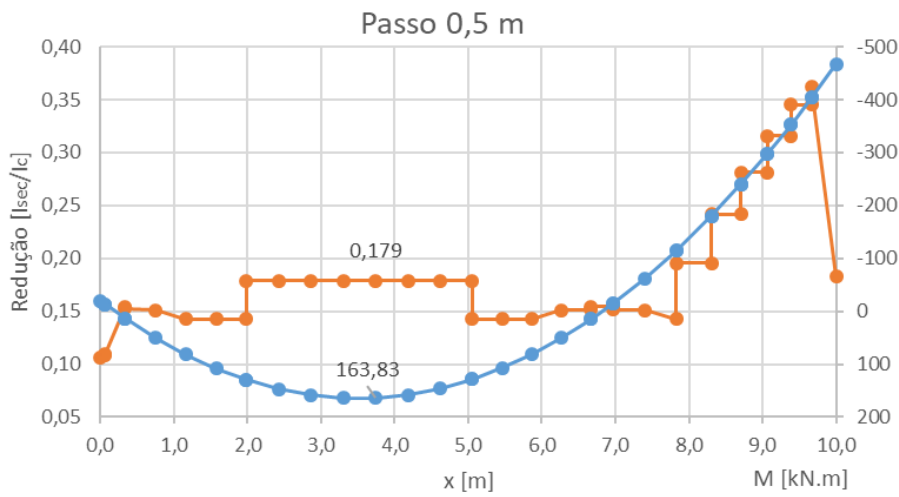

(d)

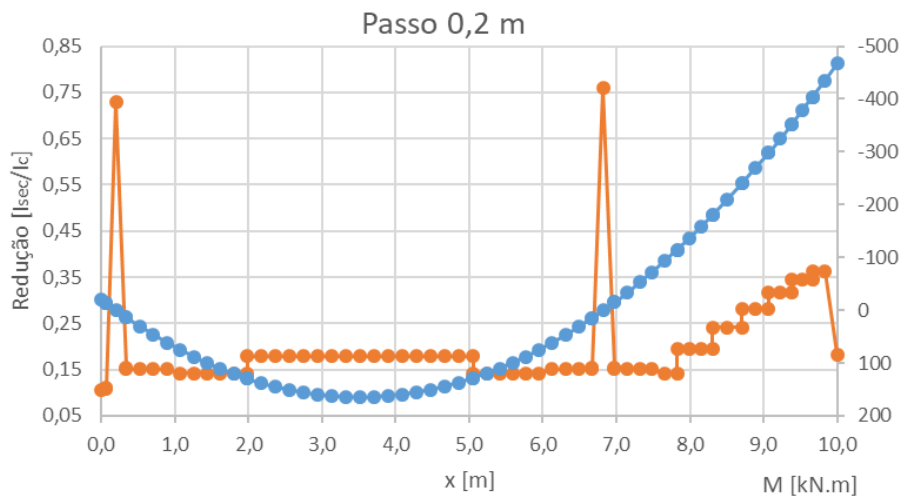

Figura 4.53 - Redução na rigidez ao longo do vão de V1a (a) Passo 0,0 m; (b) Passo 1,0 m; (c) Passo 0,5 m; (d) Passo 0,2 m; 
Para a viga V2a, todos os gráficos gerados para redução da rigidez ao longo do vão são similares, conforme figura 4.53. Isso se deve à separação em trechos das seções com variação da seção. Como há degraus no diagrama de armadura adotada, esses degraus se refletem no gráfico de redução da rigidez. A única exceção é que com o passo 0,2 , a malha passa no nó de momento fletor $0,0 \mathrm{~m}$, assim gerando um pico onde a redução da rigidez é de aproximadamente 0,70.

Portanto, assim como observado anteriormente, para a análise de vigas, o passo não tem grande influência, já que existem várias seções ao longo do vão geradas pelo escalonamento da armadura. O que é diferente da análise de pilares, onde o passo é a única subdivisão ao longo de todo a altura do pilar. Desta forma, assim como no primeiro exemplo deste trabalho sobre vigas, aqui faz-se a análise da convergência com todos os quatro passos sugeridos.

Como referência para a análise, utiliza-se o momento máximo da viga V1a e dos pilares P1a e P2a. Para demonstração do processo, adota-se o passo 0,5m para as iterações da figura 4.55 .

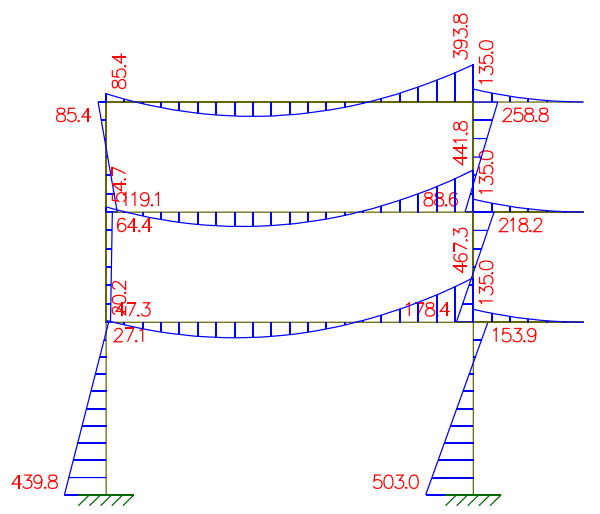

Figura 4.54 - Iteração 0 - Diagrama de Momento Fletor - Análise Linear [kN.m].

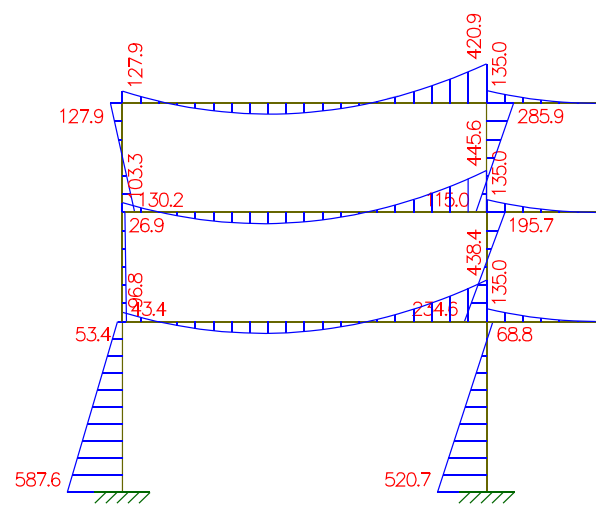

(a) Iteração 1

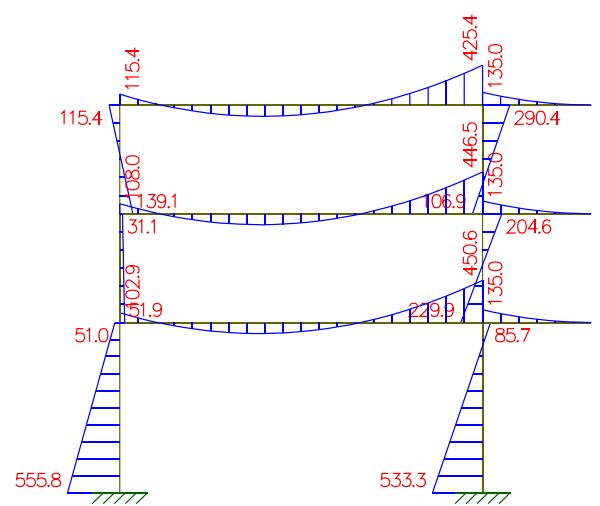

(b) Iteração 2 


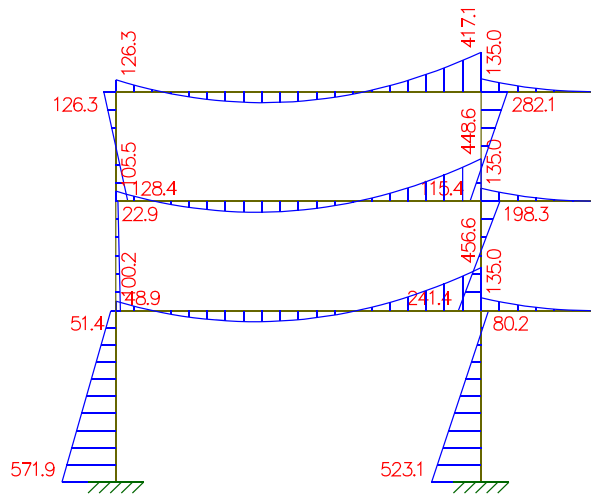

(c) Iteração 3

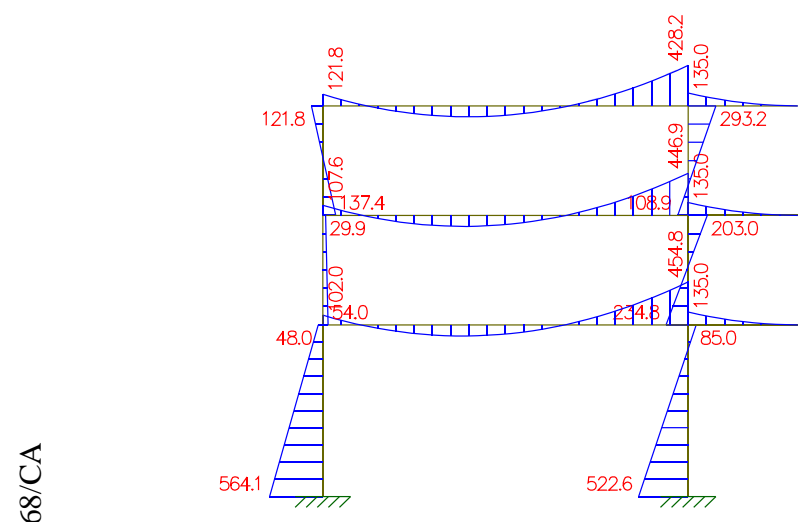

(e) Iteração 5

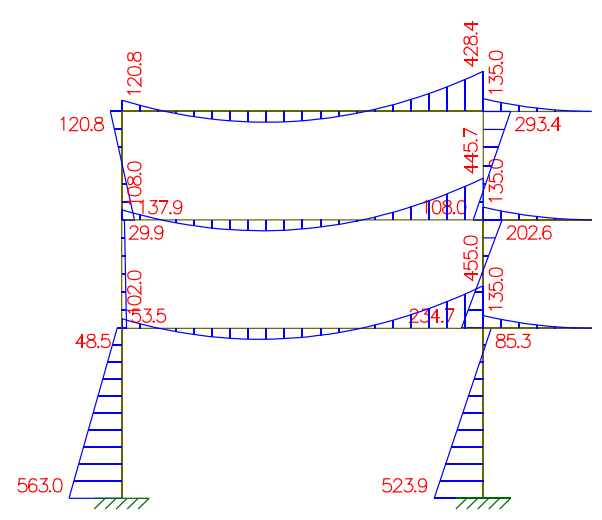

(g) Iteração 7

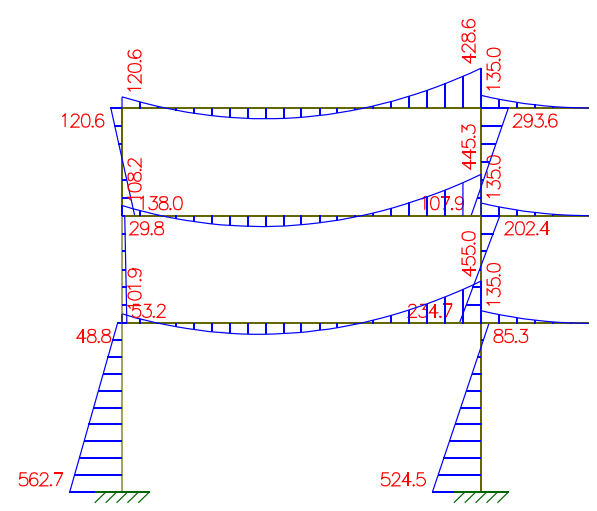

(i) Iteração 9

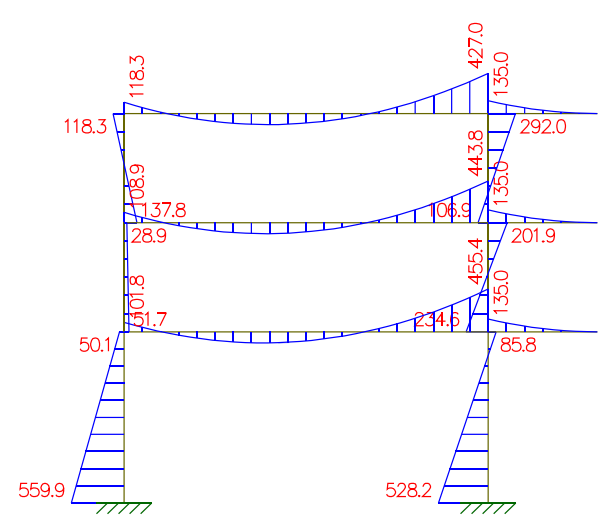

(d) Iteração 4

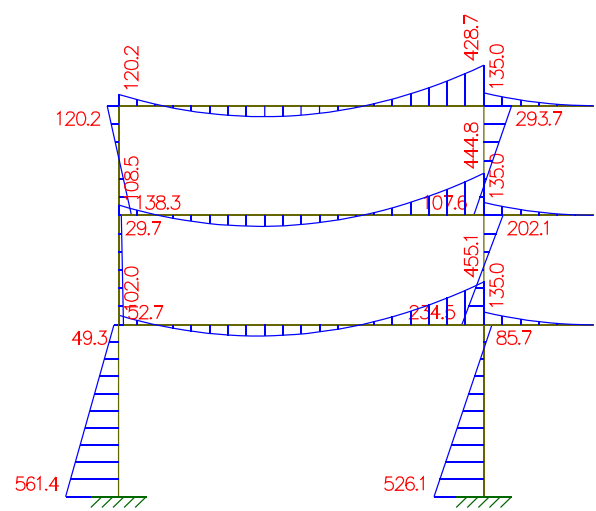

(f) Iteração 6

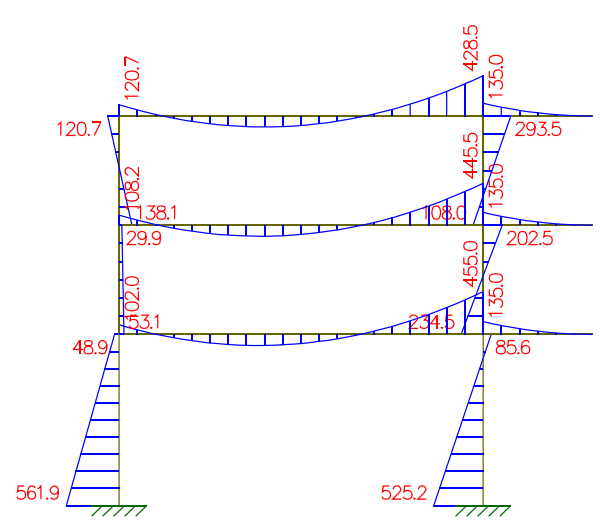

(h) Iteração 8

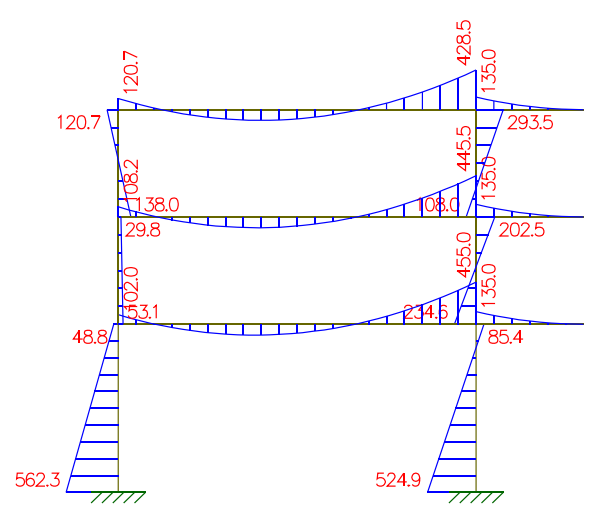

(j) Iteração 10 


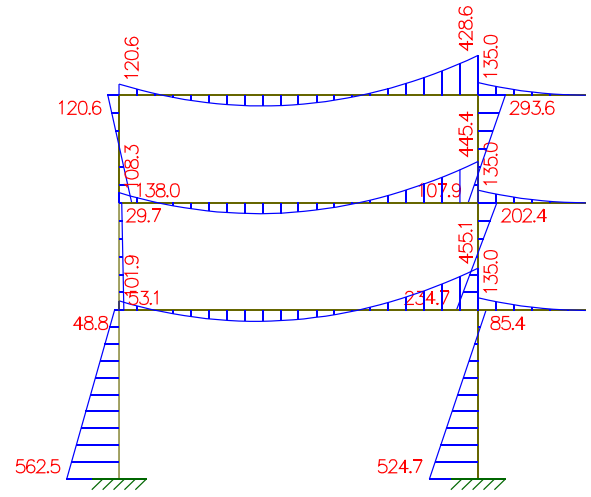

(k) Iteração 11

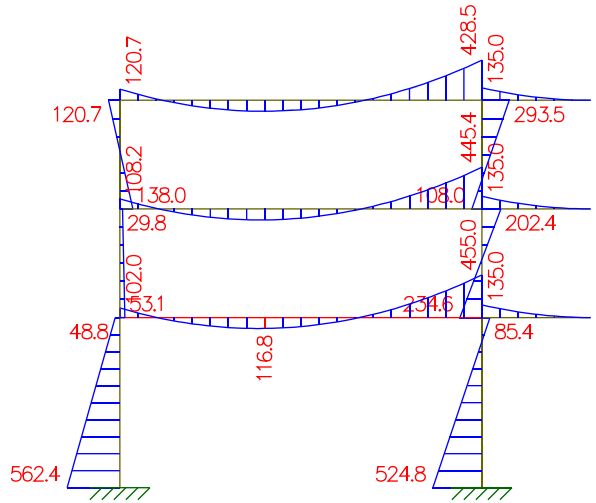

(1) Iteração 12

Figura 4.55 - Iterações - Diagrama de Momento Fletor [kN.m].

Repetindo o processo para os passos dados, faz-se o comparativo na tabela 4.18 com os momentos atuantes na viga V1a e nos pilares P1a e P2a.

Tabela 4.18 - Convergência dos modelos - Relação dos nós de integração

\begin{tabular}{|c|c|c|c|c|c|c|c|c|}
\hline Passo & \multirow{2}{*}{$\begin{array}{c}\text { Nós para } \\
{[\mathrm{m}]}\end{array}$} & \multirow{2}{*}{ Integração } & Iterações & \multicolumn{5}{|c|}{ Momento de Convergência [kN.m] } \\
\cline { 4 - 9 } & & & $\mathrm{V} 1 \mathrm{a}$ & $\Delta \mathrm{Md}[\%]$ & $\mathrm{P} 1 \mathrm{a}$ & $\Delta \mathrm{Md}[\%]$ & $\mathrm{P} 2 \mathrm{a}$ & $\Delta \mathrm{Md}[\%]$ \\
\hline 0,2 & 365 & 10 & 456,2 & $-2,38 \%$ & 562,3 & $27,85 \%$ & 526,8 & $4,73 \%$ \\
\hline 0,5 & 183 & 12 & 455,0 & $-2,63 \%$ & 562,4 & $27,88 \%$ & 524,8 & $4,33 \%$ \\
\hline 1,0 & 129 & 22 & 455,7 & $-2,48 \%$ & 563,3 & $28,08 \%$ & 521,7 & $3,72 \%$ \\
\hline
\end{tabular}

As colunas são calculadas com referência no momento calculado na análise linear, sendo na viga V1a de 467,3 kN. m, no pilar P1a de 439,8 kN.m e em P2a de 503,0 kN.m. Observa-se que os resultados para momentos para todos os passos são compatíveis. Portanto, para a análise do pórtico, os três passos sugeridos são satisfatórios para a análise. A diferença de projeto é melhor demonstrada ao analisar a armadura adotada da figura 4.56 até 4.58 .

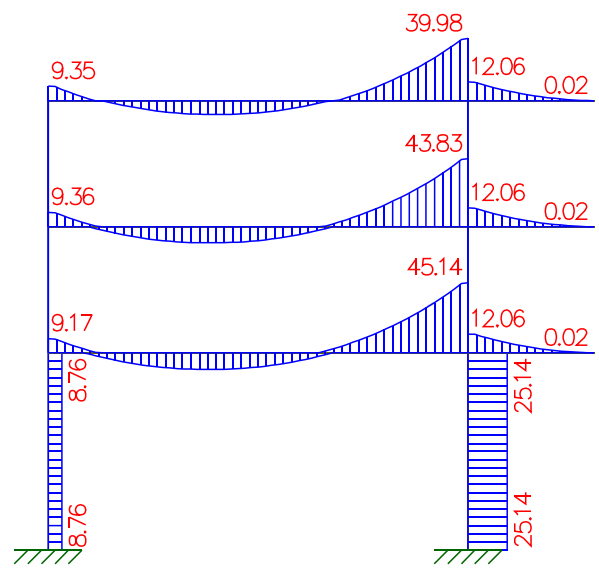

(a)

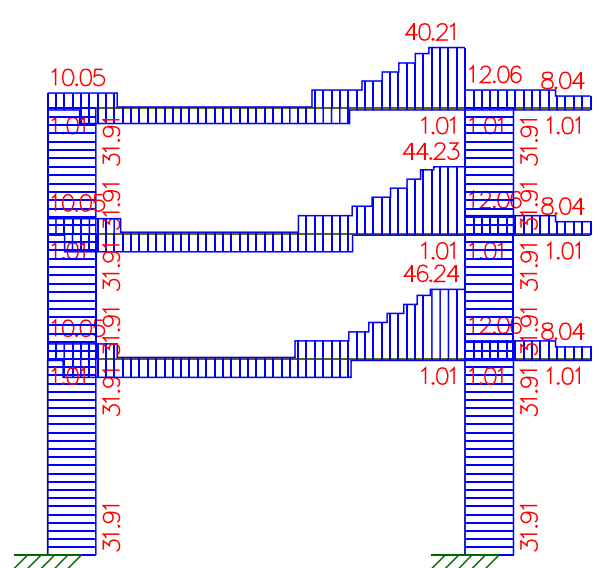

(b)

Figura 4.56 - Diagrama de armadura para o passo 0,2 m (a) Calculada [ $\left.\mathrm{cm}^{2}\right]$; (b) Adotada $\left[\mathrm{cm}^{2}\right]$. 


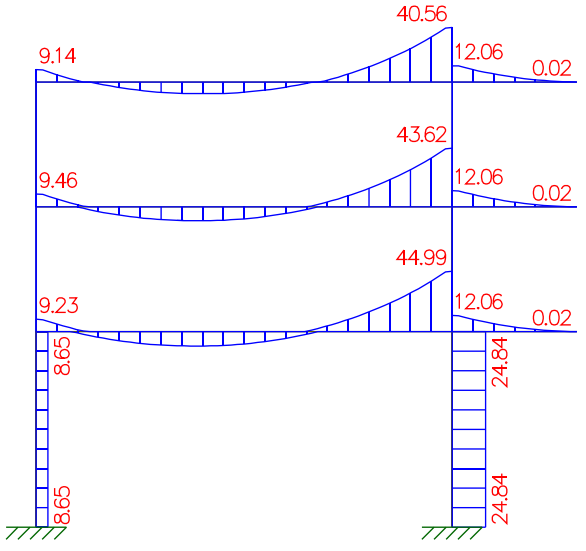

(a)

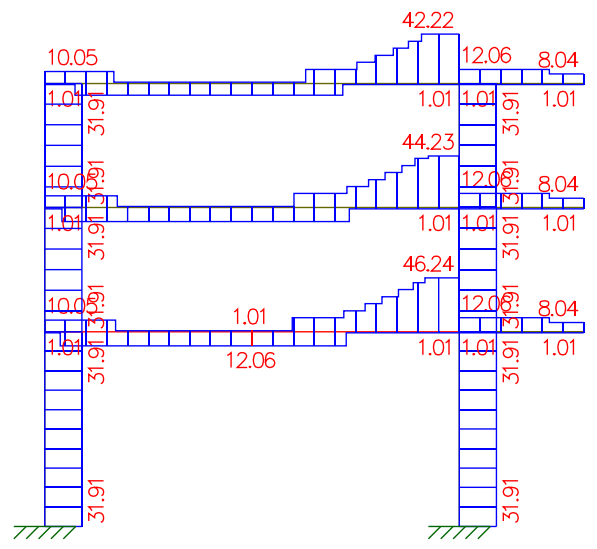

(b)

Figura 4.57 - Diagrama de armadura para o passo 0,5 m (a) Calculada [ $\left.\mathrm{cm}^{2}\right]$; (b) Adotada $\left[\mathrm{cm}^{2}\right]$.

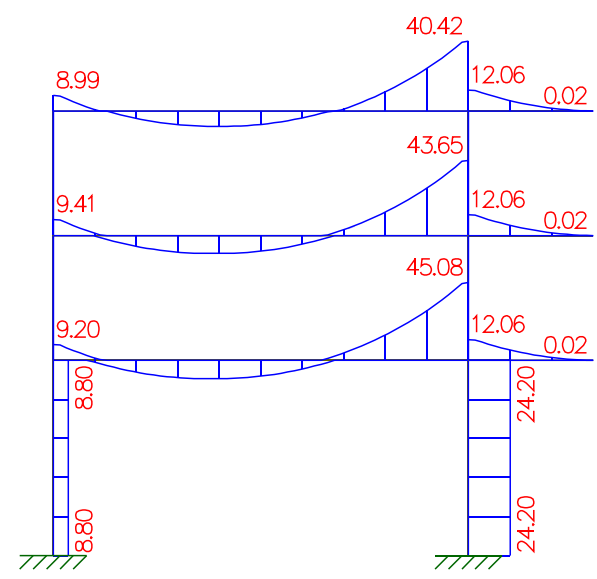

(a)

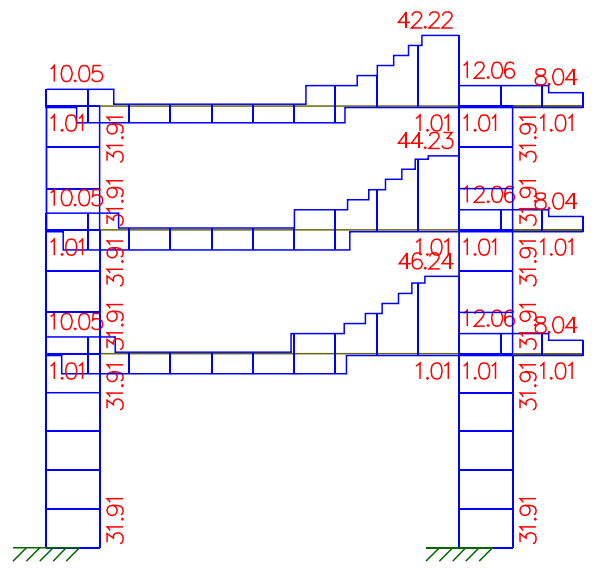

(b)

Figura 4.58 - Diagrama de armadura para o passo 1,0 m (a) Calculada [ $\left.\mathrm{cm}^{2}\right]$; (b) Adotada $\left[\mathrm{cm}^{2}\right]$.

A diferença maior é na armadura calculada, mas dadas as condições de armadura de entrada no exemplo e as áreas mínimas de armadura, as armaduras nos três passos são similares, se diferenciando na viga V3a, que tem uma barra de 16 mm a menos na região de momento máximo negativo.

Portanto, para o exemplo aqui apresentado, todos os passos fornecem resultados compatíveis, mas que em comparação com a análise linear apresentam alterações significantes.

\subsubsection{Deslocamentos}

Para a análise dos deslocamentos, opta-se pelo passo de $0,2 \mathrm{~m}$ pela maior discretização da estrutura. Escolhem-se os nós onde há carregamento horizontal aplicado, assinalados na figura 4.59, com maiores deslocamentos para o comparativo com a análise linear. 


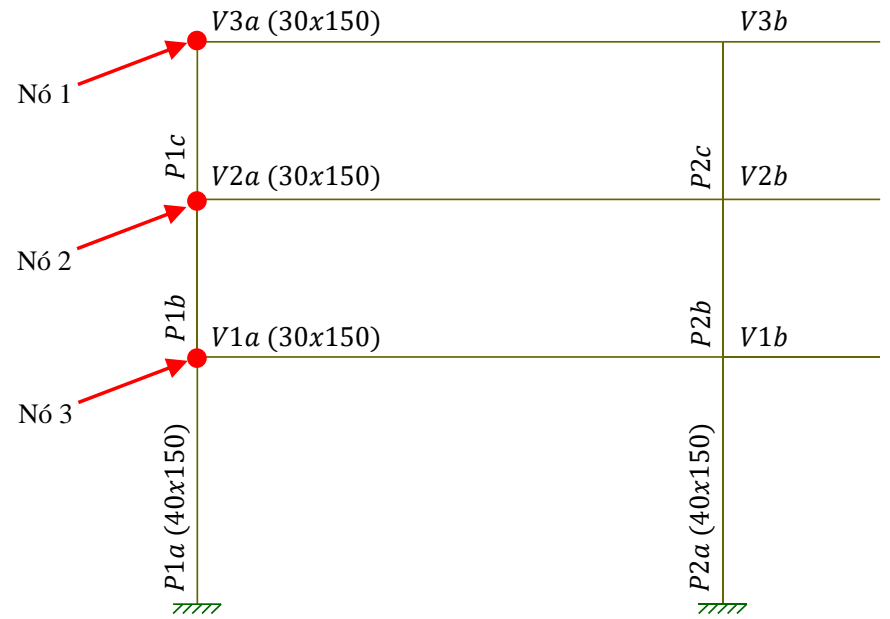

Figura 4.59 - Pórtico plano com os nós para análise dos deslocamentos.

Na figura 4.60 mostram-se as deformadas com análise inicial linear e após a convergência com a inserção da não linearidade pela redução da rigidez. Os valores do gráfico são referentes ao deslocamento horizontal dos nós:

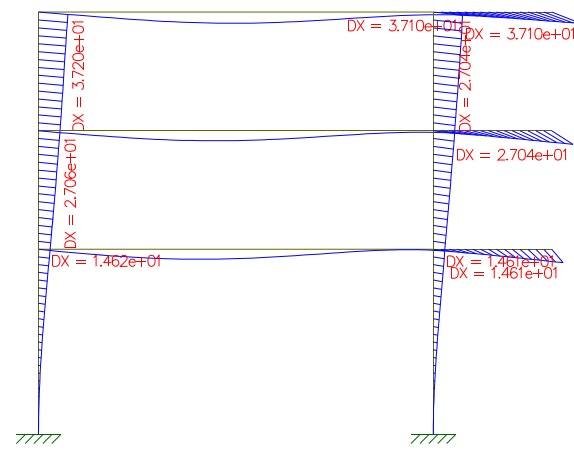

(a)

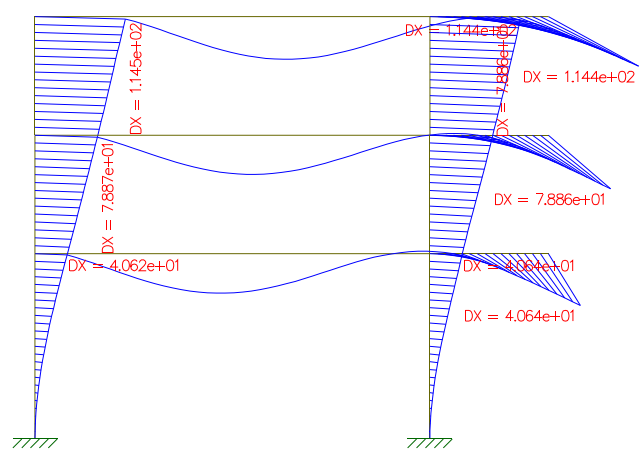

(b)

Figura 4.60 - Deformada do pórtico [mm] (a) Análise linear; (b) Análise não linear.

Anotam-se os valores dos deslocamentos horizontais e faz-se a tabela 4.19 com o cálculo do fator de amplificação dos deslocamentos em comparação com a análise linear.

Tabela 4.19 - Comparativo entre os deslocamentos com análise linear e não linear.

\begin{tabular}{|l|r|r|r|}
\cline { 2 - 4 } \multicolumn{1}{c|}{} & \multicolumn{3}{c|}{ Deslocamento [mm] } \\
\cline { 2 - 4 } \multicolumn{1}{c|}{} & \multicolumn{1}{c|}{ Nó 1 } & Nó 2 & \multicolumn{1}{c|}{ Nó 3 } \\
\hline Análise linear & 37,20 & 27,06 & 14,62 \\
\hline Análise não linear & 114,50 & 78,87 & 40,62 \\
\hline Amplificação & 3,08 & 2,91 & 2,78 \\
\hline
\end{tabular}

Observa-se o grande impacto da redução na rigidez nos deslocamentos da estrutura, com fator de amplificação por volta de 3,0. 


\subsubsection{Fluência do Concreto}

Para a consideração da fluência neste modelo, serão considerados dois valores distintos de espessura fictícia da seção. Para isto, serão utilizados dois materiais: um para viga e outro para pilares.

Considera-se a umidade média do Rio de Janeiro de 75\%, a classe C30 do concreto e a idade fictícia de 5 dias.

A espessura fictícia da viga é dada por:

$$
e_{f i c}=2 \cdot 30 \cdot 150 /(2 \cdot 30+2 \cdot 150)=25,0 \mathrm{~cm}
$$

Da mesma forma, a espessura fictícia do pilar:

$$
e_{f i c}=2 \cdot 40 \cdot 150 /(2 \cdot 40+2 \cdot 150)=31,58 \mathrm{~cm}
$$

\begin{tabular}{|c|c|c|c|c|c|c|c|c|c|c|}
\hline \multicolumn{3}{|c|}{$\begin{array}{c}\text { Umidade média } \\
\text { ambiente } \\
\%\end{array}$} & \multicolumn{2}{|c|}{40} & \multicolumn{2}{|c|}{55} & \multicolumn{2}{|c|}{75} & \multicolumn{2}{|c|}{90} \\
\hline \multicolumn{3}{|c|}{$\begin{array}{l}\text { Espessura fictícia } \\
2 A_{\mathrm{c}} / u \\
\mathrm{~cm}\end{array}$} & 20 & 60 & 20 & 60 & 20 & 60 & 20 & 60 \\
\hline \multirow{3}{*}{$\begin{array}{c}\varphi\left(t_{\infty}, t_{0}\right) \\
\text { Concreto } \\
\text { das classes } \\
\text { C20 a C45 }\end{array}$} & \multirow{9}{*}{$\begin{array}{c}t_{0} \\
\text { dias }\end{array}$} & 5 & 4,6 & 3,8 & 3,9 & 3,3 & 2,8 & 2,4 & 2,0 & 1,9 \\
\hline & & 30 & 3,4 & 3,0 & 2,9 & 2,6 & 2,2 & 2,0 & 1,6 & 1,5 \\
\hline & & 60 & 2,9 & 2,7 & 2,5 & 2,3 & 1,9 & 1,8 & 1,4 & 1,4 \\
\hline$\varphi\left(t_{\infty}, t_{0}\right)$ & & 5 & 2,7 & 2,4 & 2,4 & 2,1 & 1,9 & 1,8 & 1,6 & 1,5 \\
\hline $\begin{array}{l}\text { Concreto } \\
\text { das classes }\end{array}$ & & 30 & 2,0 & 1,8 & 1,7 & 1,6 & 1,4 & 1,3 & 1,1 & 1,1 \\
\hline C50 a C90 & & 60 & 1,7 & 1,6 & 1,5 & 1,4 & 1,2 & 1,2 & 1,0 & 1,0 \\
\hline \multirow{3}{*}{$\varepsilon_{c s}\left(t_{\infty}, t_{0}\right) \%$} & & 5 & $-0,53$ & $-0,47$ & $-0,48$ & $-0,43$ & $-0,36$ & $-0,32$ & $-0,18$ & $-0,15$ \\
\hline & & 30 & $-0,44$ & $-0,45$ & $-0,41$ & $-0,41$ & $-0,33$ & $-0,31$ & $-0,17$ & $-0,15$ \\
\hline & & 60 & $-0,39$ & $-0,43$ & $-0,36$ & $-0,40$ & $-0,30$ & $-0,31$ & $-0,17$ & $-0,15$ \\
\hline
\end{tabular}

Tabela 4.20 - Coeficientes de fluência e retração - Tabela 8.2 da NBR 6118(ABNT, 2014)

Interpolando os valores da tabela, obtém-se dois valores de fluência:

$$
\varphi_{\text {viga }}=2,75 \quad \varphi_{\text {pilar }}=2,68
$$

Escolhe-se para a análise da fluência o passo 0,5 m. Mostram-se na figura 4.61 e 4.62 os diagramas iniciais e finais da convergência com a consideração da fluência. 


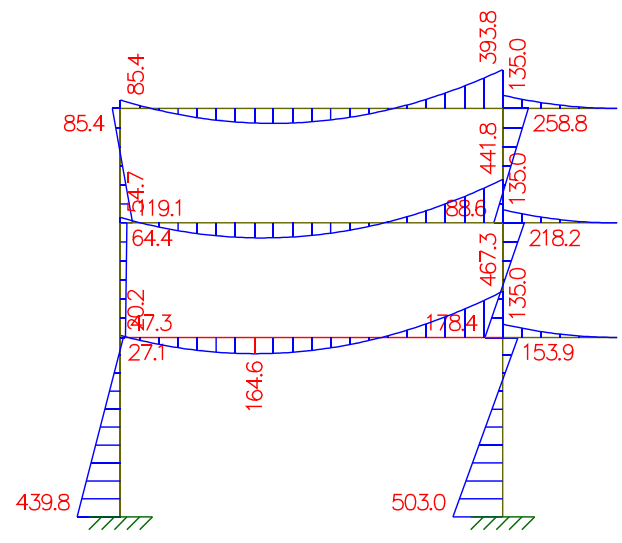

(a)

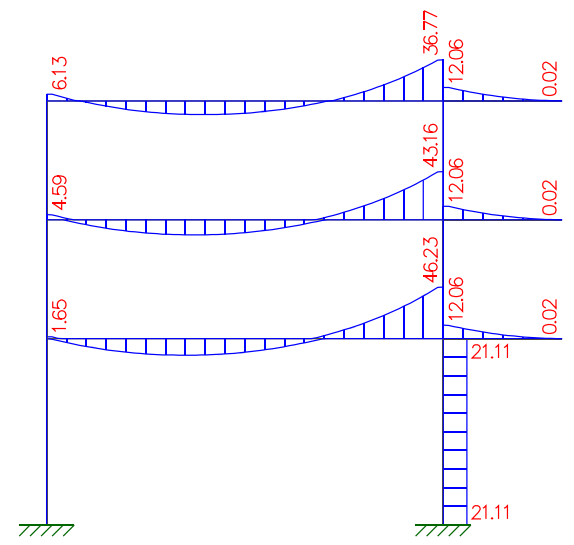

(c)

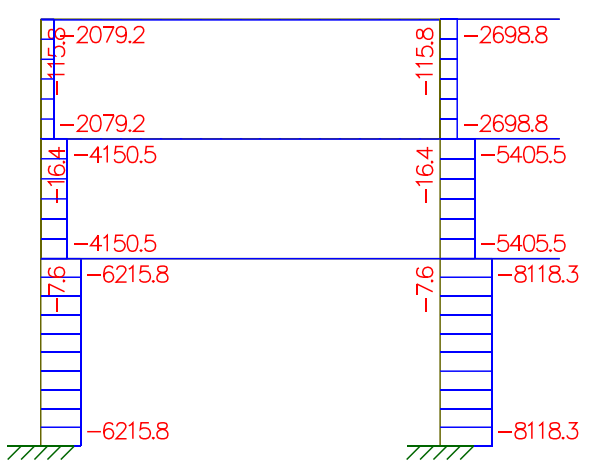

(b)

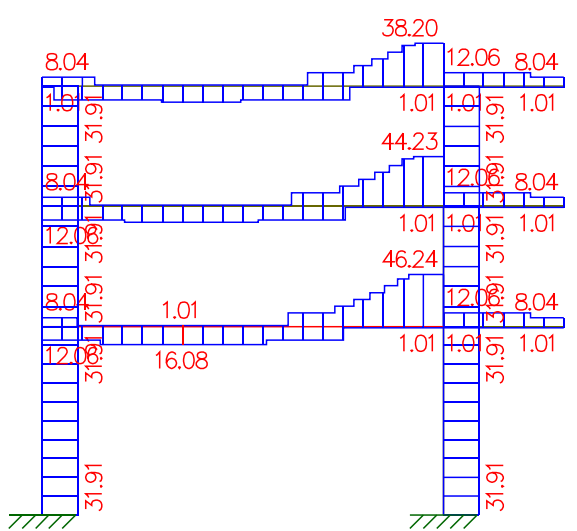

(d)

Figura 4.61 - Análise Linear (a) Diagrama de momento fletor [kN.m]; (b) Diagrama de normal [kN]; (c) Armadura calculada [cm²]; (d) Armadura adotada $\left[\mathrm{cm}^{2}\right]$.

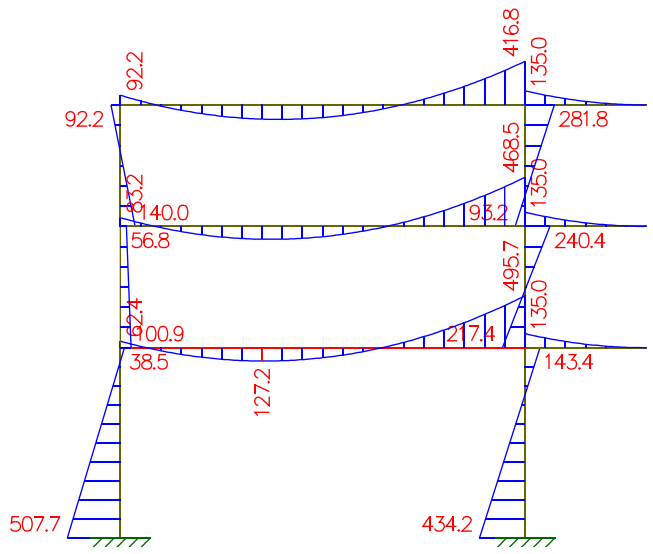

(a)

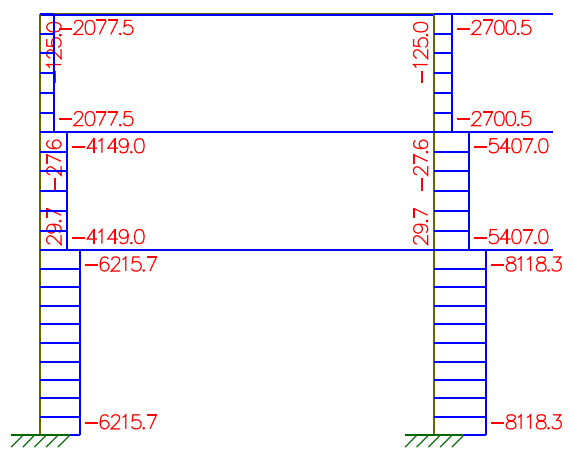

(b) 


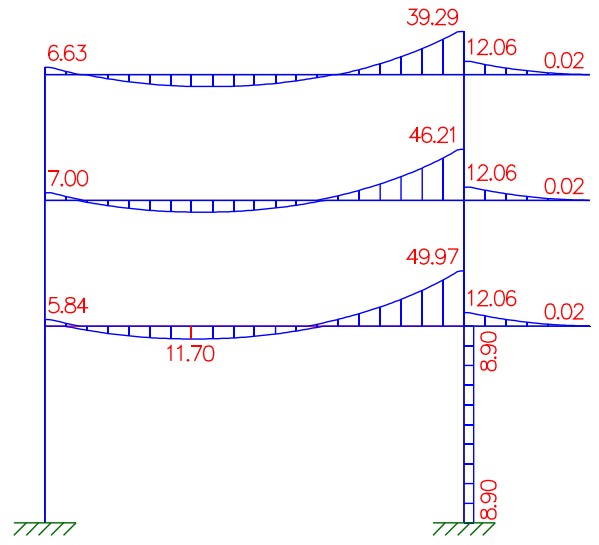

(c)

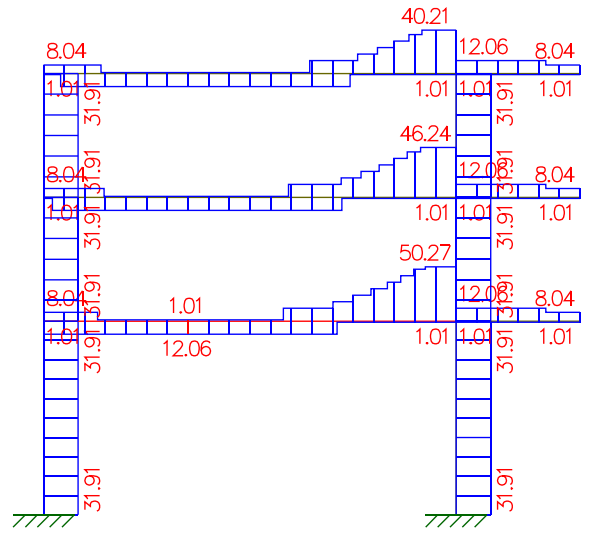

(d)

Figura 4.62 - Análise Não linear com fluência (a) Diagrama de momento fletor [kN.m]; (b)

Diagrama de normal [kN]; (c) Armadura calculada [ $\left.\mathrm{cm}^{2}\right]$; (d) Armadura adotada $\left[\mathrm{cm}^{2}\right]$.

Com os diagramas, observa-se a diferença na armadura nas vigas, porém nos pilares permanece a mesma área de aço. Isso se deve a maior redução da inércia com a consideração da fluência.

Comparam-se os diagramas de redução da rigidez na análise não linear com e sem fluência na figura 4.63 .

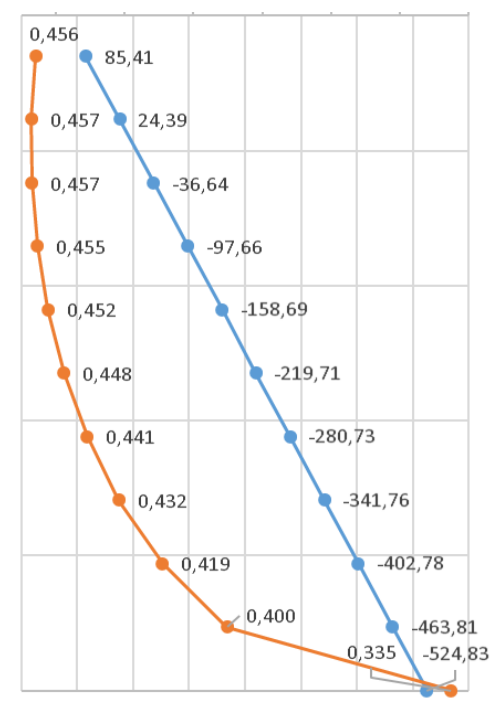

(a)

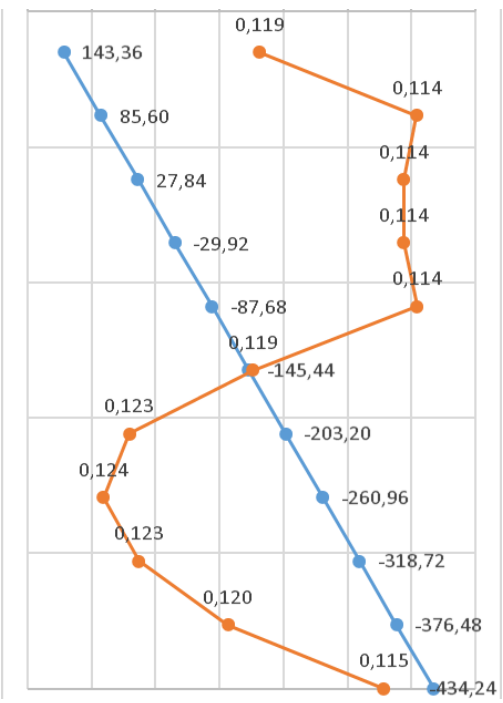

(b)

Figura 4.63 - Diagramas de redução da rigidez no pilar P2a ao final da convergência (a) Não linear; (b) Não Linear com fluência. 
Tabela 4.21 - Comparativo das três análises no pilar P2a.

\begin{tabular}{|l|r|r|r|r|}
\hline \multirow{3}{*}{ Análise } & \multicolumn{4}{|c|}{ Pilar P2a } \\
\cline { 2 - 5 } & \multicolumn{4}{|c|}{ Momento Máximo } \\
\cline { 2 - 5 } & \multicolumn{2}{|c|}{ Convergência } & \multicolumn{1}{c|}{ Inércia Secante } \\
\cline { 2 - 5 } & $\mathrm{Md}[\mathrm{kN} . \mathrm{m}]$ & $\Delta \mathrm{Md}[\%]$ & Isec [cm4] & Isec/Ic \\
\hline Linear & 503,0 & $0,00 \%$ & 0,008000 & 1,000 \\
\hline Não Linear & 524,8 & $4,33 \%$ & 0,002681 & 0,335 \\
\hline Não Linear - Fluência & 434,2 & $-13,68 \%$ & 0,000919 & 0,115 \\
\hline
\end{tabular}

A tabela 4.21 resume os resultados dos gráficos e diagramas. Observa-se que enquanto a redução da rigidez na análise linear é mais uniforme, ao considerar a fluência há uma maior variação. Isso se dá pela curva momento-curvatura ser mais inclinada com a fluência e pela armadura adotada ser muito superior à calculada.

(a)

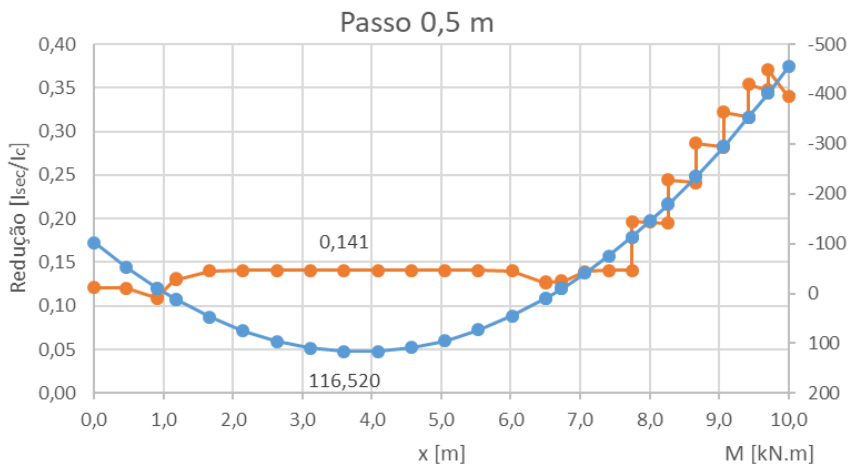

(b)

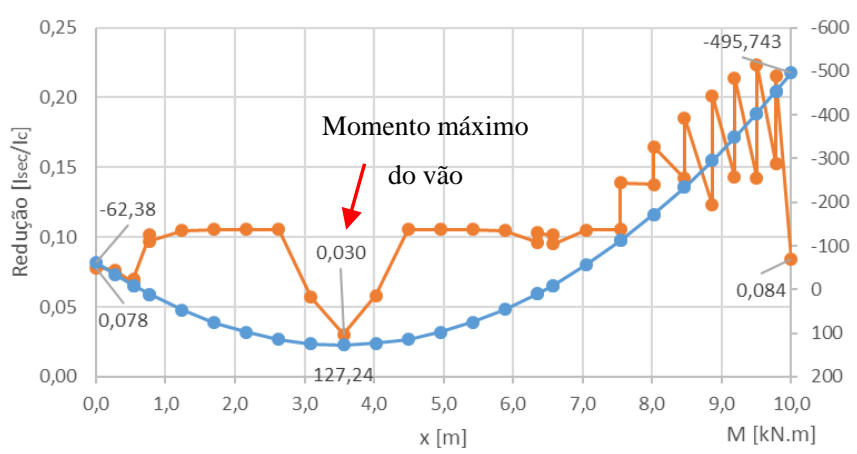

Figura 4.64 - Diagramas de redução da rigidez na viga V1a ao final da convergência (a) Não linear; (b) Não Linear com fluência.

Tabela 4.22 - Comparativo das três análises na viga V1a.

\begin{tabular}{|l|r|r|r|r|r|r|r|r|}
\hline \multirow{3}{*}{ Análise } & \multicolumn{9}{|c|}{ Viga V1a } \\
\cline { 2 - 10 } & \multicolumn{4}{|c|}{ Máximo Positivo } & \multicolumn{4}{c|}{ Máximo Negativo } \\
\cline { 2 - 9 } & \multicolumn{2}{|c|}{ Convergência } & \multicolumn{2}{c|}{ Inércia Secante } & \multicolumn{2}{c|}{ Convergência } & \multicolumn{2}{c|}{ Inércia Secante } \\
\cline { 2 - 9 } & Md [kN.m] & \multicolumn{1}{|c|}{ Md [\%] } & Isec [cm4] & Isec/Ic & Md [kN.m] & $\Delta$ Md [\%] & Isec [cm4] & Isec/Ic \\
\hline Linear & 164,6 & $0,00 \%$ & 0,003375 & 1,000 & 467,3 & $0,00 \%$ & 0,003375 & 1,000 \\
\hline Não Linear & 116,8 & $-29,04 \%$ & 0,000475 & 0,141 & 455,0 & $-2,63 \%$ & 0,001148 & 0,340 \\
\hline $\begin{array}{l}\text { Não Linear } \\
\text { - Fluência }\end{array}$ & 127,2 & $-22,72 \%$ & 0,000102 & 0,030 & 495,7 & $6,08 \%$ & 0,000283 & 0,084 \\
\hline
\end{tabular}


Diferentemente do observado no exemplo 4.1, onde a variação da inércia secante era menor ao se considerar a fluência, neste exemplo 4.3, a inércia com a fluência, apesar de ter o intervalo de variação menor, ainda assim apresenta grande variação. O que faz com que o resultado não se aproxime tanto da análise linear inicial. Porém, deve-se notar que, por exemplo, o nó de momento máximo tem redução da rigidez de 0,03 com fluência e 0,141 sem a fluência.

Plotam-se na figura 4.65 os dois gráficos da variação da rigidez ao longo do vão sobrepostas, para que fique em maior evidencia este intervalo de variação.

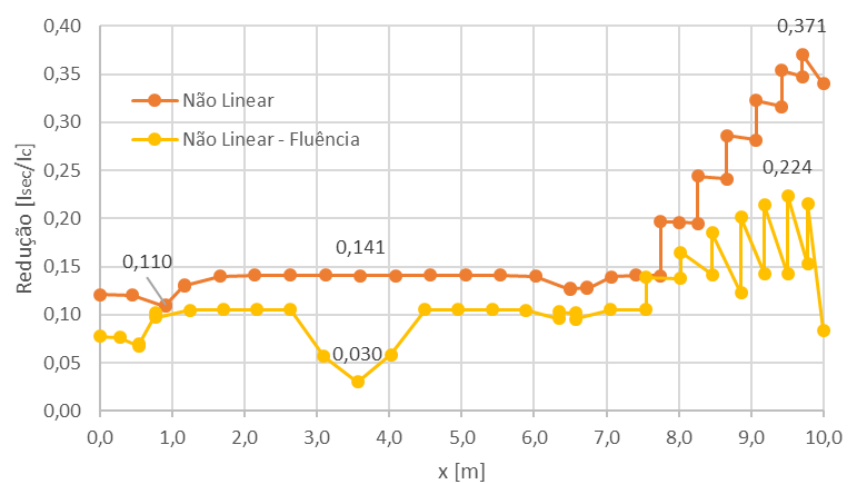

Figura 4.65 - Sobreposição dos gráficos de redução da rigidez na análise não linear com e sem fluência.

Sendo o deslocamento o resultado com maior impacto da redução da rigidez, apresenta-se a na figura 4.66 a deformada com os valores do deslocamento vertical da estrutura.

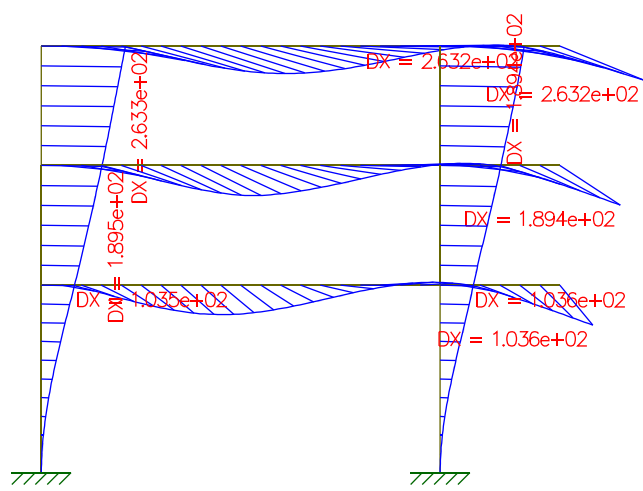

Figura 4.66 - Deformada do pórtico [mm] - Análise não linear com fluência.

Faz-se a tabela 4.23 comparativa do deslocamento horizontal dos três nós nas três análises propostas e com o fator de amplificação, referente ao valor da análise linear. 
Tabela 4.23 - Comparação dos deslocamentos obtidos.

\begin{tabular}{|l|c|c|c|c|c|c|}
\hline \multirow{2}{*}{ Análise } & \multicolumn{2}{|c|}{ Nó 1 } & \multicolumn{2}{c|}{ Nó 2 } & \multicolumn{2}{c|}{ Nó 3 } \\
\cline { 2 - 7 } & $\delta[\mathrm{mm}]$ & Amplificação & $\delta[\mathrm{mm}]$ & Amplificação & $\delta[\mathrm{mm}]$ & Amplificação \\
\hline Linear & 37,20 & 1,00 & 27,06 & 1,00 & 14,62 & 1,00 \\
\hline Não linear & 114,50 & 3,08 & 78,87 & 2,91 & 40,62 & 2,78 \\
\hline $\begin{array}{l}\text { Não linear - } \\
\text { Fluência }\end{array}$ & 263,3 & 7,08 & 189,50 & 7,00 & 103,50 & 7,08 \\
\hline
\end{tabular}

Observa-se que ao se inserir a fluência, os deslocamentos têm aumentos por volta de 7 vezes. Neste exemplo, assim como nos anteriores, o impacto da redução da rigidez é notável nos deslocamentos, enquanto que na armadura não tem grande influência.

Entretanto, ao se considerar o impacto destes deslocamentos numa análise de segunda ordem, os momentos atuantes para o dimensionamento dos pilares teriam um acréscimo que geraria um impacto maior na armadura das seções. Por exemplo, no pilar P1, que possui em cada andar uma força aplicada de $1960,0 \mathrm{kN}$, com os deslocamentos dos nós 1, 2 e 3, tem-se um momento adicional. Simulando a iteração inicial do método P-delta, apenas para esses carregamentos verticais, obtém-se o momento adicional e as forças fictícias que seriam aplicadas em cada andar para simular o efeito de segunda ordem. O braço de alavanca do momento adicional é dado pela equação (4.15) da diferença de deslocamentos entre os nós de um mesmo andar.

$$
\Delta \delta=\delta_{j}-\delta_{i}
$$

O momento adicional é calculado pela equação (4.16) com a força vertical multiplicada pela diferença entre os deslocamentos.

$$
M=N \cdot \Delta \delta
$$

A força horizontal fictícia aplicada é calculada com a equação (4.17) pela razão entre o momento e o vão do pilar.

$$
H=M / h
$$

Na figura 4.67 apresenta-se a ilustração e uma tabela com a multiplicação das forças aplicadas na vertical pelos deslocamentos. 


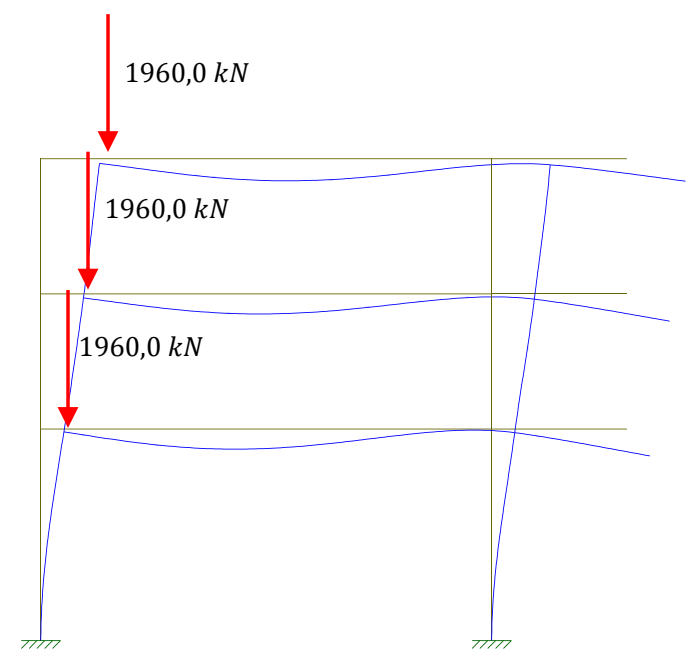

Figura 4.67 - Efeitos de segunda ordem.

Tabela 4.24 - Efeitos de segunda ordem.

\begin{tabular}{|l|r|r|r|r|r|r|}
\cline { 2 - 7 } \multicolumn{1}{c|}{} & $\delta[\mathrm{mm}]$ & \multicolumn{1}{c|}{$\Delta \delta[\mathrm{mm}]$} & $h[\mathrm{~m}]$ & \multicolumn{1}{c|}{$N[\mathrm{kN}]$} & $M[k N . m]$ & \multicolumn{1}{c|}{$H[k N]$} \\
\hline Nó 1 & 263,3 & 73,8 & 3,00 & 1960,0 & 144,65 & 48,22 \\
\hline Nó 2 & 189,5 & 86,0 & 3,00 & 1960,0 & 168,56 & 56,19 \\
\hline Nó 3 & 103,5 & 103,5 & 4,70 & 1960,0 & 202,86 & 43,16 \\
\hline
\end{tabular}

Portanto, observando a tabela 4.24 e a figura 4.67, apenas considerando-se o efeito de segunda ordem das forças verticais aplicadas diretamente no pilar P1, o trecho P1c teria um acréscimo de $202,86 \mathrm{kN} . \mathrm{m}$ no momento fletor de dimensionamento. Comparando este valor com o momento de dimensionamento de efeitos de primeira ordem, calculado com a análise linear como de 119,1 kN. m, e se baseando no item 15.4.2 da NBR 6118(ABNT, 2014), os efeitos de segunda ordem são superiores aos $10 \%$ o que classifica a estrutura como de nós móveis. Desta forma, fica obrigatória a consideração dos efeitos de segunda ordem locais e globais. 


\section{5 \\ Conclusões}

Este trabalho teve como principal resultado a inserção da não linearidade física do concreto no programa FTOOL, possibilitando que o usuário escolha fazer uma análise linear ou não linear. Conforme explicitado no texto, a não linearidade física é considerada pela adoção da rigidez secante obtida nos diagramas momentocurvatura. O programa permite que o usuário analise graficamente a variação iteração a iteração dos esforços internos, armadura e deslocamento até a convergência do modelo. Todas as figuras com resultados de análise do Capítulo 4 (Exemplos) foram retiradas da interface do programa a que o usuário tem acesso, podendo gerar os mesmos gráficos.

Observa-se que o tempo de processamento desta análise é maior que o do dimensionamento usual, dado o processo para obtenção das curvas momentocurvatura, conforme descrito no Capítulo 3. Por serem duas incógnitas para se encontrar o equilíbrio na seção com a força normal, para verificar se há convergência com o momento fletor, o programa precisa testar todas as possibilidades de uma variável; optou-se pela posição da linha neutra. Para encontrar a segunda solução, o programa utiliza o método da bisseção, diminuindo o tempo de processamento. Porém, considera-se como válido o custo computacional adicional, dado que é uma análise mais complexa que testa seção a seção a redução da rigidez.

Quanto à malha de nós para integração dos elementos de barra, como se observou nos exemplos 4.1 e 4.3, para vigas não há grande interferência na escolha do passo, dado que a cada alteração na armadura da seção, cria-se um nó. Já no caso dos pilares, conforme ficou evidenciado no exemplo 4.2, devido à armadura constante ao longo do pilar, ocorre uma grande variação da rigidez que impacta no resultado de esforços internos e deslocamentos. Desta forma, para a análise de pilares e pórticos recomenda-se o uso de uma malha refinada. Já para a análise de vigas, pode-se utilizar o passo de $0,0 \mathrm{~m}$ que não cria nós dentro dos trechos. 
Faz-se referência à recomendação da consideração da não linearidade física de maneira aproximada, conforme a NBR 6118(ABNT, 2014) em seu item 15.7.3, que define valores para a redução da rigidez bruta da seção. Considerando os elementos de viga e pilar presentes no pórtico plano, a recomendação é de 0,8 para pilares e 0,4 para vigas com armaduras superior e inferior distintas ou 0,5 quando estas armaduras forem iguais. Conforme observado nos exemplos do Capítulo 4, os valores obtidos para esta redução são inferiores e ainda menores ao se considerar a fluência do concreto. No exemplo 4.1, a região de momento máximo positivo apresentou redução de 0,23 e, ao considerar a fluência, de 0,15 . Já na região de momento negativo, a redução foi de 0,39 , se aproximando do recomendado. Porém, conforme observa-se nas figuras com a variação ao longo do vão, é uma região com rigidez secante elevada dada à armadura. Observa-se que, ao se considerar a fluência, a redução foi similar nas duas regiões. No exemplo 4.2 do pilar, apenas no topo da seção a redução se aproxima da recomendação, tendo valores próximos a 0,77, mas na base com momento máximo, a redução chega a 0,13 . Ao se inserir a fluência, o topo do pilar tem redução de 0,27 , enquanto a base de 0,06 . No exemplo 4.3 do pórtico plano, onde foi feita a análise de um pilar e de uma viga, estes, similarmente aos exemplos anteriores, também apresentaram redução inferior. A viga V1a, no meio do vão apresentou valores de 0,14 e 0,11 ao se considerar a fluência. Já o pilar P2a, tem armadura adotada muito superior à calculada; portanto, ao longo do vão, a redução tem valor próximo de 0,4 ; ao se considerar a fluência, esse valor se aproxima de 0,11. Em todos esses casos, observou-se que quando o momento fletor atuante é inferior ao momento de fissuração, estando a peça em regime linear, a redução se aproxima da recomendada pela Norma, mas ao se considerar todo o vão, essa redução apresenta valores muito inferiores.

Esses valores obtidos, portanto, levantam o mesmo questionamento feito por Gomes (2017), sobre os valores da recomendação da NBR 6118. Os valores de redução obtidos no primeiro trabalho se aproximavam de 0,3 para pilares, enquanto que aqui com um melhor refinamento da análise, obtiveram-se valores ainda menores, chegando a 0,23 no pilar do exemplo 4.2.

Ao se analisar os exemplos, observa-se que o principal impacto na redução da rigidez se dá nos deslocamentos. O chamado fator de amplificação neste trabalho foi definido como a razão entre o resultado não linear e o linear. No trabalho anterior, este fator se aproximou de 2,4. Aqui, os valores são ainda maiores com 3,6 
no exemplo 4.1, 4,4 no exemplo 4.2 e 3,9 no exemplo 4.3, aproximadamente. Como observado no exemplo 4.3, o principal impacto se dá nos efeitos de segunda ordem.

Para uma melhor avaliação do impacto da redução da rigidez, propõe-se como trabalho futuro a inserção desta análise com redução no cálculo dos efeitos de segunda ordem de estruturas, considerando o grande aumento nos momentos atuantes ao considerar a estrutura deformada, conforme cálculo brevemente apresentado no exemplo 4.3. Também se sugere como o desenvolvimento de uma ferramenta capaz de fazer análises em três dimensões, mais próximas da realidade.

O programa FTOOL ainda necessita passar por algumas adaptações e melhorias quanto ao dimensionamento de concreto armado, principalmente quanto a maneira com que apresenta os resultados. Porém, todos os resultados analisados estão coerentes com as recomendações das normas e são válidos, sendo as melhorias já em desenvolvimento, questões visuais e usabilidade para o usuário. 
6 Referências bibliográficas

AMERICAN CONCRETE INSTITUTE, Building code requirements for structural concrete. Michigan, EUA, 2015.

ASSOCIAÇÃO BRASILEIRA DE NORMAS TÉCNICAS. NBR 6118: Projeto de estruturas de concreto - Procedimento. Rio de Janeiro, 2014.

ASSOCIAÇÃO BRASILEIRA DE NORMAS TÉCNICAS. NBR 6120: Cargas para o cálculo de estruturas de edificações. Rio de Janeiro, 1980.

ASSOCIAÇÃO BRASILEIRA DE NORMAS TÉCNICAS. NBR 7480: Aço destinado a armaduras para estruturas de concreto armado Especificação. Rio de Janeiro, 2007.

CASTRO, F. M. O., M-k UFRJ Análise não linear física de seções de concreto armado versão 3.0, Julho de 2011.

CECCON, J. L., Análise dos efeitos de segunda ordem em pilares solicitados à flexão oblíqua composta. Tese de Doutorado - USP, 2008.

CHUST, R. C.; FIGUEIREDO FILHO, J. R., Cálculo e detalhamento de estruturas usuais de concreto armado: segundo a NBR 6118:2014. 4 ed. São Carlos: EdUFSCAR, 2015. 415 p.

EUROPEAN COMMITTEE FOR STANDARDIZATION, Eurocode 2: Design of concrete structues - Part 1-1: General rules and rules for building. Bruxelas, Bélgica, 2004.

FEDÉRATION INTERNATIONALE DU BETÓN, Model Code 2010. Lausanne, Suíça, 2013. 
FERRAZ, M. F. R., Reconstituição de seções geológicas utilizando subdivisões planares, transformações geométricas e computação gráfica interativa. Dissertação de Mestrado - PUC-Rio, setembro de 1993.

FTOOL, Um Programa Gráfico-Interativo para Ensino de Comportamento de Estruturas, Versão Educacional 3.01, Agosto de 2015, disponível em http://www.tecgraf.puc-rio.br/ftool.

GOMES, B. C., Estudo dos fatores de redução de rigidez da NBR 6118:2014 para análise aproximada da não linearidade física. Projeto de Graduação - Escola Politécnica da UFRJ, 2017.

MARTHA, L. F., Análise de estruturas: Conceitos e métodos básicos. 1 ed. Rio de Janeiro: Elsevier, 2015. 560p.

NISKIER, C. M., Ferramenta gráfico-interativa para o projeto de vigas e edifícios em concreto armado. Dissertação de Mestrado - PUC-Rio, setembro de 2004.

NOGUEIRA, J. L. M. S., Comparative analysis of second order effects by different structural design codes. Projeto de Graduação - Escola Politécnica da UFRJ, 2017.

SANTOS, L. M., Sub-rotinas básicas do dimensionamento de concreto armado. São Paulo: Thot, 1994.

SANTOS, S. H. C., Detalhamento de estruturas de concreto armado. Apostila - Escola Politécnica da UFRJ, 2018.

SANTOS, S. H. C., Fundamentos de concreto armado II. Apostila Escola Politécnica da UFRJ, 2018.

SILVA, F. M., Análise variacional de segunda ordem não linear em pilares de concreto armado com uso de relação momento-curvatura analiticamente ajustada. Projeto de Graduação - Escola Politécnica da UFRJ, fevereiro de 2017. 
SILVA, M. F. D. S., Ferramenta gráfico-interativa para o dimensionamento de pórticos planos de concreto armado considerando não linearidade geométrica. Dissertação de Mestrado PUC-Rio, abril de 2017.

SOUZA JÚNIOR, P. J., Análise de pórticos de concreto armado em condições sísmicas considerando o modelo de Mander. Dissertação de Mestrado. Programa de Projeto de Estruturas (PPE), Escola Politécnica da UFRJ, 2012.

SÜSSEKIND J.C., Curso de Análise Estrutural, Vol. 3: Método das Deformações e Processo de Cross, Editora Globo, Porto Alegre, 1977.

VILELA, P. de C. S., Soluções fundamentais para barras e mísula pela analogia da viga conjugada. In: CILAMCE, 29. Maceió, 2008. 